DOCUMENTOS OCASIONALES

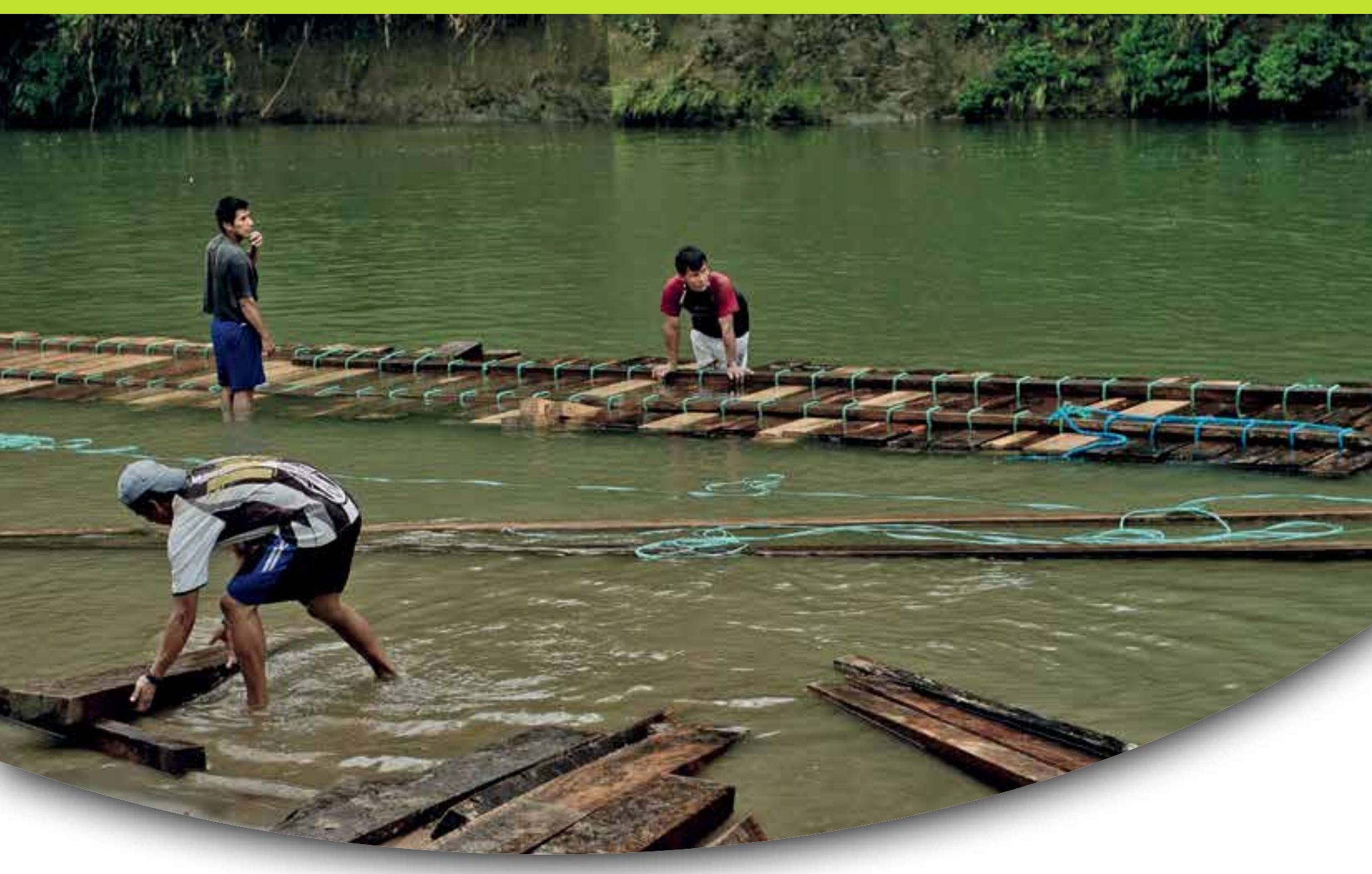





\section{Aprovechamiento forestal y mercados de la madera en la Amazonía Ecuatoriana}

Editado por

Elena Mejía

CIFOR

Pablo Pacheco

CIFOR 
Documentos Ocasionales 97

(C) 2013 Centro para la Investigación Forestal Internacional (CIFOR)

Los contenidos de esta publicación están bajo Licencia Creative Commons de Atribución-No Comercial-Sin Derivadas 3.0 Unported. Ver información detallada sobre la licencia en: http://creativecommons.org/licenses/ by-nc-nd/3.0/deed.es

ISBN 978-602-1504-14-7

Mejía E y Pacheco P. 2013. Aprovechamiento forestal y mercados de la madera en la Amazonía Ecuatoriana. Occasional Paper 97. Bogor, Indonesia: CIFOR.

Fotografías: Tomas Munita/CIFOR

Los pobladores hacen una balsa para el transporte de madera aguas abajo en el río Arajuno, Ecuador.

Este documento ha sido elaborado con la ayuda financiera de la Unión Europea a través del proyecto PRO-FORMAL (http://www.cifor.org/proformal). Las opiniones expresadas aquí son las de los autores y de ninguna manera pueden ser tomadas para reflejar la opinión oficial de la Unión Europea o de CIFOR

\author{
CIFOR \\ Jl. CIFOR, Situ Gede \\ Bogor Barat 16115 \\ Indonesia \\ $\mathrm{T}+62(251) 8622-622$ \\ $F+62(251) 8622-100$ \\ E cifor@cgiar.org
}

\title{
cifor.org
}

Quisiéramos agradecer a todos los donantes que apoyaron esta investigación a través de sus contribuciones al Fondo de CGIAR. Para ver la lista de donantes del Fondo, visite: https://www.cgiarfund.org/FundDonors

Cualquier opinión vertida en este documento es de los autores. No refleja necesariamente las opiniones de CIFOR, de las instituciones para las que los autores trabajan o de los financiadores. 


\section{Índice}

Lista de cuadros, figuras, mapas, y recuadros iv

Lista de acrónimos vii

Agradecimientos viii

1 Introducción 1

2 Elementos de contexto $\quad 4$

Elena Mejía y Pablo Pacheco
$2.1 \quad$ Uso del suelo, población y sector forestal

$\begin{array}{ll}2.2 & \text { El esquema de control forestal en el Ecuador }\end{array}$

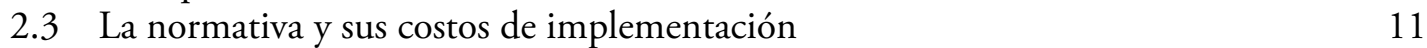

2.4 El rol del SAF en el control forestal actual $\quad 12$

2.5 Implicaciones del control para el aprovechamiento de pequeña escala 15

3 Actores, intermediación y control forestal en la Amazonía 17

Elena Mejía, Pablo Pacheco, Johanna Morocho y Santiago Alarcón

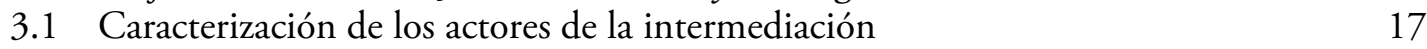

$\begin{array}{ll}3.2 & \text { Las relaciones de intermediación } \\ 3.3 & 20\end{array}$

3.3 Relaciones de confianza y conflictos con la autoridad 22

3.4 Estrategias de los actores para evadir el sistema de control 24

3.5 Evasión de otras normas vinculadas al aprovechamiento 27

3.6 Efectividad del SAF en el contexto de la intermediación 28

4 Mercado interno de la madera $\quad 30$

Alfredo Carrasco, Cristian Terán, Emilia Crespo y Elena Mejía
4.1 Aprovechamiento por tipo de bosque y especies

4.2 Principales flujos comerciales de la madera 34

$\begin{array}{lll}\text { 4.3 Una descripción de proveedores y compradores } & 37\end{array}$

4.4 Establecimientos de madera en cuatro ciudades 44

5 Aprovechamiento de madera por finqueros en Napo y Orellana 50

Aymé Muzo, Filippo del Gato, Pablo Pacheco y Bolier Torres

5.1 El caso de Napo: Análisis de las estrategias de los finqueros 51

5.2 Estrategias diferenciadas de aprovechamiento de madera 55

5.3 El caso de Orellana: Análisis de las estrategias de los finqueros 61

5.4 Estrategias diferenciadas de aprovechamiento de madera 64

5.5 Hacia un balance sobre el aprovechamiento forestal por finqueros 69

6 El aprovechamiento forestal en pequeña escala 73

Elena Mejía, Guido Fernández, Marco Vinueza y Álvaro Fuentes
6.1 Características de las operaciones forestales y sus actores

6.2 Los costos de la legalidad en los programas de aprovechamiento 76

6.3 Decisiones de aprovechamiento, productividad y calidad de la madera 77

6.4 Los costos y beneficios del aprovechamiento en pequeńa escala 78

6.5 Comparación de los beneficios para el finquero 85

$\begin{array}{llr}7 & \text { Conclusiones } & 87\end{array}$

$\begin{array}{lll}8 & \text { Referencias } & 90\end{array}$

$\begin{array}{lr}\text { Anexo } & 94\end{array}$ 


\section{Lista de cuadros, figuras, mapas, y recuadros}

\section{Cuadros}

1 Usos del suelo en unidades de producción agropecuaria en $2010 \quad 6$

2 Cambio en la población rural del Ecuador en el periodo 2001-10 6

3 Indicadores económicos en años seleccionados 7

4 Principales orígenes, tipos de bosque y destino de la madera $r$

5 Mejoras del SAF I al SAF II en el nivel del usuario 14

6 Pagos realizados por concepto de legalización madera en pie o pie de monte 15

7 Informantes clave entrevistados $\quad 18$

8 Tipología de los intermediarios $\quad 19$

9 Tipo de ejecutor $\quad 19$

10 Tipo de intermediarios y pagos realizados al finquero 21

11 Conflictos entre actores en el aprovechamiento de madera 23

12 Diferencia en cambio de uso de suelo después de un PAFSI 27

13 Aprovechamiento por región y tipo de bosques en el 2011

14 Amazonía: Aprovechamiento por tipo de programa en 2011

15 Amazonía: Aprovechamiento por tipo de programa y especie en 201133

16 Ecuador: Destino y origen de la madera movilizada en 2011

17 Principales especies movilizadas de la Amazonia y sus destinos 36

18 Ejecutores por rubro y tamańo 41

19 Compradores por rubro y tamańo 41

20 Tipo de ejecutores de programas forestales y compradores por rubro en 2011

21 Ejecutores por rubro y compradores por tamańo 45

22 Amazonía: Tipo de ejecutores de programas forestales y compradores por rubro en $2011 \quad 46$

23 Amazonía: Ejecutores por rubro y compradores por tamaño 47

24 Comparación de volúmenes de compra y procesado 48

25 Características de los hogares colonos y Kichwas 51

26 Uso de suelos en las parcelas de colonos y kichwas en hectáreas 52

27 Desmontes en parcelas de colonos y kichwas en el periodo del 2006 al $2012 \quad 53$

28 Ingresos de los colonos y kichwas en el periodo de agosto 2011-septiembre $2012 \quad 54$

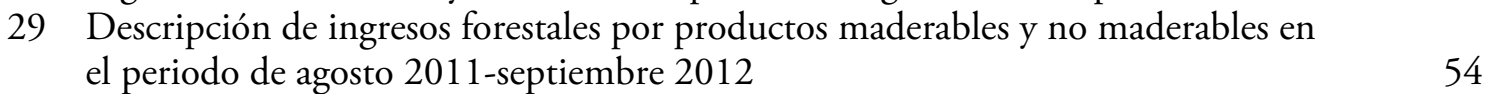

Características de los diferentes grupos de hogares según sus estrategias de
aprovechamiento de la madera

31 Características del aprovechamiento según tipo predominante $\quad 57$

32 Características de la venta de madera según la forma de aprovechamiento 58

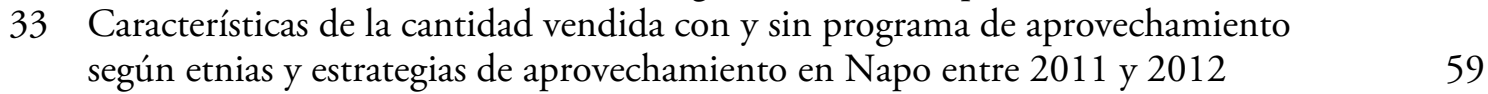

34 Costos y beneficios de los pequeños finqueros en el periodo de agosto 2011-
septiembre 2012

35 Aprovechamiento por el tipo de especie y uso de suelos 61

36 Características de los hogares colonos, kichwas y shuaras 62

37 Uso de suelos en las parcelas de colonos e indígenas (kichwas y shuaras) en hectáreas 63

38 Desmontes en parcelas de colonos e indígenas en el periodo del 2006 al $2012 \quad 63$ 
39 Ingresos de los colonos e indígenas (kichwas y shuaras) en el periodo de

febrero 2011-julio 2012

40 Descripción de los ingresos forestales por productos maderables y no maderables en el periodo de febrero 2011-julio 2012

41 Tipos según atributos de hogar y de la estrategia de aprovechamiento de recursos forestales

42 Características del aprovechamiento por la forma de aprovechamiento

68

43 Características de la venta de madera por la forma de aprovechamiento según etnias y estrategias de aprovechamiento en Orellana

45 Costos y beneficios de los pequeños finqueros en el periodo de febrero 2011julio 2012

46 Aprovechamiento por el tipo de especie y uso de suelos 70

47 Información comparativa entre Orellana y Napo 72

48 Tipos identificados y número de casos seleccionados $\quad 74$

49 Características de las operaciones $\quad 75$

50 Costos asociados a la legalización de la madera en USD 77

51 Costos de legalización en zona de estudio para diferentes volúmenes de madera aprovechada.

52 Diferencias entre promedios de desperdicios de troza y aserrado

53 Rendimiento promedio en especies estudiadas $\quad 80$

54 Costos y precios de venta promedio de especies aprovechadas 81

55 Costos y precios de venta promedio de especies aprovechadas para los casos de estudio 82

\section{Figuras}

1 Aprovechamiento de madera por formación boscosa entre 2007 y 2011

2 Amazonía: Costos de legalización en el periodo 2005-2012 12

3 El sistema de control forestal, basado en información recopilada en página web Ministerio del Ambiente del Ecuador $\quad 13$

4 La intermediación en el comercio de la madera 23

5 Amazonía: Volumen en $\mathrm{m}^{3}$ aprovechado por tipo de bosques y provincias 32

6 Amazonía: Madera movilizada según provincia de origen y 10 destinos principales $\quad 37$

7 Volumen movilizado por tamaño de ejecutor y formación boscosa 43

8 Volumen movilizado por tamaño de comprador y formación boscosa 43

9 Principales proveedores de madera de los establecimientos entrevistados 47

10 Principales compradores de madera de los establecimientos entrevistados 48

11 Rol de los ingresos forestales en los mecanismos de seguridad familiar en respuesta a crisis o imprevistos

12 Porcentaje de costos sobre los costos totales en el periodo de agosto 2011septiembre 2012

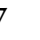

3

13 Rol de los ingresos forestales en los mecanismos de seguridad familiar en respuesta a crisis o imprevistos

14 Porcentaje de costos sobre los costos totales en el periodo de febrero 2011 a julio 2012

15 Distribución de costos por metro cúbico según principales ítems y participación del finquero, para 8 estudios de caso de aprovechamiento forestal en pequeńa escala con y sin PAFSI

16 Diferencia de ingresos y costos entre operaciones artesanales formales e informales con intervención del finquero o intermediario

17 Distribución de beneficios entre los actores del aprovechamiento 


\section{Mapas}

1 Área geográfica de estudio y localización de las comunidades encuestadas 3

2 Cobertura de uso del suelo en el Ecuador por regiones y provincias

3 Ecuador: Flujo de madera a nivel provincial elaborado según datos del SAF, Ministerio del Ambiente del Ecuador

4 Amazonía: Principales flujos de madera a nivel provincial, elaborado según información del SAF, Ministerio del Ambiente del Ecuador

5 Origen de la madera con destino a Huaquillas

\section{Recuadros}

1 Proceso de "blanqueo" o lavado de la madera 25

2 Cambio de uso de suelo después de la implementación de un PAFSI 27

$3 \quad$ Flujos de la madera con destino a la parroquia de Huaquillas 38

4 Los aserradores en el aprovechamiento de la madera $\quad 79$

5 Participación de la mujer en actividades de aprovechamiento forestal:

La mano de obra invisible en el caso de las mujeres kichwas 


\section{Lista de acrónimos}

CAPEIPI Cámara de la Pequeña y Mediana Empresa de Pichincha

CAPIA Cámara de la Pequeña Industria del Azuay

CLIRSEN Centro de Levantamientos Integrados de Recursos Naturales por Sensores Remotos

DNF Dirección Nacional Forestal

FAO Organización de las Naciones Unidas para la Agricultura y la Alimentación

FCB Formulario de corta para balsa

FCP Formulario de corta para pigüe

ITTO Organización Internacional de las Maderas Tropicales

MAE Ministerio del Ambiente del Ecuador

PAFAP Programa de Aprovechamiento forestal para árboles plantados

PAFCL Conversión Legal del Suelo

PAFEP Programa de aprovechamiento forestal para bosques cultivados (árboles de regeneración natural) / Programa de corta de especies pioneras

PAFPL Programa de aprovechamiento forestal para bosques cultivados

PAFSI Programa de Aprovechamiento Simplificado

PAFSU Programa de Aprovechamiento Sustentable

PCAR Programa de corta para corta de árboles relictos

SAF Sistema de Administración Forestal

SCF Sistema de Control Forestal

SENPLADES Secretaría Nacional de Planificación y Desarrollo | Ecuador

SGS Société Générale de Surveillance

SNDCF Sistema Nacional Descentralizado de Control Forestal

SNTCF Sistema Nacional Terciarizado de Control Forestal

SRI Servicio de Rentas Internas del Ecuador 


\section{Agradecimientos}

Los autores agradecen la valiosa colaboración de numerosas personas que han contribuido durante el proceso de recopilación de información, principalmente en las provincias de Napo y Orellana, sin ellos no hubiera sido posible la elaboración de este estudio. Nuestro agradecimiento se dirige especialmente a miembros de las comunidades kichwas, shuar y mestizas en las mencionadas provincias. Este agradecimiento se hace extensivo al Ministerio de Medio Ambiente (MAE), tanto la oficina en Quito como las oficinas de Napo y Orellana por el apoyo brindado con información y discusiones que han contribuido a mejorar nuestro análisis. También agradecemos a la GIZ Ecuador, por su apoyo durante todo el proceso de investigación, así como a la Universidad Técnica Estatal de Quevedo y la Universidad Técnica del Norte. Esta investigación no hubiera sido posible sin el apoyo financiero de la Unión Europea. 


\section{Introducción}

Diversos estudios analizan la situación del sector forestal en el Ecuador, con distintos énfasis. Por ejemplo, Owen y Thiel (2006), analizan la influencia de las políticas en la dinámica económica del sector forestal. Ibarra et al. (2008) exploran las implicaciones de la legislación forestal en el manejo de bosques en pequeña escala por finqueros.

Ańazco et al. (2010) adoptan una perspectiva más comprehensiva para analizar los problemas actuales que enfrenta el sector forestal y señalar los desafíos para avanzar hacia una gestión forestal sostenible. A diferencia de éstos, aquí se presenta un análisis centrado en la dinámica del aprovechamiento de la madera en la Amazonía por parte de finqueros, colonos e indígenas, y de sus vínculos con el mercado interno de la madera. Los trabajos más relevantes sobre temas vinculados están dedicados a describir los usos internos y flujos comerciales de la madera (Wunder, 1996), así como las dinámicas de las cadenas productivas de la madera con una perspectiva nacional (Ministerio del Ambiente del Ecuador, 2011).

Este documento forma parte de un análisis comparativo mayor que explora las opciones que existen para integrar a un numeroso sector de pequeños productores de madera que usualmente realizan sus operaciones de aprovechamiento de manera informal para el mercado interno. Esta temática es relevante en el Ecuador ya que una parte importante del aprovechamiento de bosques nativos, particularmente en la Amazonía, se realiza con el uso de motosierra en parcelas de pequeños productores o tierras de comunidades indígena. Asimismo, una porción significativa de madera es aprovechada, debido a diferentes razones, al margen de la normativa forestal, lo que tiene implicaciones diversas en los medios de vida de los pequeños productores y la economía e institucionalidad forestal. Para comprender mejor la persistencia e implicaciones del aprovechamiento informal es importante entender las características de las operaciones forestales, las condiciones de funcionamiento de los mercados de madera, las interacciones entre los diversos actores, y los acuerdos para la distribución de los beneficios obtenidos.

El análisis que aquí se ofrece proporciona elementos que reafirman la importancia del mercado interno y del aprovechamiento de madera en pequeña escala, así como las condiciones legales, institucionales y económicas que explican la racionalidad de ese tipo de aprovechamiento de los bosques. Asimismo, se destacan los esfuerzos realizados en el Ecuador para mejorar las condiciones de gobernanza del sector forestal, particularmente a través de la simplificación de la normativa forestal y la puesta en marcha de un sistema de verificación de la legalidad forestal asociado a un esquema de regencia y controles en las diferentes fases de la cadena de la madera. Cabe destacar que Ecuador, a diferencia de otros países de la cuenca amazónica, no penaliza el aprovechamiento de madera con motosierra. Estos esfuerzos han sido decisivos para avanzar hacia una gestión forestal más sostenible pero todavía se requiere de mejores opciones para integrar a los pequeños productores al mercado interno de la madera.

Los desafíos que aún quedan por resolver están vinculados con la necesidad de reducir las barreras institucionales que dificultan la posibilidad de realizar aprovechamiento formal a un numeroso grupo de pequeños productores, a través de continuar adaptando la normativa forestal a las necesidades de los finqueros y poblaciones indígenas. Asimismo es importante mejorar la distribución de los beneficios económicos entre los diferentes actores que participan del aprovechamiento, lo que posiblemente puede lograrse mediante la provisión de servicios financieros mejor desarrollados para los actores 
forestales locales, así como mejorando la transparencia de los mercados de la madera. En este sentido, es importante transitar de una visión que prioriza el control forestal hacia otra que también privilegia el estímulo a las prácticas de aprovechamiento sostenible de los bosques dentro de perspectivas más integrales de manejo de tierras agrícolas y forestales, y de los paisajes rurales.

El análisis que aquí se presenta se realiza en diferentes niveles. El capítulo 2 presenta los principales elementos de contexto sobre la gobernanza forestal en el Ecuador. Otra parte de nuestro análisis, que complementa el anterior, se basa en entrevistas a actores claves del mercado interno de la madera, principalmente productores e intermediarios de madera en las provincias de Orellana y Napo (capítulo 3), este está destinado a describir la forma en que estos actores se relacionan con los mercados y los acuerdos que establecen entre ellos, y sus implicaciones para el control forestal. Una parte importante de nuestro análisis (capítulo 4) tiene un alcance nacional destinado a entender la dinámica del aprovechamiento y de los principales flujos de la madera según estadísticas oficiales provenientes del Sistema de Aprovechamiento Forestal (SAF) del Ministerio de Medio Ambiente (MAE), que abarca los flujos de madera legal. El capítulo 5 está centrado en las provincias de Orellana y Napo, y se basa en información de encuestas a hogares para entender mejor sus decisiones de uso del suelo y manejo forestal como parte de estrategias más generales de los medios de vida. Este análisis ha sido complementado con estudios de caso sobre las diferentes formas en que se realizan las operaciones de aprovechamiento forestal y la distribución de beneficios asociada a esos diferentes tipos de operaciones forestales (capítulo 6).

El análisis sobre las redes de intermediación en el aprovechamiento formal e informal que se desarrolla en el capítulo 3 se basa en entrevistas a actores que intervienen en el aprovechamiento forestal y la comercialización de la madera, entre ellos: comerciantes, intermediarios, regentes, técnicos forestales, aserradores y presidentes comunitarios. El análisis más general sobre la dinámica de los mercados internos de la madera, contenido en el capítulo 4, tiene como fundamento información oficial del SAF proporcionada por el MAE para el año 2011, siendo el último año con datos disponibles por el SAF al momento del análisis. Esta información captura únicamente las movilizaciones de madera por origen y destino cuya procedencia es legal, es decir, que cuentan con un permiso de aprovechamiento forestal y guía de movilización, por lo que no refleja los flujos informales de madera. Pese a esa limitación, como los datos capturan solo la parte legal del volumen total aprovechado, proporcionan una imagen relativamente completa de los volúmenes movilizados dentro de las principales rutas de la madera y hacia los centros de consumo más importantes. Esta información ha sido complementada con otra información de acceso público del Servicio de Rentas Internas (SRI) para determinar los tipos de ejecutores de programas de aprovechamiento y compradores de acuerdo con su Registro Único de Contribuyentes (RUC). La combinación de estos datos permite ofrecer una perspectiva más completa sobre las principales características de los flujos de la madera asociada a los diferentes tipos de vendedores y compradores de madera para el Ecuador en su conjunto.

El análisis de las decisiones de uso del suelo y manejo de bosques realizadas por los pequeños productores se desarrolla en el capítulo 5 . Este se basa en 243 encuestas semiestructuradas a hogares en 21 comunidades localizadas en las provincias de Orellana y Napo. La selección de los hogares se llevó a cabo en dos fases: primero se identificaron las comunidades a través de un muestreo intencional basado en el origen étnico, tamaño y ubicación de las comunidades, y después se identificaron los hogares a ser entrevistados a través de un muestreo aleatorio simple. La recolección de los datos se realizó durante 7 meses de trabajo de campo entre los meses de febrero hasta septiembre de 2012. El mapa 1 detalla la localización de las comunidades seleccionadas para el levantamiento de información. Por su parte, la caracterización del análisis de las operaciones de aprovechamiento forestal que es el principal enfoque del capítulo 6 se basa en ocho estudios de caso seleccionados en las provincias de Orellana y Napo según una tipología que considera la legalidad del aprovechamiento y la participación del finquero en el aserrío de la madera. Los métodos para la recopilación de información se basaron en acompañamientos a las operaciones de corta lideradas por intermediarios y por finqueros, en donde se recolectó información de productividad y costos/beneficio. Este levantamiento se realizó entre los meses de marzo y agosto de 2012. 

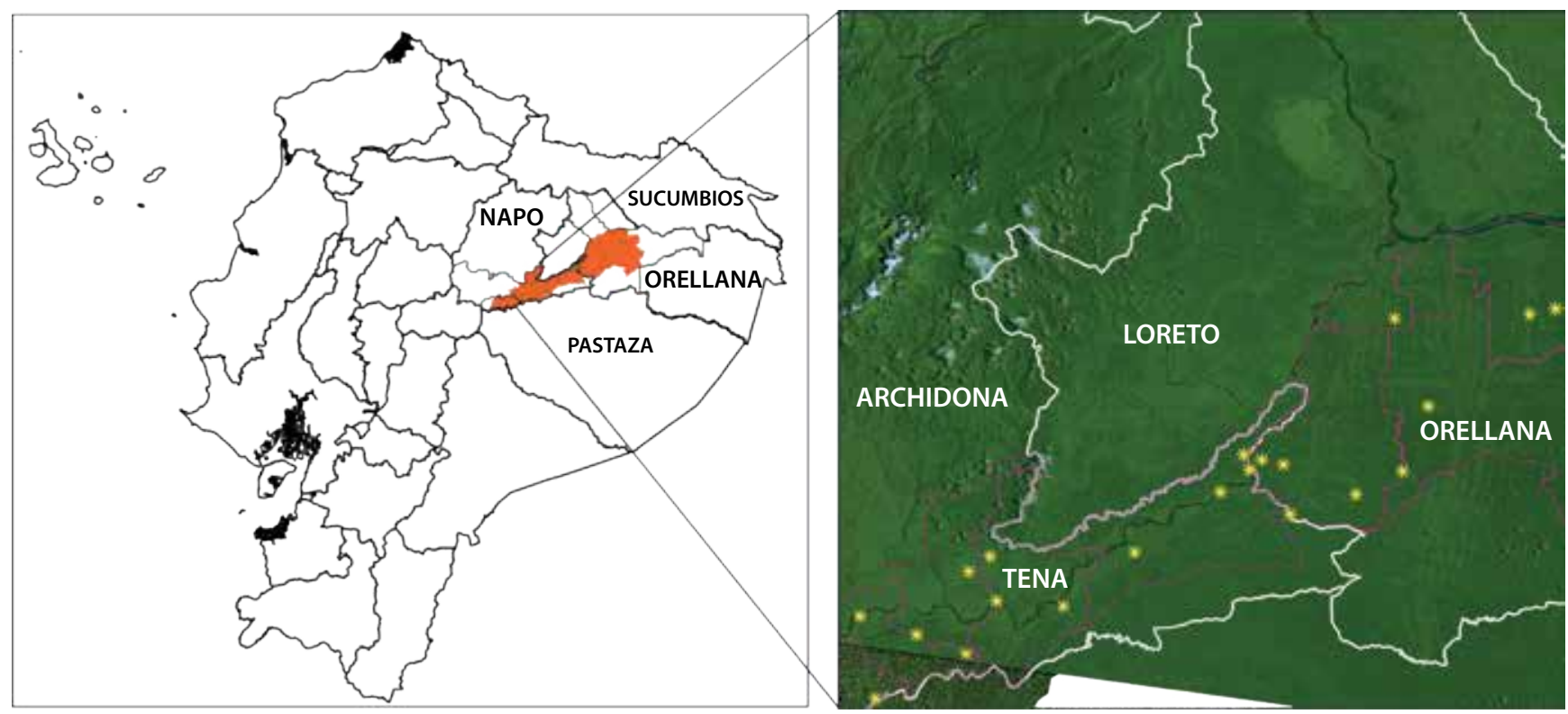

Mapa 1. Área geográfica de estudio y localización de las comunidades encuestadas. Las estrellas en amarillo corresponden a comunidades seleccionadas y las líneas en rosado a las parroquias donde se realizó el estudio. Elaboración propia basada en información de la oficina técnica del MAE en la provincia Napo. 


\title{
Elementos de contexto
}

\author{
Elena Mejía y Pablo Pacheco
}

\subsection{Uso del suelo, población y sector forestal}

El Ecuador tiene una superficie de 256370 $\mathrm{km}^{2}$. Posee 4 regiones geográficamente muy diferenciadas, a saber: la Costa a lo largo del litoral pacífico del país, la Sierra que abarca el área de la cordillera andina que cruza el centro del país de norte a sur, el Oriente que concierne las tierras bajas de la región amazónica, y la región insular de las islas Galápagos. El país se divide administrativamente en 22 provincias, que a su vez están compuestas por cantones y parroquias. La región amazónica es la más extensa, ocupando el $45 \%$ del total de la superficie del país $\left(115613 \mathrm{~km}^{2}\right) .{ }^{1}$ Esta última región está constituida por tierras bajas que están mayormente cubiertas con bosques tropicales densos que se extienden hasta el pie de la cordillera de los Andes, vegetación que contiene una importante biodiversidad (mapa 2).

La cobertura vegetal en el Ecuador depende fuertemente de las regiones geográficas. En la Amazonía predominan los bosques nativos, los cuales cobijan una importante biodiversidad (Mena, et al., 2011). Los bosques se han ido reduciendo con el tiempo, aunque la información sobre esa tendencia es contradictoria. Un estudio realizado por CLIRSEN (2003) indica que la cobertura forestal era de 11,68 millones de hectáreas en 2000. FAO (2010) estimó para ese mismo ańo una cobertura forestal de 11,84 millones de hectáreas, que se habrían reducido a 9,86 millones de hectáreas en 2010. Estos datos, no obstante, consideraron un crecimiento lineal de la deforestación de 197 mil hectáreas/año entre

1 La Amazonía ecuatoriana comprende seis provincias, que de norte a sur son las siguientes: Sucumbíos, Orellana, Napo, Pastaza, Morona Santiago y Zamora Chinchipe.
1990 y 2010, lo que resultaba en tasas anuales de deforestación del orden del 1,5\%. No obstante, un estudio del Ministerio del Ambiente del Ecuador (2012) indica que la deforestación reciente sería bastante menor, puesto que habría sido de 89,9 mil hectáreas entre $1990-2000$ (0,71\% año) y 77,6 mil hectáreas entre 2000-08 (0,66\% año). Según esta última fuente, la mayor deforestación ocurre en la Costa y en la vertiente oriental de los Andes, seguida por la Amazonía.

La información sobre usos del suelo en tierras ocupadas por unidades agropecuarias es parcial. De acuerdo a la Encuesta de Superficie y Producción Agropecuaria Continua (ESPAC), sobre una superficie total de 11,74 millones de hectáreas ocupadas por unidades económicas agropecuarias ${ }^{2}$, las mayores superficies intervenidas por unidades con finalidades predominantemente agropecuarias se encuentran tanto en la Sierra como en la Costa. No es de sorprender que los usos principales de la tierra en estas unidades estén vinculados con cultivos permanentes y temporales, pero predominantemente pastos, que ocupan casi la mitad de la superficie total. Además, únicamente en la región de la Amazonía, las unidades reportan más de la mitad de su superficie bajo bosques $(55 \%)$, proporción que es inferior en la Sierra $(27,5 \%)$ y Costa $(21,7 \%)$ (cuadro 1). El último Censo Agrícola del INEC (2011) estima que el 85\% de la población de la Amazonía depende de la agricultura ${ }^{3}$.

2 Se consideran como tales a las unidades económicas con extensión de tierra de $500 \mathrm{~m}^{2}$ o más, dedicada total o parcialmente a la producción agropecuaria, que desarrollan su actividad bajo una dirección o gerencia única independientemente de su forma de tenencia o ubicación geográfica INEC. 2010. Sintesis metodológica ESPAC. Quito, Ecuador: Instituto Nacional de Estadísticas y Censos.

3 El 70\% de los créditos provienen del Banco Nacional de Fomento para fines agrícolas y el 55\% de los créditos se destinan a la compra de ganado y el $35 \%$ a los cultivos permanentes. 


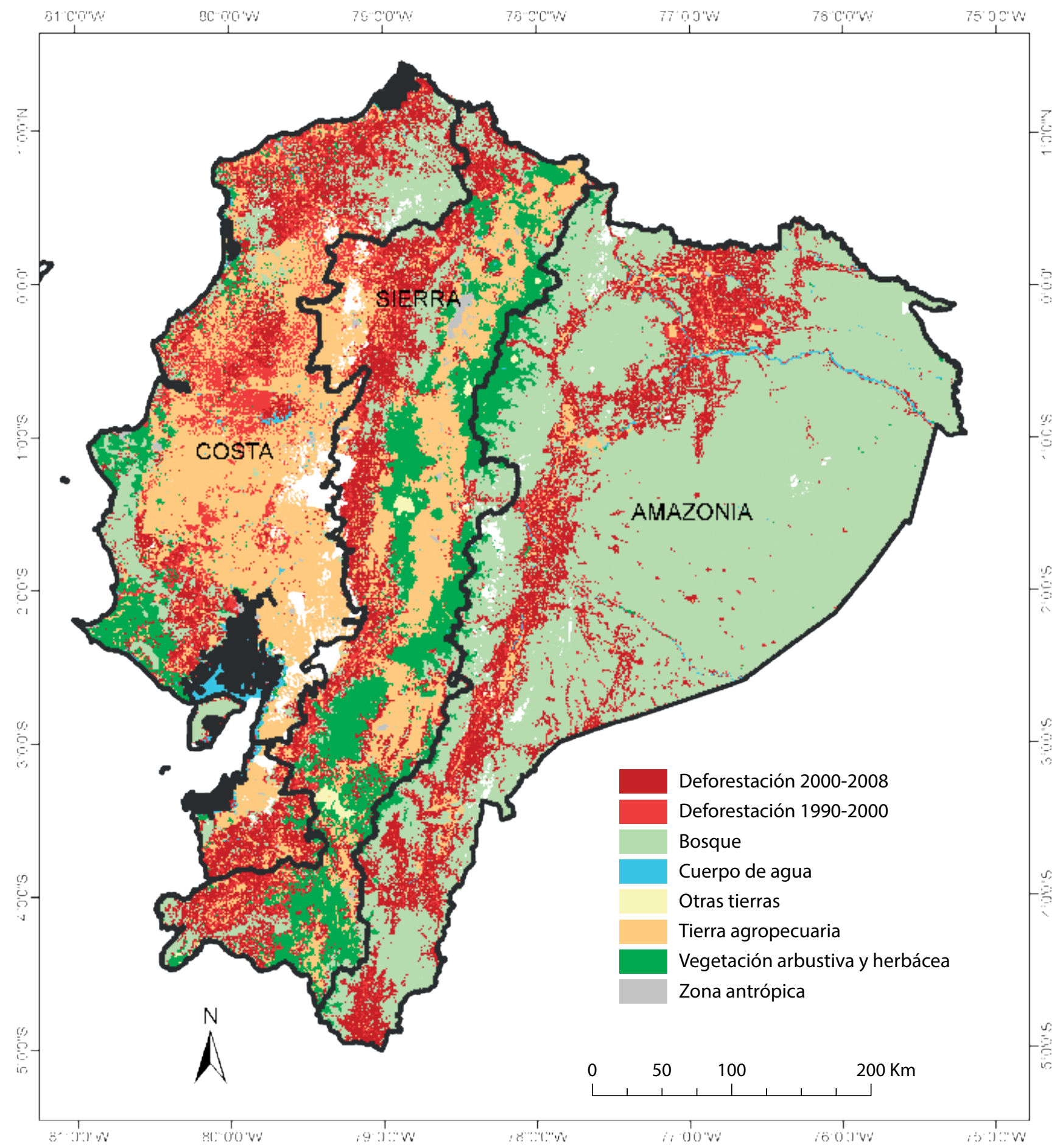

Mapa 2. Cobertura de uso del suelo en el Ecuador por regiones y provincias. La información de uso del suelo proviene del análisis de la línea base de deforestación elaborado por el Ministerio del Ambiente (MAE 2012). No incluye las islas Galápagos.

La mayor intervención sobre los recursos, con incidencia en el uso del suelo, tiene una relación casi directa con la intensidad de la ocupación humana que existe en las diferentes regiones, como se aprecia en el cuadro 2. La Sierra es la región más poblada, con un crecimiento absoluto neto de población, y donde existe una mayor intensidad de población por uso agrícola de suelo. En la Costa la población tiende a disminuir en términos absolutos, con lo que también se reduce 
Cuadro 1. Usos del suelo en unidades de producción agropecuaria en 2010

\begin{tabular}{|c|c|c|c|c|c|c|}
\hline & Cultivos & Pastos & Páramos & Bosques & Otros usos & Total (a) \\
\hline \multicolumn{7}{|c|}{ Usos del suelo por región (miles de ha) } \\
\hline Sierra & 769 & 2135 & 502 & 1176 & 98 & 4679 \\
\hline Costa & 1641 & 1882 & 2 & 944 & 105 & 4573 \\
\hline Amazonía & 155 & 904 & 36 & 1385 & 14 & 2493 \\
\hline Total & 2565 & 4920 & 539 & 3504 & 217 & 11745 \\
\hline \multicolumn{7}{|c|}{ En porcentajes por fila } \\
\hline Sierra & 18,9 & 49,5 & 1,4 & 27,5 & 2,7 & 100 \\
\hline Costa & 33,6 & 42,6 & 0 & 21,7 & 2,1 & 100 \\
\hline Amazonía & 6 & 36,2 & 1,6 & 55,3 & 1 & 100 \\
\hline Total & 22 & 43,7 & 0,9 & 31,4 & 2,1 & 100 \\
\hline
\end{tabular}

Nota: a) Los totales han sido ajustados para corregir errores observados en la base original.

Fuente: Datos obtenidos de Ecuador en Cifras (http://www.ecuadorencifras.com), Encuesta de Superficie y Producción Agropecuaria Continua (ESPAC), INEC (2011).

Cuadro 2. Cambio en la población rural del Ecuador en el periodo 2001-10

\begin{tabular}{lccccccc}
\hline \multirow{2}{*}{ Regióna $^{\text {a }}$} & \multicolumn{2}{c}{$\begin{array}{c}\text { Población rural } \\
\text { (miles) }\end{array}$} & $\begin{array}{c}\text { Cambio población } \\
\text { rural (\%) }\end{array}$ & $\begin{array}{c}\text { Población rural/ } \\
\text { total (\%) }\end{array}$ & $\begin{array}{c}\text { Población rural/Área } \\
\text { agrícola total (hab./ha) }\end{array}$ \\
\cline { 2 - 8 } & $\mathbf{2 0 0 1}$ & $\mathbf{2 0 1 0}$ & $\mathbf{2 0 0 1 - 1 0}$ & $\mathbf{2 0 0 1}$ & $\mathbf{2 0 1 0}$ & $\mathbf{2 0 0 1}$ & $\mathbf{2 0 1 0}$ \\
\hline Sierra & 2448 & 2487 & 1,6 & 44,8 & 39,9 & 0,85 & 0,86 \\
Costa & 1849 & 1820 & $(1,6)$ & 30,5 & 26,0 & 0,52 & 0,52 \\
Amazonía & 354 & 390 & 9,4 & 64,5 & 55,1 & 0,33 & 0,37 \\
Total & 4650 & $\mathbf{4 6 9 7}$ & $\mathbf{1 , 0}$ & $\mathbf{3 8 , 5}$ & $\mathbf{3 3 , 7}$ & $\mathbf{0 , 6 2}$ & $\mathbf{0 , 6 3}$ \\
\hline
\end{tabular}

Fuente: Datos obtenidos de Ecuador en Cifras (http://www.ecuadorencifras.com), Encuesta de Superficie y Producción Agropecuaria Continua (ESPAC), INEC (2011).

la participación de la población rural hasta casi una cuarta parte de la población total en 2010. Pese a ello, la intensidad de la población por uso del suelo se ha mantenido en el tiempo, debido también a la lenta expansión de los usos de cultivo del suelo en esta región en términos absolutos. Finalmente, la región de la Amazonía es donde existe un crecimiento mayor de la población rural, aunque pese a ello la población rural tiende a decrecer en términos relativos, debido a un ritmo mayor de crecimiento de la población asentada en las ciudades. La intensidad poblacional por unidad de superficie cultivada también tiende a aumentar en términos relativos en esta región (cuadro 2).

El Ecuador tiene una economía relativamente vigorosa, la cual descansa fuertemente en la exploración y exportaciones petroleras. En 2011, el PIB total ascendió a unos 78 mil millones de
USD, de los cuales la mayor parte está asociada a los sectores de petróleo y manufacturas. La contribución del sector de agricultura, ganadería y silvicultura al PIB total es de unos 9-9,5\% entre 2007 y 2011 (cuadro 3). Se desconoce el aporte del sector forestal al PIB total; sin embargo, Owen y Thiel (2006) estimaron que para el 2006 llegó a ser del $1 \%$ del PIB, tendencia que puede haberse mantenido durante los ańos siguientes.

La poca contribución del sector forestal a la economía total, en términos relativos, se refleja también en la estructura de las exportaciones, siendo que las exportaciones forestales alcanzan solamente un $1 \%$ con respecto a las exportaciones totales (Banco Central del Ecuador, 2012). Estas fueron equivalentes a USD 148 millones en 2007 y USD 228 millones en 2011. No obstante, las importaciones de productos de madera son 
Cuadro 3. Indicadores económicos en años seleccionados (millones de USD)

\begin{tabular}{lccccc}
\hline & 2007 & 2008 & 2009 & 2010 & 2011 \\
\hline Producto Interno Bruto (PIB) & & & & & \\
\hline PIB Total & 51008 & 61763 & 61550 & 67856 & 78189 \\
PIB Agricultura y silvicultura & 4772 & 5537 & 5807 & 6427 & 7189 \\
PIB Agricultura y silvicultura/Total (\%) & 9,4 & 9,0 & 9,4 & 9,5 & 9,2 \\
\hline Comercio exterior & & & & & \\
\hline Exportaciones totales & 13800 & 18818 & 13863 & 17490 & 22345 \\
Exportaciones forestales & 148 & 176 & 155 & 206 & 228 \\
Exportaciones forestales/totales (\%) & 1,1 & 0,9 & 1,1 & 1,2 & 1 \\
Importaciones forestales & 24 & 36 & 37 & 52 & 58 \\
Balance comercial forestal & 124 & 139 & 118 & 154 & 170 \\
\hline
\end{tabular}

Fuente: Elaboración propia basada en CEPAL (2011) y COMTRADE (2011).

relativamente más pequeñas, aunque han tenido a aumentar, situándose en USD 58 millones en 2011. La poca importancia de las importaciones hace que el Ecuador tenga un balance comercial forestal positivo (si se excluyen pulpa, papel y cartón). Pese a su poca contribución formal a la economía nacional, la industria forestal en el Ecuador tiene un papel importante en la generación de ingresos y empleo.

El sector forestal en el Ecuador está principalmente orientado hacia el mercado interno, pese a que la industria maderera de aglomerados y contrachapados, está articulada a los mercados externos (Sierra, 2001). Si bien los bosques nativos de la Costa han sido la principal fuente de madera en el pasado, debido a su gradual reducción en el tiempo, esta oferta ha sido reemplazada por plantaciones forestales creadas en esa misma región así como en la región Sierra. Aunque la contribución de los bosques nativos en términos relativos a la oferta interna de madera es poco significativa, y tiende a disminuir con el tiempo, en términos absolutos, la oferta de madera de los bosques nativos ha aumentado de forma progresiva, aunque lenta. Ello en parte se explica por la mayor integración caminera en la Amazonía que facilita el acceso a los bosques nativos, junto con la expansión de la demanda urbana que también ha incentivado el consumo de madera de bosques nativos (Wunder, 2005; Barbieri, et al., 2009)

El mercado interno de la madera en el Ecuador es bastante vigoroso, con múltiples flujos de la madera entre zonas de producción y consumo tal como han sido descritas por el Ministerio del Ambiente del Ecuador (2011). El cuadro 4 presenta algunas de las características del sector a nivel nacional. No existen datos muy confiables sobre los volúmenes de madera que han sido efectivamente aprovechados antes de 2007. Las estimaciones oficiales sugieren que los volúmenes de madera autorizada se han incrementado en el tiempo, oscilando entre 2,2 a 2,8 millones de $\mathrm{m}^{3}$ entre 2007 y 2011 . La figura 1 muestra la magnitud del aprovechamiento forestal en las diferentes regiones del Ecuador para el mencionado periodo. Es importante resaltar que la mayor parte de las autorizaciones de madera han sido otorgadas para plantaciones forestales, seguidas por aquellas emitidas para bosques nativos, aprovechamientos en sistemas agroforestales y formaciones pioneras. Entre 2007 y 2011, en promedio, aproximadamente el 49,8\% de los volúmenes de corta han sido autorizados en la Costa, mientras que una porción inferior de $33,7 \%$ y $16,4 \%$ se han otorgado en la Sierra y Amazonía respectivamente.

Por otro lado, el sector de la construcción realiza una aportación de 2338 millones al PIB nacional en 2010 (Banco Central del Ecuador, 2012); especialmente en las ciudades de Guayaquil y Quito, donde también se concentra la demanda de madera como lo muestran los datos del SAF analizados en el presente estudio. Desde el año 2010, el sector inmobiliario ha despegado teniendo una demanda alta de madera para puertas, pisos y ventanas; sin embargo, se desconoce si la madera es de origen legal. Es importante destacar que hasta el año 2000, según ITTO (2002), existía en Ecuador 


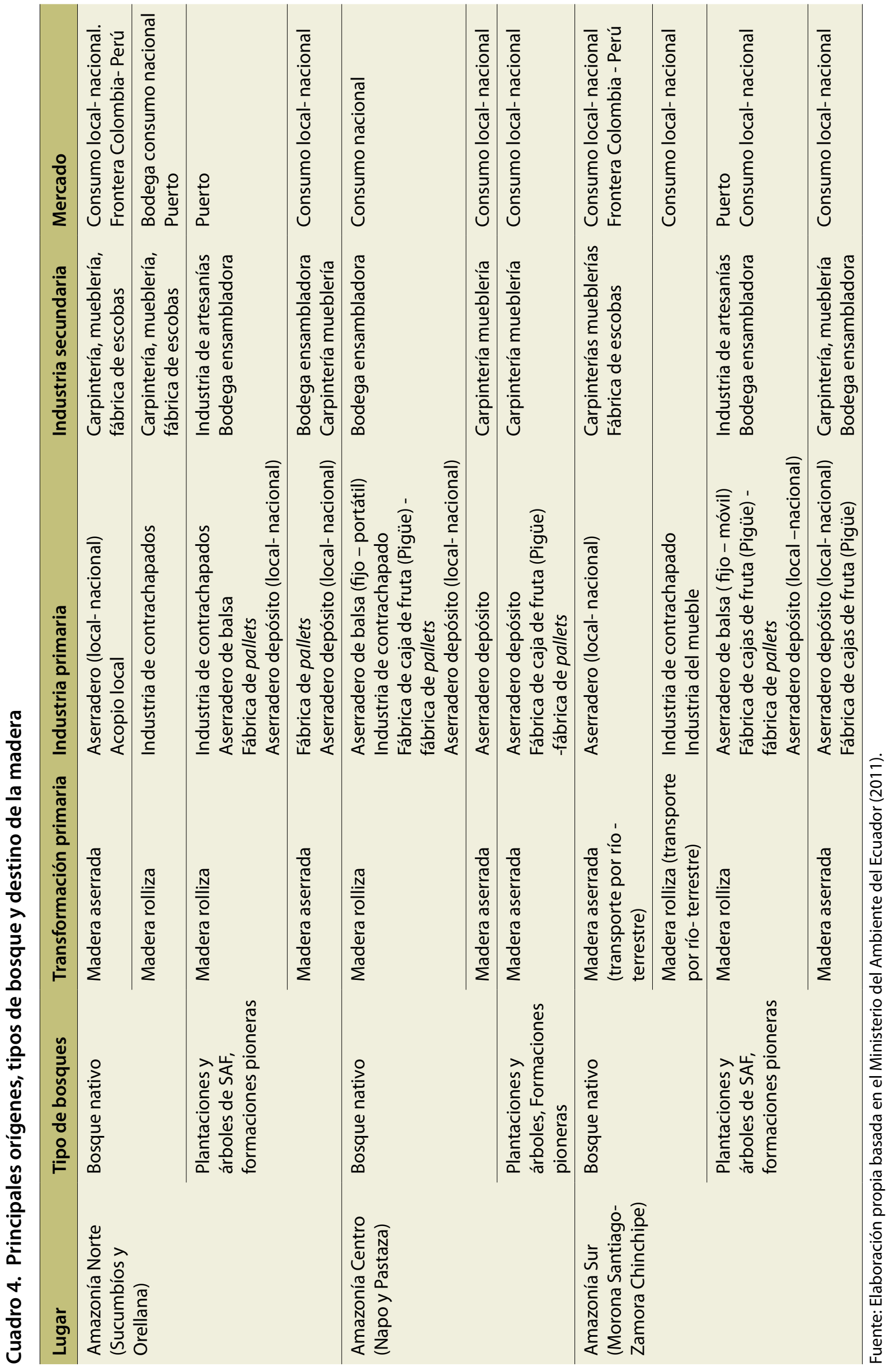




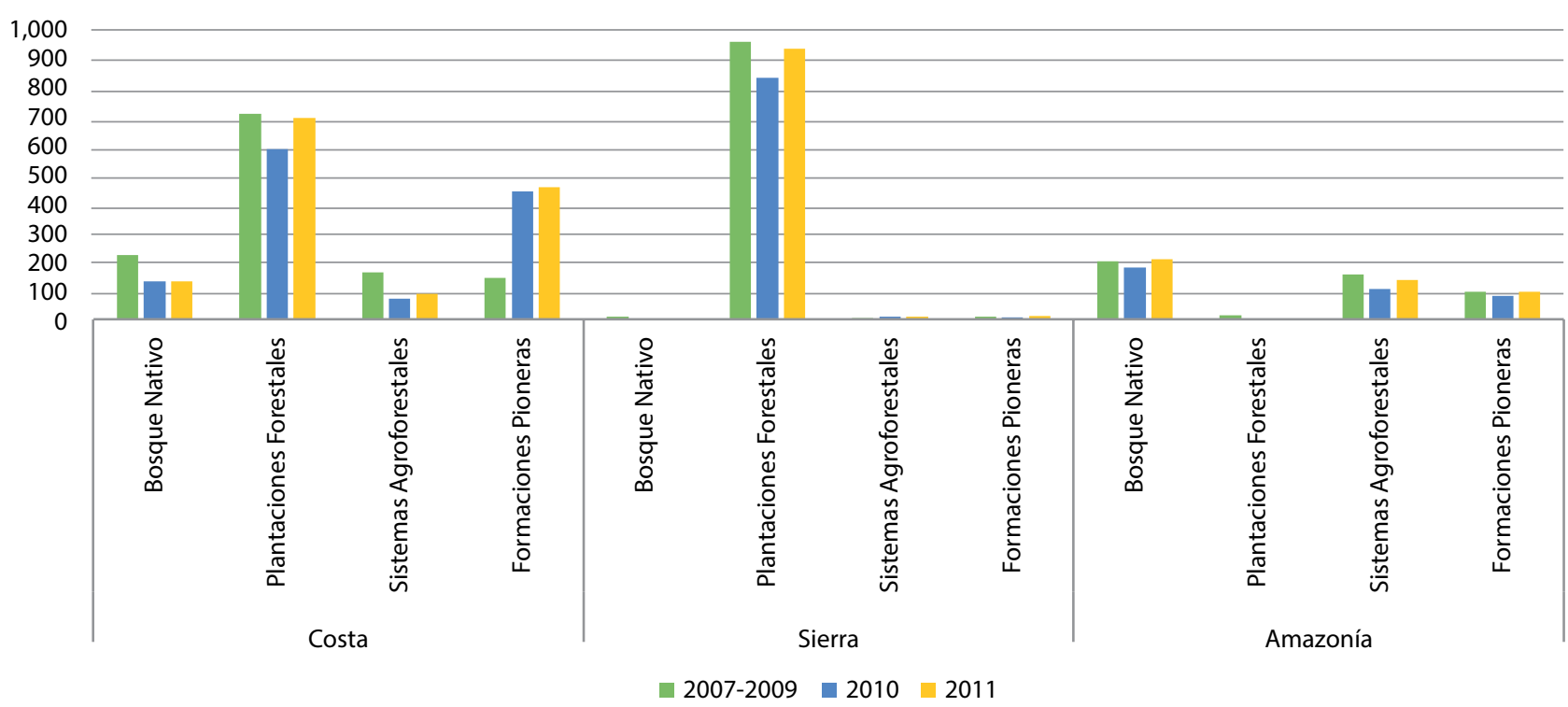

Figura 1. Aprovechamiento de madera por formación boscosa entre 2007 y $2011\left(\mathrm{~m}^{3}\right)$. Elaboración propia basada en el Ministerio del Ambiente del Ecuador (2011), SAF 2010 y 2011.

una sobredemanda y poca oferta de madera; actualmente se cree que las plantaciones forestales han venido a suplir esta demanda como lo muestran las tendencias señaladas en este capítulo y el mismo reporte de país de ITTO 2011. Sin embargo, esto no ha significado que la madera de bosques nativos haya disminuido su explotación, siendo así que especies como el chuncho, seike (Cedrelinga cateiniforme) usada para puertas y pisos han aumentado su aprovechamiento.

En el estudio de Middleton (2007) se indica que los pequeños artesanos de la madera en Ecuador están desapareciendo del mercado debido a la competencia que tienen con la industria, para proveerse de madera proveniente de intermediarios ${ }^{4}$ (depósitos). Según este mismo autor, los productores artesanos optan por redes menores - por lo general informales - de las cuales obtienen maderas finas para su trabajo, sin embargo, las importaciones de muebles de Brasil y Chile, ligadas a las grandes industrias de la madera, hacen que los precios internos no sean competitivos.

Varios trabajos destacan la importancia de la sustitución de plantaciones por bosques nativo (Izko, 2009; PNC-ONU-REDD Ecuador, 2013).

4 Esta observación también fue hecha en la versión impresa de la revista The Economist "The courts versus the rainforest". Disponible en http://www.economist.com/node/2180363
No obstante, el aprovechamiento forestal realizado a nivel nacional tiende a crecer proporcionalmente en todas las formaciones boscosas durante 2010 y 2011 (figura 1). Es decir, aunque es indudable que existe una tendencia de largo plazo de reducir la presión sobre bosques nativos mediante el aumento de la oferta de madera de plantaciones y formaciones pioneras, de forma simultánea los volúmenes autorizados de bosques nativos, sobre todo en la Amazonía, tienden a mantenerse o aumentar ligeramente, esto podría deberse a que las especies demandas de bosques nativos no cuentan con plantaciones que suplan su demanda.

Las plantaciones forestales cubren un área aproximada de 220000 hectáreas (Ecuador Forestal, 2007) Unas dos terceras partes consiste en plantaciones de pino (Pinus sp.) y eucalipto (Eucaliptus sp.) que se encuentran en la Sierra, mientras que las localizadas en la Costa están compuestas por una diversidad mayor de especies como, por ejemplo, balsa Ochroma pyramidale, teca Tectona sp., melina Gmelina sp. y laurel Cordia alliodora (Owen y Thiel, 2006).

Con la mejora de las vías de comunicación evidenciada en el último tiempo en el Ecuador, se ha mejorado la integración del mercado interno, particularmente en el caso de la Amazonía, con los principales mercados urbanos. Las políticas sectoriales han influido en aumentar la presión sobre los bosques, en especial los amazónicos, 
debido a la explotación petrolera y minera y la ampliación del sistema de carreteras ejecutada por los gobiernos provinciales, municipales y el gobierno central, los que de alguna manera han estimulado la llegada de migrantes colonos y promovido parcialmente la conversión de los bosques a usos agrícolas del suelo (Thiel y Trelles, 2008). Asimismo, una mayor fragmentación de la propiedad conduciría a aumentar la presión sobre los bosques (Holand, et al., 2013)

La demanda y oferta total de madera no están contabilizadas porque los datos oficiales cubren únicamente la porción que proviene de aprovechamientos autorizados, puesto que mientras que el SAF registra los volúmenes de madera legal, se desconocen los volúmenes que son comercializados de forma informal. El mercado de la madera combina tanto madera originada de aprovechamientos formales como informales. Con respecto a los precios, fuera de las aproximaciones realizadas por el Ministerio del Ambiente del Ecuador (2011) se desconocen los precios oficiales. Igualmente, la estacionalidad de la oferta y la demanda no ha sido claramente explorada, aunque basándose en evidencia anecdótica se presume que existe una clara tendencia de aumento de la oferta, sobre todo de la madera proveniente de la región Amazónica, durante el periodo que va entre Octubre y Diciembre.

\subsection{El esquema de control forestal en el Ecuador}

La gobernanza forestal en el Ecuador ha descansado principalmente en el control forestal, sobre todo hasta el 2008 cuando se inició el programa de incentivos Socio Bosque y en 2011 se arrancó con la asesoría forestal. Antes, entre 2000 y 2006, el modelo de gobernanza se caracterizó por impulsar la tercerización y la descentralización de las capacidades de control del Ministerio del Ambiente a terceros privados o gobiernos locales (Ministerio del Ambiente del Ecuador, 2006; Navarro, et al., 2009). En 2007 se reconoció que estas estrategias habían propiciado una débil institucionalidad, además de no haber resuelto los problemas existentes para el manejo y control de bosques $^{5}$, por lo cual el MAE asumió nuevamente

5 El reporte de SENPLADES 2010, indica que los principales problemas eran: 1 . Inexistencia de un estas competencias (SENPLADES, 2009). En este periodo, se llevó adelante un intenso proceso participativo de formulación de las políticas y la normativa forestal. .

En 2001, el MAE coordinó un proceso con diferentes grupos del sector privado y de la sociedad civil para desarrollar un sistema independiente de control forestal. En este marco y debido a la inestabilidad política/institucional en Ecuador argumentada por: falta de personal, limitados recursos financieros y corrupción, se fomentó el Sistema Nacional Terciarizado de Control Forestal (SNTCF), por el cual se delegaba la responsabilidad del monitoreo y la administración pública de las operaciones a terceros (FAO, 2006; Navarro, et al., 2009). Este sistema estuvo basado en tres componentes. El primero fue el establecimiento de una entidad de control denominada "Vigilancia Verde", con la participación del Gobierno y la sociedad civil, para monitorear los flujos de la madera desde las zonas de producción hasta los principales mercados. El segundo fue un sistema de "Regencia Forestal" con la responsabilidad de monitorear la legalidad en el aprovechamiento forestal, a través de la cual se garantizaba la transparencia en la provisión de los servicios técnicos y el cumplimiento de la normativa forestal en las operaciones de aprovechamiento. El tercero fue la entrega a una compañía privada de los servicios administrativos y de verificación. Esto último fue fuertemente cuestionado, llevando al fracaso de la iniciativa. En 2002, el MAE encomendó a SGS la supervisión del sistema del control forestal. No obstante, en 2003, la Corte Suprema del Ecuador, declaró que el nuevo sistema terciarizado de control forestal era incompatible con la normativa constitucional del país. En 2004, el contrato entre MAE y SGS fue cancelado (Navarro, et al., 2009).

En 2006 se inició un proceso de análisis y consultas para promover un nuevo sistema de

ordenamiento territorial orientado al fomento y manejo sustentable de los bosques; 2 . Trámites largos y caros para legalizar el aprovechamiento y la movilización de madera; 3. Altos costos del uso legal del bosque para los pequeños propietarios y comunidades; 4 . Falta de un sistema nacional de control forestal que regule efectivamente las áreas destinadas al uso forestal permanente y áreas con potencial para plantaciones forestales; 5 . Falta de un catastro forestal; 6. Inexistencia de un sistema de verificación de los procesos de control. 
control que culminó con el establecimiento del Sistema Nacional Descentralizado de Control Forestal (SNDCF), donde el Gobierno central, a través del MAE, asume el papel de ente rector a cargo de dictar las políticas de control forestal y dirigir a nivel nacional el SNDCF. Por su parte, los Gobiernos provinciales debían asumir las labores de aprobación de planes y programas de aprovechamiento y corta, así como emitir las licencias, las guías de circulación y verificar in situ la ejecución del aprovechamiento forestal. El MAE mantuvo a su cargo la administración forestal en los distritos regionales, oficinas técnicas y todas las jurisdicciones descentralizadas (Ibarra et al. 2007). Este proceso tuvo pocos avances debido a: 1) Capacidades mínimas de Gobiernos locales para ejecutar administración y control forestal y 2) incapacidad del Gobierno central para darle seguimiento a las competencias descentralizadas (Ministerio del Ambiente del Ecuador, 2006; Ibarra, et al., 2008; Mejia, 2010).

Con el cambio de Gobierno en 2006, el debate se centró en la deforestación y el poco control por parte del Estado del sistema de administración forestal y la gestión de bosques. En este mismo ańo se formula "El Plan Nacional de Desarrollo 2007-2010”, el cual reconoció además de la débil institucionalidad y voluntad política, los problemas de ordenamiento territorial orientado al fomento y manejo sustentable de los bosques; trámites largos, engorrosos y caros para legalizar el aprovechamiento y para la movilización de la madera, altos costos del uso legal del bosque para los pequeños propietarios y comunidades, falta de un sistema nacional de control forestal que identifique y regule efectivamente las áreas destinadas al uso forestal permanente y áreas con potencial para plantaciones forestales, falta de un catastro forestal y la inexistencia de un sistema de verificación de los procesos de control. El reconocimiento de estos factores llevó a replantearse el esquema de gobernanza forestal basado en cinco ejes: 1) sistema de incentivos, 2) sistema de información forestal, 3) sistema de administración y control forestal, 4) ordenamiento forestal y; 5) investigación, capacitación y difusión. Según Romero, M. (2013), el Gobierno del Ecuador ha invertido notables recursos para garantizar la protección y conservación de más de un millón de hectáreas para el 2013.

\subsection{La normativa y sus costos de implementación}

Las normas del régimen forestal, son las que regulan directamente la actividad de aprovechamiento del bosque nativo. Entre las principales se tienen las siguientes ${ }^{6}$ :

- Normas del sistema de Regencia Forestal (Acuerdo Ministerial \# 38, 2 de agosto de 2004). En el caso de existir por parte de los regentes casos de inobservancia e incumplimiento de las funciones y obligaciones establecidas en la normativa forestal vigente, se procede al análisis de cada caso, a través del expediente respectivo, pudiendo retirar temporal o definitivamente las atribuciones conferidas.

- Normas de procedimientos administrativos para autorizar el aprovechamiento y corta de madera y normas para el manejo forestal sustentable para aprovechamiento de madera en bosque húmedo (Acuerdo Ministerial \# 39, 31 de marzo de 2003)

- Guía de circulación de especies forestales (Acuerdo Ministerial \# 9, 2 de julio de 2001).

En este marco legal, el Ecuador busca asegurar la sostenibilidad del bosque en el contexto de las leyes macro que guían el aprovechamiento y control de los recursos forestales. (Para mayor detalle sobre las leyes referirse al Anexo 1).

La obtención del permiso para realizar el aprovechamiento forestal conlleva algunos costos fijos, principalmente el pago de pie de monte -3 USD por $\mathrm{m}^{3}$ aprovechado- $\mathrm{y}$ costos adicionales de transacción que usualmente tienden a variar. Los costos asociados a la obtención de un permiso por parte de un ejecutor dependen del tipo de mecanismo utilizado para la extracción, el tipo de la formación boscosa y el volumen aprovechado, existiendo un programa específico para cada caso. Sin embargo, cabe anotar que, según la FAO (2012), los costos asociados a la aplicación de la normativa para la legalización del aprovechamiento forestal constituyen barreras institucionales importantes, particularmente desde el punto de vista del propietario del predio que no posee la

6 Véase el Anexo I para una descripción más detallada de la normativa. 


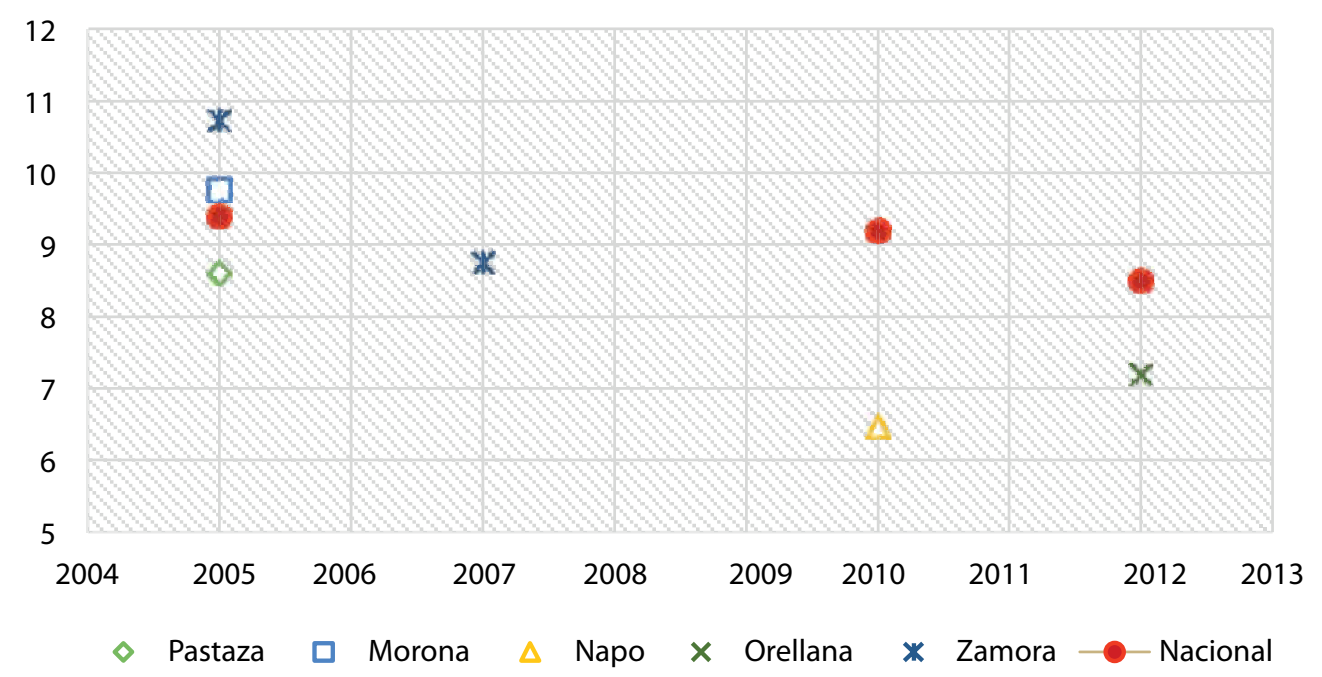

Figura 2. Amazonía: Costos de legalización en el periodo 2005-2012 (en USD/m³). Elaboración propia basada en estudios de caso en las provincias de la Amazonía ecuatoriana (Hetsch, 2004; Díaz y Gatter, 2004; Merino, 2010; FAO, 2012;

Schlotzhauer, 2012) y datos propios proveniente del trabajo de campo de los autores.

capacidad de pago, por lo cual recurre a terceros (intermediarios) para obtener la liquidez y cumplir con los trámites.

Los costos que deben ser cubiertos por los finqueros e intermediarios pueden distinguirse en directos e indirectos. Los costos directos se refieren a los pagos formales realizados al MAE y otras entidades del Estado como el Servicio de Rentas Internas (SRI), notarías públicas y municipalidades, los que hacen parte de los requisitos especificados para el procesamiento de los programas. Por su parte, los costos indirectos están relacionados con los costos de transacción en los que tienen que incurrir los actores para tramitar los programas de aprovechamiento como, por ejemplo, transporte y pagos de jornales a finqueros ${ }^{7}$, entre otros. Ambos costos varían y dependen sobre todo del volumen de metros cúbicos que serán aprovechados, el tamaño de la propiedad y la distancia a la ciudad. La figura 2 muestra los costos en que los que se incurriría para aprobar los programas de corta de la madera en fincas.

La legalización de un programa de corta o aprovechamiento, requiere de un tercero o regente forestal, quien levanta la información en campo

7 Es costumbre pagar el día del finquero para que este realice los trámites respectivos en la ciudad. Este pago lo realiza el intermediario y oscila entre 10 y 15 USD. de las especies y aplica las reglas de la normativa para corta y selección de los árboles idóneos, proporcionando al mismo tiempo información a quien ejecuta el programa. Este procedimiento es parte de los requisitos para la aprobación de la licencia de aprovechamiento (Tandazo y Gatter, 2004). El MAE otorga al usuario el permiso de corta por un ańo y las respectivas guías de movilización de madera, además cumple un rol de verificador del cumplimiento de la norma en el lugar donde se realizan las operaciones y las vías por donde transita la madera (figura 3).

\subsection{El rol del SAF en el control forestal actual}

En el periodo 2007-2008, el Ministerio del Ambiente inició una nueva estrategia dentro del Sistema de Control Forestal (SCF). Según el MAE (2011), el SCF basa sus acciones en la implementación del SAF como sistema transversal para la gestión de la actividad forestal, genera información que permite el control forestal y supervisa la verificación forestal con la finalidad de asegurar la legalidad en las operaciones forestales desde el aprovechamiento en el bosque hasta la movilización al destino final (figura 3). Aunque este sistema ha agilizado notablemente el proceso de otorgación de guías para el transporte de madera, no ha logrado necesariamente mejorar el control del origen de la madera, siendo que según 


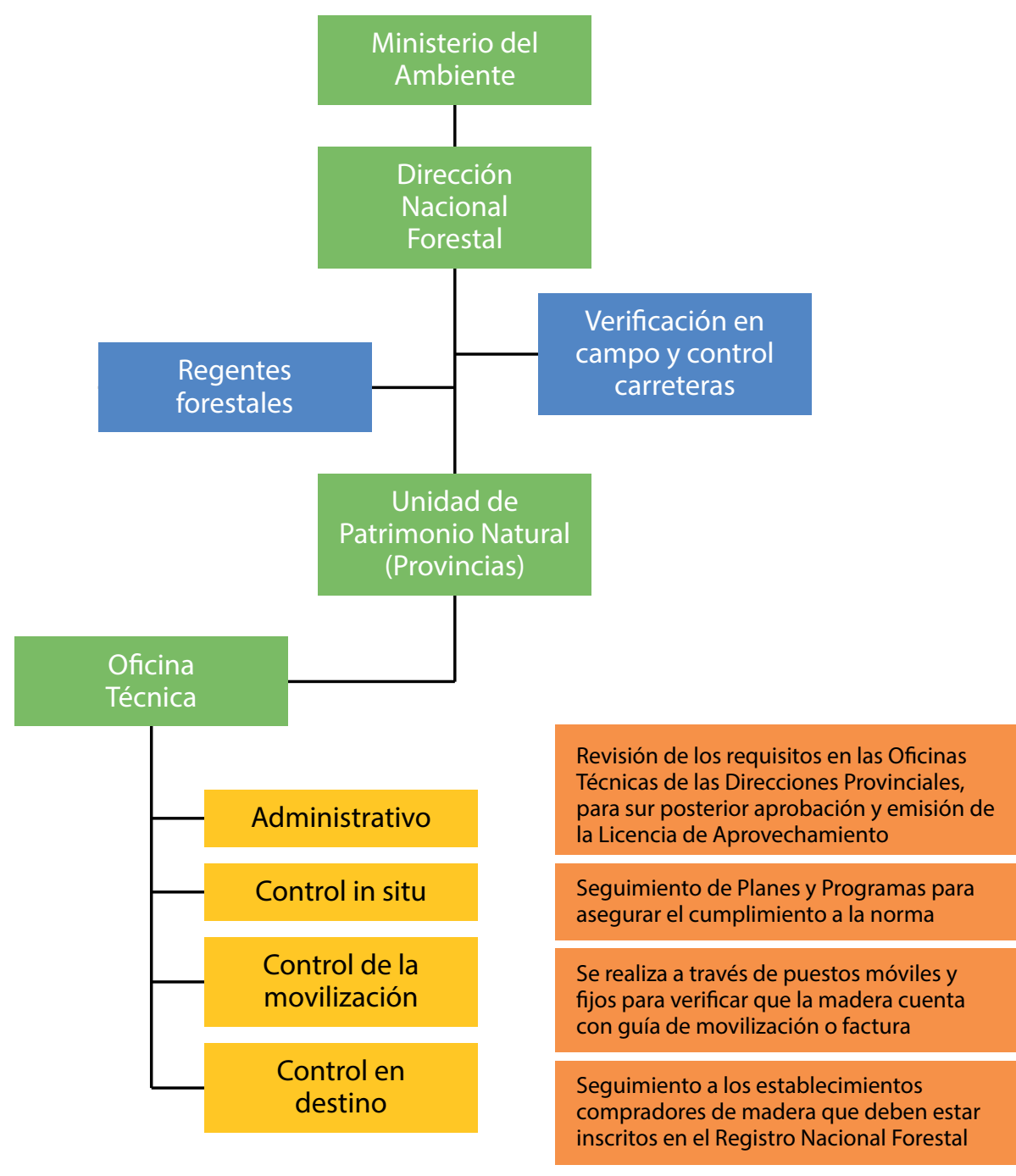

Figura 3. El sistema de control forestal, basado en información recopilada en página web Ministerio del Ambiente del Ecuador. http://www.ambiente. gob.ec/sistema-nacional-de-control-forestal/

evidencias anecdóticas todavía existe un mercado informal importante de guías de circulación, el uso de dichas guías para más de un recorrido, y una fiscalización poco estricta en algunos puestos de control que facilita la evasión.

El SAF descansa en una serie de normas legales e institucionales que permite una clara visión de su implementación por parte de las oficinas centrales y regionales del MAE. Los objetivos que el MAE espera alcanzar con el SAF son: 1) administrar e informar sobre los recursos forestales a nivel nacional, 2) realizar un seguimiento de cada uno de los procedimientos a lo largo de la cadena de valor forestal, es decir desde el aprovechamiento en el bosque hasta la comercialización de productos terminados en el mercado nacional e internacional y, 3) conocer las características y condiciones de los recursos naturales para su uso con la finalidad de realizar un análisis de los Planes y Programas de Aprovechamiento Forestal para su correcta aprobación.

La primera fase del SAF (conocida ahora como SAF I) se inició en 2008, y hacia mediados del 2009 se inició la segunda fase (conocida como SAF II) destinada a resolver las deficiencias observadas en los procedimientos previos del sistema. La nueva versión del SAF está en operación desde 2012 y ha sido diseñada principalmente para mejorar la articulación entre el registro de los planes de aprovechamiento, las guías de movilización de madera y los procesos de verificación del origen de la madera una vez que llegan a los centros de procesamiento. Con estas mejoras se espera que el 


\section{Cuadro 5. Mejoras del SAF I al SAF II en el nivel del usuario}

\begin{tabular}{|c|c|}
\hline SAF I & SAF II \\
\hline $\begin{array}{l}\text { Certificación de los actores del aprovechamiento con } \\
\text { documentos físicos }\end{array}$ & $\begin{array}{l}\text { Certificación y registro con documentos y subirlos al } \\
\text { sistema }\end{array}$ \\
\hline $\begin{array}{l}\text { Se ingresa dos puntos dentro del predio para } \\
\text { ubicación del aprovechamiento }\end{array}$ & $\begin{array}{l}\text { Se registra espacialmente el predio y el área de } \\
\text { aprovechamiento con mínimo cuatro puntos geográficos }\end{array}$ \\
\hline No se puede mirar el predio en imágenes satelitales & Posibilidad de mirar el predio en imágenes satelitales \\
\hline $\begin{array}{l}\text { Se piden los documentos cada vez que los usuarios } \\
\text { van a realizar un trámite }\end{array}$ & $\begin{array}{l}\text { Los documentos son almacenados, por lo que los usuarios } \\
\text { no tienen que volver a realizar el trámite completo }\end{array}$ \\
\hline $\begin{array}{l}\text { Transporte guía de movilización con el RUC } \\
\text { indistinto sin verificación }\end{array}$ & Transporte con un RUC registrado en el SAF y certificado \\
\hline Los depósitos no necesitaban estar registrados & $\begin{array}{l}\text { Guías de canje hacia el depósito que también debe estar } \\
\text { registrado (sólo Pigüe) }\end{array}$ \\
\hline \multirow[t]{2}{*}{ Inspección } & Inspección al 100\% sólo en Napo, Orellana \\
\hline & $\begin{array}{l}\text { En los controles tienen internet, por lo tanto se puede } \\
\text { revisar la cadena de custodia }\end{array}$ \\
\hline \multirow[t]{2}{*}{ El registro del guías se visualiza tal cual } & El registro no se visualiza \\
\hline & Exportación, seguimiento de guías de exportación \\
\hline
\end{tabular}

Fuente: Elaboración propia basada en entrevistas a técnicos del Ministerio del Ambiente del Ecuador.

control pueda realizarse a lo largo de toda la cadena de valor, cerrando con eso la cadena de custodia de la madera. El cuadro 5 presenta una comparación de los rasgos básicos del SAF I y II.

Las principales mejoras que se han introducido en el SAF II son las siguientes:

- El cambio más importante es que el SAF II permite al usuario (propietario, regente y/o ejecutor), registrar a través del internet el programa a ser ejecutado, con lo cual se espera disminuir notablemente la espera en la aprobación.

- Se modificó el módulo de control para permitir a los puestos fijos de control ingresar al sistema y verificar la numeración de las especies valoradas; adicionalmente se pueden visualizar las firmas conjuntas y las de los ejecutores, optimizando la relación de especies valoradas con su respectiva licencia.

- Se mejoró el módulo de cambio de regente, pudiendo realizarse de manera inmediata el procedimiento de cambio, optimizando el tiempo de trámite.

- Se establecieron con la Corporación Aduanera Ecuatoriana los mecanismos necesarios para acceder a la base de datos de dicha institución y poder mejorar los procesos de control de exportación de Productos Forestales y no Maderables.
- Se estableció a través de la plataforma Google Earth@ la posibilidad de verificar los puntos GPS del predio a ser registrado. En caso de que el técnico del MAE considere que la cobertura boscosa es menor a la delimitada en la norma, el permiso queda nulo.

- Se regula por primera vez a través del Registro Único del Contribuyente el destino final de la madera, con esto se prevé cerrar el círculo de la comercialización y trazabilidad del producto forestal desde el bosque hasta la industria

- Se espera (no definido) tener un portal de compras públicas responsables. ${ }^{8}$

- El SAF II es parte del Sistema Único de Información Ambiental (SUIA), que pretende articular la base de datos del MAE dentro del Sistema de Información Nacional dirigido por SENPLADES, en un esfuerzo del Gobierno para mejorar la planificación territorial.

Para asumir los costos del SAF, el MAE cuenta con un presupuesto asignado por el Gobierno central, además de las contribuciones directas de los usuarios. El presupuesto se coordina a través de los

8 El propósito del Sistema Nacional de Compras Públicas, es el de transparentar y dinamizar la producción nacional a través de la compras pública del Estado Ecuatoriano. http:// capacitacion.compraspublicas.gov.ec 
Cuadro 6. Pagos realizados por concepto de legalización madera en pie o pie de monte (No incluye plantaciones)

\begin{tabular}{|c|c|c|c|c|c|c|}
\hline & \multirow{2}{*}{ Programas de aprovechamiento } & \multicolumn{5}{|c|}{ En USD } \\
\hline & & 2007 & 2008 & 2009 & 2010 & Promedio USD/ año \\
\hline PAFSI & $\begin{array}{l}\text { Programa de aprovechamiento } \\
\text { forestal simplificado }\end{array}$ & 499,5 & 750 & 558 & 577 & 596,1 \\
\hline PAFSU & $\begin{array}{l}\text { Programa de aprovechamiento } \\
\text { forestal sustentable }\end{array}$ & 573 & 565,5 & 524,4 & 488,2 & 537,8 \\
\hline PCAR & Programa de corta de árboles relictos & 381 & 494,7 & 510,3 & 643,5 & 507,4 \\
\hline PCZCL & $\begin{array}{l}\text { Programa de corta para zonas } \\
\text { conversión legal }\end{array}$ & 28,5 & 39 & 107,1 & 125,8 & 75,1 \\
\hline \multicolumn{2}{|c|}{ Monto total por madera autorizada } & 1482 & 1849,2 & 1699,8 & 1834,6 & 1716,4 \\
\hline
\end{tabular}

Fuente: Tomado de FAO (2012).

Planes Operativos Anuales ${ }^{9}$. Según la FAO (2012), el pago por el aprovechamiento forestal de madera, llamado madera en $\mathrm{pie}^{10}$, ha sido en promedio de 1,7 millones/año. Estos pagos son parte del sistema de administración forestal (SAF), pues es un requisito más dentro del proceso de legalización de las operaciones forestales. El cuadro 6 muestra los ingresos por madera legal. Nótese que los ingresos provenientes de bosques nativos (PAFSI y PAFSU) son de alrededor del $66 \%$ en promedio del total recibido.

Además de los recursos económicos, el MAE cuenta con 1671 funcionarios y funcionarias a nivel nacional. La Dirección Nacional Forestal cuenta con un total de 136 funcionarias(os), esto representa el $8 \%$ del total de los recursos humanos del MAE. Según el Ministerio del Ambiente del Ecuador (2011), esta Dirección cuenta con la suficiente capacidad técnica y administrativa para responder $\mathrm{y}$ atender las necesidades y solicitudes del sector forestal; sin embargo, para Thiel y Trelles (2008) una de las limitantes para mejorar la gestión forestal es la falta de personal, en especial en la Amazonía. Según los registros del MAE 2012 se han incorporado nuevos funcionarios a las oficinas técnicas; no obstante, el número de trámites también se han incrementado. En perspectiva, según la base de datos del SAF 2011, se atendieron en este año alrededor de 3050 usuarios y se

9 POA 2012. http://www.ambiente.gob.ec/wp-content/ uploads/downloads/2012/07/Plan-estrategico-MAE-2012.pdf 10 Artículo 29, literal g, Ley Forestal movilizaron a través de los nueve puestos fijos unas 140000 guías de movilización.

\subsection{Implicaciones del control para el aprovechamiento de pequeña escala}

Como se indicó previamente, el mercado interno es principalmente abastecido con madera de plantaciones, pero se sugiere que estaría en aumento la madera originada en la Amazonía (Vásquez, 2011). Una parte de la madera aserrada que consume la industria de procesamiento secundario de muebles, molduras, pisos, puertas $\mathrm{y}$ ventanas, proviene de madera producida con motosierra proveniente de los PAFSI y de operaciones informales, en bosque nativo. Por lo mismo, la normativa y el sistema de control forestal tienen implicaciones importantes sobre los aprovechamientos de pequeña escala, al permitir su viabilidad tanto técnica como económica.

Según Thiel y Trelles (2008) la normativa forestal ecuatoriana tiene la ventaja de que se ha adaptado a las exigencias vigentes de uso de los bosques según el tipo de usuario, la clase de aprovechamiento forestal y estrato boscoso (por ejemplo, bosque nativo o plantado, árboles remanentes, sistemas agroforestales). En bosques nativos, considerando los criterios generales para el manejo forestal, se han diseñado y expedido parámetros técnicos para el aprovechamiento forestal que exigen un plan de ordenamiento de uso del suelo y un PAFSU cuando el aprovechamiento incluye uso de maquinaria para el arrastre de las trozas; $y$, cuando se trata de aprovechamiento sin 
arrastre mecanizado, se exige un programa de aprovechamiento forestal simplificado (PAFSI), programa que es accesible en pequeñas superficies y para facilitar a los pequeños productores forestales el acceso expedito de la autorización de corta que otorga la autoridad forestal. Una de las características más importantes de este tipo de programa es que se permite el aserrío de la madera dentro del bosque con el uso de motosierra.

Pese a esos ajustes, todavía persiste la informalidad en el aprovechamiento de pequeña escala, lo que está posiblemente asociado a las barreras institucionales y costos de transacción mencionados anteriormente, tal como lo sugiere también la FAO (2012). La informalidad en el aprovechamiento y movilización de la madera es reconocida por varios autores (Añazco, et al., 2010; Ministerio del Ambiente del Ecuador, 2011; Vásquez, 2011). Sin embargo, fuera de estudios de casos específicos existe poca evidencia sólida sobre la magnitud de los aprovechamientos informales. Algunos trabajos sugieren que existen redes bastante bien estructuradas de aprovechamiento de madera e intermediación entre diferentes actores del mercado que operan de forma informal (Palacios y Malessa, 2010). Otros han realizado un mayor esfuerzo para documentar la distribución de los beneficios del aprovechamiento informal para el finquero (Hetsch, 2004; Gatter y Romero, 2005; Kautz, 2005). 


\title{
Actores, intermediación y control forestal en la Amazonía
}

\author{
Elena Mejía, Pablo Pacheco, Johanna Morocho y Santiago Alarcón
}

El debate sobre el control del patrimonio forestal del Estado se inició en 1990, década en la cual se adoptaron las políticas forestales de áreas naturales y vida silvestre (Vinueza, 2012). A finales de esa década, acompañando el proceso de modernización del Estado, se adoptó el sistema de tercerización del control forestal, por el cual las actividades claves de monitoreo y control fueron transferidas a terceros, como se señaló en el capítulo 2, el mismo que tuvo vigencia hasta 2006, cuando se interrumpió para dar paso al Sistema Nacional de Control Forestal (FAO, 2006; MAE, 2006; Navarro y otros, 2009; Mejía, 2010). Esta propuesta se centró en que el Gobierno nacional tuvo a su cargo la implementación de procesos para asegurar el cumplimiento de la normativa forestal sobre aprovechamiento y la comercialización de madera legal a través de la aplicación del Sistema de Administración Forestal (SAF).

Existe una amplia discusión sobre el hecho que las normas y regulaciones para el aprovechamiento forestal tienden a constituir barreras económicas e institucionales que conducirían a la exclusión de los pequeños productores del acceso a recursos y mercados forestales (Chommitz, 2007; Pokorny y Johnson, 2008; Brown, et al., 2009; Pacheco, et al., 2009). Pese a lo anterior, todavía existen pocas evidencias empíricas detalladas sobre el impacto que tienen las normas y regulaciones forestales sobre los diferentes actores que intervienen en el aprovechamiento forestal, especialmente pequeños productores y comunidades indígenas. Usualmente se asume que los actores que no están en condiciones de adoptar la norma forestal no dejan de aprovechar la madera de sus bosques sino que tenderían a desarrollar sus actividades forestales de forma informal, las que en muchos casos son consideradas ilegales.

Este capítulo explora los factores que llevan a usuarios locales del bosque a optar por mecanismos informales el momento de aprovechar y comercializar la madera. Para ello se realizaron 123 entrevistas semiestructuradas a diversos informantes que cumplen diferentes funciones en la cadena de aprovechamiento y comercialización de la madera. Estas entrevistas fueron realizadas entre los meses de mayo a septiembre de 2012. El propósito principal fue comprender en qué medida las normas existentes, acompañadas del control forestal, repercuten en la forma en que los actores (incluyendo finqueros, indígenas, aserradores intermediarios, y otros) interactúan entre sí durante el aprovechamiento y la comercialización, así como las estrategias que dichos actores forestales utilizan para evadir las barreras institucionales y legales.

Los informantes clave fueron seleccionados de acuerdo con un muestreo de tipo oportunista que aprovechó la información proporcionada por otros informantes. Este estudio se realizó en paralelo a los estudios de costos y beneficios del aprovechamiento (capítulo 6), razón por la que la selección de comunidades en las que se realizaron las entrevistas a los actores claves corresponde a las mismas que para el estudio de encuestas por hogar, por lo cual se procuró incluir los mismos sitios teniendo así una muestra de fincas de colonos, kichwas y shuar. El número de informantes entrevistados se encuentra en el cuadro 7 .

\subsection{Caracterización de los actores de la intermediación}

\subsubsection{Los pequeños finqueros}

Gatter y Romero (2005), estima para la Amazonía que un finquero colono posee en promedio 50 hectáreas bajo tenencia individual mientras que un finquero indígena tendría un promedio de 75 hectáreas ya sea bajo tenencia individual o comunitaria. En el caso de Napo, como 


\section{Cuadro 7. Informantes clave entrevistados}

\begin{tabular}{lcl}
\hline Informantes & No. de entrevistados & Observación \\
\hline Pequeños finqueros & 6 & Presidentes actuales y expresidentes \\
Dueños de depósitos & 40 & Compradores y vendedores de madera \\
Intermediarios & 30 & Diferentes tipos de intermediación \\
Ejecutores y ejecutoras & 6 & Vinculados al intermediario \\
Regente y técnicos & 9 & Trabajan en la región, no viven en la región \\
Aserradores & 10 & Independientes y asalariados \\
Transportistas & 19 & Locales y externos \\
Acarreadores y/o barqueadores & 3 & Independientes y asalariados \\
Total & 123 & \\
\hline
\end{tabular}

Fuente: Elaboración propia

resultado de la fragmentación de la tierra los pequeños finqueros tienen un estimado de una a 40 hectáreas. ${ }^{11}$.

Indígenas: cuentan con una reserva comunitaria usualmente con titulación comunitaria. La Asamblea Comunitaria tiene la facultad de adjudicar nuevas parcelas de tierra de la reserva comunitaria a los hijos de los socios que contraen matrimonio y forman una nueva familia. Este proceso de adjudicación es válido para los hombres pero no lo es para las mujeres, pues estas adquieren tierra cuando contraen matrimonio (FAO, 1997). Las mujeres que poseen tierra son generalmente viudas. ${ }^{12}$ Los indígenas entrevistados se consideran pequeños finqueros sin importar el tamaño de su propiedad.

Colonos: los colonos (migrantes mestizos), tienen títulos de propiedad individual de sus tierras o algún tipo de reconocimiento de posesión individual. Los colonos se consideran pequeños finqueros cuando poseen menos de 100 hectáreas o no cuentan con un capital suficiente para hacer de sus fincas productivas. Los colonos se dedican principalmente a la agricultura de cacao, café y ganadería.

\subsubsection{El intermediario}

El aprovechamiento y comercialización están marcados por la velocidad de la demanda del

11 Tomado de encuesta realizada a familias Kichwa RUNA (2012).

12 En las entrevistas con los presidentes, admitieron que las nuevas generaciones están otorgando los mismos derechos a las hijas solteras, pero no así a las casadas. mercado para volúmenes, calidad y especies, por esta razón existe un actor que realiza el trabajo de intermediación entre el finquero y el mercado final, éste es conocido como "intermediario". Los intermediarios entrevistados en Napo y Orellana, mayormente provienen de la Sierra (61\%). El 75\% tenían una actividad diferente y se interesaron en la madera debido a que migraron a la Amazonía; el restante $25 \%$ siempre se dedicó a la actividad de la madera debido a que era una actividad familiar. Del total de intermediarios entrevistados, el 66\% admitió que ser intermediario maderero era su ocupación principal y el $34 \%$ dijo que su actividad principal era la agricultura y ganadería. La actividad secundaria de los intermediarios usualmente se compone de $74 \%$ agricultura y ganadería y $26 \%$ comercio. En el caso de los intermediarios se desconoce la población total de estos actores a nivel de las zonas de estudio, no existe una organización $u$ asociación que los vincule, por tal razón no se pudo establecer una muestra sino que se realizó un seguimiento oportunista.

Estos intermediarios cumplen diferentes funciones y tienen un trabajo establecido según el volumen de capital a su disposición. Una tipología de intermediarios se presenta en el cuadro 8. Es importante mencionar que, dependiendo de las condiciones, los intermediarios pueden transitar de un tipo de intermediación a otra según las oportunidades.

\subsubsection{Ejecutores y ejecutoras}

El ejecutor o ejecutora es la persona legalmente responsable del aprovechamiento de la madera de 


\section{Cuadro 8. Tipología de los intermediarios}

\begin{tabular}{ll}
\hline Tipo de intermediario & Acciones \\
\hline Intermediario-Maderero & Realiza la negociación con el comprador final \\
(A veces ejecutor) & Realiza la negociación con el finquero (compra árboles en pie, pieza, hectárea) \\
& Paga los gastos de formalización \\
& Paga los gastos relacionados con la operación \\
& Paga los gastos de transporte \\
& Vende al destino final \\
\hline Intermediario-Transportista & Realiza la negociación con el comprador final \\
& Realiza la negociación con el finquero o intermediario-aserrador \\
& Paga los costos de transporte \\
& Vende al destino final \\
\hline Intermediario-Broker & Realiza la negociación con el intermediario-maderero \\
(Regente o técnico forestal) & Realiza la negociación con el finquero \\
& No vende madera \\
\hline Intermediario-Aserrador & Realiza la negociación con el comprador final \\
(Operaciones pequeñas) & Realiza la negociación con el finquero (compra árboles en pie) \\
& Paga los gastos relacionados a la operación \\
& Vende al filo de la carretera al intermediario-transportista \\
\hline
\end{tabular}

Fuente: Elaboración propia basada en entrevistas realizadas entre mayo y septiembre de 2012

\section{Cuadro 9. Tipo de ejecutor(a)}

\begin{tabular}{ll}
\hline Tipo de ejecutor & Acciones \\
\hline Ejecutor maderero & Es el mismo intermediario que ejecuta el aprovechamiento \\
\hline Ejecutor finquero & $\begin{array}{l}\text { Es el finquero quien ejecuta el aprovechamiento } \\
\text { Es el finquero quien presta su nombre al intermediario para el aprovechamiento }\end{array}$ \\
\hline Ejecutor contratado & $\begin{array}{l}\text { Es contratado por el intermediario para prestar su nombre en el Registro Nacional Forestal } \\
\text { Se encarga de firmar la petición de registro y otros trámites relacionados } \\
\text { No está relacionado con las actividades de aprovechamiento }\end{array}$
\end{tabular}

Fuente: Elaboración propia basada en entrevistas realizadas entre mayo y septiembre de 2012

un predio. En algunas ocasiones son los propios finqueros los que cumplen este rol. Sin embargo, muchas veces este actor no necesariamente participa de la operación de extracción o intermediación, sino que presta su estatus jurídico para que el intermediario pueda ejecutar un plan de manejo, especialmente cuando este ha sido legalmente sancionado. El ejecutor es quien se registra en el SAF con su nombre y número de RUC, que lo acredita para poder firmar los documentos necesarios ante la autoridad del MAE, responsabilizándose del cumplimiento de la ley durante el aprovechamiento y movilización. Este actor no está presente en el aprovechamiento informal. En este sentido se establece una tipología de ejecutores que se presenta en el cuadro 9.

\subsubsection{Regentes y técnicos de los regentes} El regente pertenece al sistema tercerizado de control forestal implementado por el MAE; actualmente es un profesional autónomo que recibe remuneración por el volumen de madera que movilicen los programas de manejo aprobados por él mismo. En el caso de los programas de aprovechamiento y corta, los regentes realizan un conteo de árboles por especie o un inventario forestal de la finca asegurando que las normas legales de aprovechamiento sean cumplidas. Los regentes entrevistados provienen de la Sierra y la Costa, de los cuales el 50\% aseguró que la regencia es su actividad principal, el otro $50 \%$ realiza actividades privadas y públicas complementarias. Todos admitieron que trabajan más con los 
intermediarios y que son excepcionales los casos en los cuales el finquero realiza un programa por sí mismo. En el 2011, los regentes encuestados afirmaron tener más Programas de Corta que Programas de Aprovechamiento, lo cual indica que en su mayoría la madera proviene de propiedades con sistemas agroforestales.

La demanda del trabajo de regencia es alta. Muchas veces los regentes no residen en la región, por lo que contratan servicios de terceras personas que se denominan técnicos forestales, quienes en algunos casos, forman equipos de trabajo para cumplir con la demanda de programas de corta y aprovechamiento. Los técnicos forestales realizan los planes de manejo y se encargan de supervisar todos los trámites necesarios. En muchos de los casos, los técnicos forestales también son una suerte de intermediarios-brokers (cuadro 10). El técnico forestal constituye en la práctica un informante sobre especies y precios entre intermediarios y finqueros, recibiendo una "propina" por la información y además muchas veces se vincula la elaboración de un programa formal.

\subsubsection{Aserradores}

Los aserradores o motosierristas son mayormente personas asalariadas que trabajan en la extracción de madera; sin embargo, también se convierten en intermediarios cuando organizan operaciones generalmente pequeñas y muchas veces informales. Los aserradores en Orellana cuentan con una Asociación de Aserradores Profesionales (ASOPEM); sin embargo no se cuenta con un reconocimiento claro de la profesionalización de esta actividad.

Los aserradores provienen principalmente de las provincias de Orellana y Napo, y de la Costa, $60 \%$ y $40 \%$, respectivamente. Ninguno de los encuestados terminó la secundaria, la cual es una de las razones más importantes para dedicarse a actividades forestales o agrícolas y no optar por un trabajo asalariado en una compañía petrolera. El 60\% lleva en la actividad entre 4 a 9 ańos y el $40 \%$ más de 10 ańos. Los motosierristas se dedican de forma simultánea a trabajo asalariado por jornales y otras actividades varias para compensar los meses que no se dedican a la actividad de extracción. Los aserradores poseen en promedio una motosierra. El 90\% adquirió la motosierra con ayuda del intermediario con el cual trabajan, en almacenes en las ciudades de Tena y Coca.

\subsubsection{Acarreadores (barqueros) y asistentes en el aprovechamiento forestal}

Los acarreadores, también conocidos como arrastradores o barqueros, son los actores que se encargan de abrir pequeños caminos en el bosque para movilizar en mulas la madera aserrada de los lugares de corta a las "guardarrayas". El trabajo de los acarreadores se realiza de dos formas principales: 1) pueden ser contratados directamente por el intermediario-maderero para manejar los animales de propiedad del intermediario o 2) pueden prestar sus servicios y alquilar a sus animales por días según las necesidades de la operación. Las y los asistentes, se encargan de realizar trabajos menores para los otros actores de la cadena de producción como cocinar, manejar vehículos para movilizar los materiales de la operación y personal, ayudar con el cuidado de los animales y manejar motocicletas para revisar diferentes operaciones, entre otras.

\subsubsection{Depósitos y aserraderos}

Los dueños de estos establecimientos fueron entrevistados en Tena, Coca, Huaquillas y Ambato. El 100\% se dedica exclusivamente a la compra y venta de madera procesada y en menor volumen rolliza. El 100\% de los entrevistados vinieron de otras provincias. El 70\% se inició en la actividad como intermediarios hasta que tuvieron el capital suficiente para colocar maquinaria de procesamiento, el restante $30 \%$ heredó el negocio de sus padres. Todos los entrevistados aseguran no haber tenido ningún problema con la autoridad forestal debido a que son pocas las veces que realizan un programa de aprovechamiento, su negocio es comprar, transformar y vender la madera.

\subsection{Las relaciones de intermediación}

El aprovechamiento y comercialización de la madera está fuertemente influenciado por la demanda del mercado y la forma como se vinculan los finqueros en esos mercados. Estas interacciones son facilitadas a través del trabajo de intermediación que es realizado por los denominados "intermediarios" quienes cumplen diferentes funciones, las que usualmente están relacionadas con sus capacidades financieras y logísticas. Dependiendo de las circunstancias, los intermediarios pueden adoptar diferentes estrategias, como se indicó en el cuadro 8. 
Cuadro 10. Tipo de intermediarios y pagos realizados al finquero

\begin{tabular}{lll}
\hline Intermediario & Operación & Pago \\
\hline Intermediario-maderero & $\begin{array}{l}\text { Intermediario asierra y transporta } \\
\text { Finquero asierra la madera }\end{array}$ & $\begin{array}{l}\text { Adelanto } \\
\text { Todo al final }\end{array}$ \\
\hline Intermediario-transportista & $\begin{array}{l}\text { Finquero asierra la madera y la saca al } \\
\text { filo de la vía. }\end{array}$ & $\begin{array}{l}50 \% \text { en la compra } \\
50 \% \text { en 15 días }\end{array}$ \\
\hline Intermediario-aserrador & Intermediario asierra y transporta & Pago de árbol en pie, entre 20 y \\
& & 30 USD por árbol \\
\hline Intermediario broker & Intermediario busca un intermediario & No paga al finquero \\
& maderero, transportista o aserrador & \\
\hline
\end{tabular}

Fuente: Elaboración propia basada en entrevistas realizadas entre mayo y agosto de 2012.

\subsubsection{El intermediario y el comprador final}

El primer eslabón de la intermediación se establece entre el comprador final (generalmente externo), quien suele ser el dueńo de un depósito $o$ aserradero y el intermediario cuando se define entre estos "el pedido". El pedido es la demanda de madera del comprador final hacia el intermediario. Usualmente constituye un acuerdo informal entre ambas partes que asegura la entrega de la madera en un tiempo determinado con las características de tamaño, calidad de aserrío y especie establecidas. El pago final al intermediario una vez recibida la madera por el comprador demora entre 15 a 20 días, tiempo durante el cual los costos que tiene que incurrir el intermediario por nuevas operaciones de extracción forestal se cubren con ingresos provenientes de rubros como la ganadería u otros pagos por venta de madera. Este tiempo de espera por parte del intermediario tiende también a influir en el precio y los plazos de pago por la madera al finquero y al personal que trabaja en el aprovechamiento. Existen intermediarios, que son dueńos de depósitos y aserraderos que realizan aprovechamientos directamente y venden la madera procesada local o externamente a comerciantes más grandes en ciudades como Quito, Guayaquil, Ambato y Huaquillas ${ }^{13}$.

Tanto "el pedido" como "el pago" constituyen un contrato informal entre compradores e intermediarios, excepto cuando existe de por medio la figura legal de la factura de compra. De acuerdo a la información obtenida, únicamente uno de cada dos intercambios verbales culmina en un acuerdo de compra y venta. Los contratos entre el comprador final y el intermediario

13 La madera procesada y posteriormente movilizada con facturas de compra no cuenta con un registro claro. maderero se realizan mayormente a través de contacto telefónico o por internet. Los pagos se realizan mediante transferencias bancarias, ya sea en dos o tres plazos durante el tiempo que dura la operación forestal. Los factores que hacen que no se concrete una transacción de compra y venta están relacionados con el incumplimiento de los tiempos de entrega de la madera por parte del intermediario, lo que hace que el comprador procure otros intermediarios para suplir sus existencias.

Los intermediarios dueños de depósitos o aserraderos en las cabeceras cantonales de Tena y Coca, también suplen la demanda de compañías petroleras y gobierno locales, quienes compran madera especialmente destinada a la construcción. La madera que se compra genera una factura por la cual se podría conocer el volumen de estas compras. Sin embargo, no existe aún certeza si esta madera proviene de orígenes legales o no ${ }^{14}$.

\subsubsection{El finquero y el intermediario}

La comercialización de la madera se realiza por dos tipos diferentes de intermediarios a los que se denomina aquí como "intermediario-maderero" e "intermediario-transportista", cuyas características son descritas en el cuadro 8. La transacción entre finqueros e intermediarios puede ser formal o informal, lo que normalmente depende de los volúmenes de madera comercializada, las especies y el mercado al que va destinada. El resultado final de la negociación es la determinación de los precios y la forma de pago, como se indica en el

14 Las compras del Gobierno se realizan por el portal de compras públicas, sin embargo, para el año 2011 se registra únicamente una compra realizada por un Gobierno local. http://www.compraspublicas.gob.ec/compraspublicas/ 
cuadro 10. El contacto con los finqueros, según los intermediarios entrevistados, se establece a partir de vínculos familiares, a través de compañeros de trabajo o regentes, y en algunos casos son los mismos finqueros quienes procuran a los intermediarios.

Aunque los intermediarios trabajan con finqueros indígenas y colonos, según los intermediarios entrevistados, estos prefieren trabajar con colonos por la seguridad del cumplimiento de los acuerdos, sin embargo, trabajan más con indígenas porque estos poseen superficies mayores de bosques. En ambos casos, los intermediarios, luego de solicitar los permisos para el aprovechamiento dentro de las comunidades o parcelas individuales, negocian verbalmente "el pedido". Esta negociación incluye sobre todo acordar algunos aspectos específicos sobre: 1) volúmenes por especie a ser extraídos, 2) tipo de producto, 3) calidad, 4) tiempo de entrega, y 5) precio y forma de pago. Habitualmente, estos pedidos son producto de contratos previos establecidos entre el intermediario y el comprador final, como se indicó antes.

\subsubsection{Los regentes, los intermediarios y los finqueros}

El 60\% de los intermediarios entrevistados negocia los programas de corta y aprovechamiento directamente con los finqueros, mientras que el $40 \%$ restante prefiere que sea el técnico o regente forestal quien se encargue de la negociación. En este caso, los técnicos forestales o regentes se clasifican como "intermediario-broker". Los presidentes comunales entrevistados, afirman que prefieren tener una negociación previa con un intermediario-broker para "explorar" los precios que recibirán por las diferentes especies y productos a aprovechar.

Los finqueros entrevistados aseguraron que "el pedido" se negocia directamente con el intermediario y que no aprovechan madera sin tener certeza sobre el tipo de pedido. Los finqueros afirmaron que algunas veces se busca al intermediario para ofrecerle especies valiosas como chuncho (Cedrelinga catenaeformis) y manzano (Guarea sp), sin embargo, es el intermediario quien específica el volumen del producto que requiere para completar su pedido con el comprador final, aunque estas especies tienen un mercado seguro.
Muchas veces, el intermediario acude a madera obtenida de varios programas, o compra madera de parcelas que no cuentan con un programa. Según información obtenida de las entrevistas, se estima que el $65 \%$ de la madera no legalizada comprada por intermediarios sería blanqueada a través de planes de manejo aledaños a los aprovechamientos informales, esto podría deberse a que el desperdicio del 50\% autorizado por la normativa muchas veces no es alcanzado en árboles con dańos mecánicos y patológicos.

El intermediario-transportista suele negociar el pedido de manera directa con el finquero, y por lo general, la madera obtenida sin planes de manejo es vendida a los mercados locales de madera en Tena y Coca, mientras que la madera obtenida de manera formal, o que es posteriormente blanqueada, se dirige a los mercados externos. La diferencia entre este tipo de intermediario con el intermediario maderero, es que el intermediario-transportista realiza el transporte por su propia cuenta, no realiza el aprovechamiento y compra volúmenes menores.

La figura 4 muestra de forma simplificada las relaciones de intermediación de la madera entre el comprador final y los diferentes tipos de intermediarios y entre este con el finquero, sea indígena o colono.

\subsection{Relaciones de confianza y conflictos con la autoridad}

Según lo observado, las relaciones de confianza entre los actores del aprovechamiento y comercialización son la base de las transacciones en el mercado. En este sentido, por ejemplo los intermediarios y técnicos forestales prefieren trabajar con su propia familia. Los conflictos con otros actores, según mencionaron la mayoría de los entrevistados, se dan en relación al cumplimiento de acuerdos verbales y la movilización de la madera; ninguno mencionó conflictos con el proceso de legalización pero sí con los procesos de control del MAE, como en el caso de la verificación en campo y en las vías (cuadro 11).

El 77\% de los intermediarios entrevistados confían en los regentes, y el 52\% dice confiar también en el MAE. El 70\% de los encuestados admite que 


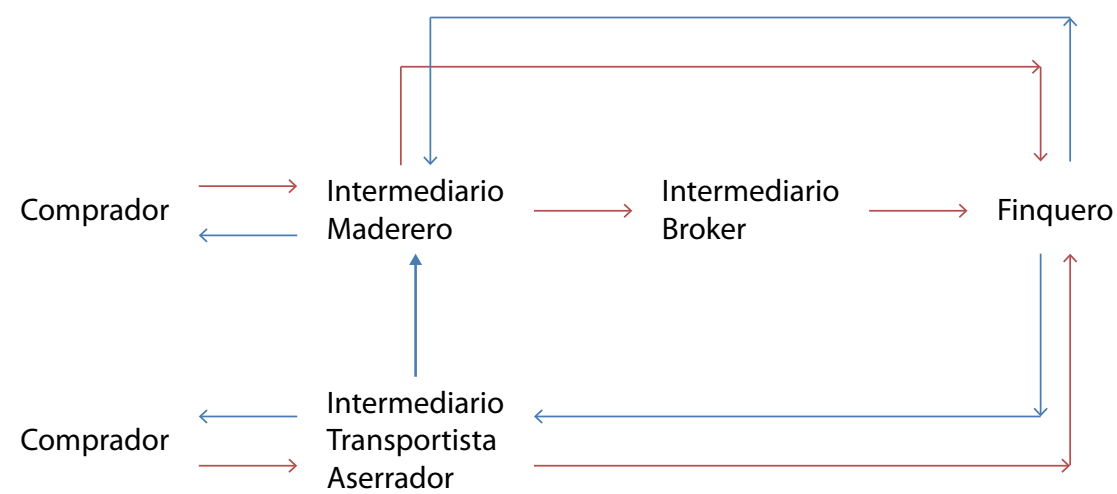

Figura 4. La intermediación en el comercio de la madera, basada en información obtenida de entrevistas entre mayo y septiembre de 2012.

\section{Cuadro 11. Conflictos entre actores en el aprovechamiento de madera}

\begin{tabular}{lccccc} 
& \multicolumn{4}{c}{ Conflictos } \\
\cline { 2 - 5 } Actores & Control MAE & $\begin{array}{c}\text { Confiscaciones } \\
\text { en controles }\end{array}$ & No pagos a tiempo & $\begin{array}{c}\text { No hay seriedad } \\
\text { en el acuerdo }\end{array}$ & $\begin{array}{c}\text { No capacitados para } \\
\text { uso de tecnologías }\end{array}$ \\
\hline Finqueros & $\mathrm{X}$ & $\mathrm{X}$ & $\mathrm{X}$ & $\mathrm{X}$ \\
Intermediarios & $\mathrm{X}$ & $\mathrm{X}$ & & $\mathrm{X}$ \\
Transportistas & $\mathrm{X}$ & & $\mathrm{X}$ & \\
Regentes & & & & \\
\hline
\end{tabular}

Fuente: Elaboración propia basada en entrevistas realizadas entre mayo y agosto de 2012.

el control ha mejorado los precios de la madera legal e informal, debido a que este control ha eliminado la competencia de intermediarios que no tuvieron el capital suficiente para cubrir los costos de la legalización. Estos actores consideran que los conflictos más frecuentes se refieren al tiempo de espera para la aprobación de los programas de aprovechamiento y las confiscaciones del control fijo y móvil del MAE. También sobre la confianza con los finqueros. Los intermediarios admitieron que de cuatro predios escogidos para ser aprovechados de manera formal con programas de corta o aprovechamiento, únicamente dos terminan en corta por diferentes factores, en especial que los contratos verbales no son cumplidos por los finqueros. Por estas razones, la opinión de la totalidad de los intermediarios entrevistados es que el negocio de la madera es muy inestable y no ven un futuro claro.

Los regentes entrevistados afirmaron que los principales problemas que han tenido con el MAE se relacionan con la mala ejecución de los programas, el mal uso de guías de circulación y la falta de supervisión de los programas. Si bien consideran que la normativa aún no reconoce la realidad de los pequeños finqueros, el incremento del control y los esfuerzos del MAE han mejorado notablemente las cifras de legalización de los intermediarios, tanto así que prefieren realizar planes de manejo antes que usar medios informales de aprovechamiento y transporte de madera. Esto, en consecuencia, mejoró las actividades de regencia.

Por su parte, los aserradores reconocieron que conocen las implicaciones de la informalidad, sin embargo, observan que el pago que reciben es mayor cuando trabajan con un intermediario que tiene un programa de aprovechamiento aprobado, por lo cual su percepción sobre la legalización es positiva; no obstante, esto también está asociado a que estas operaciones formales tienden a aprovechar madera de valor comercial. Ninguno ha trabajado con un finquero que realizara un programa de aprovechamiento por su cuenta, aunque han trabajado con estos actores en cortas informales esporádicamente. 
Existen transportistas de madera que no son transportistas-intermediarios, es decir, que son contratados para movilizar los productos de la corta, pero no han participado del aprovechamiento. Estos actores analizan que el control del MAE no es el adecuado, debido a que sostienen que en su trabajo muchas veces deben movilizar cargas de madera, de la cual ellos desconocen el origen o las especies a trasladar. Por este desconocimiento, al menos una vez sus camiones han sido retenidos en los controles forestales en las vías y la madera ha sido confiscada, generando pérdidas diarias y gastos extras. $\mathrm{La}$ estrategia actual de estos actores es pagar al regente o técnico forestal una cantidad aproximada de 15 USD por camión para que éste revise la carga y certifique que las especies corresponden a las listadas en las guías de movilización.

Es interesante anotar que ninguno de los dueños de depósitos o aserraderos que fueron entrevistados admite haber tenido problemas con el MAE, sin embargo, afirman que el control ha llevado a aumentar los precios de la madera.

\section{"El control ha llevado a aumentar los precios de la madera en ciertas especies, son los pequeños negocios, o aquellos depósitos que manejan volúmenes de 1 a $5 \mathrm{~m}^{3} /$ mes quienes fomentan una mayor comercialización de madera de origen informal lo que baja los precios de la madera formal en el mercado local." Dueño de depósito entrevistado}

Los establecimientos pequeños se localizan en las zonas periurbanas y rurales y no han sido catastrados por lo cual es difícil conocer una cifra aproximada de la comercialización de madera a través de estos actores.

Los finqueros entrevistados, así como los presidentes de las comunidades, mencionaron no haber experimentado problemas directos con el MAE. Esto se debe posiblemente a que son los intermediarios y regentes/técnicos forestales quienes deben realizar los trámites correspondientes y pagos necesarios para la aprobación de los programas de aprovechamiento, mientras que los propietarios únicamente dan sus firmas y consentimiento en los trámites. Adicionalmente, sostienen que el blanqueo de la madera (recuadro 1), es una práctica que nunca ha ocasionado problemas en sus comunidades.

\subsection{Estrategias de los actores para evadir el sistema de control}

En las zonas de estudio, la evasión al sistema de control ocurre principalmente para evitar pérdidas de la madera ya aprovechada de manera formal o informal. Según los resultados de las entrevistas se utilizan como principal estrategia de evasión, en orden de importancia preguntada a los entrevistados: 1) la compra de guías de movilización; 2) la venta de la madera en las capitales de las provincias; 3) el blanqueo mediante el uso de programas de corta y aprovechamiento aprobados; 4) el uso de pagos ilegales a la policía y personal de la vigilancia forestal (conocidos como "coimas") en los controles; 5) la movilización con facturas como documentos de soporte; $y$ 6) la aprobación de planes ficticios para generar guías de movilización. Algunas de estas formas de evasión se utilizan durante el aprovechamiento y otras durante la movilización, no son excluyentes unas de las otras. Estas estrategias se detallan a continuación.

\subsubsection{Durante el aprovechamiento}

Es difícil estimar el volumen de madera en pie a ser extraído de un bosque. La normativa forestal establece que el rendimiento de un árbol es del 50\% del volumen maderable, no obstante, observaciones propias sugieren que muchas veces, por defectos mecánicos y patológicos, los desperdicios alcanzan hasta un 70\% (capítulo 6). Los regentes entrevistados admitieron que usualmente se sobrestima el volumen de los árboles el momento de realizar el inventario forestal, que es uno de los primeros pasos para la elaboración del programa de aprovechamiento. En esa línea, el Ministerio del Ambiente del Ecuador (2011), en un informe técnico sobre control forestal, sugiere que alrededor del $27 \%$ de las irregularidades encontradas en las verificaciones en campo corresponden a errores en mediciones del Diámetro a Altura al Pecho (DAP) y alturas.

"Las mediciones de DAP se realizan con la ayuda de una cinta métrica o diamétrica, sin embargo, debido a las condiciones de forma de los árboles, estas no son medidas exactas. La altura es estimada y no se cuenta con un instrumento técnico que ayude a tener mayor precisión." Entrevista a regente forestal 


\section{Recuadro 1. Proceso de "blanqueo" o lavado de la madera}

El blanqueo de madera hace referencia al proceso de legalización de madera informal por medio de una red de actores con suficiente capacidad para adaptarse a la demanda de los productos de madera y que poseen la flexibilidad necesaria para realizar dichas operaciones, principalmente porque trabajan con bajos volúmenes de madera. Existen dos modalidades de blanqueo. La primera, "más formal", es la realizada en el aprovechamiento legal dentro de planes o programas de aprovechamiento en el momento en que los intermediarios compran madera contigua a los predios autorizados a la corta formal. La segunda, y tal vez la más frecuente, es la que involucra madera obtenida de forma informal al "filo de la vía" o "filo del río".

La madera blanqueada de la segunda manera es movilizada a través de una extensa red de pequeños depósitos o aserraderos establecidos dentro de las comunidades o en las periferias de las ciudades como Coca y Tena. La madera por lo general es transportada por pequeños intermediarios-transportistas y vendida a depósitos, aserraderos o carpinterías, quienes transforman las piezas en productos intermedios para la construcción o productos finales como, por ejemplo, muebles y cajas de fruta. La madera procesada es posteriormente movilizada con una factura de compra hacia otros depósitos, aserraderos o almacenes donde es vendida al consumidor final.

Esta actividad otorga bastante flexibilidad a los finqueros con respecto a los volúmenes a ser extraídos. Los volúmenes aprovechados están de promedio en un rango de 1 a $3 \mathrm{~m}^{3}$. Los productos comercializados más frecuentemente son tablas de especies blandas y tablones simples de especies duras. Usualmente los productos extraídos en las fincas dependen del pedido previo que tienen los pequeños intermediarios, los que a su vez dependen del pedido realizado por depósitos, aserraderos o carpinterías.

Otra facilidad para el blanqueo es que, siendo que los depósitos, aserraderos o carpinterías son reconocidos por el SRI como microempresas, eso les ofrece la posibilidad de generar comprobantes de compraventa de productos. En el momento en que la madera es vendida en estos depósitos y transformada, ya puede ser movilizada como madera legal simplemente con la presentación de un comprobante o factura. Esta actividad está siendo regulada en la actualidad por el SAF II.

Por consiguiente, el desperdicio no contabilizado por la norma podría ser de alrededor del $25 \%$ mayor que el estimado en ciertas especies ${ }^{15}$. Este porcentaje que no es contabilizado por razones prácticas, le da un margen al ejecutor, maderero o finquero para negociar árboles de otras fincas aledañas con los cuales completar los volúmenes no aprovechados dentro de los programas de aprovechamiento aprobados. Este proceso es considerado por los diferentes actores involucrados en el aprovechamiento como una acción apropiada para no perder la inversión del pago de regencia realizado y el cupo de movilización aprobado por el MAE. De igual manera, este ejercicio ofrece a otros finqueros la posibilidad de vender volúmenes menores de madera sin la necesidad de realizar un programa de aprovechamiento. Este procedimiento de blanqueo ha sido ya explicado en el recuadro 1 .

15 Según datos recolectados en operaciones formales e informales.

\subsubsection{Durante la movilización}

Según las entrevistas realizadas, la decisión de los intermediarios y comerciantes locales de mantenerse en la informalidad está en función del tiempo que los compradores finales o comerciantes externos pueden esperar por la madera solicitada. Estos pedidos son realizados a través de llamadas telefónicas, las cuales movilizan a los intermediarios-madereros e intermediarios-transportistas para conseguir los volúmenes de las especies solicitadas. En algunos casos los intermediarios cuentan con programas de aprovechamiento ya aprobados con los que estarían en condiciones de satisfacer los pedidos. En caso contrario, los intermediarios precisan cubrir los pedidos a través de la aprobación de nuevos programas o mediante el blanqueo de la madera.

La totalidad de los intermediarios entrevistados admiten que obtienen mejores beneficios cuando transportan madera legalizada, puesto que les 
permite ahorrar en "coimas" en los puestos de control aproximadamente entre 10 y 1000 USD por camión de madera transportada, dependiendo del volumen y del tipo de especie. Debido a los prolongados tiempos de espera para obtener los permisos de aprovechamiento, que se han acentuado últimamente desde que el MAE ha decidido verificar todas las operaciones en vista de las irregularidades presentadas por regentes y ejecutores, los intermediarios admiten que deben complementar las actividades forestales legales con las informales para compensar los costos de la espera hasta la aprobación de los programas de aprovechamiento. A pesar, de que los pagos ilegales o coimas son relativamente frecuentes, los intermediarios admitieron que no es algo que realicen con agrado, debido a que se vuelve una costumbre por parte de quienes realizan este cobro, alentando redes de corrupción locales.

El tiempo de espera para la aprobación de un programa de aprovechamiento en las oficinas técnicas del MAE localizadas en las provincias de Orellana y Napo, según los entrevistados, es en promedio de tres meses. Los intermediarios entrevistados sugieren que no están en condiciones de esperar durante ese lapso de tiempo, por lo cual optan por la compra de guías de movilización de programas ficticios o de aquellos que tienen volúmenes extra de madera tableada. Aunque los entrevistados declararon que hacer esto es bastante más costoso que legalizar el aprovechamiento, el pedido del comprador final tiende a compensar por los costos incurridos al legalizar la madera, lo que constituye un precedente favorable para realizar futuras transacciones.

Otra estrategia de evasión del control forestal consiste en usar una misma guía de movilización durante varias veces consecutivas. Esto es posible porque existe una diferencia entre el tiempo de aprobación de las guías y el transporte de la madera. En el SAF I el tiempo estándar de movilización era de 72 horas, mientras que el SAF II estima la distancia en kilómetros y el tiempo necesario para cubrirla, con lo cual se espera resolver esa falencia técnica del monitoreo forestal. Es así que en el caso de Orellana los intermediarios normalmente suelen tener los documentos en orden para movilizar la madera a otras ciudades más lejanas, como por ejemplo a Huaquillas $(736 \mathrm{~km})$, debido a que esta madera tendrá que pasar por varios controles en las vías. Por el contrario, en Napo, los mercados de destino de la madera como Ambato son más cercanos $(180 \mathrm{~km})$ y existe un control móvil en el camino, por lo cual se usaba una misma guía de movilización para varios viajes debido a que el trayecto era más corto.

\subsubsection{Después del aprovechamiento}

La normativa de aplicación de los PAFSI reconoce que se debe esperar al menos cinco ańos antes de iniciar otro proceso de corta en una misma área. Sin embargo, existe la posibilidad que se genere un cambio de uso del suelo por parte del finquero. Según las entrevistas realizadas a los regentes, estos estiman que el $80 \%$ de los aprovechamientos bajo cualquier modalidad terminan en un cambio de uso de suelo de bosque a agricultura y/o los finqueros deciden cortar informalmente los árboles sobrantes en el área legalizada aprovechando los caminos creados para sacar la madera. En este sentido se realizó un muestreo rápido para conocer el cambio de uso de suelo en propiedades que aplicaron la normativa y forman parte del SAF entre los años 2010 y 2011 (recuadro 2).

\subsubsection{Otras estrategias simultáneas al aprovechamiento}

Uno de los casos más interesantes observados consiste en el uso de las ganancias obtenidas de los Programas de Corta y Aprovechamiento Simplificado (incluyendo las ganancias del blanqueo), para generar más programas. De acuerdo a los intermediarios entrevistados, el dinero obtenido de las ganancias se utiliza para tramitar otros programas de forma simultánea. Es así que el promedio de programas por intermediario varía entre dos y cuatro por año. Este procedimiento es completamente legal. No obstante, según las opiniones de los actores entrevistados, los intermediarios-madereros que realizan esta práctica de trabajar con varios programas de forma simultánea están en condiciones de ofrecer mejores precios por pago de la madera a los finqueros y cuentan con la capacidad económica necesaria para mantener operaciones de extracción forestal de forma continua. Lo anterior, a su vez, se expresa en pagos puntuales a la mano de obra y a los proveedores de insumos.

El hecho de trabajar con varios programas de aprovechamiento de forma simultánea también ofrece la posibilidad a los intermediarios de intercambiar madera de un sitio para otro, con la finalidad de compensar la falta de madera debido a daños patológicos o mecánicos de los árboles en 


\section{Recuadro 2. Cambio de uso de suelo después de la implementación de un PAFSI}

Guido Fernández y Walter García

En el caso de la Amazonía centro norte y sur del Ecuador, el único instrumento legal aplicado en fincas individuales se denomina Programa de Aprovechamiento Forestal Simplificado (PAFSI). Un PAFSI establece parámetros que regulan la temporalidad y la frecuencia de las especies forestales a ser aprovechadas; consiste en una planificación de tala selectiva de maderas con valor comercial de un año de ejecución. Al término del PAFSI el área cosechada debe ser inmovilizada por los 5 años siguientes, lo que conduce a preguntarse si los pequeños finqueros inmovilizan o no el área, si continúan la cosecha de árboles que quedaron en el bosque o si cambian el uso forestal del suelo. En orden a clarificar mejor esta pregunta con ayuda de la base de datos del SAF 2010 y 2011 de la Oficina Técnica del Ministerio del Ambiente, Regional Napo, se seleccionó una muestra de un total de 153 PAFSI que fueron concluidos en estos años, los cuales fueron estratificados en tres categorías según el volumen aprovechado: pequeños $\left(0\right.$ a $\left.50 \mathrm{~m}^{3}\right)$, medianos $\left(51-200 \mathrm{~m}^{3}\right)$ y grandes (mayores a $200 \mathrm{~m}^{3}$ ).

El total de la muestra se determinó al azar en 20 programas, los cuales fueron visitados y se realizó un proceso de verificación de la normativa forestal. Los resultados muestran que el cambio de uso de suelo llegó a ser total para dos fincas pasando de bosque a pastos y agricultura. Los restantes admitieron haber realizado un cambio de suelo posterior al aprovechamiento con el PAFSI, pero en otros bosques que no fueron incluidos en el conteo de árboles legales. Estos resultados proponen que el PAFSI como mecanismo de protección de la cobertura forestal es exitoso, sin embargo los resultados no son concluyentes, debido a que en el $100 \%$ de las fincas visitadas cambiaron alguna parte de su bosque nativo a otro uso. Por su parte, información proveniente de 243 encuestas a hogares en 21 comunidades de las provincias de Orellana y Napo (capítulo 6) sugiere que después de realizado un PAFSI se ha producido finalmente un cambio de uso de suelo a cultivos perennes y anuales según lo muestra el cuadro 12, a continuación.

\section{Cuadro 12. Diferencia en cambio de uso de suelo después de un PAFSI}

\begin{tabular}{|c|c|c|c|c|c|}
\hline Legalidad & Años & Hectáreas & $\begin{array}{l}\text { Diferencia en } \\
\text { hectáreas }\end{array}$ & $\begin{array}{l}\text { Diferencia } \\
\text { porcentual }\end{array}$ & $\begin{array}{c}\text { Diferencia } \\
\text { porcentual anual }\end{array}$ \\
\hline \multirow[t]{2}{*}{ Con programa $n=28$} & 2006 & 18,26 & \multirow[t]{2}{*}{1,55} & \multirow[t]{2}{*}{$8,48 \%$} & \multirow[t]{2}{*}{$1,4 \%$} \\
\hline & 2012 & 16,71 & & & \\
\hline \multirow[t]{2}{*}{ Sin programa $n=32$} & 2006 & 18,07 & \multirow[t]{2}{*}{0,78} & \multirow[t]{2}{*}{$4,32 \%$} & \multirow[t]{2}{*}{$0,36 \%$} \\
\hline & 2012 & 17,28 & & & \\
\hline
\end{tabular}

Fuente: Elaboración propia basada en encuestas realizadas entre enero y septiembre de 2012.

ciertos programas. Es decir, que los intermediarios que consiguen funcionar con mayor número de programas llegan a tener también una mayor flexibilidad para satisfacer más rápidamente los pedidos de los compradores finales, lo que les permite generar retornos más rápidos.

\subsection{Evasión de otras normas vinculadas al aprovechamiento}

\subsubsection{Normas laborales}

Aunque los sistemas de control del comercio ilegal de madera han mejorado bastante, existen otras formas de incumplimiento de la normativa, como la que ocurre a través del incumplimiento de las normas laborales. En las entrevistas realizadas a operadores aserradores, acarreadores y asistentes, ninguno de los entrevistados indicó poseer un contrato formal, por lo que no cuentan con un seguro social o beneficios extras en el marco de la ley laboral por su trabajo ${ }^{16}$. Normalmente, los salarios dependen del número de piezas aserradas

16 De acuerdo a la ley laboral, en Ecuador todas las personas en relación de dependencia deben contar con las aportaciones al seguro social y otras prestaciones como sobresueldos. 
o transportadas, del número de días trabajados y de la calidad de su trabajo. En promedio, según la información proporcionada por los entrevistados el salario de un aserrador profesional es de 800 USD por mes, y de los acarreadores y asistentes de $350 \mathrm{y}$ 300 USD mensuales, respectivamente.

Una gran mayoría de los trabajadores entrevistados no cuenta con más de seis años de educación formal, por lo que difícilmente pueden aspirar a un trabajo remunerado con beneficios. Usualmente los requisitos para desempeñar otro tipo de trabajo asalariado en la zona, diferente al del aprovechamiento forestal, como por ejemplo el empleo en las petroleras, incluyen la finalización de la secundaria y el servicio militar. El 20\% de los entrevistados cuentan con el Seguro Campesino que brinda el Estado ecuatoriano a los agricultores, y el $80 \%$ depende del Servicio Público para su atención médica. Únicamente tres personas del total de entrevistados estaban descontentas con la situación de trabajo debido a incumplimientos en los pagos por parte del intermediario-maderero. La mayoría de los entrevistados aseguraron que sus salarios son mejores que el salario mínimo vital ${ }^{17}$ y esto compensa otros beneficios que no pueden obtener como el de la seguridad laboral y social.

\subsubsection{Normas tributarias}

La normativa forestal exige que los ejecutores y/o ejecutoras de programas registren su número de Registro Único del Contribuyente (RUC) o Régimen Impositivo Simplificado (RISE) dentro del SAF. La mayoría de finqueros y ejecutores entrevistados está incluido en el RISE, lo que los acredita como pequeños productores o artesanos. Este registro no exige un pago alto de impuestos, por lo que algunas veces las facturas son utilizadas para transportar madera blanqueada. El SAF II, espera reducir el uso de facturas para el blanqueo de madera implementando un registro más minucioso en el destino final.

En el capítulo 4 de este estudio se indica que alrededor del $15 \%$ de las movilizaciones de madera que se realizaron durante 2011 no tenían un destino declarado, y tampoco un registro del SRI que indicará su destino principal por rubro.

17 El salario mínimo vigente durante este estudio fue de 292 USD, además del pago obligatorio por parte del empleado y empleador del seguro social de salud de 62,34 USD incluido en el salario mínimo.
Igualmente, existen indicios de que frecuentemente no concuerdan los volúmenes movilizados declarados en el SAF con las declaraciones impositivas al SRI.

\subsubsection{Incumplimiento de acuerdos verbales}

Los contratos de compra y venta en el caso de aprovechamientos formales no tienen un acuerdo escrito que comprometa a ninguna de las partes a cumplir con el pedido y el pago. Igualmente, las relaciones laborales implican un acuerdo verbal. Los contratos verbales según las leyes en Ecuador permiten que una de las partes demande a la otra por sus obligaciones adquiridas. En el caso de compra y venta, por ejemplo de madera, existe la figura legal de la Confesión Judicial, que se basa en la "buena fe" de la parte demandada a declarar bajo juramento que realizó la venta o compra de madera.

En las entrevistas se identificaron intermediarios que no cumplieron con sus obligaciones de pagos a finqueros y de finqueros que no cumplieron con la entrega de la madera solicitada. Sin embargo, ninguna de las partes llevó a cabo ningún procedimiento legal para intentar recuperar la inversión realizada tanto en dinero como de mano de obra. Realizar un contrato de compra y venta bajo términos legales no sería una cuestión difícil de efectuar por parte del intermediario, sin embargo se reconoce por parte de los actores entrevistados que no han recibido la capacitación adecuada para este tipo de trámites. Los intermediarios tienen conflictos principalmente con los finqueros. "La falta de seriedad de algunos finqueros ha hecho que pierdan dinero y tiempo" (Entrevista a intermediario), debido a que no hay un respeto del acuerdo verbal sobre tiempos y calidad del pedido. Asimismo, los presidentes de comunidades entrevistados afirmaron que en muchas ocasiones los finqueros han sido víctimas de engaños por parte de intermediarios que no completan los pagos o simplemente desaparecen con el producto aserrado.

\subsection{Efectividad del SAF en el contexto de la intermediación}

Los avances desde 2008 cuando se implementó el SAF hasta la fecha han sido bastante notorios, especialmente en el manejo de la información que ha hecho posible que se recolecten estadísticas 
forestales en tiempo real. Sin embargo, por lo expuesto en este capítulo, la puesta en marcha del SAF no ha sido suficiente para hacer frente a diferentes estrategias de informalidad por parte de los usuarios del bosque.

El SAF I ofreció la oportunidad de explorar nuevas posibilidades de control mediante la obtención del RUC de los ejecutores y compradores. El SAF II complementó esta actividad con la posibilidad de verificación en el lugar de destino de la madera. No obstante, según lo expuesto en este capítulo, el comercio informal adapta sus estrategias de venta a través de pequeños depósitos periurbanos que transforman la madera y emiten una factura de venta, con lo cual en estos casos la madera no entra al registro del SAF, pero podría ser ingresada en las declaraciones al SRI. El SAF II ofrece una plataforma para el cruce de datos con aquellos provenientes del SRI, en donde se podría detectar este tipo de casos, siempre y cuando una factura sea emitida.

En este sentido, el SAF II prevé el control del destino en los depósitos a través de la guía de movilización con las respectivas especies y volumen. A pesar de que esta verificación pueda resultar efectiva para el control de la cadena de custodia, no podrá asegurar que sea la única fuente de aprovisionamiento de la madera para depósitos en las ciudades como Quito y Cuenca, donde la demanda por madera de bosques nativos tiende a aumentar (cf. Vásquez, 2011). Según lo mencionado por los actores en este capítulo, los permisos de madera legal demoran más de lo necesario, pero los pedidos "no esperan", por lo cual se puede intuir que existirá madera formal e informal a pesar de cualquier control, al menos hasta que se pueda suplir al 100\% al mercado con madera de origen legal.

Otro aspecto importante dentro de este marco es el rol del regente. El regente forestal es el aporte del MAE para mejorar el conocimiento de la normativa en campo, y es parte esencial del sistema de control y del SAF. Sin embargo, al ser un profesional independiente, este no cuenta con recursos para invertir en traspasar tecnología o información hacia los usuarios. En el análisis de redes de este capítulo se puede observar que los regentes son parte fundamental en los procesos de intermediación entre los finqueros y los intermediarios, además de ofrecer información referente a los precios. En el contexto rural, son de los pocos actores que brindan cierta asesoría a los finqueros sobre manejo de bosques. El SAF no integra un paquete de tecnología asociado a la implementación del control, con lo cual deja un vacío que impide a los usuarios dueños del bosque hacer uso de esta herramienta.

Tanto el SAF I como el SAF II se han preocupado de establecer mejoras para la trazabilidad de la madera formal, pero esto no es suficiente para asegurar que los usuarios adopten esta tecnología, o que esta herramienta esté mejor adaptada a las realidades locales. Lo que ha generado el SAF a nivel local en los centros urbanos próximos, como es el caso de Tena y Coca, es que terceras personas sean ocupadas en el uso del sistema que se encuentra disponible online en el internet y cobran por sus servicios a los usuarios locales, sean tanto intermediarios como finqueros, lo que en último término lleva a aumentar los costos de transacción. 


\title{
Mercado interno de la madera
}

\author{
Alfredo Carrasco, Cristian Terán, Emilia Crespo y Elena Mejía
}

En este capítulo se analizan la magnitud y las dinámicas del aprovechamiento y de los diferentes flujos de la madera de acuerdo con información oficial contenida en el SAF para 2011, la misma que es complementada con otra proveniente de del Servicio de Rentas Internas (SRI). Mientras que la información del SAF proporciona los volúmenes extraídos y movilizados por origen y destino, la información del SRI permite determinar las características de las personas jurídicas y naturales, según su Registro Único de Contribuyente (RUC), registradas en el sistema. La combinación de estos datos hace posible ofrecer una perspectiva más completa sobre las principales características de los flujos de la madera según los vendedores y compradores de madera para el Ecuador en su conjunto. Parte del análisis en este capítulo se refiere al Ecuador en su conjunto, mientras que existen secciones específicas que se refieren únicamente a la oferta de la región de la Amazonía.

\subsection{Aprovechamiento por tipo de bosque y especies}

\subsubsection{Aprovechamiento en el Ecuador por región}

Datos oficiales del MAE, obtenidos de los registros del SAF, indican que en 2011 se autorizó la extracción de un total de 2,8 millones de $\mathrm{m}^{3}$, de los cuales se movilizaron únicamente unos 2 millones de $\mathrm{m}^{3}$ (cuadro 13) ${ }^{18}$. De acuerdo a esta fuente, el mayor volumen de madera fue movilizado en la región de la Costa (49\%), seguido por la Sierra (38\%) y finalmente la Amazonía (12\%). La mayor oferta de madera proviene de las plantaciones

\footnotetext{
18 El hecho que únicamente se movilice una porción del total de los volúmenes aprobados sucede principalmente por el desperdicio desde árbol en pie (aprovechado) a árbol cortado (movilizado), debido sobre todo a daños patológicos o mecánicos en la madera, además del desperdicio propio del aserrado.
}

forestales, tanto de la Sierra como de la Costa, las que contribuyen con el $65 \%$ del volumen total movilizado. La madera aprovechada en bosques nativos proviene de la Costa y Amazonía, lo que representa el $12 \%$ del total nacional. Por último, los sistemas agroforestales, formaciones pioneras y otros principalmente localizados en la Costa y Sierra, suman el restante 23\%. En general, se puede decir que la región de la Sierra tiene un escaso o casi nulo aprovechamiento forestal en bosques primarios o secundarios, mientras que la región de la Amazonía aparece como una región en donde no se han desarrollado las plantaciones forestales. En la Costa el aprovechamiento forestal es más diverso porque ocurre en diferentes tipos de bosques.

Según el MAE, citado por Grijalva, et al., (2012), las diez especies más aprovechadas entre los años 2008 y 2009 fueron las siguientes: balsa (Ochroma pyramidale, lagopus), laurel (Cordia alliodora), pigüe (Pollalesta discolor), sande (Brosimum utile), y chalviande (Virola sebifera). Entre las principales especies exóticas están las siguientes: eucalipto (Eucalyptus globulus), pino (Pinus radiata y Pinus patula), pachaco (Schizolobium parahybum), teca (Tectona grandis) y melina (Gmelina arborea). Según los datos del SAF 2010 y SAF 2011 estas mismas especies continúan siendo las más aprovechadas, tomando importancia la especie Otoba spp. Algunas especies que sobresalen por su importancia para la industria de la construcción son el chuncho (Cedrelinga catenaeformis) y el colorado (Guarea kunthiana).

\subsubsection{Aprovechamiento en la Amazonía por tipo de bosque \\ El aprovechamiento de madera en la Amazonía se ha incrementado de $357 \mathrm{mil} \mathrm{m}^{3}$ en 2007 hasta $458 \mathrm{mil} \mathrm{m}^{3}$ en 2011 (Ministerio del Ambiente del Ecuador, 2010; Ministerio del Ambiente del Ecuador, 2011). La madera aprovechada}


Cuadro 13. Aprovechamiento por región y tipo de bosques en el 2011 (miles de $\mathrm{m}^{3}$ )

\begin{tabular}{|c|c|c|c|c|c|c|}
\hline & \multicolumn{5}{|c|}{ Tipo de bosques(en miles de $\mathrm{m}^{3}$ ) } & \multirow[b]{2}{*}{ Total } \\
\hline & $\begin{array}{c}\text { Bosques } \\
\text { nativos (a) }\end{array}$ & $\begin{array}{l}\text { Plantaciones } \\
\text { forestales (b) }\end{array}$ & $\begin{array}{l}\text { Sistemas } \\
\text { agroforestales (c) }\end{array}$ & $\begin{array}{c}\text { Formaciones } \\
\text { pioneras (d) }\end{array}$ & $\begin{array}{c}\text { Conversión } \\
\text { legal (e) }\end{array}$ & \\
\hline \multicolumn{7}{|l|}{ Aprobado } \\
\hline Costa & 129 & 684 & 535 & 30 & 13 & 1391 \\
\hline Sierra & 1 & 920 & 228 & & 0 & 942 \\
\hline Amazonía & 204 & 1 & 20 & 11 & 15 & 458 \\
\hline Total & 334 & 1604 & 784 & 41 & 28 & 2791 \\
\hline \multicolumn{7}{|l|}{ Movilizado } \\
\hline Costa & 121 & 547 & 295 & 30 & 7 & 1000 \\
\hline Sierra & 1 & 768 & 115 & & 0.15 & 780 \\
\hline Amazonía & 113 & 0,4 & 11 & 11 & 7 & 246 \\
\hline Total & 235 & 1316 & 420 & 41 & 15 & 2026 \\
\hline
\end{tabular}

Notas: Las categorías de tipos de bosques corresponden con los siguientes planes de aprovechamiento incluidos en la normativa forestal ecuatoriana: (a) PAFSI: Programa de aprovechamiento forestal simplificado, y PAFSU: Programa de aprovechamiento forestal sustentable, (b) PAFPL: Programa de aprovechamiento forestal para bosques cultivados, PAFAP: Programa de aprovechamiento forestal para árboles plantados; (c) PAFEP: Programa de aprovechamiento forestal para bosques cultivados (arboles de regeneración natural), PCAR: Programa de corta para corta de árboles relictos, (d) FCB: Formulario de corta para balsa, FCP: Formulario de corta para pigüe considerando que estos formularios no han sido ingresados en su totalidad en el SAF, por lo que únicamente representan cifras parciales); y (e) PAFCL: Programa de aprovechamiento forestal en conversión legal.

Fuente: Elaboración de los autores basado en SAF, Ministerio del Ambiente del Ecuador (2011).

\section{Cuadro 14. Amazonía: Aprovechamiento por tipo de programa en 2011 (miles de $\mathrm{m}^{3}$ )}

\begin{tabular}{|c|c|c|c|c|c|c|c|}
\hline & \multicolumn{6}{|c|}{ Tipo de programa (en miles $\mathrm{m}^{3}$ ) } & \multirow{3}{*}{ Total } \\
\hline & \multicolumn{3}{|c|}{ Plantaciones } & \multicolumn{2}{|c|}{ Bosques nativos } & \multirow{2}{*}{ Otros $^{f}$} & \\
\hline & PAFPL $^{a}$ & PAFEPb $^{b}$ & PCAR $^{\mathrm{c}}$ & PAFSI $^{d}$ & PAFSU & & \\
\hline Aprobado (miles m³) & 0,5 & 94,3 & 133,9 & 173,6 & 30,5 & 25,3 & 458 \\
\hline Aprobado (\%) & 0,1 & 20,6 & 29,2 & 37,9 & 6,7 & 5,5 & 100 \\
\hline Movilizado (miles $\mathrm{m}^{3}$ ) & 0,4 & 47,2 & 67,9 & 86,8 & 25,8 & 18,0 & 246,2 \\
\hline Movilizado (\%) & 0,2 & 19,2 & 27,6 & 35,3 & 10,5 & 7,3 & 100 \\
\hline
\end{tabular}

Notas: a) PAFPL: Programa de aprovechamiento forestal para bosques cultivados, PAFAP : Programa de aprovechamiento forestal para árboles plantados, b) PAFEP: Programa de aprovechamiento forestal para bosques cultivados (arboles de regeneración natural) / Programa de corta de especies pioneras, c) PCAR: Programa de corta para árboles relictos, d) PAFSI: Programa de aprovechamiento forestal simplificado; e) PAFSU: Programa de aprovechamiento forestal sustentable; f) FCB: Formulario de corta para balsa, FCP: Formulario de corta para pigüe, PAFCL: Programa aprovechamiento forestal en conversión legal.

Fuente: Elaboración de los autores basada en SAF, Ministerio del Ambiente del Ecuador (2011).

en esta región abastece la demanda de madera para la industria del mueble y la construcción principalmente en los mercados de Quito, Cuenca y Ambato (Vásquez, 2011). En 2011, del total de $458 \mathrm{mil} \mathrm{m}^{3}$ de madera aprobada en la Amazonía, únicamente se movilizaron $246 \mathrm{mil} \mathrm{m}^{3}$ (cuadro 14). Del total de madera movilizada, un 35\% fue extraída mediante el uso de PAFSI, lo que indica que fueron extraídas de parcelas de pequeños finqueros, así como la madera extraída a través de programas de relictos $(27 \%)$, seguida por madera proveniente de bosques cultivados o bosques de regeneración natural (19\%). Aunque el uso de PAFSU no es muy importante en la Amazonía, el $10 \%$ de la madera fue extraída a través de operaciones mecanizadas. 


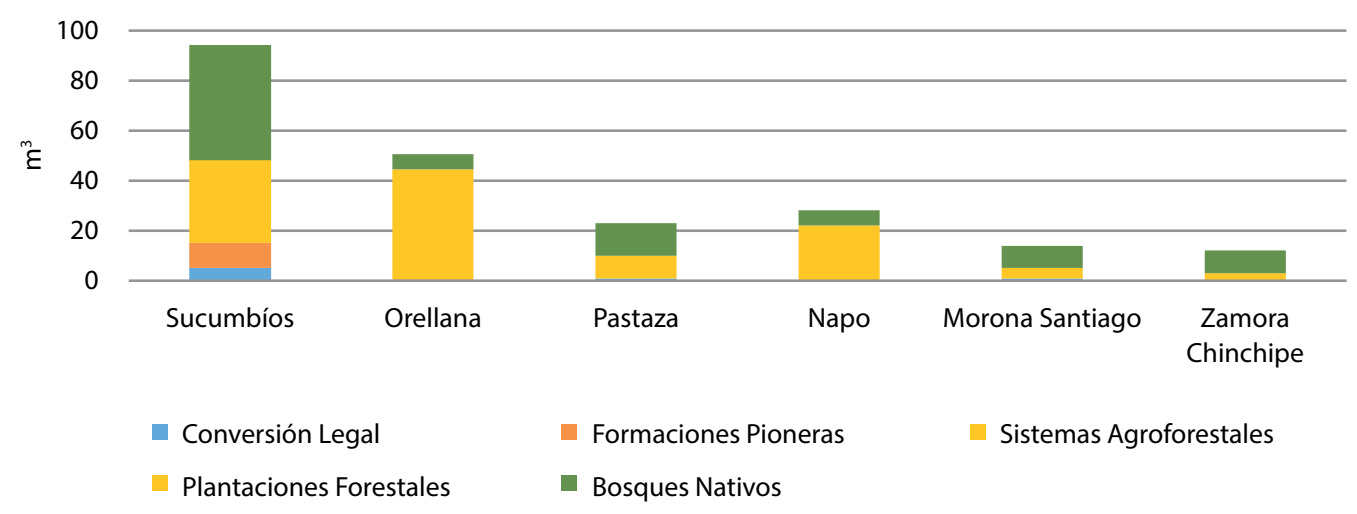

Figura 5. Amazonía: Volumen en $\mathrm{m}^{3}$ aprovechado por tipo de bosques y provincias. Los datos se han agrupado según Bosques nativos (PAFSU y PAFSI), Plantaciones forestales (PAFAP y PAFPL), Sistemas agroforestales (PCAR y PAFEP), Formaciones pioneras (FCB y FCP) y Conversión legal del suelo (PAFCL). Elaboración propia basada en SAF, Ministerio del Ambiente del Ecuador (2011).

Una mayor parte de la madera originada en la Amazonia proviene de las provincias de Sucumbíos y Orellana (figura 5), situadas en el noreste del Ecuador y norte de la Amazonía, mientras que aprovechamientos menores se realizan en las provincias del centro y sur de la Amazonía. En gran parte, el hecho de que exista una mayor oferta de madera en las provincias de Sucumbíos y Orellana tiene relación con el mayor desarrollo de las carreteras vinculadas con las actividades de extracción petrolera que se ha establecido en esas provincias, y la migración subsecuente que ha implicado mayor presión sobre los recursos forestales (Wunder, 2000; Wunder, 2003).

Un aspecto importante de resaltar está relacionado con las especies aprovechadas y su procedencia. El cuadro 15 indica las principales especies (duras, semiduras y blandas) procedentes de los bosques amazónicos que están asociadas a los diferentes programas utilizados. Es así que el $50 \%$ de las especies más comerciales tienen como origen el bosque nativo, el $30 \%$ provienen de sistemas agroforestales y el $27 \%$ se originan en formaciones pioneras. Entre las especies duras y semiduras más aprovechadas se encuentran las especies como laurel, chuncho, arenillo, colorado y copal, que se utilizan en la industria del mueble y pisos. Las especies blandas más aprovechadas son el doncel, sapote, coco y tamburo, que tienen como principal destino la industria del contrachapado y la construcción. De acuerdo a datos del SAF, en 2010 los programas de aprovechamiento autorizaron la extracción de un total de 222 especies, mientras que éstas fueron alrededor de 300 en 2011 (SAF 2010, 2011). El incremento del número de especies es un fenómeno que se debe posiblemente a la disminución de volúmenes de ciertas especies que han sido aprovechadas con mayor intensidad y el mercado está demandando más volumen de madera, obligando de esta manera a que se incursione en ingresar nuevas especies al mercado, como es el caso de Otoba spp. También podría deberse a una mala identificación de las especies.

Existen tres especies de valor económico importante para los finqueros, estas son laurel, chuncho y doncel. La primera especie, el laurel, reportó volúmenes movilizados de $39,2 \mathrm{mil} \mathrm{m}^{3}$ en 2010 y $42,1 \mathrm{mil} \mathrm{m}^{3}$ en 2011 . En el caso del chuncho, se registraron $16,1 \mathrm{mil} \mathrm{m}^{3}$ en 2010 y 10,9 mil m³ en 2011.

El laurel (Cordia alliodora), una especie aprovechada de sistemas agroforestales, representa el $17,3 \%$ del total del volumen movilizado de la Amazonia. Al realizar el análisis de la figura legal de aprovechamiento, el $96,75 \%$ provino del PAFEP, programa que permite el aprovechamiento de árboles de regeneración natural, ya que la especie se desarrolla en áreas que han sido intervenidas o transformadas como pastizales, dado que requiere mucha radiación solar para alcanzar un apropiado crecimiento.

En relación al doncel es interesante destacar que en los últimos años ha aumentado su aprovechamiento reportando volúmenes de 
Cuadro 15. Amazonía: Aprovechamiento por tipo de programa y especie en 2011

\begin{tabular}{|c|c|c|c|c|}
\hline \multirow[b]{2}{*}{ Especies } & \multicolumn{4}{|c|}{ Volumen aprovechado (miles de $\mathrm{m}^{3}$ ) } \\
\hline & $\begin{array}{c}\text { Bosques } \\
\text { nativos }\end{array}$ & $\begin{array}{l}\text { Sistemas } \\
\text { agroforestales }\end{array}$ & $\begin{array}{l}\text { Formaciones } \\
\text { pioneras }\end{array}$ & Total \\
\hline Laurel (Cordia alliodora) $(*)$ & 0,3 & 42,1 & 0 & 42,4 \\
\hline Doncel, sangre de gallina, (Otoba spp) & 16,5 & 8,9 & 0 & 25,4 \\
\hline Sapote (Sterculia spp) & 8,1 & 5,4 & 0 & 13,5 \\
\hline Balsa, boya (Heliocarpus americanus) & 0,1 & 0 & 10,6 & 10,7 \\
\hline Chuncho, seique, (Cedrelinga catenaiformes) (*) & 9 & 1,9 & 0 & 10,9 \\
\hline Ceiba, ceibo, (Ceiba insignis) & 7,9 & 5,3 & 0 & 13,2 \\
\hline Chalviande, coco, (Virola spp) & 6,2 & 3,6 & 0 & 9,8 \\
\hline Arenillo, pondo (Erisma uncinatum) $\left(^{*}\right)$ & 7,3 & 2 & 0 & 9,3 \\
\hline Tamburo, bella María, Juan Colorado (Vochysia spp) & 4,9 & 2,8 & 0 & 7,7 \\
\hline Colorado, manzano, piaste (Guarea Kunthiana) $\left(^{*}\right)$ & 3,6 & 2,9 & 0 & 6,5 \\
\hline Copal, copalillo, anime, pulgande (Dacryodes spp) & 4,2 & 1,5 & 0 & 5,7 \\
\hline Jigua, canelo (Jigua spp.) & 3,7 & 1,3 & 0 & 5 \\
\hline Algodón, lao, ceibo rojo, ceiba, sumauma (Ceiba spp) & 2,7 & 2,4 & 0 & 5,1 \\
\hline Lechero, sande rojo, sande blanco (Brosimun spp) & 3,2 & 1,5 & 0 & 4,7 \\
\hline Guarango, yonrunta (Acacia glomerosa) & 2,7 & 1,7 & 0 & 4,4 \\
\hline Matapalo, higuerón (Ficus spp) & 1,8 & 2,2 & 0 & 4 \\
\hline Abio, caimitillo (Pouteria spp) & 2,2 & 1,6 & 0 & 3,8 \\
\hline Canelo, alcanfor, jigua, amarillo, canelón (Ocotea spp) (a) & 1,7 & 1,8 & 0 & 3,5 \\
\hline Guayabillo, yunyun, roble, winegro (Terminalia spp) & 1,2 & 2,3 & 0 & 3,5 \\
\hline Copal, anime (Dacryodes peruviana) & 2,2 & 1,1 & 0 & 3,3 \\
\hline Damagua, majagua, yamila (Poulsenia armata) & 2,6 & 0,4 & 0 & 3 \\
\hline $\begin{array}{l}\text { Cutanga, guarango, cacepo, tankam, yurutz (Parkia } \\
\text { multijuga) }\end{array}$ & 1,5 & 1,4 & 0 & 2,9 \\
\hline Guabillo (Inga spp) & 2,2 & 0,3 & 0 & 2,5 \\
\hline Guaba, guabo (Inga spp) & 1,5 & 0,7 & 0 & 2,2 \\
\hline Otros & 24,2 & 18 & 0 & 42,2 \\
\hline Otros provenientes de conversión legal & & & & 0,6 \\
\hline Otros provenientes de plantaciones forestales & & & & 0,4 \\
\hline Total & 121,5 & 113,1 & 10,6 & 246,22 \\
\hline
\end{tabular}

Nota: Las especies marcadas con * son duras y semiduras, el resto son consideradas blandas.

Fuente: Elaboración propia basada en SAF, Ministerio del Ambiente del Ecuador (2011)

$9,3 \mathrm{mil} \mathrm{m}^{3}$ en 2010 y 16 mil en 2011. Ocupa el segundo lugar respecto al total de la madera aprovechada en la Amazonía con el 6,5\% del total del volumen movilizado. La figura legal más empleada para el aprovechamiento de doncel fue el PAFSI con el 41,39\% del volumen total movilizado, seguido del PCAR con el 33,27\%, que en conjunto significan el $75 \%$ de madera en el mercado del país. Su madera, conocida en el mercado como ordinaria, es empleada para todo tipo de actividad de la construcción. En Sucumbíos esta especie es utilizada para la elaboración de palos de escoba y en Pastaza se utiliza para la elaboración de pallets (Ministerio del Ambiente del Ecuador, 2011). 
Cuadro 16. Ecuador: Destino y origen de la madera movilizada en 2011

\begin{tabular}{llcccccc}
\hline & & \multicolumn{5}{c}{ Destino $\left(\right.$ miles $\mathbf{m}^{3}$ ) } \\
\cline { 3 - 8 } & & Costa & Sierra & Amazonía & Galápagos & No especifica & Total \\
\hline \multirow{2}{*}{} & Costa & 591 & 224 & 7 & 0,1 & 178 & 1000 \\
은 & Sierra & 232 & 448 & 1 & 0 & 99 & 779 \\
Total & Amazonía & 27 & 185 & 19 & 0 & 15 & 246 \\
\hline
\end{tabular}

Fuente: Elaboración propia basada en SAF, Ministerio del Ambiente del Ecuador (2011)

El chuncho o seike (Cedrelinga catenaeformis), es una especie de alta demanda aprovechada en los bosques nativos y utilizada principalmente para la fabricación de puertas y marcos. Según el SAF (2011) representa el 4,5\% del volumen total movilizado en la región de la Amazonía. Es necesario mencionar que se desconoce el tipo de presión que se ejerce sobre la especie como resultado de su extracción actual. Esta especie no tiene restricción en el CITES. Es especialmente comercializada para puertas y pisos, exportándose estos productos a mercados regionales como Venezuela.

\subsection{Principales flujos comerciales de la madera}

\subsubsection{Origen y destino de la madera movilizada a nivel provincial}

Los flujos de la madera en el Ecuador son relativamente complejos porque la madera que se origina en las zonas de producción de la Costa, Sierra y Amazonia se moviliza hacia diferentes mercados locales, regionales o fuera del país. Las regiones de la Sierra y Costa son las principales receptoras de madera movilizada, representando el $43 \%$ y $42 \%$ respectivamente, y la mayoría de la producción de la Amazonía se comercializa fuera de esta región (cuadro 16). La mayor parte de la madera consumida en la Costa proviene de la misma región, otra porción importante se origina en la Sierra, sobre todo de plantaciones. La Sierra es también una importante consumidora de madera originada en la propia región, especialmente plantaciones de eucalipto y pino, puesto que concentra la industria de tableros aglomerados. No obstante, los bosques nativos de la Amazonia son también importantes oferentes de madera para los mercados de muebles de la región (Ministerio del Ambiente del Ecuador, 2011).
Aunque los flujos de madera al interior de cada una de las regiones son importantes, también existe un significativo flujo de madera entre las diferentes regiones. Entre los principales flujos de madera identificados (mapa 3) se detallan por región los siguientes:

- En la Costa: los principales centros de consumo son Guayas, Esmeraldas y Los Ríos. Guayas, recibe madera principalmente de Esmeraldas en un promedio de $200 \mathrm{mil} \mathrm{m}^{3}$ en 2011 , a su vez Esmeraldas recibe madera de plantaciones forestales de Pichincha y Cotopaxi para la industria de las astillas de exportación. La madera que se destina a estos mercados se utiliza principalmente en la industria del contrachapado en Esmeraldas y para uso en mueblería y construcción en Guayas y Los Ríos (Ministerio del Ambiente del Ecuador, 2011)

- En la Sierra: los principales centros de consumo son las provincias de Pichincha y Cotopaxi, en donde se encuentra la empresa Aglomerado Cotopaxi (ACOSA) que consume gran parte de esta madera. Pichincha consumió más de $400 \mathrm{mil} \mathrm{m}^{3}$ en 2011 proveniente de las provincias de Esmeraldas, Cotopaxi, Sucumbíos y Orellana, por citar las más importantes. Por su parte, Cotopaxi consumió aproximadamente $188 \mathrm{mil} \mathrm{m}^{3}$ en 2011, de los cuales $151 \mathrm{mil} \mathrm{m}^{3}$ se produjeron internamente. Cabe destacar que la mayor cantidad de artesanos mueblistas están concentrados en esta región en Azuay y Pichincha (cerca de un $80 \%$ se encuentran agremiados en la CAPIA $^{19}$ y en la CAPEIPI ${ }^{20}$ ). Estos artesanos se abastecen principalmente de madera proveniente de Esmeraldas, de la especie Fernán Sánchez (Triplaris cumingiana), que es la madera más utilizada en la fabricación de

19 Cámara de la Pequeña Industria del Azuay.

20 Cámara de la Pequeña y Mediana Empresa de Pichincha 


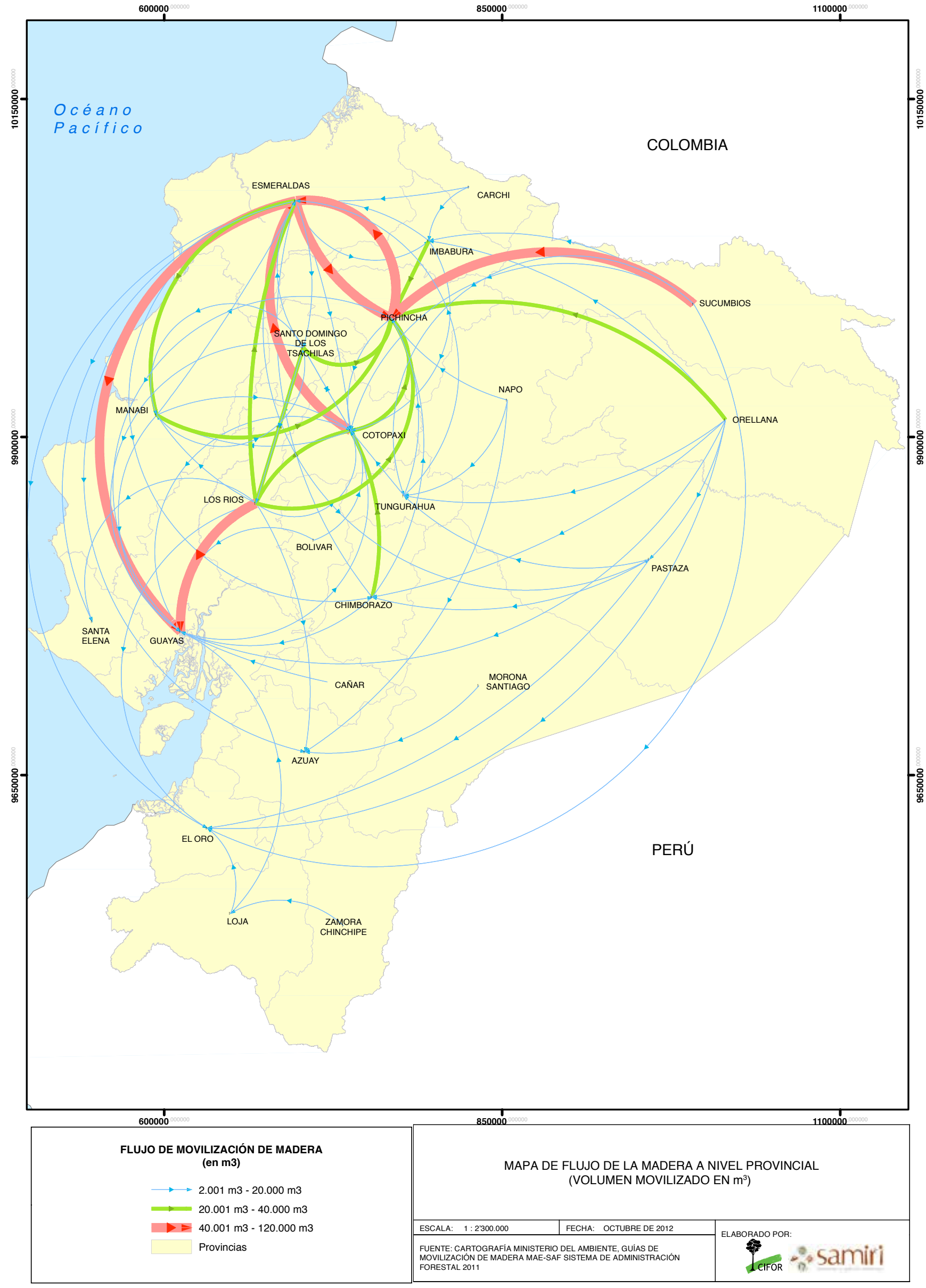

Mapa 3. Ecuador: Flujo de madera a nivel provincial elaborado según datos del SAF, Ministerio del Ambiente del Ecuador (2011) 
muebles, seguida de las especies que vienen de la Amazonia (Terán, 2012).

- En la Amazonía: las provincias de Sucumbíos y Orellana abastecen de madera a Pichincha $y$, en menor grado, Orellana abastece los mercados de Guayas, especialmente con madera de exportación, como el caso del chuncho (Cedrelinga cateniformeis) utilizada para la fabricación de puertas. Las otras provincias de esta región (Napo, Pastaza, Morona Santiago, Zamora-Chinchipe) abastecen mercados más pequeños como los de Ambato, Cuenca y Loja. La madera destinada a estos mercados se usa principalmente en la industria del mueble y la construcción. A continuación, el cuadro 17 detalla los principales destinos de las especies más aprovechadas de la Amazonia; posteriormente el mapa 4 muestra los flujos generales de los destinos de esta madera.

\subsubsection{Origen y destino de la madera movilizada de la Amazonia}

Como ya se ha mencionado, las seis provincias de la Amazonia movilizan el $12 \%$ de la madera que es ofertada en el mercado. De esta el $46 \%$ se origina en bosques nativos (aprovechados a través de programas PAFSI y PAFSU), el $28 \%$ corresponde a madera aprovechada dentro de sistemas agroforestales y el 19\% proviene de formaciones pioneras. La proporción de la madera que se consume localmente en la Amazonía es relativamente pequeña ( $8 \%$ o $19 \mathrm{mil} \mathrm{m}^{3}$ en 2011$)$, lo que significa que el $92 \%$ se consume en la Costa y Sierra (cuadro 16). La provincia de Sucumbíos es la que aporta la mayor parte de la madera con el 38\%, seguida de Orellana con el $30 \%$ y las restantes 4 provincias aportan un $22 \%$ del total.

Se estima que una importante proporción de la madera consumida localmente en la Amazonía es de procedencia informal. Por ejemplo, Palacios (2008), observa para Napo que la madera comercializada localmente es mayor que la declarada legalmente, sugiriendo que aproximadamente el $80 \%$ de la madera comercializada en Tena tiene origen informal. Por su parte, Sierra (2000), sugiere que los mercados locales son muy importantes en la comercialización de madera para los pequeños productores, y que una buena parte de la oferta provendría del mercado informal.

La única industria que se localiza en la región amazónica es Arboriente S.A. Esta compañía se abastece mayormente de madera rolliza para su planta de contrachapados (Ministerio del Ambiente del Ecuador, 2011). Es por esto que la mayoría de la madera que se origina en la Amazonía se transporta a otras regiones donde se encuentran concentradas las industrias madereras, como es el caso de la provincia Pichincha (figura 6). Asimismo, como ya se mencionó, la industria del mueble que se concentra en las provincias de Azuay y Pichincha se abastecen de madera proveniente de la región amazónica (Vásquez, 2011; Terán, 2012).

\section{Cuadro 17. Principales especies movilizadas de la Amazonia y sus destinos}

\begin{tabular}{ll}
\hline Especies & Destino principal \\
\hline Laureles (Cordia alliodora) & Tungurahua, Pichincha, Imbabura \\
Doncel, sangre de gallina, (Otoba spp) & Pichincha, El Oro, Pastaza \\
Sapote (Sterculia spp) & Pichincha, Imbabura, Sucumbíos, Pastaza \\
Balsa, boya (Heliocarpus americanus) & El Oro, Guayas \\
Chuncho, seique, (Cedrelinga catenaiformes) & El Oro, Guayas, Pichincha, Tungurahua, Loja \\
Ceiba, ceibo, (Ceiba insignis) & Pichincha, Tungurahua, Imbabura \\
Chalviande, coco, (Virola spp) & El Oro, Pichincha, Tungurahua, Pastaza \\
Arenillo, pondo (Erisma uncinatum) & El Oro, Pichincha, Tungurahua, Imbabura \\
Tamburo, bella María, Juan Colorado (Vochysia spp) & El Oro, Pichincha, Tungurahua, Chimborazo \\
Colorado, manzano, piaste (Guarea Kunthiana) & Pichincha, Tungurahua, El Oro \\
Copal, copalillo, anime, pulgande (Dacryodes spp) & Azuay, Pichincha, Tungurahua \\
\hline
\end{tabular}

Fuente: Elaboración propia basada en SAF, Ministerio del Ambiente del Ecuador (2011) 


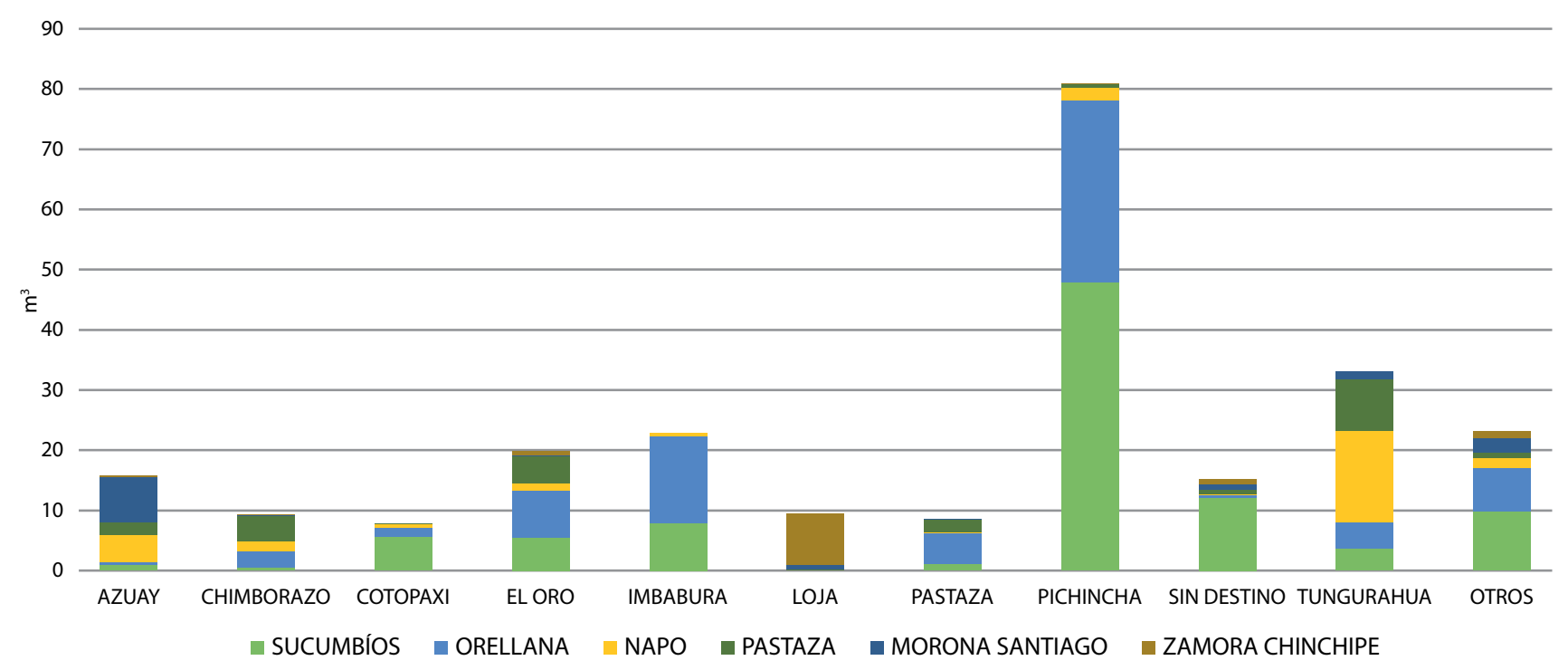

Figura 6. Amazonía: Madera movilizada según provincia de origen y 10 destinos principales (miles de $\mathrm{m}^{3}$ ). Elaboración propia basada en el SAF, Ministerio del Ambiente del Ecuador (2011).

Las provincias receptoras de madera de la Amazonía con volúmenes superiores a $10000 \mathrm{~m}^{3} /$ año son la provincia de Pichincha, Tungurahua, Imbabura, El Oro y Azuay (figura 6).

- La provincia de Tungurahua recibe madera de la provincia de Napo (85\%), esto es debido a la cercanía y facilidad de transportar la madera por la vía principal, además en esta provincia se está potenciando la fabricación de muebles a gran escala (Terán, 2012).

- Por su parte, la provincia de Imbabura recibe el 49\% de madera de sistemas agroforestales localizados en la provincia de Orellana, el destino final es la parroquia de San Antonio de Ibarra en donde se concentran artesanos y carpinteros de la madera.

- La provincia del Oro recibe madera de Sucumbíos y Orellana. Esta movilización se realiza a pesar de la lejanía debido a que existe una demanda y precios diferenciados por madera aserrada en Huaquillas (recuadro 3).

- La provincia del Azuay es la única que recibe un volumen importante de la provincia de Morona Santiago.

- Finalmente, aunque en volúmenes más reducidos, la madera de Zamora Chinchipe es una de las pocas fuentes de origen de madera hacia la provincia de Loja (mapa 4). Igualmente el Ministerio del Ambiente del Ecuador (2011), detalla que desde Loja se moviliza madera semiprocesada a Cuenca y Huaquillas (mapa 5).

\subsection{Una descripción de proveedores y compradores}

\subsubsection{Ejecutores y compradores por rubro y tamaño a nivel nacional}

Un total de 3053 ejecutores han sido registrados en el SAF, quienes recibieron guías de movilización en 2011. Un 86\% de ellos se encuentran registrados en el Sistema de Rentas Internas (SRI) como "Personas naturales" (PN) mientras que el resto corresponden a "Personas jurídicas" conocidas como Sociedades o Empresas (SOC). ${ }^{21}$ Es importante anotar que los ejecutores son quienes, según la base de datos, realizan las operaciones forestales de extracción de madera. ${ }^{22}$ Adicionalmente, en el SAF se registran 3559 compradores de madera. Más adelante se presentan las interacciones que establecen ejecutores y compradores según esta información.

En 2011, los tipos de ejecutores más importantes considerando el volumen de madera que movilizaron, son aquellos clasificados como depósitos, aserraderos y transporte, según se

21 Únicamente dos ejecutores registrados en la base de datos del SAF no cuentan con registro en el SRI.

22 Los ejecutores, no obstante, muy pocas veces son los propietarios de los bosques, sino más bien son aquellos quienes hicieron las veces de intermediarios o tienen alguna relación familiar con los mismos 


\section{Recuadro 3. Flujos de la madera con destino a la parroquia de Huaquillas}

Patricia Aguirre, Johanna Morocho y Santiago Alarcón

Según Salazar (2006), una de las fronteras con mayor flujo de madera en Ecuador es la parroquia de Huaquillas, que constituye un centro de comercio regular de madera, generalmente a través de contrabando. Huaquillas es uno de los principales mercados de la madera movilizada originada en las provincias de Orellana, Sucumbíos y Pastaza (38,6\%, 24,1\% y $23,1 \%$, respectivamente, de la madera movilizada a Huaquillas). El $58 \%$ de la madera proviene de bosques nativos (SAF 2011), la misma que es cepillada y dimensionada por aserraderos locales para luego ser comercializada en Perú ( (Ministerio del Ambiente del Ecuador, 2011))

Pese a que se dispone de las cifras oficiales de ingreso de madera que se comercializa en Huaquillas, no se conoce el destino final de esta madera, así como las dinámicas de su comercialización en el Perú. Para suplir estos vacíos de información, se realizaron entrevistas a los propietarios de 13 de un total de 18 establecimientos registrados en el SAF ubicados en el cantón Huaquillas, que recibieron madera en 2011. De acuerdo al SAF y SRI, 14 de dichos establecimientos se clasificarían como depósitos, los que recibieron el 59.9\% de la madera y 4 son aserraderos, los que recibieron el $34,1 \%$ de la madera.

La madera, según los entrevistados, proviene principalmente de Coca (provincia Orellana) y Lago Agrio (provincia Sucumbíos). El volumen de madera que reciben en sus aserraderos ha sido reportada en un promedio de dos carros por mes, aproximadamente $60 \mathrm{~m}^{3}$ en total. Las entrevistas con dueños de depósitos y aserraderos indican que el $53 \%$ de la madera se queda en Huaquillas y el $47 \%$ restante se dirigiría a Perú. No obstante, según entrevistas complementarias con actores locales, la demanda interna no es tan alta como la sugerida anteriormente. La madera que se comercializa en Perú es transportada por medio de triciclos en pequeñas cantidades para evitar los controles. Muchas veces no llega a ser descargada en Huaquillas y pasa directamente a territorio peruano en horas de la madrugada con destino final a la ciudad de Piura y algunas veces Chiclayo.

Los propietarios de depósitos y aserraderos en Huaquillas indican que las especies más demandas en Perú son las semiduras, entre ellas: chuncho (Cedrelinga cateniformis), sangre de gallina (Otoba spp.) y arenillo (Erisma uncinatum). También se indica que el producto principal son tablas destinadas a la construcción, aunque muchas veces llegan en forma de tablón simple que es posteriormente dimensionado. El mayor problema que enfrentan estos establecimientos es la falta de cumplimiento en los acuerdos de la calidad de la madera con los intermediarios, especialmente con respecto a la rectitud del aserrado y las dimensiones de la madera; algunas veces esta madera presenta defectos mecánicos o patológicos que hacen que la madera se abarate en el mercado final.

detalla en el cuadro 18. Los depósitos son los principales abastecedores del mercado nacional (35\% del total), movilizan madera principalmente a otros depósitos $\left(238 \mathrm{mil} \mathrm{m}^{3}\right)$, a la industria $\left(203 \mathrm{mil} \mathrm{m}^{3}\right)$ y a otros consumidores sin RUC registrado $\left(102 \mathrm{mil} \mathrm{m}^{3}\right)$. Los depósitos se encuentran localizados en las tres regiones del país, aunque su participación en el volumen comercializado es mayor en la Costa $(53 \%)$ que en Sierra (28\%) y Amazonia (19\%). Un hecho que no deja de sorprender es que, pese a que la mayor oferta de madera se concentra en las categorías de establecimientos económicos mencionados anteriormente, existe un grupo numeroso de ejecutores con actividades bastante diversas (por ejemplo, minería, agricultura, pecuaria, alimentos) que también se dedican a la venta y/o intermediación de madera.

En relación a los compradores de la madera, los más importantes por rubro son la industria, depósitos, aserraderos y carpinterías (cuadro 19). Asimismo, existe un grupo bastante diverso de compradores que tienen su RUC registrado en un número diverso de actividades económicas. La industria consume casi la mitad de toda la madera que ingresa al mercado formal (905 $\mathrm{mil} \mathrm{m}^{3} /$ año), y está localizada principalmente en la Costa y Sierra, mientras que en la Amazonía esta industria es casi inexistente. Los establecimientos 


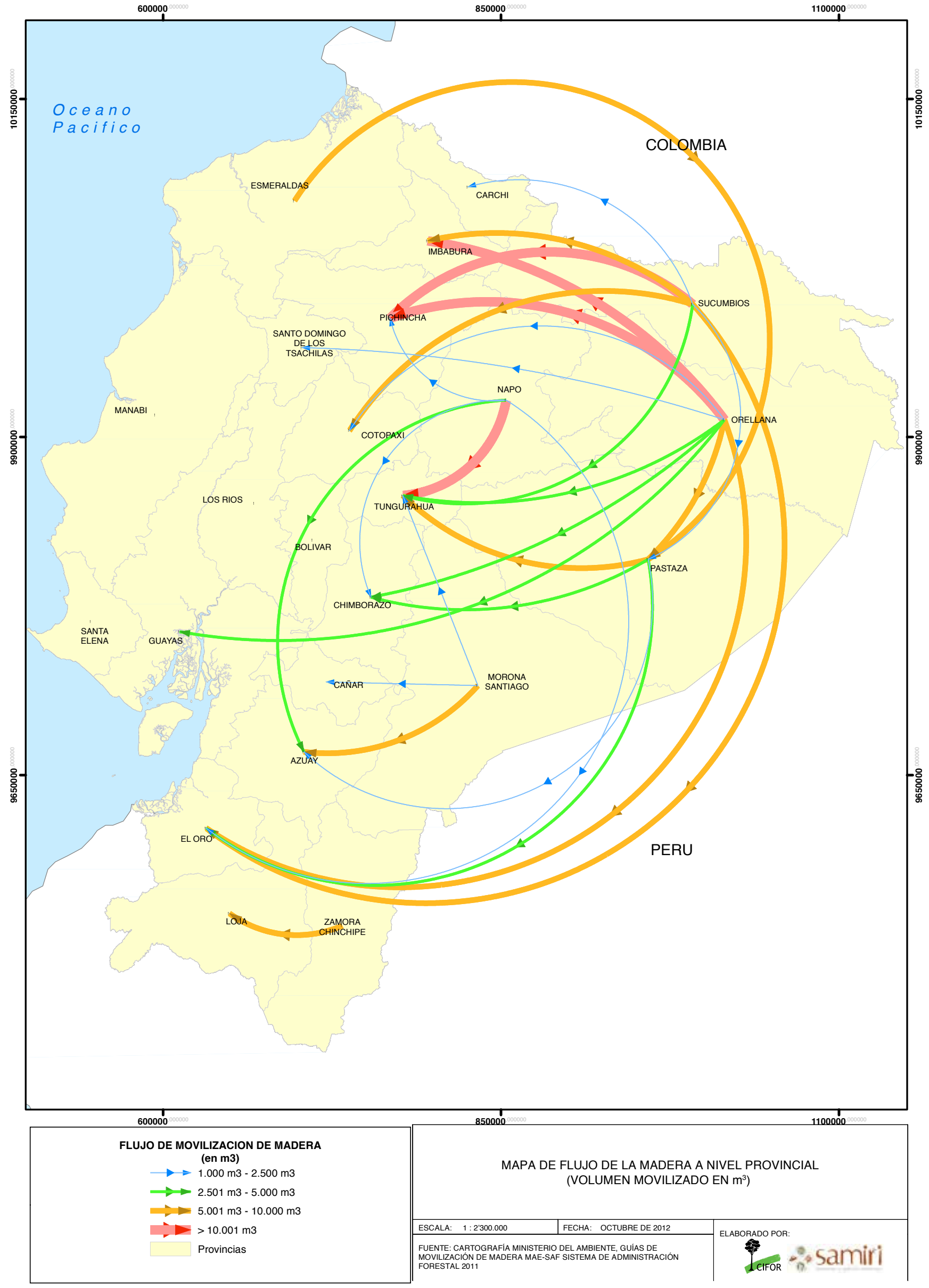

Mapa 4. Amazonía: Principales flujos de madera a nivel provincial, elaborado según información del SAF, Ministerio del Ambiente del Ecuador (2011). 


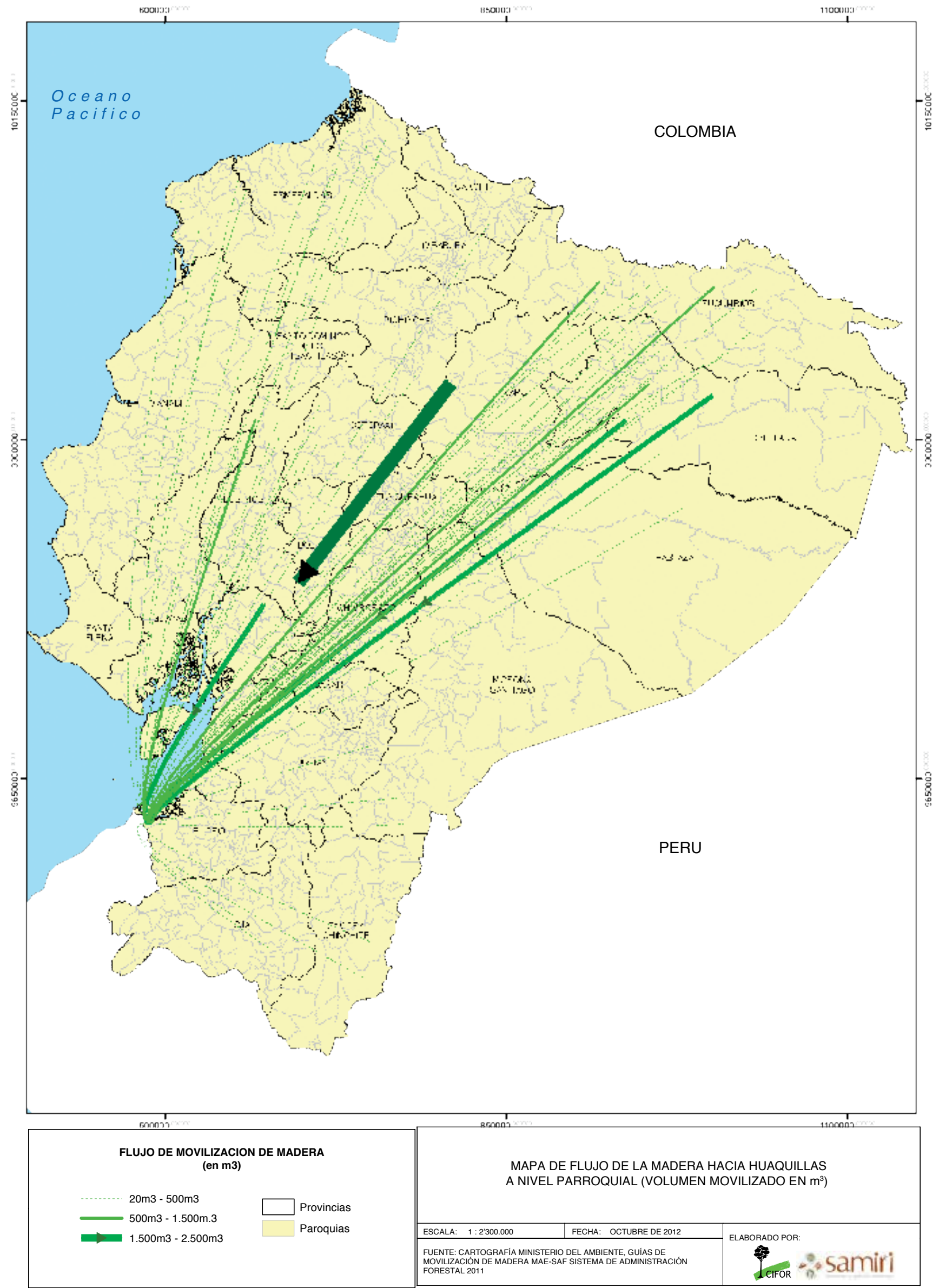

Mapa 5. Origen de la madera con destino a Huaquillas, elaborado de acuerdo con información del SAF, Ministerio del Ambiente del Ecuador (2011). 
Cuadro 18. Ejecutores por rubro y tamaño

\begin{tabular}{|c|c|c|c|c|c|c|c|}
\hline \multirow{2}{*}{ Rubro } & \multicolumn{6}{|c|}{ Ejecutores $\left(\text { miles de } \mathrm{m}^{3}\right)^{\mathrm{a}}$} & \multirow{2}{*}{ Total en $\%$} \\
\hline & Muy grande & Grande & Mediano & Pequeño & Muy pequeño & Total general & \\
\hline Depósito & 28,4 & 393,8 & 256,1 & 30,1 & 0,5 & 708,8 & 35 \\
\hline Transporte & 189,4 & 100,9 & 41,6 & 5,1 & 0,1 & 337 & 16,6 \\
\hline Aserradero & 0 & 97,5 & 105,7 & 11,6 & 0,2 & 215 & 10,6 \\
\hline Servicios & 123,8 & 39,4 & 21,0 & 2,9 & 0,1 & 187,1 & 9,2 \\
\hline No declarab & 64,7 & 51,6 & 12,1 & 2,4 & 0,2 & 131 & 6,5 \\
\hline Pecuario & 52,5 & 7 & 15,6 & 14,1 & 0,2 & 89,3 & 4,4 \\
\hline Industria & 67,9 & 10,1 & 7,2 & 0,3 & 0 & 85,4 & 4,2 \\
\hline Minería & 73,4 & 0 & 0,4 & 0,2 & 0 & 74 & 3,7 \\
\hline Agrícola & 0 & 40,1 & 20,2 & 3,9 & 0,2 & 64,4 & 3,2 \\
\hline Otros ${ }^{c}$ & 0 & 73,7 & 49,6 & 7,1 & 0,2 & 130,8 & 6,5 \\
\hline $\operatorname{Sin} R U C^{d}$ & 0 & 2,8 & 0 & 0,1 & 0 & 2,9 & 0,1 \\
\hline Total & 600 & 816,8 & 529,4 & 77,9 & 1,7 & 2025,8 & 100 \\
\hline
\end{tabular}

Nota: a) Estos grupos han sido clasificados por el volumen de movilización anual. Muy grandes: más de $12000 \mathrm{~m}^{3} /$ año; grandes: 1200,1 a $12000 \mathrm{~m}^{3} /$ año; medianos: 120,1 a $1200 \mathrm{~m}^{3} /$ año; pequeños: 12,1 a $120 \mathrm{~m}^{3} /$ año; y muy pequeños: 0,1 a $12 \mathrm{~m}^{3} /$ año b) Significa que el ejecutor no ha consignado en el SRI el nombre comercial o la actividad comercial principal. c) Incluye a los ejecutores cuyos registros del nombre comercial o la actividad comercial principal no tiene relación con la actividad forestal. d) Sin RUC: el RUC consignado en el SAF no tiene registro en el SRI.

Fuente: Elaboración propia basada en información del SAF, Ministerio del Ambiente del Ecuador (2011)

\section{Cuadro 19. Compradores por rubro y tamaño}

\begin{tabular}{|c|c|c|c|c|c|c|c|c|}
\hline & \multicolumn{7}{|c|}{ Compradores $\left(\text { miles de } \mathrm{m}^{3}\right)^{\mathrm{a}}$} & \multirow{2}{*}{$\begin{array}{l}\text { Total } \\
\text { en } \%\end{array}$} \\
\hline & Muy grande & Grande & Mediana & Pequeña & Muy Pequeña & No identificado ${ }^{b}$ & Total & \\
\hline Industria & 659,7 & 68,6 & 221,1 & 1,5 & 0,1 & 0 & 950,9 & 46,9 \\
\hline Depósito & 15 & 205,4 & 150,5 & 19,7 & 1,2 & 0 & 391,7 & 19,3 \\
\hline Sin destino & 0 & 0 & 0 & 0 & 0 & 291,8 & 291,8 & 14,4 \\
\hline Aserradero & 0 & 72,1 & 72,3 & 6,8 & 0,4 & 0 & 151,6 & 7,5 \\
\hline Transporte & 13,5 & 6,2 & 20,9 & 4,2 & 0,4 & 0 & 45,2 & 2,2 \\
\hline Carpintería & 0 & 4,9 & 27,5 & 8,9 & 0,5 & 0 & 41,8 & 2,1 \\
\hline Mueblería & 0 & 5,8 & 22,9 & 9,2 & 0,4 & 0 & 38,4 & 1,9 \\
\hline Ferretería & 0 & 8,1 & 16,7 & 7,7 & 0,3 & 0 & 32,8 & 1,6 \\
\hline Servicios & 15,9 & 5,5 & 6,6 & 1,9 & 0,4 & 0 & 30,2 & 1,5 \\
\hline No declarac & 0 & 4,4 & 4,5 & 2,2 & 0,4 & 0 & 11,5 & 0,6 \\
\hline Agrícola & 0 & 4,7 & 3,7 & 2,4 & 0,6 & 0 & 11,3 & 0,6 \\
\hline Otros $^{\mathrm{d}}$ & 0 & 7,4 & 14,5 & 5,7 & 0,8 & 0 & 28,6 & 1,4 \\
\hline Total & 704 & 393,1 & 561,4 & 70,1 & 5,4 & 291,8 & 2025,8 & 100 \\
\hline
\end{tabular}

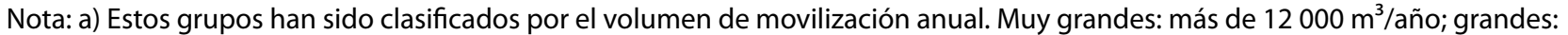
1200,1 a $12000 \mathrm{~m}^{3}$ /año; medianos: 120,1 a $1200 \mathrm{~m}^{3} /$ año; pequeños: 12,1 a $120 \mathrm{~m}^{3} /$ año y muy pequeños: 0.1 a $12 \mathrm{~m}^{3} / \mathrm{año}$. b) Corresponde a las guías de movilización que no especifican RUC de destino final. c) No declara significa que el ejecutor no ha consignado en el SRI el nombre comercial o la actividad comercial principal. d) Incluye a los establecimientos donde el registro del nombre comercial o la actividad comercial principal no tiene relación con la actividad forestal, etc.).

Fuente: Elaboración propia basada en datos del SAF, Ministerio del Ambiente del Ecuador (2011) 


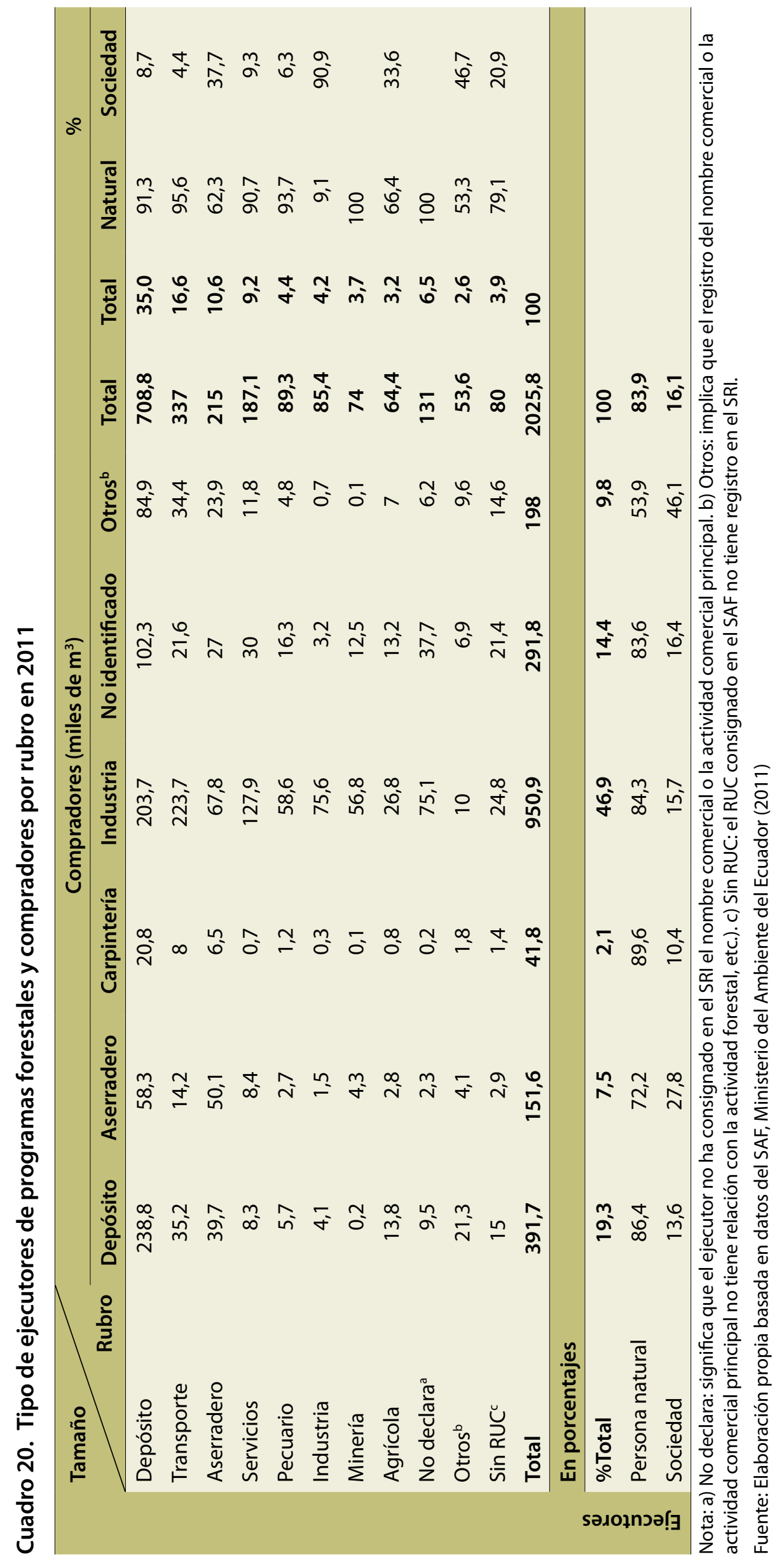


registrados como depósitos constituyen también un grupo importante en la demanda de madera, estos posiblemente venden luego la madera a consumidores directos, o la revenden a otros establecimientos del sector incluyendo otros depósitos y aserraderos. Por su parte, las carpinterías no constituyen un grupo relevante de establecimientos como compradores directos de madera, ya que posiblemente establecen relaciones comerciales con los depósitos o aserraderos para abastecerse de la madera requerida (cuadro 20).

De acuerdo a una clasificación por tamaño de los ejecutores, según los criterios detallados en el cuadro 18 , la mayor parte de la oferta se concentra en ejecutores "muy grandes" y "grandes". Como se ha mencionado anteriormente, una buena parte de la madera que es movilizada por los ejecutores proviene de plantaciones forestales. Los ejecutores "muy grandes" aprovechan bosque nativo únicamente a través de operaciones mecanizadas en programas PAFSU. Los "grandes" y "medianos" tienden a aprovechar madera de diferentes tipos de bosques y bajo diferentes planes de aprovechamiento (figura 7). En cuanto a los compradores, la mayor parte son "muy grandes" y "medianos". Los "muy grandes" compran mayormente madera de plantaciones, mientras que los "grandes" y "medianos" se abastecen parcialmente de bosques nativos (figura 8).

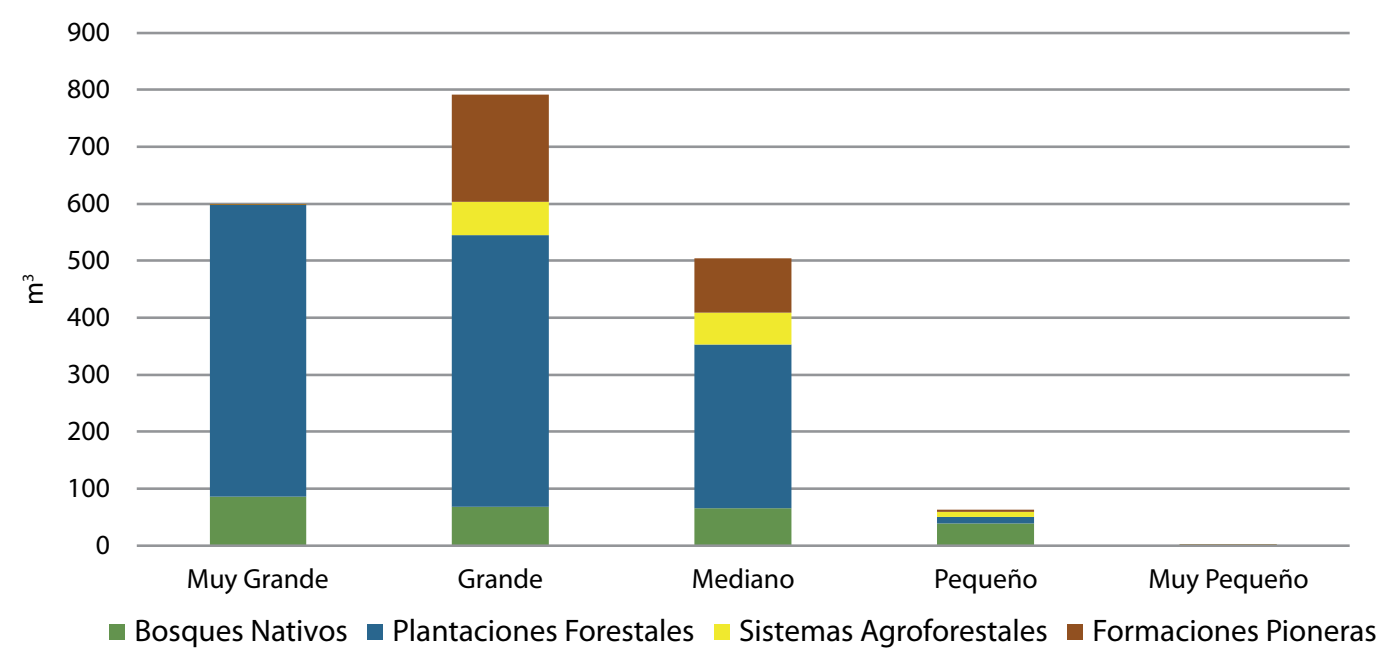

Figura 7. Volumen movilizado por tamaño de ejecutor y formación boscosa (miles de $\mathrm{m}^{3}$ ). Elaboración propia basada en datos del SAF, Ministerio del Ambiente del Ecuador (2011).

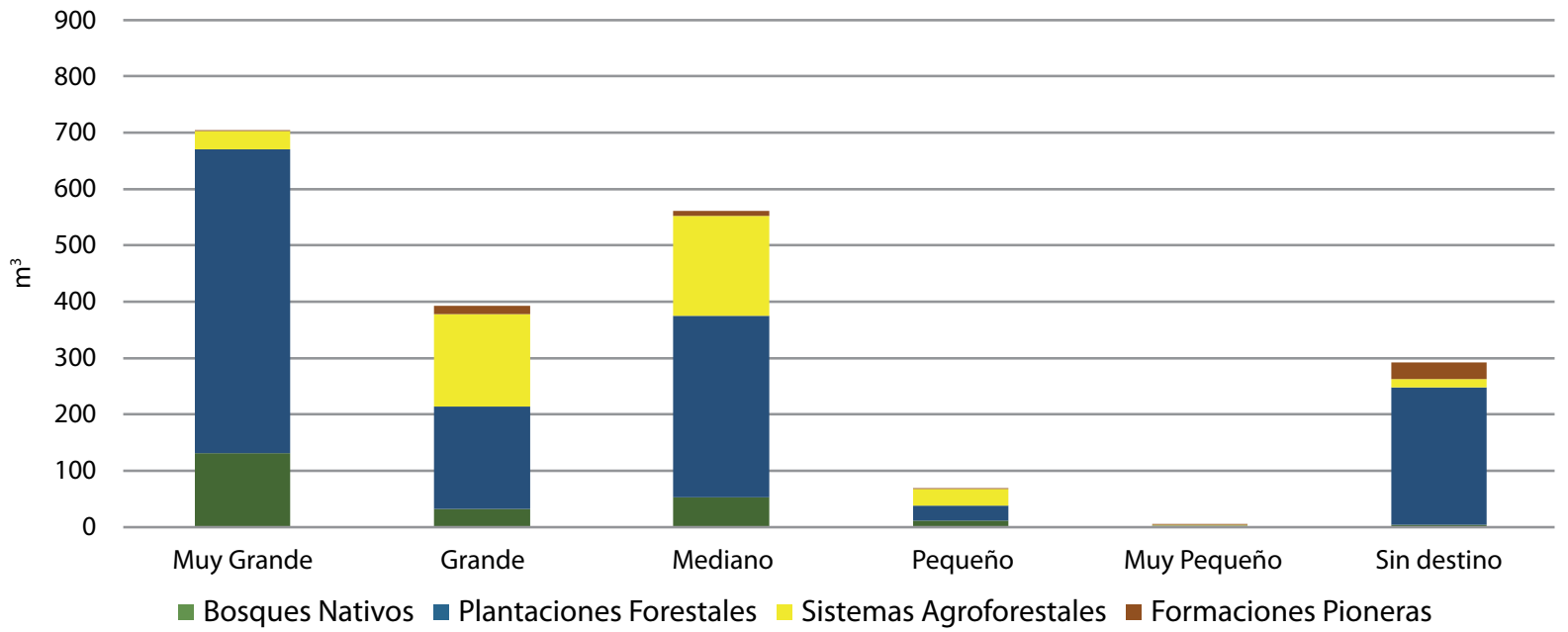

Figura 8. Volumen movilizado por tamaño de comprador y formación boscosa (miles de $\mathrm{m}^{3}$ ). Elaboración propia basada en datos del SAF, Ministerio del Ambiente del Ecuador (2011). 
Tanto los ejecutores como compradores que se clasifican como pequeños tienen una participación muy pequeńa tanto en la oferta como en la demanda de madera.

Cuando se analizan los flujos entre ejecutores y compradores, considerando el tamaño de las operaciones de estos últimos, se observa que los compradores "muy grandes", que son los que dominan el mercado junto con los "grandes," son abastecidos sobre todo por depósitos de madera y proveedores de servicios, posiblemente empresas dedicadas al aprovechamiento forestal de tipo industrial. No obstante, los compradores "medianos" se abastecen principalmente de aserraderos y transportistas. Este posiblemente constituye un mercado menos estructurado donde interviene un mayor número de agentes como se muestra en el cuadro 21 .

\subsubsection{Ejecutores y compradores por rubro y tamaño en la Amazonía}

Los datos analizados del SAF en 2011 sugieren que los depósitos constituyen el principal abastecedor y comprador de madera en la Amazonía. Este dato ratifica los hallazgos de Ministerio del Ambiente de Ecuador (2001), quienes sugieren que la mayor parte de la madera de la región se comercializa a través de depósitos y aserraderos. A pesar que la mayoría de la madera de la Amazonía proviene de pequeños finqueros, usualmente los programas forestales son procesados y ejecutados por los dueños de depósitos, aserraderos y transportistas, la mayoría de las cuales tienen registradas sus operaciones como personas naturales.

A diferencia de la situación observada a nivel nacional, donde los establecimientos industriales consumen la mayor parte de la madera movilizada, en el caso de la Amazonia son los depósitos y aserraderos quienes compran el $44 \%$ de la madera que se produce en la región, madera que a su vez es comercializada en los establecimientos industriales cerrando el círculo de la comercialización (cuadro 22). La madera que se origina en la Amazonia es principalmente destinada a la industria del mueble y a la construcción, proveniente en su mayoría de aprovechamientos de pequeña escala del bosque nativo tal como se ha discutido anteriormente, siendo las especies más cotizadas el chuncho y laurel (véase también Vásquez 2011). A nivel nacional, en cambio, las especies más comercializadas son aquellas provenientes de plantaciones forestales, principalmente el eucalipto, pino y teca. Esto hace suponer que las especies del bosque nativo de la Amazonía son importantes para algunos segmentos del mercado urbano. Para el Ministerio del Ambiente del Ecuador (2011), el bosque nativo provee de madera aserrada a la industria del mueble y la construcción en las principales ciudades como Quito, Guayaquil, Cuenca, Ambato y Manta.

Un aspecto interesante es que, cuando se observan los compradores de la madera proveniente en la Amazonia, el grupo más importante corresponde a los "medianos", quienes comprarían cerca del $45 \%$ de la madera suministrada por ejecutores que operan en esta región, lo que junto con los grandes representaría el 74\%. Estos compradores estarían conectados con ejecutores registrados como depósitos y aserraderos, quienes son los que ofertan la mayor parte de la madera que se origina en la Amazonía. Normalmente, son estos compradores medianos y grandes los que consiguen pedidos que luego son solicitados a una extensa red de depósitos y aserraderos localizados en los centros intermedios urbanos de esta región (cuadro 23). En este sentido, los depósitos, aserraderos y transportistas compran madera que termina sobre todo en la industria, a pesar que el principal destino declarado en el SAF sea otros depósitos y/o aserraderos.

\subsection{Establecimientos de madera en

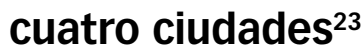

Los depósitos son los establecimientos que registran mayores volúmenes de madera movilizados. Para tener un mejor conocimiento de la composición del sector se realizó un inventario de establecimientos dedicados al acopio y transformación de la madera en los centros urbanos de Quito, Cuenca, Tena y Coca durante los meses de diciembre 2011 a marzo de 2012. En total se entrevistaron 189 establecimientos, los cuales se clasificaron en depósitos, aserraderos, carpinterías y establecimientos mixtos. Estas ciudades fueron priorizadas por ser parte de los circuitos de movilización de la madera en las zonas de estudio.

23 La información de esta sección ha sido recogida por Maritza Cifuentes (Quito), Francisco Zaruma Pinguil (Cuenca), Rolando López (Tena) y John Arruti (Coca). 


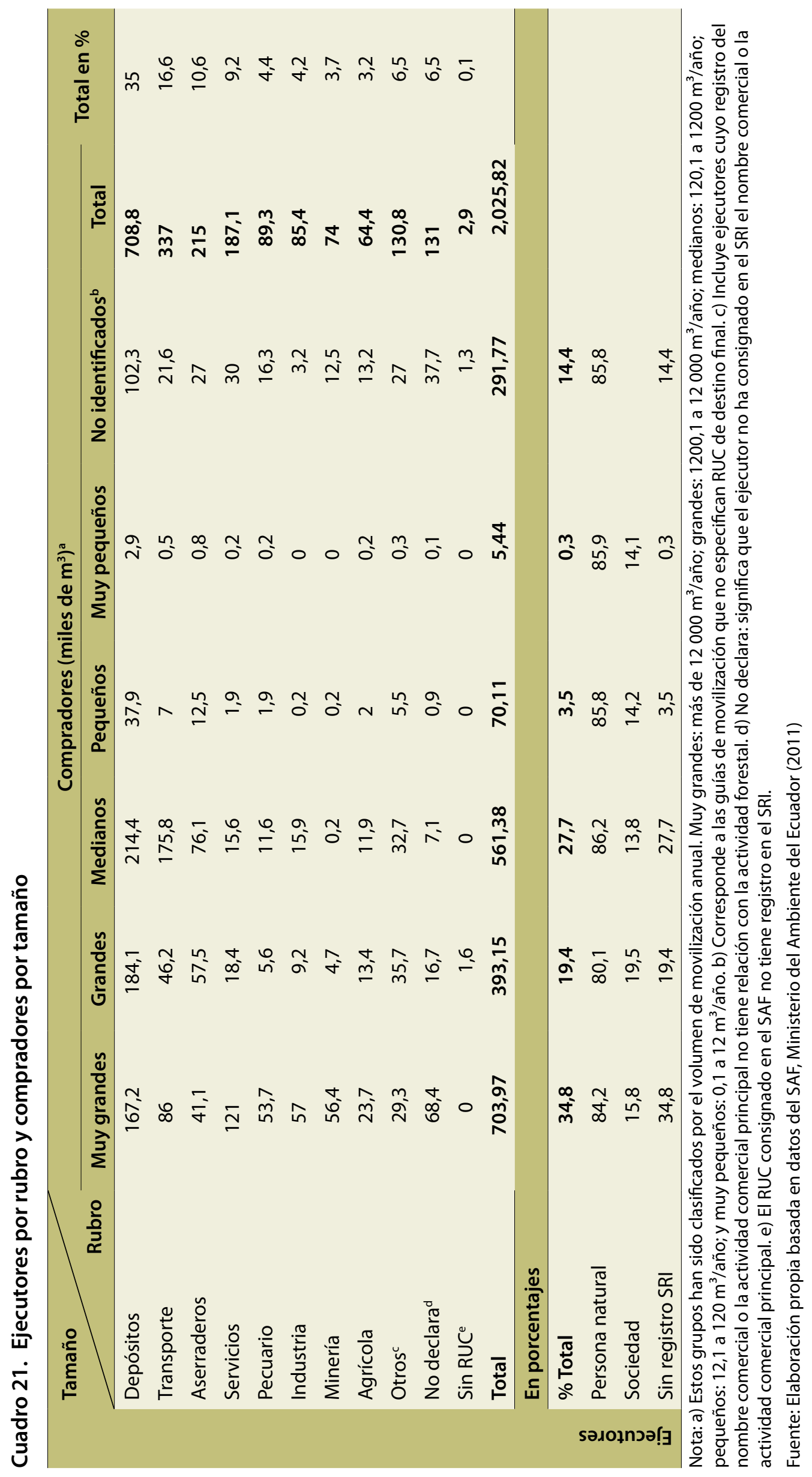




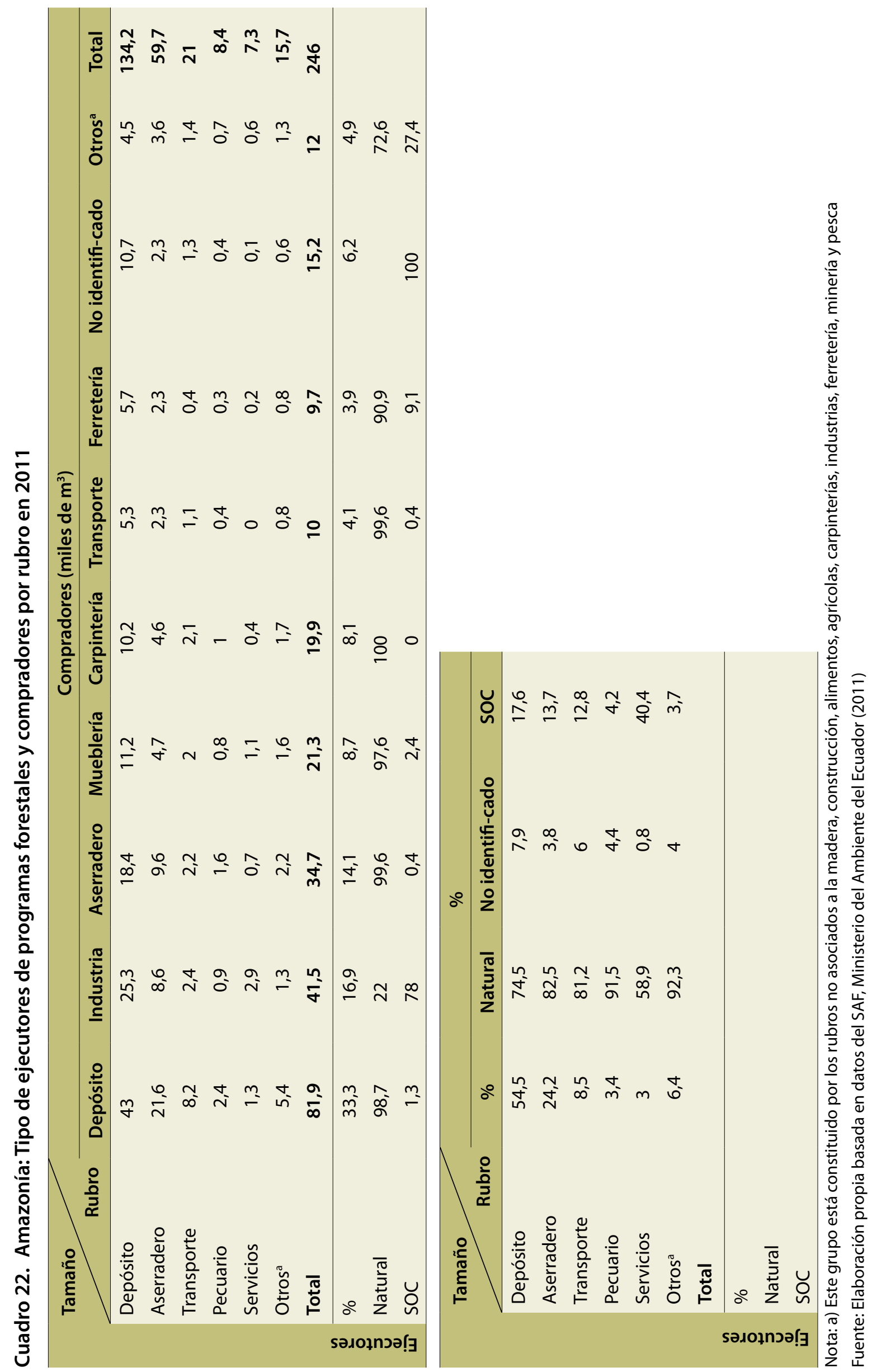


Cuadro 23. Amazonía: Ejecutores por rubro y compradores por tamaño

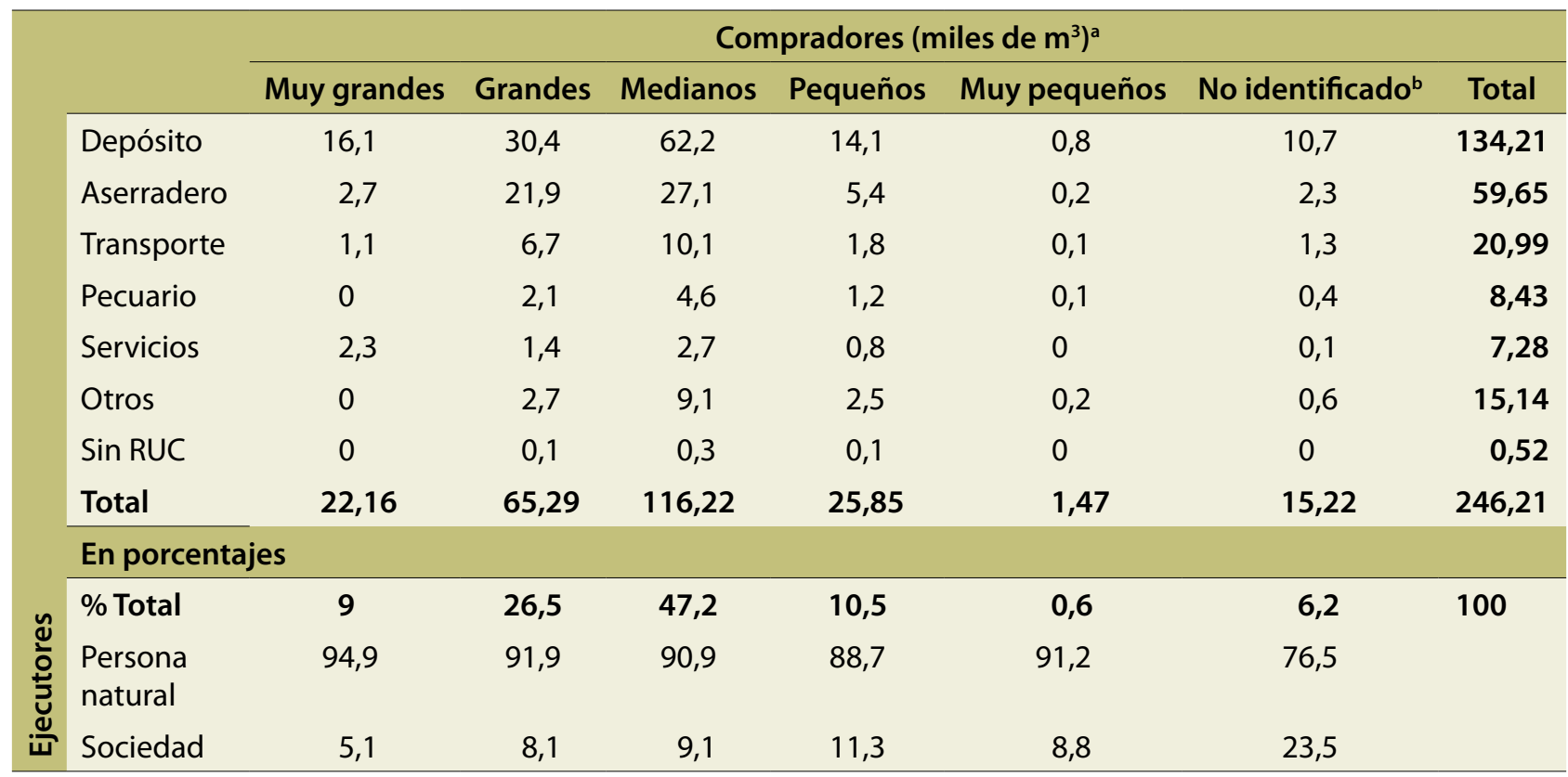

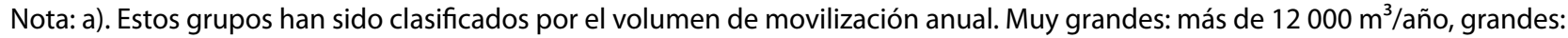
1200,1 a $12000 \mathrm{~m}^{3}$ /año, medianos: 120,1 a $1200 \mathrm{~m}^{3} /$ año, pequeños: 12,1 a $120 \mathrm{~m}^{3} /$ año, y muy pequeños: 0,1 a $12 \mathrm{~m} / \mathrm{año}$; b) Corresponde a las guías de movilización que no especifican RUC de destino final.

Fuente: Elaboración propia basada en datos del SAF, Ministerio del Ambiente del Ecuador (2011).

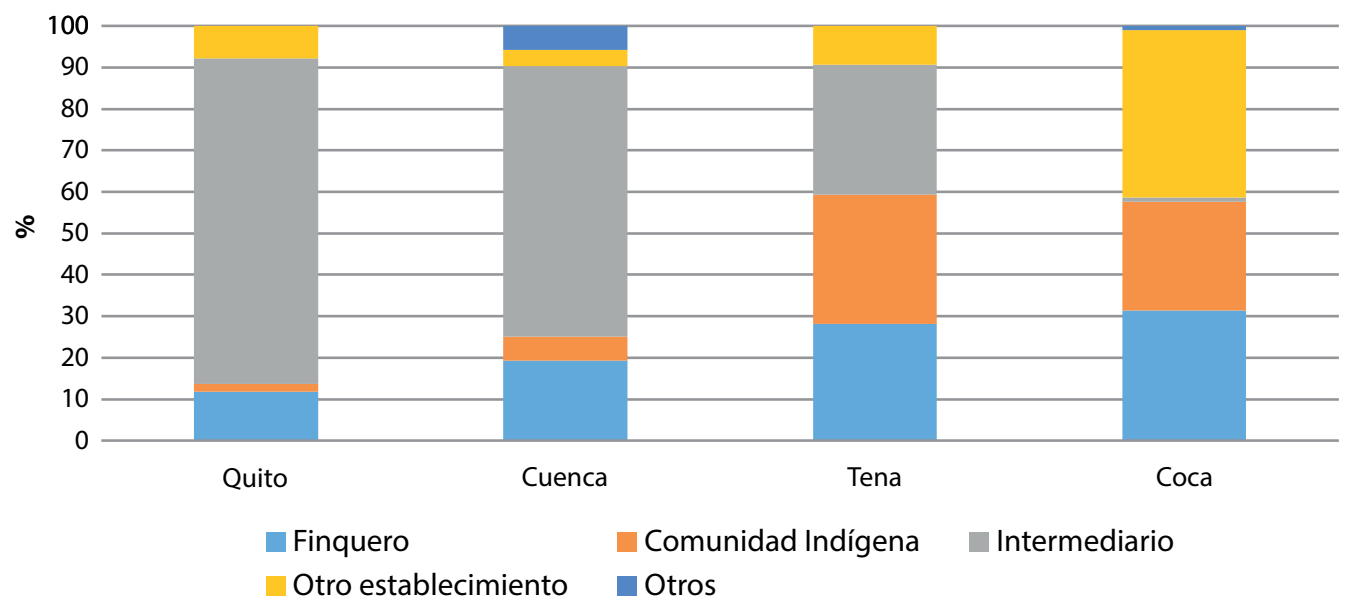

Figura 9. Principales proveedores de madera de los establecimientos entrevistados. Elaboración propia basada en entrevistas realizadas en el periodo de enero a marzo de 2012.

Con respecto a los proveedores, los establecimientos de las ciudades Quito y Cuenca reciben madera principalmente de intermediarios (figura 9), mientras que en Tena y Coca además de intermediarios, los finqueros y comunidades indígenas tienen un rol importante en el abastecimiento, lo cual no necesariamente significa que finqueros o comunidades realizaron la venta directa a los establecimientos. En la mayoría de los casos un intermediario realiza el transporte desde el bosque hasta el establecimiento.

La comercialización en Cuenca y Quito posiblemente consta de varios actores de intermediación, debido a que como lo muestra el cuadro 21, son los depósitos quienes venden 
a otros depósitos y a la industria. Según Terán (2012), los depósitos compran y venden madera de diferentes proveedores pero un porcentaje importante tiene como destino final a la industria. Lo anterior indicaría que existe una cierta aglomeración en ciertas empresas tal como ha sido sugerido por Southgate et. al., 2000 y Sierra, 2001.

Sobre el destino final de la madera, los establecimientos de Quito y Cuenca muestran que los mayores compradores son los sectores de la carpintería y construcción, mientras que Tena y Coca comercializan más a consumidores finales dentro de la misma localidad (figura 10). El principal destino reconocido para la madera de la Amazonia fue Quito con 82\%, lo cual concuerda con lo observado en el mapa 4. Por otro lado, según los establecimientos entrevistados, la ciudad de Cuenca recibe el $18 \%$ de madera proveniente de la Amazonia y el $82 \%$ de la Costa y la Sierra.
En el caso de Tena y Coca se observó que los establecimientos compran más madera para secarla $\mathrm{y}$ venderla posteriormente, una menor parte se destina al mercado local de la construcción. En Quito y Cuenca se destina al mercado de la construcción y mueblería como se indicó anteriormente.

Las principales especies comercializadas en Quito y Cuenca son maderas para la construcción como el eucalipto y la mueblería como el chuncho (Cedrelinga cateniformis), el laurel (Cordia alliodora) y el manzano fino (Guarea sp.), estas especies coinciden con las presentadas en el cuadro 15 de las especies aprovechadas en la Amazonia. En cuanto al Tena, las principales especies presentes en los establecimientos fueron el yunyún (Terminalia amazonica), laurel (Cordia alliodora) y doncel (Otoba spp.). En Coca, las

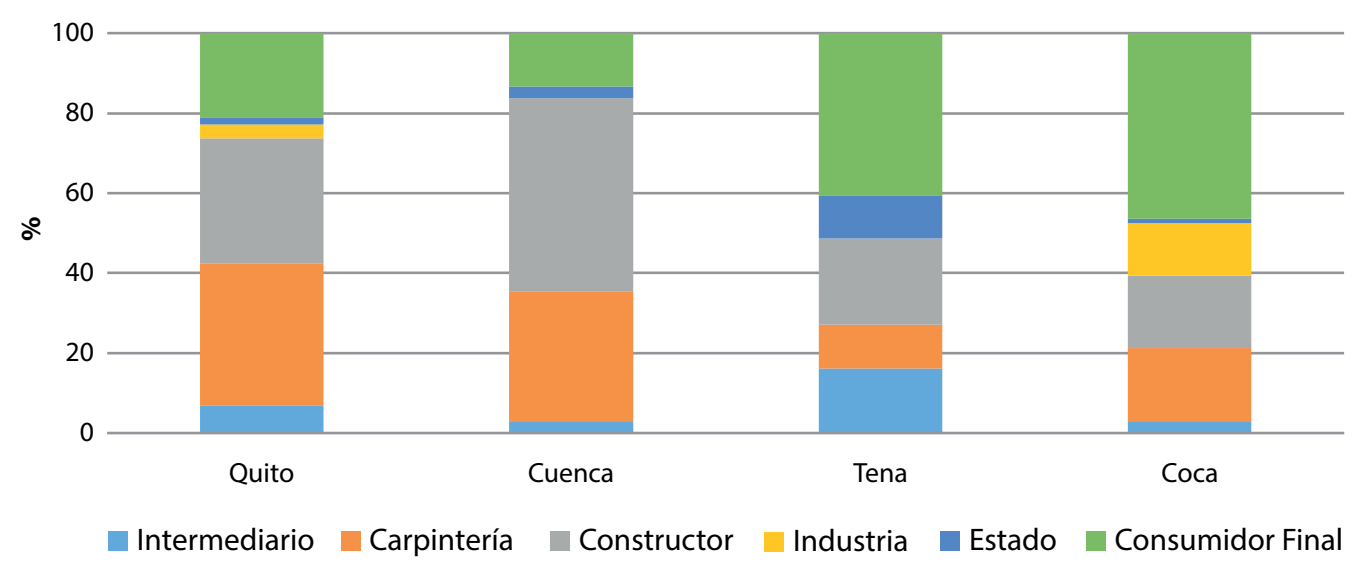

Figura 10. Principales compradores de madera de los establecimientos entrevistados. Elaboración propia basada en entrevistas realizadas en el periodo de enero a marzo de 2012.

Cuadro 24. Comparación de volúmenes de compra y procesado.

\begin{tabular}{lllccc}
\hline Empresa & Línea de producción & Categoría SRI & $\begin{array}{c}\text { Volumen de } \\
\text { compra }\left(\mathbf{m}^{3}\right)\end{array}$ & $\begin{array}{c}\text { Volumen } \\
\text { procesado }\left(\mathbf{m}^{3}\right)\end{array}$ & Diferencia negativa \\
\hline 1 & Pisos & Industrial & 126,5 & 166 & 39,5 \\
2 & Puertas, ventanas & Industrial & 906,2 & 1440 & 533,8 \\
3 & Puertas, ventanas & Industrial & 1028 & 840 & \\
4 & Pisos & Industrial & 40 & 160 & 120 \\
5 & Muebles & Industrial & 134,4 & 800 & 665,6 \\
\hline
\end{tabular}

Fuente: Elaboración propia basada en entrevistas realizadas en el periodo de enero a marzo de 2012 y base de datos SAF/SRI 
principales especies son el chuncho (Cedrelinga cateniformis) y el arenillo (Erisma uncinatum).

En la comercialización y movimiento de madera existen algunos vacíos que se encontraron a lo largo de la investigación sobre el rol de las empresas en el acopio de madera. En este sentido, para tener un panorama más detallado de los compradores de madera, se recogieron datos de cinco empresas categorizadas entre pequeńas, medianas y grandes. Los datos comparados se obtuvieron de las bases de datos del SAF y el SRI. Los resultados se muestran en el cuadro 24, en donde se puede observar que el volumen movilizado de madera registrado en el SAF es menor que el volumen procesado. 


\title{
Aprovechamiento de madera por finqueros en Napo y Orellana
}

\author{
Aymé Muzo, Filippo del Gato, Pablo Pacheco y Bolier Torres
}

Los recursos forestales, en particular la madera, contribuyen de forma significativa a la generación de ingresos para los pequeños agricultores (Angelsen, A. et. al., 2001). Los estudios sobre manejo de recursos naturales y medios de vida han prestado mayor atención a las decisiones que explican el uso del suelo en las fincas de los agricultores, con especial énfasis en la conversión de los bosques a usos agrícolas, más que a entender sus decisiones de manejo del bosque (Southgate, et al., 1991; Bilsborrow, et al., 2004). Este capítulo analiza los factores que explican el uso de los recursos forestales, especialmente la madera, $y$ su contribución a los ingresos de los hogares de pequeños agricultores localizados en las provincias de Napo y Orellana en la Amazonía ecuatoriana.

El análisis que se ofrece se centra en las siguientes preguntas:

- ¿Cuáles son las principales características de los finqueros, colonos e indígenas, que influencian las estrategias de aprovechamiento de la madera y sus ingresos?

- ¿Cuál es la importancia de los ingresos derivados de la madera para el sustento de los finqueros sean colonos o indígenas?

- ¿Qué factores explican las variaciones de ingresos provenientes de la venta de madera?

La decisión de los finqueros para vender la madera de sus bosques depende de factores tanto endógenos vinculados con las características del hogar y su acceso a recursos productivos, así como exógenos vinculados con el contexto económico e institucional. Entre los primeros está la disponibilidad de activos físicos y financieros (Barret, 2008), así como el acceso a información para decidir sobre el uso de los recursos en diferentes actividades productivas (Wollni, 2006) que influyen sobre el manejo de la tierra y los bosques (De Sherbinin et. al., 2008). Entre los segundos están las condiciones de los mercados de madera caracterizadas por relaciones asimétricas de información y poder entre los diferentes actores, que tienden a afectar su relación con los mercados (Pacheco, 2012), así como otras decisiones de manejo de sus recursos (Key, et al., 2000). Tanto las asimetrías de información como los requisitos de la normativa forestal, además de influir en las decisiones de uso de bosques, llevan también a costos de transacción adicionales (Pacheco et al. 2008).

El análisis que se presenta se basa en información primaria obtenida a nivel de las fincas en las provincias de Napo y Orellana. En la provincia Napo se seleccionó el cantón Tena, donde se realizaron entrevistas a 126 familias (77 colonas y 49 indígenas kichwa) distribuidas en 12 comunidades (véase nuevamente el mapa 1). Este cantón fue seleccionado porque una proporción considerable de finqueros asentados en el mismo se dedican a la extracción de madera. En la provincia Orellana se realizaron entrevistas a 120 familias ( 48 colonas, 46 indígenas kichwa y 26 indígenas shuar) distribuidas en 9 comunidades en el municipio de Francisco de Orellana. Este municipio registra el mayor volumen de extracción de madera de los bosques nativos de la provincia.

La selección de los hogares a ser entrevistados se basó en un muestreo en dos etapas, la primera para la selección de las comunidades y la segunda para escoger los hogares al interior de cada comunidad seleccionada. La primera etapa utilizó el método de muestreo intencional para seleccionar comunidades que ofrecieran variedad en las siguientes características: 1) origen étnico de los finqueros incluyendo colonos e indígenas (kichwas y shuaras), 2) distancia hasta el camino más cercano transitable todo el año, 3) tamaño de las comunidades incluyendo comunidades grandes (más de 40 hogares) y pequeñas (menos de 40 hogares). La selección de hogares se realizó con un muestreo aleatorio simple. Para ello, se elaboró un censo de todos los hogares mediante entrevistas 
Cuadro 25. Características de los hogares colonos y Kichwas

\begin{tabular}{|c|c|c|}
\hline Variables & Colonos & Kichwas \\
\hline Procedencia & $\begin{array}{l}\text { El } 85 \% \text { no nacieron en Napo y provienen } \\
\text { principalmente de las provincias de Bolívar } \\
\text { y Loja. }\end{array}$ & $\begin{array}{l}\text { El } 53 \% \text { no nacieron en la comunidad y } \\
\text { provienen de otras comunidades dentro de } \\
\text { la provincia de Napo. }\end{array}$ \\
\hline $\begin{array}{l}\text { Número de } \\
\text { miembros del hogar }\end{array}$ & 4 adultos y 1 niño. & 6 adultos y 3 niños \\
\hline $\begin{array}{l}\text { Edad promedio del } \\
\text { jefe de hogar }\end{array}$ & 53 años & 43 años \\
\hline \multirow[t]{2}{*}{ Educación } & \multicolumn{2}{|c|}{$\begin{array}{l}\text { Los niveles de educación formal son bajos entre los cabezas de familia. No difieren entre } \\
\text { hogares de colonos y kichwas. La tasa de analfabetismo es del } 5 \% \text {, y el } 81 \% \text { de todos los } \\
\text { jefes de hogar ha finalizado la escuela primaria }\end{array}$} \\
\hline & \multicolumn{2}{|c|}{$\begin{array}{l}\text { Los otros miembros (no jefe de hogar) de los hogares colonos presentan mejores índices } \\
\text { de educación formal primaria y secundaria respecto a los otros miembros de familias } \\
\text { kichwas. }\end{array}$} \\
\hline Tipo de tenencia & $\begin{array}{l}\text { Individual, } 83 \% \text { tiene registro o título de } \\
\text { propiedad }\end{array}$ & $\begin{array}{l}\text { Comunitaria, } 49 \% \text { tiene registro o título de } \\
\text { propiedad }\end{array}$ \\
\hline
\end{tabular}

Fuente: Elaboración propia basada en encuesta a hogares realizada entre agosto y septiembre de 2012.

con líderes locales y posteriormente se eligieron al azar los hogares a ser entrevistados mediante un sorteo en presencia de uno o más líderes de la comunidad. Se utilizó una fracción de muestreo constante para garantizar que la muestra no tuviera proporcionalmente más hogares de comunidades pequeñas que de comunidades grandes.

Las encuestas a hogares se realizaron entre enero y septiembre de 2012 en Napo y Orellana. El cuestionario fue modificado con base en el prototipo desarrollado por el Proyecto PEN del $\mathrm{CIFOR}^{24}$. El cuestionario recoge información sobre las características demográficas del hogar y educación (capital humano); casa, tierra y otros activos físicos (capital físico) y uso del suelo y estado del bosque (capital natural). También se recogió información sobre ingresos relacionados con el aprovechamiento de recursos forestales, maderables y no maderables, y otros ingresos del hogar incluyendo ingresos dentro y fuera de la finca. También se preguntó sobre las percepciones en relación a la normativa forestal vigente.

Para el análisis de las estrategias de los finqueros se realizará de forma separada el caso de Napo y el de Orellana, debido a que la recolección de datos se realizó en diferentes lapsos de tiempo y

24 Disponible en http://www.cifor.org/fileadmin/ fileupload/PEN/pubs/pdf_files/Cuestionario_Prototipo_ PEN_Espanol-version4.pdf además se quieren mostrar las diferencias entre ambas provincias.

\subsection{El caso de Napo: Análisis de las estrategias de los finqueros}

\subsubsection{Características de los hogares}

Las principales diferencias que existen entre los hogares de colonos y kichwas tienen relación con la procedencia, edad del cabeza de familia y el número de miembros dentro del hogar. En el cuadro 25 se muestran las características de estos dos grupos. Destaca que el número de miembros del hogar es mayor en los kichwas, los jefes de hogar de las familias kichwas son más jóvenes, y el nivel de educación de los adultos kichwas es menor comparado con los hogares de colonos. En cuanto a la tenencia de tierra, los colonos poseen sólo propiedades privadas y los kichwas tienen sobre todo propiedades de tipo comunitario. Los hogares colonos deciden sobre el uso de su tierra y tienen títulos de propiedad de la mayoría de sus fincas. En cambio, los hogares kichwas cuentan con un título de propiedad colectivo y la asamblea comunitaria designa el acceso a la tierra y deben respetar ciertas reglas. Por ejemplo, en algunas comunidades la venta de la madera deber ser discutida con el presidente de la comunidad, a diferencia de las propiedades privadas de los colonos donde cada familia decide qué hacer con su madera. 


\subsubsection{Usos de suelo y sistemas de producción}

Ambos grupos desarrollan sistemas de producción relativamente diversificados. Dentro de las fincas los bosques ocupan la mayor extensión de la parcela en ambos grupos. Los hogares colonos en Napo tienen una mayor área de terreno; sin embargo, la superficie de bosque es bastante similar a la de los hogares kichwas. Esto se debe a que las áreas cultivadas, incluyendo cultivos perennes y anuales y pastos, son mayores en las parcelas de colonos (10 hectáreas) que en las de los kichwas (4 hectáreas), destacándose las áreas dedicadas a pastos y cultivos perennes. Las superficies con pasto son cuatro veces más extensas en las fincas de colonos que en las de kichwas. Tanto los colonos como los kichwas siembran cacao y café, además de guayusa en los hogares kichwas, todos destinados al mercado. No obstante, los cultivos perennes duplican en extensión en las fincas de colonos respecto a las de los kichwas. El área destinada a cultivos anuales, bosques secundarios, realce y chacra dentro de las fincas es similar entre ambos grupos (cuadro 26).

Del total de los hogares de colonos y kichwas entrevistados, el 57\% de los hogares ha desmontado un promedio de 2,8 hectáreas en sus parcelas durante 2006-2012, lo que equivale a 0,47 hectáreas por año. Un poco más de la mitad de los encuestados (52\%) desmontaron en bosques nativos, el $18 \%$ en bosques secundarios y el $30 \%$ en rastrojos o realces. Lo anterior indica que el desmonte no sólo se realiza en los bosques nativos sino también en los bosques secundarios y realces, siendo más fácil para los finqueros trabajar en un bosque que ya ha sido intervenido si su propósito es la siembra, debido a que se empleará menos mano de obra en la limpieza. Tanto colonos como kichwas han desmontado una superficie similar de terreno en el mencionado periodo. Sin embargo, es importante mencionar que la frecuencia de desmonte es mayor en los hogares kichwas aunque el área desmontada por operación es menor. El área desmontada se dedica generalmente a cultivos para el mercado (maíz y cacao) y en menor proporción para pastos. Los desmontes se practican en terrenos con mejor aptitud para los cultivos que se encuentran cerca de la casa, a una distancia promedio de $1,2 \mathrm{~km}$. Los hogares kichwas mencionan además que las áreas desmontadas se localizan en las únicas tierras que tenían disponible debido a la fragmentación de los terrenos entre los miembros del hogar.

El $61 \%$ de las tierras forestales convertidas a usos agrícolas no fueron intervenidas para la extracción de madera antes del desmonte en el periodo indicado. De los 71 hogares que desmontaron bosques en sus parcelas, 49 hogares contaban con especies demandas por el mercado en sus fincas; sin embargo, de éstas solo 28 vendieron la madera

Cuadro 26. Uso de suelos en las parcelas de colonos y kichwas en hectáreas

\begin{tabular}{lcccc} 
& \multicolumn{2}{c}{ Colonos } & \multicolumn{2}{c}{ Kichwas } \\
\cline { 2 - 5 } & Media & Desviación estándar & Media & Desviación estándar \\
\hline Bosque nativo $^{\mathrm{a}}$ & 14,27 & 17,52 & 9,86 & 13,31 \\
Bosque secundariob $^{\mathrm{b}}$ & 0,61 & 2,34 & 1,56 & 4 \\
Realce $^{\mathrm{c}}$ & 4,16 & 5,97 & 3,07 & 5,78 \\
Pasto & 5,90 & 9,18 & 1,36 & 2,63 \\
Cultivos anuales $^{\mathrm{d}}$ & 1,22 & 1,61 & 1,10 & 1,87 \\
Cultivos perennes $^{\mathrm{e}}$ & 3,13 & 3,58 & 1,67 & 1,57 \\
Chacra $^{\mathrm{f}}$ & 0,15 & 0,43 & 0,19 & 0,46 \\
Otros $^{\mathrm{g}}$ & 0,94 & 2,09 & 0,60 & 1,36 \\
Total & $\mathbf{3 0 , 3 8}$ & $\mathbf{2 3 , 0 3}$ & $\mathbf{1 9 , 4 1}$ & $\mathbf{1 7 , 2 6}$ \\
\hline
\end{tabular}

Nota: a) se refiere a bosques no intervenidos o perturbados, b) son bosques de regeneración natural, c) se refiere a un bosque secundario joven que se ha regenerado de forma natural después de su intervención o perturbación por actividades humanas, d) incluye maíz, plátano, yuca y naranjilla, e) comprende cacao, café, guayusa, f) es el área destinada para el consumo del hogar incluye, por ejemplo, yuca y plátano y g) son áreas del terreno dónde no se puede cultivar, por ejemplo, zonas pantanos y rocosas.

Fuente: Elaboración propia basada en encuesta a hogares realizada entre agosto y septiembre de 2012. 
Cuadro 27. Desmontes en parcelas de colonos y kichwas en el periodo del 2006 al 2012

\begin{tabular}{lccc} 
& Colonos & Kichwas & Total \\
\hline No. total de parcelas & 48 & 76 & 124 \\
$\begin{array}{l}\text { No. de parcelas con } \\
\text { desmontes }\end{array}$ & 24 & 47 & 71 \\
$\begin{array}{l}\text { No. de desmontes con } \\
\text { extracción forestal }\end{array}$ & 9 & 19 & 28 \\
$\begin{array}{l}\text { previa } \\
\text { Destino principal de la } \\
\text { madera }\end{array}$ & Venta & Venta & \\
\hline
\end{tabular}

Fuente: Elaboración propia basada en encuesta a hogares realizada entre agosto y septiembre de 2012.

ya sea antes o durante el desmonte y el resto no lo hizo. Esto se debe a que no existían especies valiosas en la finca o se desconocía el valor de la madera y, en el caso de las familias kichwas, a los factores anteriores se suma la falta de vías de acceso y la distancia excesiva de transporte desde el bosque al punto de venta. Es decir, apenas el 38\% del total de hogares ha obtenido madera para la venta como subproducto del desmonte con la finalidad de ampliar sus áreas de cultivo (cuadro 27).

\subsubsection{Ingresos totales y forestales}

Los hogares tienen ingresos monetarios bastante diversificados, los que provienen de cultivos agrícolas, transferencias del gobierno (bono de desarrollo humano) $)^{25}$, aprovechamiento maderero e ingresos salariales fuera de la finca (cuadro 28). Los hogares colonos presentan mayores ingresos que los kichwas, siendo los principales ingresos aquellos derivados de la producción forestal y trabajo asalariado. Las fuentes principales de ingreso monetario en los hogares kichwas son el trabajo asalariado y el bono de desarrollo humano. Los ingresos por salarios provienen principalmente de trabajos fuera de la finca, sobre todo como motosierristas. Cabe destacar que el trabajo asalariado fuera de la finca y la venta de otros productos ayudan a relajar las limitaciones de

25 Es un programa de transferencia monetaria condicional que consiste en la entrega mensual de 50 USD mensuales a familias de bajos ingresos. Según Carillo P. y Ponce J., (2009) la transferencia es dirigida a madres con hijos menores de 16 ańos y personas mayores o discapacitados con la finalidad de aliviar la pobreza. El condicionamiento va dirigido a las madres con la finalidad de que sus hijos asistan a la escuela y sean atendidos en centros de salud. crédito dando mayor liquidez a los finqueros. En el caso del bono solidario, este es un ingreso mensual directo para los finqueros que también contribuye a dar liquidez a los hogares.

Los ingresos forestales constituyen una importante fuente de ingreso de las familias rurales en la provincia de Napo, destacándose los ingresos provenientes de la venta de madera, sobre todo para las familias de colonos. La contribución de los ingresos de la madera con relación al total de los ingresos netos anuales representa el 23\% y $8 \%$ respectivamente en familias colonas y kichwas durante el periodo de agosto 2011 y septiembre 2012 (cuadro 29). En este mismo periodo, si se considera únicamente las 63 familias que recibieron ingresos provenientes de la madera, el porcentaje que representa la venta de madera dentro de los ingresos totales es mayor, $46 \%$ en las familias colonas (rango 3\%-88\%) y 17\% en las familias kichwas (rango 0,5\%-71\%). Es importante destacar que no se incluyen dentro de los ingresos forestales los provenientes de salarios obtenidos por trabajar en actividades forestales como motosierristas. Se menciona esto debido a que otros autores como Godoy et. al. (2002) si los incluyen dentro de los cálculos de ingresos forestales.

De los hogares entrevistados, 59 del total (48\%) presentaron alguna clase de crisis que enfrentaron a través de la ayuda y el préstamo familiar (22\%), uso de ahorros $(19 \%)$, cosecha de más productos maderables (18\%), venta de ganado y activos $(17 \%)$, entre otros (figura 11). En la provincia de Napo, por consiguiente, los bosques no son necesariamente considerados como un recurso importante para enfrentar las crisis financieras de las familias. No obstante, estos cumplen una función importante, particularmente el aprovechamiento de madera, para solventar gastos esenciales de las familias relacionados con la salud, educación, alimentación y vivienda. En ese sentido, se considera que los meses de mayor venta de madera corresponden a julio y agosto, que son los meses previos al inicio de clases en el mes de octubre en la Amazonia.

En respuesta a los beneficios que entrega la madera a los finqueros y la carencia de especies maderables en las fincas, el $51 \%$ de los hogares kichwas y el 33\% de los hogares colonos han plantado algunos árboles en sus fincas, dispersos 
Cuadro 28. Ingresos de los colonos y kichwas en el periodo de agosto 2011-septiembre 2012

\begin{tabular}{|c|c|c|c|c|c|c|c|c|}
\hline \multirow{3}{*}{ Fuentes de Ingresos } & \multicolumn{6}{|c|}{ Ingresos promedios } & \multicolumn{2}{|c|}{$\begin{array}{l}\text { No. de hogares que } \\
\text { reciben ingresos por } \\
\text { estas actividades }\end{array}$} \\
\hline & \multicolumn{2}{|c|}{ Colonos $(n=47)$} & \multicolumn{2}{|c|}{ Kichwas $(n=76)$} & \multicolumn{2}{|c|}{ Total $(n=123)$} & \multirow{2}{*}{ Colonos } & \multirow{2}{*}{ Kichwas } \\
\hline & USD & $\%$ & USD & $\%$ & USD & $\%$ & & \\
\hline Trabajo asalariado ${ }^{a * *}$ & 1064 & 33 & 813 & 43 & 909 & 38 & 24 & 52 \\
\hline Venta de productos forestales ${ }^{b^{* * *}}$ & 1019 & 31 & 210 & 11 & 519 & 22 & 30 & 54 \\
\hline Bono de desarrollo humano ${ }^{c}$ & 458 & 14 & 437 & 23 & 445 & 18 & 36 & 66 \\
\hline Venta producción agrícola d & 435 & 13 & 322 & 17 & 366 & 15 & 38 & 73 \\
\hline Venta de producción pecuaria ${ }^{* * *}$ & 218 & 7 & 45 & 2 & 111 & 5 & 21 & 11 \\
\hline Negocio propio ${ }^{f}$ & 121 & 4 & 37 & 2 & 69 & 3 & 7 & 10 \\
\hline Otros & 29 & 1 & 10 & 1 & 17 & 1 & 3 & 8 \\
\hline Venta de pescado*** & 0 & 0 & 20 & 1 & 13 & 1 & 0 & 8 \\
\hline Total***i & 3259 & 100 & 1884 & 100 & 2410 & 100 & & \\
\hline
\end{tabular}

Nota: a) El trabajo asalariado incluye todo trabajo que se realice fuera de la finca y reciba un salario a cambio de su trabajo, por ejemplo, trabajo en agricultura, motosierristas y trabajos por contratos fijos, b) Los ingresos forestales se refieren a ingresos en efectivo por venta de madera, venta de productos forestales no maderables (PFNM) e ingresos obtenidos a través del programa gubernamental Socio Bosque (PSB), c) El ingreso por Bono de desarrollo humano se explicó anteriormente, d) Los ingresos agrícolas se refieren al ingreso de dinero en efectivo por la venta de productos agrícolas, por ejemplo, cacao, maíz, café, guayusa, etc. e) Los ingresos agropecuarios son obtenidos por la venta de algún animal y/o sus subproductos, por ejemplo, ganado, gallinas, leche, entre otros, f) Los ingresos por negocio propio se refieren a cualquier actividad donde el finquero trabaja por su propia cuenta, es decir, es su propio jefe, por ejemplo, comerciantes, dueños de tiendas, etc. g) Otros ingresos corresponden a ingresos que no forman parte de ninguna categoría mencionada, $h$ ) Los ingresos de venta de pescado son principalmente cosechados en los ríos de las comunidades, i) Prueba t para muestras independientes en las diferencias de diversificación de ingresos entre colonos y kichwas al $1 \%\left({ }^{* *}\right)$ y $5 \%\left({ }^{* *}\right)$ de nivel de significancia.

Fuente: Elaboración propia basada en encuesta a hogares realizada entre agosto y septiembre de 2012.

Cuadro 29. Descripción de ingresos forestales por productos maderables y no maderables en el periodo de agosto 2011-septiembre 2012

\begin{tabular}{|c|c|c|c|c|c|c|c|c|}
\hline \multirow{3}{*}{ Ingresos forestales } & \multicolumn{6}{|c|}{ Ingreso promedio } & \multicolumn{2}{|c|}{$\begin{array}{c}\text { No. de hogares que } \\
\text { reciben ingresos } \\
\text { por estos rubros }\end{array}$} \\
\hline & \multicolumn{2}{|c|}{ Colonos $(n=47)$} & \multicolumn{2}{|c|}{ Kichwas $(n=76)$} & \multicolumn{2}{|c|}{ Total $(n=123)$} & \multirow{2}{*}{ Colonos } & \multirow{2}{*}{ Kichwas } \\
\hline & USD & $\%$ & USD & $\%$ & USD & $\%$ & & \\
\hline Ingresos totales del hogar & 3259 & 100 & 1884 & 100 & 2.410 & 100 & 47 & 76 \\
\hline \multicolumn{9}{|l|}{ Total ingresos forestales ${ }^{* * *}$} \\
\hline Venta de madera ${ }^{* * *}$ & 764 & 23 & 159 & 8 & 381 & 16 & 24 & 39 \\
\hline Venta PFNM & 78 & 2 & 43 & 2 & 56 & 2 & 7 & 16 \\
\hline Programa Socio-bosque $\mathrm{e}^{\mathrm{b} * * *}$ & 90 & 3 & 8 & 0,4 & 39 & 2 & 3 & 24 \\
\hline
\end{tabular}

Nota: a) Prueba t para muestras independientes en las diferencias de ingresos forestales entre colonos y kichwas al $1 \%\left(^{* * *}\right)$ de nivel de significancia b) En el caso de las comunidades kichwas el ingreso es divido entre todos los miembros de la comunidad por lo cual los pagos recibidos por hogar son menores que los obtenidos por los colonos.

Fuente: Elaboración propia basada en encuesta a hogares realizada entre agosto y septiembre de 2012. 


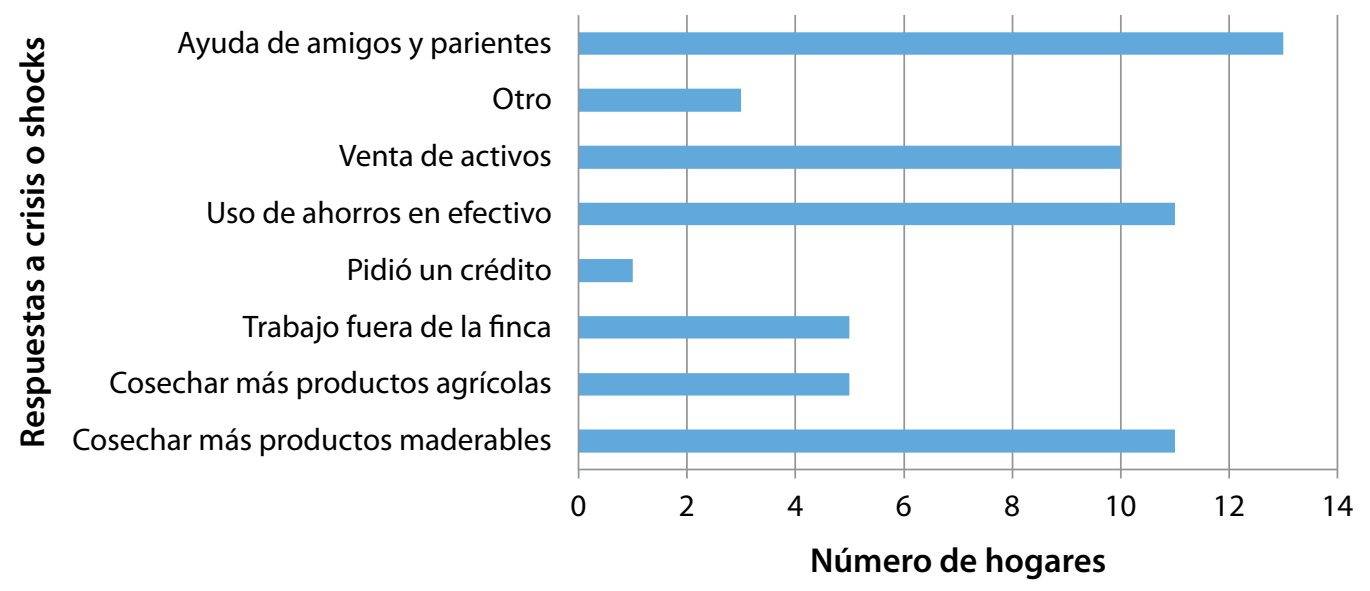

Figura 11. Rol de los ingresos forestales en los mecanismos de seguridad familiar en respuesta a crisis o imprevistos. Basado en encuesta a hogares realizada entre agosto y septiembre de 2012.

en diferentes puntos de su propiedad o como asociaciones agroforestales, por ejemplo, caoba/ ahuano (Swietenia macrophylla), cedro (Cedrela odorata), chuncho (Cedrelinga catenaiformes). La principal motivación para plantar manifestada por las personas entrevistadas sería la de poder disponer de madera para la venta y en menor proporción para destinarla a usos domésticos, por ejemplo, para leña y para la construcción de viviendas.

\subsection{Estrategias diferenciadas de aprovechamiento de madera}

El análisis de la participación y beneficios del finquero en el aprovechamiento de la madera no es uniforme. Por ello, se ha procedido a la elaboración de una tipología considerando los siguientes grupos. El grupo 1 corresponde a los finqueros que realizan la extracción por su propia cuenta, el grupo 2 son los finqueros que emplean personal contratado ${ }^{26}$, el grupo 3 son los finqueros que venden la madera al intermediario para que realice la extracción y el grupo 4 son los finqueros que no se dedican a la venta de madera. El cuadro 30 ofrece una descripción de las principales características de estos diferentes grupos considerando atributos del hogar y acceso a activos.

26 Dentro de este grupo se incluye a los finqueros con operación mixta; es decir, realizan la extracción los finqueros con terceros y las ganancias se dividen entre ambos.
La información presentada indica que los finqueros que realizan la actividad por su cuenta poseen en su mayoría motosierras y tienen un mayor número de miembros del hogar, lo que les da mayor disponibilidad de mano de obra y los diferencia de los otros grupos que tienen menos miembros, por lo que tienen que contratar mano de obra o buscar otras estrategias de aprovechamiento. Asimismo, el tamańo de la finca es mayor con respecto al grupo que no vende madera. Los grupos 1 y 2 se localizan geográficamente más cerca de una ciudad principal y ambos poseen la mayor cantidad de activos en bienes con respecto a otros grupos, lo que sugiere que estos grupos cuentan con cierta liquidez para el aprovechamiento de la madera, y los del grupo 2 tendrían dinero para poder contratar mano de obra. Por su parte, el grupo 3 se caracteriza por tener un menor número de personas en el hogar, jefes del hogar con una mayor edad en promedio y una ubicación geográficamente más lejana a la ciudad principal comparado con los otros grupos, lo cual incrementaría los costos de transporte y quizás limitaría la comercialización de la madera por lo que el aprovechamiento lo llevarían a cabo intermediarios que se encargan del proceso de aprovechamiento y comercialización.

\subsubsection{Estrategias de aprovechamiento de la madera}

Un total de 79 hogares entrevistados (66\%) han vendido madera entre el 2004 y septiembre de 2012, mientras que 62 hogares $(50 \%)$ vendieron madera en los últimos 12 meses a partir de agosto y septiembre de 2012. Este análisis se refiere a 
Cuadro 30. Características de los diferentes grupos de hogares según sus estrategias de aprovechamiento de la madera

\begin{tabular}{|c|c|c|c|c|}
\hline & \multicolumn{2}{|c|}{ El finquero realiza la extracción } & \multirow{2}{*}{$\begin{array}{l}\text { El intermediario } \\
\text { realiza toda la } \\
\text { extracción }\end{array}$} & \multirow{2}{*}{$\begin{array}{l}\text { No vende } \\
\text { madera }\end{array}$} \\
\hline & $\begin{array}{l}\text { Por su propia } \\
\text { cuenta }\end{array}$ & $\begin{array}{l}\text { Personal } \\
\text { contratado }\end{array}$ & & \\
\hline Número de hogares & 43 hogares & 25 & 11 & 44 \\
\hline Etnia del jefe de hogar ${ }^{b^{* * *}}$ & $\begin{array}{l}\text { El } 74 \% \text { son } \\
\text { kichwas }\end{array}$ & $\begin{array}{l}\text { El } 60 \% \text { son } \\
\text { kichwas }\end{array}$ & $\begin{array}{l}\text { Todos son } \\
\text { colonos }\end{array}$ & $\begin{array}{l}\text { El } 66 \% \text { son } \\
\text { kichwas }\end{array}$ \\
\hline Género del jefe hogar ${ }^{\text {b }}$ & \multicolumn{4}{|c|}{$\begin{array}{l}\text { El } 5 \% \text { de jefes del hogar son mujeres (no hay ninguna mujer en el caso de } \\
\text { finquero que opera por su cuenta) }\end{array}$} \\
\hline Número de personas por hogar ${ }^{a}$ & 7 personas & 5 personas & 4 personas & 5 personas \\
\hline Número de adultos por hogar ${ }^{\mathrm{a}}$ & \multicolumn{4}{|l|}{3 personas } \\
\hline Edad del jefe del hogar ${ }^{b^{* * *}}$ & $\begin{array}{l}\text { El } 60 \% \text { son } \\
\text { menores de } 45 \\
\text { años }\end{array}$ & $\begin{array}{l}\text { El } 60 \% \text { son } \\
\text { mayores de } 45 \\
\text { años }\end{array}$ & $\begin{array}{l}\text { El } 100 \% \text { son } \\
\text { mayores de } 45 \\
\text { años }\end{array}$ & $\begin{array}{l}\text { El } 45 \% \text { son } \\
\text { mayores de } 45 \\
\text { años }\end{array}$ \\
\hline Edad del jefe del hogar ${ }^{a * * *}$ & 43 años & 50 años & 64 años & 44 años \\
\hline Tamaño finca (ha) $\mathrm{a}^{* *}$ & 24 hectáreas & 26 hectáreas & 40 hectáreas & 18 hectáreas \\
\hline Tamaño finca cultivada (ha) $\mathrm{a}^{*}$ & 5 hectáreas & 8 hectáreas & 11 hectáreas & 5 hectáreas \\
\hline Participación en organizaciones b & \multicolumn{4}{|c|}{$\begin{array}{l}\text { El } 60 \% \text { de los encuestados o algún miembro de su hogar forma parte de una } \\
\text { organización, especialmente agrícolas. }\end{array}$} \\
\hline Trabajo fuera de la finca ${ }^{b^{* * *}}$ & \multicolumn{4}{|c|}{$\begin{array}{l}\text { El } 57 \% \text { de los encuestados trabaja como jornalero fuera de su finca y apenas } \\
\text { el } 8 \% \text { tienen un contrato laboral de } 12 \text { meses. }\end{array}$} \\
\hline & $\begin{array}{l}\text { El 33\% recibe } \\
\text { ingresos como } \\
\text { motosierrista } \\
\text { fuera de su finca }\end{array}$ & $\begin{array}{l}\text { El } 8 \% \text { recibe } \\
\text { ingresos como } \\
\text { motosierrista } \\
\text { fuera de su finca }\end{array}$ & $\begin{array}{l}\text { Nadie } \\
\text { trabaja como } \\
\text { motosierrista } \\
\text { fuera de su finca }\end{array}$ & $\begin{array}{l}\text { El } 11 \% \text { recibe } \\
\text { ingresos como } \\
\text { motosierrista } \\
\text { fuera de su finca }\end{array}$ \\
\hline Tiene cuenta de ahorros ${ }^{b}$ & \multicolumn{4}{|c|}{$\begin{array}{l}\text { El 70\% de los hogares no tienen acceso a una cuenta de ahorro en algún } \\
\text { banco, cooperativa, asociaciones, etc. }\end{array}$} \\
\hline \multicolumn{5}{|l|}{ Activos } \\
\hline Tiene celular ${ }^{\text {b**}}$ & $\begin{array}{l}\text { El } 74 \% \text { tiene } \\
\text { celular }\end{array}$ & $\begin{array}{l}\text { El } 60 \% \text { tiene } \\
\text { celular }\end{array}$ & $\begin{array}{l}\text { El } 55 \% \text { tiene } \\
\text { celular }\end{array}$ & $\begin{array}{l}\text { El } 45 \% \text { tiene } \\
\text { celular }\end{array}$ \\
\hline Tiene motosierra ${ }^{b^{* * *}}$ & $\begin{array}{l}\text { El } 77 \% \text { posee } \\
\text { motosierras }\end{array}$ & $\begin{array}{l}\text { El } 24 \% \text { tiene } \\
\text { motosierras }\end{array}$ & $\begin{array}{l}\text { El 9\% tiene } \\
\text { motosierras }\end{array}$ & $\begin{array}{l}\text { El } 27 \% \text { tiene } \\
\text { motosierras }\end{array}$ \\
\hline Tiene canoa ${ }^{b^{* *}}$ & $35 \%$ tiene canoas & $16 \%$ tiene canoas & No tienen canoas & $16 \%$ tiene canoas \\
\hline Tiene cabezas de ganado ${ }^{b^{*}}$ & $\begin{array}{l}\text { El } 21 \% \text { posee } \\
\text { ganado }\end{array}$ & $\begin{array}{l}\text { El } 36 \% \text { posee } \\
\text { ganado }\end{array}$ & $\begin{array}{l}\text { El } 55 \% \text { posee } \\
\text { ganado }\end{array}$ & $\begin{array}{l}\text { El } 18 \% \text { posee } \\
\text { ganado }\end{array}$ \\
\hline Otros activos & \multicolumn{4}{|c|}{ El 54\% tiene bombas de fumigar y el $30 \%$ posee animales de acarreo } \\
\hline Cantidad total de bienes $(\$) \mathrm{a}^{* *}$ & $\begin{array}{l}\text { Tiene en } \\
\text { promedio } 1140 \\
\text { USD }\end{array}$ & $\begin{array}{l}\text { Tiene en } \\
\text { promedio } 1320 \\
\text { USD }\end{array}$ & $\begin{array}{l}\text { Tiene en } \\
\text { promedio } 682 \\
\text { USD }\end{array}$ & $\begin{array}{l}\text { Tiene en } \\
\text { promedio } 530 \\
\text { USD }\end{array}$ \\
\hline Distancia a la ciudad principal ${ }^{\mathrm{a}^{* * *}}$ & 79 km & $78 \mathrm{~km}$ & 167 km & 134 km \\
\hline
\end{tabular}

Nota a): se refiere a los resultados de análisis de ANOVA en las diferencias sobre las características entre los tipos de

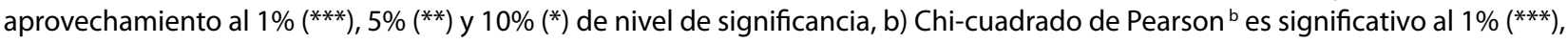
$5 \%\left(^{* *}\right)$ y $10 \%\left({ }^{*}\right)$ del nivel de significancia.

Fuente: Elaboración propia basada en encuesta a hogares realizada entre agosto y septiembre de 2012. 
los 79 hogares clasificados en los grupos 1 al 3 mencionados arriba. Estos grupos representan el $54 \%$, 32\% y $14 \%$ respecto al total de los 79 hogares que realizaron extracción de madera de sus bosques. Como ya se mencionó, el grupo 1 se caracteriza por realizar el aprovechamiento en su mayoría con mano de obra familiar, el grupo 2 por utilizar mano de obra contratada en el aprovechamiento, y el grupo 3 son los hogares que no participan del aprovechamiento puesto que este es realizado por los intermediarios.

Para llevar a cabo el aprovechamiento de madera algunos hogares tuvieron que solicitar permiso a la comunidad para realizar la extracción, principalmente las comunidades kichwa, quienes poseen títulos comunitarios. La extracción de la madera se realiza en su mayoría en las propias fincas, especialmente en el caso del grupo 3, ya que es el intermediario quien realiza la extracción y tiene que solicitar el permiso a los dueños de las fincas. Sin embargo, también se extrajo madera de fuera de las fincas, aunque la mayoría de estos aprovechamientos se realizaron en la misma comunidad en terrenos de parientes o vecinos, siendo en algunos casos aprovechamientos de carácter mixto. Por ejemplo, dos finqueros hacen el aprovechamiento en la finca de uno de ellos y llegan a un acuerdo mutuo sobre la extracción y los beneficios (cuadro 31).

Los tres grupos realizan la búsqueda y negociación con el comprador de la misma manera. La mayoría de los hogares (56\%) ha recibido un pedido de compra antes de realizar el aprovechamiento, otros hogares $(32 \%)$ buscaron un comprador tanto antes como después del aprovechamiento de la madera y finalmente el resto de hogares (12\%) esperó a que vinieran a comprar en el camino. La búsqueda del comprador y la estrategia de dejar la madera en el camino hasta que llegue un comprador sugiere la necesidad de venta que tienen los finqueros y un cierto grado de seguridad con respecto a la venta de su producto. Usualmente, los compradores de la madera son los intermediarios ya identificados por los finqueros, así el $75 \%$ de los finqueros vende su madera al mismo comprador. La mayor proporción de los finqueros no ha recibido dinero adelantado por parte de los compradores, así el 85\% no ha recibido adelantos de dinero, y los que han recibido ha sido en un rango de 40-1000 USD.

Con respecto a la negociación el 68\% de los finqueros respondió que el comprador impone el precio de la madera, el $16 \%$ por mutuo acuerdo y el 16\% respondieron que ellos imponen el precio. Además, es importante mencionar que cuando se les pregunto sí las dos últimas operaciones fueron adquiridas por el mismo o diferente comprador, el $75 \%$ de los finqueros respondieron que fue el mismo comprador, especialmente la categoría de finqueros que realizan el aprovechamiento por su propia cuenta. La información sobre los precios de la madera en el mercado nacional es mínima; sin embargo, el 64\% de los finqueros conoce el precio que pagan los diferentes compradores en el mercado local. La información de los precios se obtiene en un $45 \%$ por parte de los compradores y el $50 \%$ por parte de un vecino o familiar.

El 82\% de los hogares vendieron la madera en su propia comunidad, estos finqueros recorrieron en promedio $1,8 \mathrm{~km}$ hasta el punto de venta; en cambio, los finqueros que vendieron fuera de la comunidad recorrieron $10,6 \mathrm{~km}$, en promedio. Los finqueros que venden la madera dentro de

Cuadro 31. Características del aprovechamiento según tipo predominante

\begin{tabular}{|c|c|c|c|c|}
\hline & & \multicolumn{2}{|c|}{ Finquero realiza la extracción } & \multirow{2}{*}{$\begin{array}{c}\text { Intermediario } \\
\text { realiza la } \\
\text { extracción }\end{array}$} \\
\hline & & Por su propia cuenta & Personal contratado & \\
\hline \multirow{2}{*}{$\begin{array}{l}\text { Solicito permiso a } \\
\text { la comunidad }\end{array}$} & Si & $4(10 \%)$ & $4(17 \%)$ & \\
\hline & No & $38(90 \%)$ & $20(83 \%)$ & $11(100 \%)$ \\
\hline \multirow{2}{*}{$\begin{array}{l}\text { Lugar de extracción } \\
\text { de la madera }\end{array}$} & En su finca & $31(72 \%)$ & $21(84 \%)$ & $11(100 \%)$ \\
\hline & Fuera de su finca & $12(28 \%)$ & $4(16 \%)$ & \\
\hline \multirow{2}{*}{$\begin{array}{l}\text { Lugar de venta de } \\
\text { la madera }\end{array}$} & En la misma comunidad & $35(85 \%)$ & $18(72 \%)$ & $7(100 \%)$ \\
\hline & Fuera de la comunidad & $6(15 \%)$ & $7(18 \%)$ & \\
\hline
\end{tabular}

Fuente: Elaboración propia basada en encuesta a hogares realizada entre agosto y septiembre de 2012. 
la comunidad requieren usualmente transporte animal, debido a la distancia. En cambio, los finqueros que venden fuera de la comunidad acuden a transporte que incluye fluvial y vehicular.

En el cuadro 32 se describe la situación de formalidad de los aprovechamientos (sin y con programa) y la cantidad del producto vendido por tipo de productos. El grupo 1 se caracteriza por vender la mayor parte de su madera sin un programa de aprovechamiento (84\%), comercializar la menor cantidad de madera tanto en número de árboles como en volumen y tener una frecuencia de venta de 2 veces al año comparado con los otros dos grupos. El grupo 2 vende las tres cuartas partes $(76 \%)$ sin un programa de aprovechamiento, la cantidad vendida en $\mathrm{m}^{3}$ es intermedia entre los otros grupos, y la frecuencia de venta es de tres veces al año, siendo la misma que tiene el grupo 3. Este último se caracteriza por comercializar un mayor volumen de madera con un programa de aprovechamiento (64\%) y tener una frecuencia de venta de tres veces al año.

La mayoría de la venta de la madera se realiza como madera aserrada, apenas un 3\% se vende como árboles en pies dentro del grupo 3. En el cuadro 33 se observa que la mayoría de hogares kichwas $(87 \%)$ venden la madera aserrada sin un programa de aprovechamiento comparados con los hogares colonos (55\%). Una de las razones que podría explicar esta tendencia es la cantidad vendida por cada grupo, por ejemplo, los kichwas venden en promedio menor cantidad de madera aserrada que los colonos, por lo que no compensaría realizar un programa de aprovechamiento; además que la mayoría de hogares carecen de un título de propiedad, requisito indispensable para realizar un programa de aprovechamiento. La informalidad se ve reflejada en casi todas las

Cuadro 32. Características de la venta de madera según la forma de aprovechamiento

\begin{tabular}{|c|c|c|c|c|c|}
\hline & & \multicolumn{2}{|c|}{ Finquero realiza la extracción } & \multirow{2}{*}{$\begin{array}{l}\text { Intermediario } \\
\text { realiza la } \\
\text { extracción }\end{array}$} & \multirow[b]{2}{*}{ Total } \\
\hline & & $\begin{array}{l}\text { Por su propia } \\
\text { cuenta }\end{array}$ & $\begin{array}{l}\text { Personal } \\
\text { contratado }\end{array}$ & & \\
\hline \multicolumn{6}{|c|}{ Periodo de agosto 2011 - septiembre 2012} \\
\hline Sin programa ${ }^{b^{* * *}}$ & No. de hogares & 27 & 16 & 2 & 45 \\
\hline Con programa $\mathrm{b}^{\text {***}}$ & & $6(18 \%)$ & $5(24 \%)$ & $7(78 \%)$ & 18 \\
\hline \multirow{2}{*}{$\begin{array}{l}\text { Madera vendida en } \mathrm{m}^{3} \\
\text { en el } 2012^{\mathrm{a}^{* *}}\end{array}$} & No. de hogares & 33 & 21 & 9 & 63 \\
\hline & Promedio & $8,9 \mathrm{~m}^{3}$ & $21,3 \mathrm{~m}^{3}$ & $59,8 \mathrm{~m}^{3}$ & \\
\hline \multirow{2}{*}{$\begin{array}{l}\text { Número de árboles } \\
\text { vendidos en el } 2012^{\mathrm{a}^{* * *}}\end{array}$} & No. de hogares & 33 & 21 & 9 & 63 \\
\hline & Promedio & 6 & 23 & 35 & \\
\hline \multirow{2}{*}{$\begin{array}{l}\text { Frecuencias de venta de } \\
\text { madera en el } 2012^{\mathrm{a}}\end{array}$} & No. de hogares & 33 & 21 & 9 & 62 \\
\hline & Promedio & 2 & 3 & 3 & \\
\hline \multicolumn{6}{|l|}{ Periodo 2004-2012 } \\
\hline Sin programa ${ }^{b^{* * *}}$ & No. de hogares & 36 & 19 & 4 & 59 \\
\hline Con programa ${ }^{b^{* * *}}$ & & $7(16 \%)$ & $6(24 \%)$ & $7(64 \%)$ & 20 \\
\hline \multirow{2}{*}{$\begin{array}{l}\text { ¿Usted ejecutó el } \\
\text { programa? }\end{array}$} & Sí & 1 & 1 & & \\
\hline & No. de hogares & $7(88 \%)$ & $5(83 \%)$ & $7(100 \%)$ & \\
\hline \multirow{2}{*}{$\begin{array}{l}\text { Madera vendida en } \mathrm{m}^{3} \\
\text { en diferentes años }{ }^{\mathrm{a**}, \mathrm{c}}\end{array}$} & No. de hogares & 43 & 25 & 10 & 78 \\
\hline & Promedio & $9,90 \mathrm{~m}^{3}$ & $22,38 \mathrm{~m}^{3}$ & $54,83 \mathrm{~m}^{3}$ & \\
\hline \multirow{2}{*}{$\begin{array}{l}\text { Número de árboles } \\
\text { vendidos en diferentes } \\
\text { años }^{\mathrm{a}^{* *}}\end{array}$} & No. de hogares & 43 & 25 & 11 & 79 \\
\hline & Promedio & 9 & 22 & 31 & \\
\hline
\end{tabular}

Nota: a) ANOVA a en las diferencias características entre los tipos de aprovechamiento al $1 \%\left(^{* * *}\right)$ y $5 \%\left(^{* *}\right)$ de nivel de significancia. b) Chi-cuadrado de Pearson ${ }^{b}$ es significativo al $1 \%\left(^{* * *}\right)$ del nivel de significancia. c) el número de hogares por madera vendida debería ser 79, pero la información de 1 finquero que vendió en pie no se tiene en $\mathrm{m}^{3}$. 


\section{Cuadro 33. Características de la cantidad vendida con y sin programa de aprovechamiento según etnias y estrategias de aprovechamiento en Napo entre 2011 y 2012}

\begin{tabular}{|c|c|c|c|c|}
\hline & & & \multicolumn{2}{|c|}{ Madera aserrada $\left(\mathrm{m}^{3}\right)$} \\
\hline & & & Colonos & Kichwas \\
\hline \multirow[t]{4}{*}{ Por su propia cuenta } & \multirow[t]{2}{*}{ Informal } & No. de hogares & 8 & 28 \\
\hline & & Promedio & $9,6^{b^{* *}}$ & $6,3^{b^{* * *}}$ \\
\hline & \multirow[t]{2}{*}{ Formal } & No. de hogares & 3 & 4 \\
\hline & & Promedio & $30,5^{b^{* *}}$ & $19,6^{b^{* * *}}$ \\
\hline \multirow[t]{4}{*}{ Personal contratado } & \multirow[t]{2}{*}{ Informal $\mathrm{a}^{*}$} & No. de hogares & 6 & 13 \\
\hline & & Promedio & $22,1^{b^{* *}}$ & $7,8^{b^{*}}$ \\
\hline & \multirow[t]{2}{*}{ Formal } & №. de hogares & 4 & 2 \\
\hline & & Promedio & $69,2^{b^{* *}}$ & $24,0^{b^{*}}$ \\
\hline \multirow[t]{4}{*}{ El intermediario realiza la extracción } & \multirow[t]{2}{*}{ Informal } & $N^{\circ}$. de hogares & 3 & \\
\hline & & Promedio & 32,1 & \\
\hline & \multirow[t]{2}{*}{ Formal } & $N^{\circ}$. de hogares & 7 & \\
\hline & & Promedio & 64,5 & \\
\hline \multirow[t]{2}{*}{ Total } & & No. de hogares & 31 & 47 \\
\hline & & Promedio & 36,3 & 8,6 \\
\hline
\end{tabular}

Nota: a) Prueba t para muestras independientes entre colonos y kichwas que tiene programa y colonos y kichwas que no tienen programa, al $10 \%\left({ }^{*}\right)$ de nivel de significancia y b) Prueba t para muestras independientes entre la misma etnia $1 \%\left({ }^{* * *}\right), 5 \%\left({ }^{* *}\right)$ y al $10 \%\left({ }^{*}\right)$ de nivel de significancia.

Fuente: Elaboración propia basada en encuesta a hogares realizada entre agosto y septiembre de 2012.

estrategias de aprovechamiento, pero ésta ocurre en una proporción menor en el grupo 3, donde el intermediario realiza la extracción en su totalidad.

En el caso que el finquero decida realizar un aprovechamiento formal, el volumen de madera en $\mathrm{m}^{3}$ vendida será en promedio tres veces mayor que si decidiera vender su madera de manera informal (cuadro 33). El grupo 2, que utiliza la estrategia informal donde se hace uso de la mano de obra contratada, se caracteriza por una diferencia muy marcada entre la cantidad extraída entre colonos y kichwas. Es decir, el grupo de kichwas tiene los recursos para realizar el aprovechamiento, ya sea porque se asocia a otros finqueros o cuenta con recursos propios; sin embargo, se creería que los recursos no son lo suficientemente altos comparados con los colonos para realizar un aprovechamiento forestal de mayor volumen.

\subsubsection{Costos y beneficios del aprovechamiento}

$\mathrm{El}$ análisis del ingreso neto (ingresos brutos menos costos) de los finqueros considera únicamente los últimos 12 meses a partir de agosto de 2011 hasta septiembre de 2012. Los principales rubros que se incluyen en los costos del aprovechamiento son los insumos, repuestos, salarios, alquiler de animales y alimentación. Los salarios pagados al personal contratado, incluyendo familiares remunerados, es el principal rubro que marca la diferencia entre el grupo 1 y 2, así el salario representa el mayor costo del aprovechamiento para el grupo 2 (75\%), siendo solo el $38 \%$ en el grupo 1, quienes emplean la mano de obra familiar. Los insumos representan el mayor porcentaje de los costos totales en el aprovechamiento con relación al grupo 2 (figura 12).

No se determinó el costo de transporte; sin embargo, se conoce que el $82 \%$ de los hogares vendieron la madera en su propia comunidad. Estos finqueros recorrieron en promedio $1,80 \mathrm{~km}$ hasta el punto de venta; en cambio, los finqueros que vendieron fuera de la comunidad recorrieron $10,60 \mathrm{~km}$, en promedio. Los finqueros que venden la madera dentro de la comunidad requieren usualmente transporte animal, debido a la distancia. En cambio, los finqueros que venden fuera de la comunidad utilizan transporte animal, 


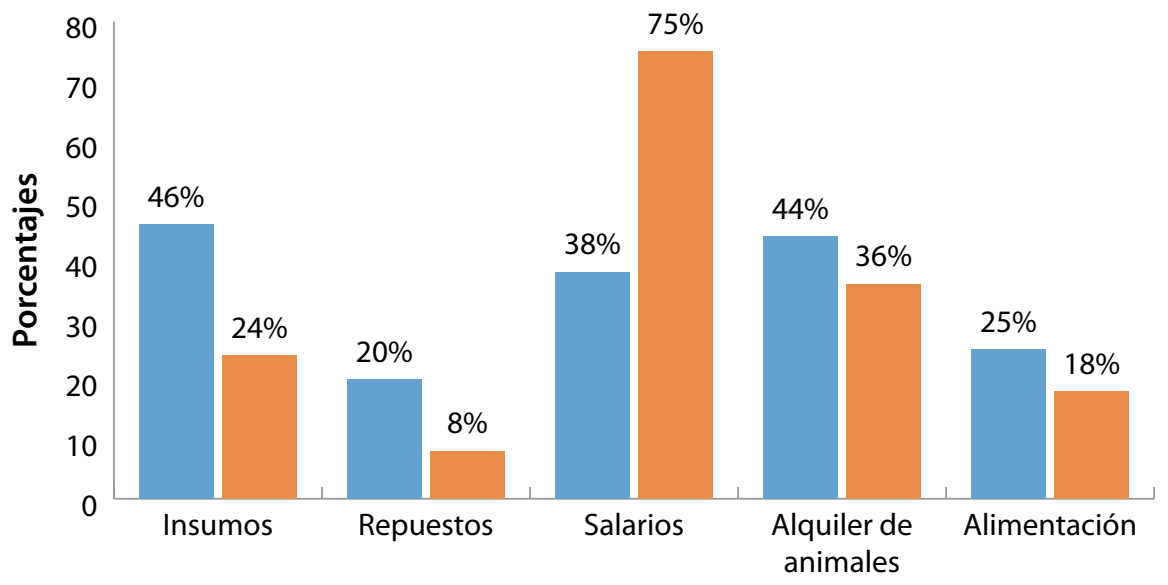

- Finquero que extrae por su cuenta (Grupo 1) — Finquero que contrata personal (Grupo 2)

Figura 12. Porcentaje de costos sobre los costos totales en el periodo de agosto 2011-septiembre 2012. Basado en encuesta a hogares realizada entre agosto y septiembre de 2012. No se incluye al grupo 3 porque los finqueros no disponían de la información de gastos realizados.

Cuadro 34. Costos y beneficios de los pequeños finqueros en el periodo de agosto 2011-septiembre 2012 (en USD)

\begin{tabular}{lccc} 
& \multicolumn{2}{c}{ Finquero realiza la extracción } & Intermediario realiza \\
\cline { 2 - 3 } & Por su propia cuenta & Personal contratado & $\begin{array}{c}\text { toda la extracción } \\
\text { Ingresos brutos }\end{array}$ \\
Costos & 185 & 2068 & - \\
Ingreso neto madera & 369 & 910 & - \\
Ingreso neto madera $/ \mathrm{m}^{3}$ & 48 & 1058 & 1516 \\
vendido de madera & & 46 & 26 \\
\hline
\end{tabular}

Fuente: Elaboración propia basada en encuesta a hogares realizada entre agosto y septiembre de 2012.

fluvial y/o vehicular. Los costos de transporte son altamente variables y dependen de varios factores como topografía, número de animales utilizados o número de acarreadores contratados.

Los ingresos netos varían para cada categoría. El grupo 1 se caracteriza por tener los menores ingresos netos en comparación a los otros dos grupos. El grupo 2 y 3 tienen ingresos netos similares debido a la cantidad de madera que venden en volumen. $\mathrm{Al}$ calcular los beneficios que reciben los finqueros por $\mathrm{m}^{3}$ de madera vendida, los finqueros en el grupo 3 reciben un menor ingreso comparado con los otros grupos (cuadro 34). Si bien es cierto que el grupo que realiza la extracción por su propia cuenta tuvo menos ingresos, la intensidad de aprovechamiento fue mucho más baja, lo cual puede permitir rotar en diferentes áreas de bosque a través del tiempo.

\subsubsection{Especies y cantidad de madera}

El área donde se llevó a cabo el aprovechamiento es la misma para los tres grupos: bosques nativos (40\%), bosque secundario (19\%), áreas agroforestales $(16 \%)$, áreas silvopastoriles (14\%) y realce-rastrojo (11\%). Para poder realizar una comparación con los programas de aprovechamiento se ha tomado la clasificación que tiene el MAE y que unifica bosques secundarios, rastrojos-realces, áreas silvopastoriles en sistemas agroforestales (cuadro 35). El total de madera vendida en el periodo de agosto 2011 a septiembre 2012 es de $893 \mathrm{~m}^{3}$, el $86 \%$ de esta madera se encuentra descrita en el cuadro 35, el 12\% faltante 
Cuadro 35. Aprovechamiento por el tipo de especie y uso de suelos (en $\mathrm{m}^{3}$ )

\begin{tabular}{|c|c|c|c|c|}
\hline & $\begin{array}{c}\text { Bosques } \\
\text { nativos }\end{array}$ & $\begin{array}{c}\text { Sistemas } \\
\text { agroforestales }\end{array}$ & $\begin{array}{l}\text { Formaciones } \\
\text { pioneras }\end{array}$ & Total \\
\hline Laurel (Cordia alliodora) $\left(^{*}\right)$ & 15,54 & 81,95 & & 97,49 \\
\hline Doncel, sangre de gallina, (Otoba spp) ${ }^{*}$ ) & 120,39 & 27,48 & & 147,87 \\
\hline Balsa, boya (Ochroma pyramidale) & & & 132 & 132 \\
\hline Lechero, sande rojo, sande blanco (Brosimun spp) & & 63,76 & & 63,76 \\
\hline Colorado, manzano, tucuta, piaste (Guarea Kunthiana) (*) & 33,75 & 17,43 & & 51,18 \\
\hline Guarango, yonrunta (Acacia glomerosa) & 25,54 & & & 25,54 \\
\hline Arenillo, pondo (Erisma uncinatum) (*) & 32,42 & 1,2 & & 33,62 \\
\hline Chalviande, coco, (Virola spp) & 21,25 & 12,12 & & 33,37 \\
\hline Ceiba, ceibo, (Ceiba insignis) & 6,91 & 20,33 & & 27,24 \\
\hline Mascarey, motilón (Hyeronima spp) $\left(^{*}\right)$ & 23,94 & 12,30 & & 36,24 \\
\hline Tamburo, bella María, Juan Colorado (Vochysia spp) (*) & & 20,23 & & 20,23 \\
\hline Abio, caimito (Pouteria spp) $\left(^{*}\right)$ & 12,94 & 7,34 & & 20,28 \\
\hline Higueron, matapalo (Ficus spp) & & 16,85 & & 16,85 \\
\hline Canelo (Nectandra reticulata) $\left(^{*}\right)$ & 2,88 & 10,50 & & 13,38 \\
\hline Corcho (Apeiba membranacea) & & 8,64 & & 8,64 \\
\hline Sapote (Sterculia spp) & 7,20 & 4,68 & & 11,88 \\
\hline Copal, anime (Dacryodes spp) & & 5,34 & & 5,34 \\
\hline Chuncho, seique, (Cedrelinga catenaiformes) (*) & & 4,20 & & 4,20 \\
\hline Otros & 1,08 & 20,44 & & 21,52 \\
\hline Total & 303,84 & 334,79 & 132 & 770,62 \\
\hline Porcentaje & $40 \%$ & $43 \%$ & $17 \%$ & $100 \%$ \\
\hline
\end{tabular}

Nota: Las especies marcadas con * son duras y semiduras, el resto son consideradas blandas.

Fuente: Elaboración propia basada en encuesta a hogares realizada entre agosto y septiembre de 2012.

se debe a que los finqueros desconocían la cantidad vendida por cada especie. Este desconocimiento responde a que el finquero no participa del aprovechamiento en casos donde la extracción fue realizada por un intermediario. El restante $2 \%$ corresponde a la madera que es utilizada con fines domésticos en los hogares.

La mayor cantidad del volumen de madera para el conjunto de la provincia Napo no proviene de los bosques nativos según los datos del cuadro 35. Las cinco primeras especies que han sido comercializadas considerando el volumen aprovechado, el laurel (Cordia alliodora), balsa (Ochroma pyramidale) y sande rojo (Brosimun spp) se caracterizan por originarse en áreas diferentes a las de bosque nativo en las comunidades estudiadas.

\subsection{El caso de Orellana: Análisis de las estrategias de los finqueros}

\subsubsection{Características de los hogares}

Las principales diferencias que existen entre los hogares de colonos y los de comunidades indígenas es que la mayor parte de los colonos provienen de otras provincias del país. El número de miembros en el hogar es mayor en los indígenas, los jefes de familia indígenas son más jóvenes, y el nivel de educación de los adultos kichwas es menor comparado con los hogares colonos (cuadro 36). En relación a la tenencia, al igual que en Napo, los colonos tienen acceso individual a sus tierras aunque generalmente no tienen título oficial y cada comunidad indígena tiene un título colectivo para toda la comunidad y la asignación de fincas familiares es decidida por la organización 
Cuadro 36. Características de los hogares colonos, kichwas y shuaras

\begin{tabular}{|c|c|c|c|}
\hline Variables & Colonos & Kichwas & Shuaras \\
\hline Procedencia & $\begin{array}{l}\text { El } 96 \% \text { no nació en Orellana } \\
\text { y provienen de la Sierra y } \\
\text { Costa, principalmente Loja, } \\
\text { Bolívar y Manabí. }\end{array}$ & $\begin{array}{l}\text { El } 93 \% \text { no nació en Orellana } \\
\text { y provienen principalmente } \\
\text { de la provincia de Napo. }\end{array}$ & $\begin{array}{l}\text { El } 85 \% \text { no nació en Orellana } \\
\text { y provienen de la provincia } \\
\text { de Morona Santiago. }\end{array}$ \\
\hline $\begin{array}{l}\text { Número de } \\
\text { miembros del hogar }\end{array}$ & 4 adultos y 2 niños & 6 adultos y 3 niños & 5 adultos y 2 niños \\
\hline $\begin{array}{l}\text { Edad promedio del } \\
\text { jefe de hogar }\end{array}$ & 47 años & 39 años & \\
\hline \multirow[t]{2}{*}{ Educación } & \multicolumn{3}{|c|}{$\begin{array}{l}\text { El nivel de educación formal de los jefes de hogar es bajo. No difieren entre hogares } \\
\text { colonos e indígenas. La tasa de analfabetismo es del } 6 \% \text { ( } 10 \% \text { colonos y } 3 \% \text { indígenas) y un } \\
79 \% \text { ha finalizado la escuela primaria }\end{array}$} \\
\hline & \multicolumn{3}{|c|}{$\begin{array}{l}\text { Los otros miembros (no jefe de hogar) de los colonos presentan mejores índices de } \\
\text { educación formal primaria y secundaria respecto a los otros miembros de familias kichwas. }\end{array}$} \\
\hline Tipo de tenencia & $\begin{array}{l}\text { Individual, } 41 \% \text { tiene un } \\
\text { registro o título. }\end{array}$ & $\begin{array}{l}\text { Comunitaria, } 98 \% \text { tiene un } \\
\text { registro. }\end{array}$ & $\begin{array}{l}\text { Comunitaria, } 100 \% \text { tiene un } \\
\text { título. }\end{array}$ \\
\hline
\end{tabular}

Fuente: Elaboración propia basada en encuesta a hogares realizada entre febrero y julio de 2012.

comunitaria. La posesión de la tierra es percibida como bastante segura incluso cuando no existe ningún título formal de tenencia, aunque un porcentaje considerable tiene algún tipo de registro. De hecho, aunque 27 finqueros colonos declararon que no tenían título de propiedad de su finca, ninguno indicó sentirse inseguro acerca de su derecho de tenencia.

\subsubsection{Usos de suelo y sistemas de producción}

Los sistemas de producción en las fincas son bastante diversificados tanto en colonos como indígenas. Las fincas de las comunidades indígenas son ligeramente más grandes ( $40 \%$ más) en relación a las fincas de los colonos. En general practican los mismos sistemas de producción en fincas caracterizadas por mosaicos de bosque primario, pequeñas manchas de bosque secundario, rastrojos, pastizales, cultivos perennes como cacao y café para la comercialización, además de chacras con yuca, platanáceas y otros cultivos para satisfacer las necesidades alimentarias de las familias. La principal diferencia entre las fincas de colonos e indígenas es la superficie con bosques y pasto. Las fincas tienen unos dos tercios de su superficie cubiertos por bosque maduro, áreas que son relativamente mayores en parcelas de hogares indígenas. El área cultivada es ligeramente superior en los hogares colonos que en los hogares indígenas, sobre todo por la superficie de pasto mayor en las parcelas de colonos (cuadro 37).
El 72\% del total de 120 finqueros encuestados han desmontado alguna área de bosque durante el periodo de 2006 a 2012. Las actividades de conversión del área deforestada han ocurrido con mayor frecuencia en los hogares indígenas, aunque la superficie media desmontada por operación es menor. No obstante, tanto colonos como indígenas han desmontado un promedio de 3 hectáreas (0,5 hectáreas por año) en el periodo indicado. Esto sugiere que los hogares kichwas tienden a realizar actividades de desmonte más pequeñas pero más frecuentes que los colonos, dando como resultado la misma cantidad de bosque convertido a usos agrícolas. La mayoría de desmontes se ha llevado a cabo en bosques nativos (75\%), otra parte en los bosques secundarios (4\%), y en rastrojos o realces $(21 \%)$. El propósito de los desmontes ha sido el establecimiento de pastizales, cultivos anuales como maíz y perennes como café y cacao. Normalmente los colonos tienen una mayor preferencia para el establecimiento de pastizales y cultivos perennes, los hogares shuaras para el establecimiento de pastizales y cultivos anuales y los hogares kichwas para cultivos perennes. Los terrenos donde se realizan los desmontes son áreas que se localizan relativamente cerca de la casa, aproximadamente a $1 \mathrm{~km}$ de distancia.

El $67 \%$ de las parcelas desmontadas no fueron intervenidas para la extracción de madera antes del desmonte en el periodo indicado. De los 86 hogares que realizaron actividades 
Cuadro 37. Uso de suelos en las parcelas de colonos e indígenas (kichwas y shuaras) en hectáreas

\begin{tabular}{|c|c|c|c|c|}
\hline & \multicolumn{2}{|c|}{ Colonos } & \multicolumn{2}{|c|}{ Indígenas } \\
\hline & Media & Desviación estándar & Media & Desviación estándar \\
\hline Bosque nativo $^{a}$ & 23,19 & 22,05 & 39,71 & 26,94 \\
\hline Bosque secundario ${ }^{b}$ & 0,38 & 1,23 & 0,78 & 1,63 \\
\hline Realce $^{c}$ & 2,60 & 4,80 & 2,68 & 4,06 \\
\hline Pasto & 6,10 & 6,30 & 3,45 & 3,38 \\
\hline Cultivos anuales $^{d}$ & 0,17 & 0,41 & 0,45 & 0,69 \\
\hline Cultivos perennes $^{e}$ & 1,97 & 2,69 & 1,81 & 2,08 \\
\hline Chacra $^{f}$ & 0,36 & 0,82 & 0,38 & 0,83 \\
\hline Otros $^{9}$ & & & 1,05 & 2,37 \\
\hline Total & 34,77 & 23,52 & 50,31 & 26,67 \\
\hline
\end{tabular}

Nota: a) se refiere a bosques no intervenidos o perturbados, b) son bosques de regeneración natural, c) se refiere a un bosque secundario joven que se ha regenerado de forma natural después de su intervención o perturbación por actividades humanas, d) incluye maíz, plátano y yuca, e) comprende cacao y café, f) es el área destinada para el consumo del hogar e incluye, por ejemplo, yuca y plátano, y g) son áreas del terreno dónde no se puede cultivar, por ejemplo, zonas pantanos y rocosas Fuente: Elaboración propia basada en encuesta a hogares realizada entre febrero y julio de 2012.

Cuadro 38. Desmontes en parcelas de colonos e indígenas en el periodo del 2006 al 2012

\begin{tabular}{llll}
\hline & Colonos & Indígenas & Total \\
\hline $\begin{array}{l}\text { No. total de parcelas } \\
\text { No. parcelas con }\end{array}$ & 48 & 72 & 120 \\
$\begin{array}{l}\text { desmontes } \\
\text { No. de desmontes }\end{array}$ & 6 & 58 & 86 \\
$\begin{array}{l}\text { con extracción } \\
\text { forestal previa }\end{array}$ & & 23 & 29 \\
$\begin{array}{l}\text { Destino principal de } \\
\text { la madera }\end{array}$ & Venta & Venta & \\
\hline
\end{tabular}

Fuente: Elaboración propia basada en encuesta a hogares realizada entre febrero y julio de 2012.

de desmonte, 57 hogares tenían la presencia de especies demandadas por el mercado, pero sólo 17 vendieron la madera debido a que no existían especies valiosas en la finca, falta de comprador, deficientes vías de acceso a la comunidad y la distancia relativamente grande al punto de venta más cercano. La principal finalidad del desmonte es la conversión de los bosques hacia actividades agrícolas, importando poco la disponibilidad de madera en esas tierras (cuadro 38).

\subsubsection{Ingresos totales y forestales}

La economía familiar de los hogares encuestados se caracteriza por una combinación de múltiples actividades de producción y generación de ingresos. No existen diferencias significativas en la composición de los ingresos percibidos entre hogares colonos e indígenas. El cuadro 39 sugiere que para la mayoría de las familias las producciones agropecuaria y forestal son la base de sus ingresos, aunque el trabajo asalariado fuera de la finca y los negocios propios también son actividades importantes para un número significativo de familias. La producción agrícola y pecuaria, además de proveer ingresos, es importante para asegurar la base alimenticia de las familias. Entre los ingresos generados fuera de las parcelas son especialmente importantes las remuneraciones por trabajo asalariado con instituciones públicas (por ejemplo, el Ministerio de Educación o entidades de los Gobiernos locales) o con el sector privado (en las compañías petroleras establecidas en la provincia). Los negocios propios se refieren principalmente a pequeñas actividades de comercio, pero incluyen también otras actividades como la provisión de servicios de transporte o la venta de productos de artesanía. El Bono de Desarrollo Humano es también una ayuda económica importante por muchas familias rurales de la provincia.

Durante febrero de 2011 y julio de 2012, hubo 66 hogares $(55 \%)$ que tuvieron ingresos relacionados con la venta de productos forestales. La madera es, por sobre los otros productos del bosque, la fuente más importante de ingresos. Aunque el bosque tiene potencial para generar ingresos significativos, solo para pocas familias constituye la base casi exclusiva de la renta familiar. Tomando como base el total de 120 hogares 
Cuadro 39. Ingresos de los colonos e indígenas (kichwas y shuaras) en el periodo de febrero 2011-julio 2012

\begin{tabular}{|c|c|c|c|c|c|c|c|c|}
\hline \multirow{3}{*}{ Fuentes de ingresos } & \multicolumn{6}{|c|}{ Ingresos promedios } & \multicolumn{2}{|c|}{$\begin{array}{l}\text { No. de hogares que } \\
\text { perciben ingresos por } \\
\text { estas actividades }\end{array}$} \\
\hline & \multicolumn{2}{|c|}{ Colonos $(n=48)$} & \multicolumn{2}{|c|}{ Indígenas $(\mathrm{n}=72)$} & \multicolumn{2}{|c|}{ Total $(n=120)$} & \multirow{2}{*}{ Colonos } & \multirow{2}{*}{ Indígenas } \\
\hline & USD & $\%$ & USD & $\%$ & USD & $\%$ & & \\
\hline Trabajo asalariado ${ }^{a * * *}$ & 2052 & 62 & 923 & 47 & 1375 & 55 & 25 & 39 \\
\hline Venta de productos forestal ${ }^{\mathrm{b}}$ & 341 & 10 & 410 & 21 & 382 & 15 & 27 & 39 \\
\hline Bono Desarrollo Humano ${ }^{c}$ & 210 & 6 & 233 & 12 & 224 & 9 & 24 & 40 \\
\hline Venta producción agrícola d & 217 & 7 & 155 & 8 & 180 & 7 & 34 & 50 \\
\hline Venta producción pecuaria ${ }^{e}$ & 177 & 5 & 150 & 8 & 160 & 6 & 31 & 47 \\
\hline Negocio propio f** & 169 & 5 & 50 & 3 & 98 & 4 & 6 & 10 \\
\hline Otros $^{9}$ & 53 & 2 & 8 & 0 & 26 & 1 & 4 & 1 \\
\hline Total***h & 3298 & 100 & 1945 & 100 & 2486 & 100 & & \\
\hline
\end{tabular}

Nota: a) El trabajo asalariado incluye todo trabajo que se realice fuera de la finca y reciba un salario a cambio de su trabajo, por ejemplo, trabajo en agricultura, motosierristas y trabajos por contratos fijos; b) Los ingresos forestales se refieren a ingresos en efectivo por venta de madera, venta de productos forestales no maderables (PFNMs) e ingresos obtenidos a través del programa gubernamental Socio Bosque (PSB); c) El ingreso por Bono de desarrollo humano se explicó anteriormente; d) Los ingresos agrícolas se refieren al ingreso de dinero en efectivo por la venta de productos agrícolas, por ejemplo, cacao, maíz, café, guayusa, etc.; e) Los ingresos agropecuarios son obtenidos por la venta de algún animal y/o sus subproductos, por ejemplo, ganado, gallinas, leche, entre otros; f) Los ingresos por negocio propio es cualquier actividad donde el finquero trabaja por su propia cuenta, es decir, es su propio jefe, por ejemplo, comerciantes, dueños de tiendas; g) Otros ingresos corresponden a ingresos que no forman parte de ninguna categoría mencionada; h) Prueba t para muestras independientes en las diferencias de diversificación de ingresos entre colonos y kichwas al $1 \%\left(^{* * *}\right)$ y $5 \%\left({ }^{* *}\right)$ de nivel de significancia.

Fuente: Elaboración propia basada en encuesta a hogares realizada entre febrero-julio de 2012.

entrevistados, la venta de madera constituye el $10 \%$ de los ingresos totales anuales en las familias colonas y el $22 \%$ en los hogares indígenas en el periodo mencionado. Sin embargo, en términos absolutos, la cantidad vendida por ańo de madera en promedio es relativamente similar tanto para colonos como para grupos indígenas. Es importante anotar que, de los hogares que vendieron madera (66), los ingresos por productos maderables son mayores dentro de los ingresos totales anuales del hogar, $18 \%$ en las familias colonas (rango $0,40 \%-100 \%$ ) y $41 \%$ en las familias kichwas (rango 3\%-100\%) (cuadro 40).

De forma similar a lo mencionado para el caso de los hogares entrevistados en la provincia de Napo, los ingresos forestales no parecen desempeñar un papel central en los mecanismos de seguridad familiar en respuesta a crisis o imprevistos en los hogares entrevistados en la provincia de Orellana. Un total de 73 hogares (61\%) declararon haber sufrido algún tipo de crisis o gasto inesperado dentro del ańo anterior a la encuesta, pero solo 12 $(16 \%)$ dijeron que habían vendido más productos forestales para hacer frente a tales situaciones (figura 13).

Puesto que la madera significa una fuente importante de ingresos, los hogares buscan estrategias para conservar esos ingresos a futuro a través de la siembra de especies como chuncho (Cedrelinga catenaiformes), caoba/ahuano (Swietenia macrophylla) y guayacán (Tabebuia Chrysantha), entre otras. Del total de los encuestados, 70 de los hogares (58\%) declararon haber plantado árboles de las especies mencionadas dentro de sus fincas.

\subsection{Estrategias diferenciadas de aprovechamiento de madera}

En esta sección se utiliza una tipología similar a la elaborada para el mismo análisis presentado en el caso de la provincia Napo. Como se mencionó, se han identificado tres grupos: el grupo 1 corresponde a los finqueros que realizan la extracción por su propia cuenta, el grupo 2 
Cuadro 40. Descripción de los ingresos forestales por productos maderables y no maderables en el periodo de febrero 2011-julio 2012

\begin{tabular}{|c|c|c|c|c|c|c|c|c|}
\hline \multirow{3}{*}{ Ingresos forestales } & \multicolumn{6}{|c|}{ Ingresos promedios } & \multicolumn{2}{|c|}{$\begin{array}{l}\text { No. de hogares que reciben } \\
\text { ingresos por estos rubros }\end{array}$} \\
\hline & \multicolumn{2}{|c|}{ Colonos $(n=48)$} & \multicolumn{2}{|c|}{$\begin{array}{l}\text { Indígenas } \\
(n=72)\end{array}$} & \multicolumn{2}{|c|}{ Total $(n=120)$} & \multirow{2}{*}{ Colonos } & \multirow{2}{*}{ Kichwas } \\
\hline & USD & $\%$ & USD & $\%$ & USD & $\%$ & & \\
\hline Ingresos totales *** & 3298 & 100 & 1945 & 100 & 2486 & 100 & 48 & 72 \\
\hline \multicolumn{9}{|l|}{ Total ingresos forestales } \\
\hline Venta de madera & 332 & 10 & 426 & 22 & 388 & 16 & 27 & 39 \\
\hline Venta PFNM & 11 & 0,3 & 1 & 0 & 4 & 0,2 & 2 & 1 \\
\hline Programa Socio-Bosque & 31 & 1 & 0 & 0 & 13 & 1 & 1 & 0 \\
\hline
\end{tabular}

Nota: a) Prueba t para muestras independientes en las diferencias de diversificación de ingresos entre colonos y kichwas al 1\% $\left.{ }^{* * *}\right)$ de nivel de significancia

Fuente: Elaboración propia basada en encuesta a hogares realizada entre febrero y julio de 2012

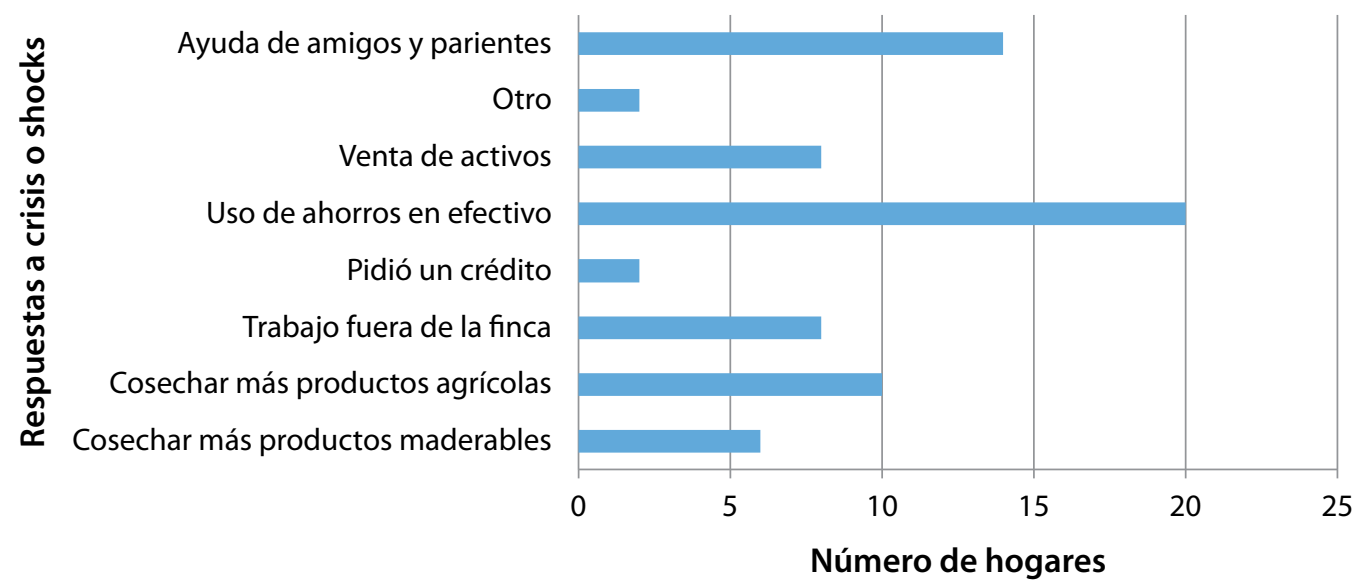

Figura 13. Rol de los ingresos forestales en los mecanismos de seguridad familiar en respuesta a crisis o imprevistos. Con base en encuesta a hogares realizada entre febrero y julio de 2012.

está integrado por finqueros que utilizan personal contratado, el grupo 3 son los finqueros que venden la madera al intermediario para que realice toda la extracción y, finalmente, el grupo 4 está integrado por los finqueros que no se dedican a la venta de madera. En el cuadro 41 y 42 se describen las principales características que presentan los diferentes hogares según esta clasificación.

La información presentada indica que los finqueros que realizan la actividad por su cuenta poseen en su mayoría motosierras con las cuales pueden trabajar en el aprovechamiento de la madera, además que tienen un mayor número de miembros en el hogar, lo que marca la diferencia con los otros grupos que probablemente tienen que contratar mano de obra o buscar otras estrategias de aprovechamiento. Los grupos 2 y 3 se caracterizan por recibir menores ingresos por trabajo asalariado comparándolos principalmente con el grupo que no se dedica a la venta de madera. Finalmente, el grupo 3 se caracteriza además por tener un mejor nivel relativo de educación de los jefes del hogar y un promedio mayor en la edad de los jefes de familia.

\subsubsection{Estrategias de aprovechamiento de la madera}

Un total de 89 hogares (74\%) han vendido madera entre el 2004 y julio de 2012, mientras que 66 hogares vendieron madera en los últimos 12 meses a partir de febrero y julio de 2012. Basándose en los 89 hogares y en función de las estrategias 
Cuadro 41. Tipos según atributos de hogar y de la estrategia de aprovechamiento de recursos forestales

\begin{tabular}{|c|c|c|c|c|}
\hline & \multicolumn{2}{|c|}{ El finquero realiza la extracción } & \multirow{2}{*}{$\begin{array}{l}\text { El intermediario } \\
\text { realiza toda la } \\
\text { extracción }\end{array}$} & \multirow{2}{*}{$\begin{array}{l}\text { No se vende } \\
\text { madera }\end{array}$} \\
\hline & $\begin{array}{l}\text { Por su propia } \\
\text { cuenta }\end{array}$ & $\begin{array}{l}\text { Personal } \\
\text { contratado }\end{array}$ & & \\
\hline \multicolumn{5}{|l|}{ Características del hogar } \\
\hline Número de hogares & 43 hogares & 11 & 35 & 31 \\
\hline Etnia del jefe de hogar ${ }^{b}$ & \multicolumn{4}{|c|}{$40 \%$ colonos y $60 \%$ indígenas ( $37 \%$ kichwas y $23 \%$ shuaras) } \\
\hline Género del jefe hogar ${ }^{b}$ & \multicolumn{4}{|c|}{ El 4\% de jefes del hogar son mujeres } \\
\hline Número de personas por hogar ${ }^{a^{* * *}}$ & 6 personas & 3 personas & 5 personas & 4 personas \\
\hline Número de adultos por hogar ${ }^{\mathrm{a}}$ & 4 personas & 2 personas & 3 personas & 3 personas \\
\hline Edad del jefe del hogar ${ }^{b}$ & \multicolumn{4}{|c|}{ El 58\% son menores de 45 años, y el resto son mayores de 45 años } \\
\hline Edad del jefe del hogar ${ }^{a}$ & \multicolumn{4}{|c|}{ Edad promedio 42 años. } \\
\hline Tamaño finca (ha) $\mathrm{a}^{* *}$ & $\begin{array}{l}\text { Tiene en } \\
\text { promedio } 48 \\
\text { hectáreas }\end{array}$ & $\begin{array}{l}\text { Tiene en } \\
\text { promedio } 33 \\
\text { hectáreas }\end{array}$ & $\begin{array}{l}\text { Tiene en } \\
\text { promedio } 56 \\
\text { hectáreas }\end{array}$ & $\begin{array}{l}\text { Tiene en } \\
\text { promedio } 38 \\
\text { hectáreas }\end{array}$ \\
\hline Tamaño finca cultivada (ha) a & Tienen en promec & o 7 hectáreas & & \\
\hline \multirow[t]{3}{*}{$\begin{array}{l}\text { Trabajo fuera de la finca }{ }^{b^{*} \text { (jornalero) y }} \\
b^{* * *} \text { (motosierrista) }\end{array}$} & \multicolumn{4}{|c|}{$\begin{array}{l}\text { El 19\% de todos los hogares tienen un contrato laboral en los últimos } 12 \\
\text { meses }\end{array}$} \\
\hline & $\begin{array}{l}\text { El 49\% trabajan } \\
\text { como jornaleros } \\
\text { fuera de su finca }\end{array}$ & $\begin{array}{l}18 \% \text { trabajan } \\
\text { como jornaleros } \\
\text { fuera de su finca }\end{array}$ & $\begin{array}{l}\text { El } 26 \% \text { trabajan } \\
\text { como jornaleros } \\
\text { fuera de su finca }\end{array}$ & $\begin{array}{l}\text { El } 48 \% \text { trabajan } \\
\text { como jornaleros } \\
\text { fuera de su finca }\end{array}$ \\
\hline & $\begin{array}{l}\text { El 28\% recibe } \\
\text { ingresos como } \\
\text { motosierrista } \\
\text { fuera de su finca }\end{array}$ & $\begin{array}{l}\text { El 9\% recibe } \\
\text { ingresos como } \\
\text { motosierrista } \\
\text { fuera de su finca }\end{array}$ & $\begin{array}{l}\text { El 3\% recibe } \\
\text { ingresos como } \\
\text { motosierrista } \\
\text { fuera de su finca }\end{array}$ & $\begin{array}{l}\text { El } 32 \% \text { recibe } \\
\text { ingresos como } \\
\text { motosierrista } \\
\text { fuera de su finca }\end{array}$ \\
\hline Tiene cuenta de ahorros ${ }^{b}$ & \multicolumn{4}{|c|}{$\begin{array}{l}\text { El 84\% de los hogares no tienen acceso a una cuenta de ahorro en algún } \\
\text { banco, cooperativa, asociaciones, etc. }\end{array}$} \\
\hline \multicolumn{5}{|l|}{ Activos } \\
\hline Tiene celular y canoas ${ }^{\text {b }}$ & \multicolumn{4}{|c|}{ El $51 \%$ de los hogares tienen celulares y cerca del $2 \%$ tiene canoas } \\
\hline Tiene motosierra ${ }^{b^{* * *}}$ & $\begin{array}{l}\text { El } 81 \% \text { tiene } \\
\text { motosierras }\end{array}$ & $\begin{array}{l}\text { El 55\% tiene } \\
\text { motosierras }\end{array}$ & $\begin{array}{l}\text { El } 40 \% \text { tiene } \\
\text { motosierras }\end{array}$ & $\begin{array}{l}\text { El } 42 \% \text { tiene } \\
\text { motosierras }\end{array}$ \\
\hline Tiene cabezas de ganado ${ }^{\mathrm{b}}$ & \multicolumn{4}{|c|}{ El 68\% poseen ganado } \\
\hline Tiene animales de acarreo ${ }^{b^{* * *}}$ & $\begin{array}{l}\text { El } 65 \% \text { posee } \\
\text { animales }\end{array}$ & $\begin{array}{l}\text { El } 18 \% \text { posee } \\
\text { animales }\end{array}$ & $\begin{array}{l}\text { El } 26 \% \text { posee } \\
\text { animales }\end{array}$ & $\begin{array}{l}\text { El } 26 \% \text { posee } \\
\text { animales }\end{array}$ \\
\hline Cantidad total de bienes $(\$)^{\text {a }}$ & \multicolumn{4}{|c|}{ Tienen en promedio $\$ 1248$} \\
\hline Distancia a la ciudad a principal & \multicolumn{4}{|c|}{ La distancia promedio de las comunidades la ciudad del Coca es de 48 Km. } \\
\hline
\end{tabular}

Nota: a) se refiere a los resultados de análisis ANOVA sobre las diferencias características entre los tipos de aprovechamiento al $1 \%\left({ }^{* *}\right), 5\left(^{* *}\right)$ y $10 \%\left({ }^{*}\right)$ de nivel de significancia, b) Chi-cuadrado de Pearson es significativo al $1 \%\left({ }^{* *}\right), 5 \%\left({ }^{* *}\right)$ y $10 \%\left({ }^{*}\right)$ del nivel de significancia.

Fuente: Elaboración propia basada en encuesta a hogares realizada entre febrero y julio de 2012.

de extracción y comercialización identificadas anteriormente, se tiene que el $48 \%$ corresponden al grupo $1,12 \%$ al grupo 2 y $39 \%$ al grupo 3 . Para recordar lo ya dicho, el grupo 1 incluye a los finqueros que realizan el aprovechamiento en su mayoría con mano de obra familiar, el grupo 2 contrata mano de obra para el aprovechamiento y los intermediaros se encargan del aprovechamiento en el grupo 3.

Mientras que los colonos toman sus decisiones individualmente, los hogares kichwas y shuaras, 
Cuadro 42. Características del aprovechamiento por la forma de aprovechamiento

\begin{tabular}{|c|c|c|c|c|}
\hline & & \multicolumn{2}{|c|}{ Finquero realiza la extracción } & \multirow{2}{*}{$\begin{array}{c}\text { Intermediario } \\
\text { realiza la } \\
\text { extracción }\end{array}$} \\
\hline & & $\begin{array}{c}\text { Por su propia } \\
\text { cuenta }\end{array}$ & $\begin{array}{c}\text { Personal } \\
\text { contratado }\end{array}$ & \\
\hline \multirow[t]{2}{*}{ Solicitó permiso a la comunidad } & Sí & $18(45 \%)$ & $2(22 \%)$ & $16(47 \%)$ \\
\hline & No & $22(55 \%)$ & $7(78 \%)$ & $18(53 \%)$ \\
\hline \multirow[t]{2}{*}{ Lugar de extracción de la madera } & En su finca & $35(81 \%)$ & $8(73 \%)$ & $34(97 \%)$ \\
\hline & Fuera de su finca & $8(19 \%)$ & $3(27 \%)$ & $1(3 \%)$ \\
\hline \multirow[t]{2}{*}{ Lugar de venta de la madera } & En la misma comunidad & $39(95 \%)$ & $9(72 \%)$ & $21(95 \%)$ \\
\hline & Fuera de la comunidad & $2(5 \%)$ & $2(18 \%)$ & $1(5 \%)$ \\
\hline
\end{tabular}

Fuente: Elaboración propia basada en encuesta a hogares realizada entre febrero y julio de 2012

en iguales proporciones, pidieron permiso a su comunidad para poder sacar y vender la madera, aproximadamente el $43 \%$ de los hogares pidió permiso a su comunidad. Gran parte de los aprovechamientos de madera se realizan en las propias fincas, sobre todo las extracciones realizadas por el grupo 3. Sin embargo, también se realizan extracciones fuera de las fincas aunque en menor proporción. Estas extracciones se llevan a cabo en fincas de la misma comunidad, aunque también pueden realizarse en fincas ubicadas en otras comunidades.

Las negociaciones de compra se llevan a cabo principalmente a través de pedidos de compra por parte del comprador $(66 \%)$ y en otros casos los productores buscan al comprador (34\%), especialmente antes de la corta. El 65\% de los finqueros ha recibido un adelanto de dinero por la venta de su madera con la finalidad de financiar las actividades de extracción cuando el comprador no realiza la operación, el dinero recibido varía entre 20 y 1500 USD. Este dinero adelantado ayudaría a suplir las carencias de fuentes de financiamiento de los finqueros. El comprador de la madera es principalmente el intermediario, que en la mayoría de los casos es ya conocido por los finqueros. Sin embargo, el comprador no siempre es el mismo, ya que la mitad de los encuestados dijeron que venden a distintos compradores. La mayoría de la madera se comercializa dentro de la misma comunidad, apenas el $7 \%$ se vende fuera de la ella.

En promedio, el 68\% de todas operaciones realizadas por las tres categorías identificadas anteriormente se han llevado a cabo sin un programa de aprovechamiento forestal. El finquero que realiza toda la operación a través de un intermediario es el que vende mayor cantidad de madera en comparación con los otros grupos; es decir, las operaciones que son llevadas a cabo por los finqueros tienden a extraer y movilizar menores volúmenes de madera (cuadro 43).

La mayoría de hogares vende su madera de forma aserrada aunque también se venden árboles en pie, de forma que, del total de los 89 hogares que realizaron aprovechamiento, 12 de ellos vendieron en pie al grupo 3. En general, la informalidad de los aprovechamientos de madera está presente en todas las estrategias utilizadas por los finqueros. En la mayoría de los casos, tanto los árboles en pie como los volúmenes de madera aserrada son mayores cuando se realizan con un programa de aprovechamiento forestal (cuadro 44). La cantidad vendida de madera aserrada no difiere significativamente entre colonos e indígenas, a excepción del grupo 2, donde los indígenas venden una cantidad mucho menor que los hogares colonos. En el caso de Orellana se conoce que la mayoría de hogares reciben dinero en efectivo con anterioridad para la extracción de la madera conocido como un adelanto. Sin embargo, el caso del grupo 2 corresponderían extracciones que probablemente no recibieron un adelante, por lo tanto, estos hogares indígenas no tuvieron los recursos suficientes para realizar un aprovechamiento de mayor volumen. Aunque el grupo 3 tiende a aprovechar mayores volúmenes, ellos también realizan pequeñas extracciones de madera, de tipo informal, sobre todo cuando precisan completar los volúmenes para sus pedidos más grandes. 
Cuadro 43. Características de la venta de madera por la forma de aprovechamiento

\begin{tabular}{|c|c|c|c|c|c|}
\hline & & \multicolumn{2}{|c|}{ El finquero realiza la extracción } & \multirow{2}{*}{$\begin{array}{c}\text { El intermediario } \\
\text { realiza la } \\
\text { extracción }\end{array}$} & \multirow[b]{2}{*}{ Total } \\
\hline & & $\begin{array}{l}\text { Por su propia } \\
\text { cuenta }\end{array}$ & $\begin{array}{l}\text { Personal } \\
\text { contratado }\end{array}$ & & \\
\hline \multicolumn{6}{|c|}{ Periodo de febrero2011-julio 2012} \\
\hline Sin programa & №. de hogares & 30 & 4 & 13 & 47 \\
\hline Con programa & & $7(19 \%)$ & $3(43 \%)$ & $9(41 \%)$ & 19 \\
\hline \multirow{2}{*}{$\begin{array}{l}\text { Madera vendida en } \mathrm{m}^{3} \text { en } \\
\text { el } 2012^{\mathrm{a}^{* * *}}\end{array}$} & No. de hogares & 34 & 6 & 18 & 58 \\
\hline & Promedio & $12,4 \mathrm{~m}^{3}$ & $29,9 \mathrm{~m}^{3}$ & $38,8 \mathrm{~m}^{3}$ & \\
\hline \multirow{2}{*}{$\begin{array}{l}\text { Número de árboles vendidos } \\
\text { en el } 2012^{a^{*}}\end{array}$} & №. de hogares & 33 & 5 & 22 & 60 \\
\hline & Promedio & 13 & 5 & 25 & \\
\hline \multicolumn{6}{|l|}{ Periodo 2004-2012 } \\
\hline Sin programa ${ }^{b}$ & No. de hogares & 35 & 7 & 23 & 65 \\
\hline Con programa & & $14(29 \%)$ & $4(40 \%)$ & $12(34 \%)$ & 30 \\
\hline \multirow{2}{*}{$\begin{array}{l}\text { Madera vendida en } \mathrm{m}^{3} \text { en } \\
\text { diferentes años }{ }^{a^{*}, c}\end{array}$} & No. de hogares & 42 & 10 & 22 & 74 \\
\hline & Promedio & $21,1 \mathrm{~m}^{3}$ & $37,9 \mathrm{~m}^{3}$ & $43,7 \mathrm{~m}^{3}$ & \\
\hline \multirow{2}{*}{$\begin{array}{l}\text { Número de árboles vendidos } \\
\text { en diferentes años }{ }^{a, c}\end{array}$} & No. de hogares & 43 & 8 & 35 & 86 \\
\hline & Promedio & 17 & 10 & 22 & \\
\hline
\end{tabular}

Nota: a) ANOVA en las diferencias características entre los tipos de aprovechamiento al $1 \%\left({ }^{* * *}\right)$ y $10 \%\left({ }^{*}\right)$ de nivel de significancia y b) el número de hogares que han vendido madera es 89; sin embargo, en el total de los que hicieron o no un programa el número es 95 , eso se debe a que 6 finqueros vendieron tanto con programa y sin programa y c) la venta de madera y de árboles no llega a los 89 debido a que algunos finqueros vendieron en pie y otros no recordaban la cantidad vendida.

Fuente: Elaboración propia basada en encuesta a hogares realizada entre febrero y julio de 2012

\section{Cuadro 44. Características de la cantidad vendida con y sin programa de aprovechamiento según etnias y estrategias de aprovechamiento en Orellana}

\begin{tabular}{|c|c|c|c|c|}
\hline & & & \multicolumn{2}{|c|}{ Madera aserrada $\left(\mathrm{m}^{3}\right)$} \\
\hline & & & Colonos & Indígenas \\
\hline \multirow[t]{4}{*}{ Por su propia cuenta } & \multirow[t]{2}{*}{ Informal } & No. de hogares & 13 & 21 \\
\hline & & Promedio & $13,3^{c^{* *}}$ & $11,2^{\mathrm{c}^{* * *}}$ \\
\hline & \multirow[t]{2}{*}{ Formal } & №. de hogares & 2 & 11 \\
\hline & & Promedio & $18,7^{c^{* *}}$ & $40,8^{\mathrm{c}^{* * *}}$ \\
\hline \multirow[t]{4}{*}{ Personal contratado } & \multirow[t]{2}{*}{ Informal $\mathrm{a}^{*}$} & No. de hogares & 4 & 2 \\
\hline & & Promedio & 13,0 & $3,7^{c^{* * *}}$ \\
\hline & \multirow[t]{2}{*}{ Formal } & No. de hogares & 2 & 2 \\
\hline & & Promedio & 34,0 & $80^{* * *}$ \\
\hline \multirow[t]{4}{*}{ El intermediario realiza la extracción } & \multirow[t]{2}{*}{ Informal } & No. de hogares & 4 & 8 \\
\hline & & Promedio & 12,3 & $13,9^{c^{* * *}}$ \\
\hline & \multirow[t]{2}{*}{ Formal } & No. de hogares & 1 & 9 \\
\hline & & Promedio & 50,0 & $80,4^{c^{* * *}}$ \\
\hline \multirow[t]{2}{*}{ Total } & & $N^{\circ}$. de hogares ${ }^{b}$ & 26 & 53 \\
\hline & & Promedio & 18,9 & 35,5 \\
\hline
\end{tabular}

Nota: a) Prueba t para muestras independientes con y sin programas de aprovechamiento al 10\% $\left(^{*}\right)$ de nivel de significancia, b) La suma de hogares es de 79; sin embargo este número debería ser 74 hogares como se observa en el cuadro 41. La diferencia se debe a que algunos hogares han vendido en el último año con y sin programa de aprovechamiento, por lo tanto, los datos se incrementan y c) el número de datos de los hogares colonos en el grupo 3 es bajo ( 1 hogar) para realizar la comparación. Con los datos de los kichwas se realizó una prueba t para muestras independientes entre esta etnia, al 1\%(***) de nivel de significancia. 


\subsubsection{Costos y beneficios del aprovechamiento}

En el análisis de costos se incluyen los gastos realizados por el finquero en el uso de insumos, repuestos, salarios, alquiler de animales y alimentación, tal como fue explicado previamente durante el análisis referido al caso de la provincia Napo. En el caso de Orellana los principales gastos son el pago de salarios a los trabajadores para ambos grupos. Para el grupo 2 los principales gastos dentro de los gastos totales son pago a trabajadores y pago del alquiler de equipo y animales. En el grupo 1, el porcentaje de sus gastos se concentra en el pago de trabajadores y la compra de insumos, los gastos por salarios son altos con respecto a los gastos totales, esto no significa que sean iguales a los que contratan personal (figura 14).

Se registraron los ingresos netos de los 12 últimos meses correspondientes desde febrero 2011 hasta julio 2012. Los ingresos netos de la madera no varían significativamente entre grupos. Sería de esperar que los ingresos del grupo 3 fueran más altos ya que un intermediario no realizaría una operación pequeña. Una de las razones es que los intermediarios compraron pequeñas cantidades a estos productores para poder completar el viaje de un programa. Con respecto al pago que reciben los productores por $\mathrm{m}^{3}$, el grupo 3 es el que menor ingreso recibe con respecto a los otros grupos (cuadro 45).

\subsubsection{Especies y cantidad de madera} Para poder realizar una comparación con los programas de aprovechamiento, se ha tomado la clasificación que tiene el MAE unificando bosques secundarios, rastrojos-realces y áreas silvopastoriles en sistemas agroforestales. El cuadro 46 muestra un estimado de la cantidad vendida por los finqueros en Orellana, la mayor cantidad de madera vendida proviene principalmente del bosque nativo.

\subsection{Hacia un balance sobre el aprovechamiento forestal por finqueros}

En la provincia de Orellana los hogares se caracterizan por tener una mayor extensión de superficie en sus parcelas en comparación con los hogares localizados en la provincia de Napo. Los grupos indígenas de dicha provincia usualmente tienen acceso a una mayor superficie de tierra y bosques con respecto a los indígenas de Napo, lo que puede deberse al hecho de que Napo es una provincia más antigua donde ha habido una mayor fragmentación de las parcelas entre los diferentes miembros del hogar durante el transcurso del tiempo. Como resultado de la fragmentación de las parcelas, el área de bosque secundario y realce es también mayor en la provincia de Napo. El área dedicada a cultivos es similar en ambas provincias, aunque los hogares de familias colonas

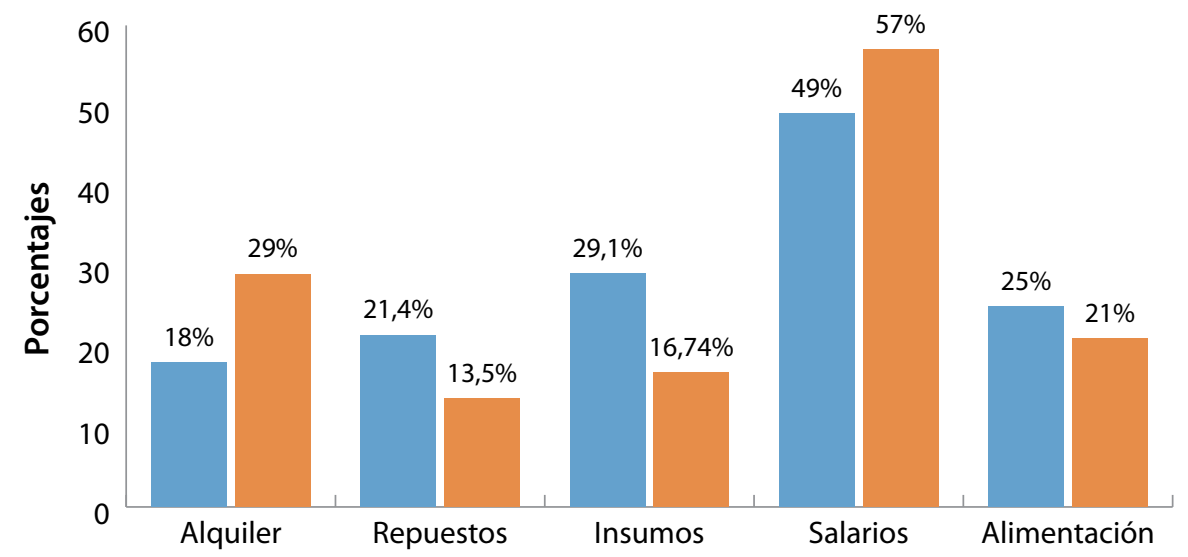

Finquero que extrae por su cuenta (Grupo 1) I Finquero que contrata personal (Grupo 2)

Figura 14. Porcentaje de costos sobre los costos totales en el periodo de febrero 2011 a julio 2012. Basado en encuesta a hogares realizada entre agosto y septiembre de 2012. No se incluyó al grupo 3 porque los finqueros desconocían los gastos realizados. 
Cuadro 45. Costos y beneficios de los pequeños finqueros en el periodo de febrero 2011-julio 2012 (en USD)

\begin{tabular}{|c|c|c|c|}
\hline & \multicolumn{2}{|c|}{ Finquero realiza la extracción } & \multirow{2}{*}{$\begin{array}{l}\text { Intermediario realiza } \\
\text { toda la extracción }\end{array}$} \\
\hline & Por su propia cuenta & Personal contratado & \\
\hline Ingresos brutos & 970 & 2032 & - \\
\hline Costos & 295 & 1090 & - \\
\hline Ingreso neto madera & 675 & 942 & 747 \\
\hline $\begin{array}{l}\text { Ingreso neto madera } / \mathrm{m}^{3} \\
\text { vendido de madera }\end{array}$ & 60 & 49 & 30 \\
\hline
\end{tabular}

Fuente: Elaboración propia basada en encuesta a hogares realizada entre febrero y julio de 2012

\section{Cuadro 46. Aprovechamiento por el tipo de especie y uso de suelos (en $\mathrm{m}^{3}$ )}

\begin{tabular}{lccc}
\hline & Bosques nativos & Sistemas agroforestales & Total \\
\hline Arenillo, Pondo (Erisma uncinatum) $\left(^{*}\right)$ & 178,04 & 9,65 & 187,69 \\
Chuncho, seique, (Cedrelinga catenaiformes) $\left(^{*}\right)$ & 136,54 & 4,80 & 141,34 \\
Doncel, sangre de gallina, (Otoba spp) $\left(^{*}\right)$ & 115,66 & & 115,66 \\
Laurel (Cordia alliodora) $\left(^{*}\right)$ & & 81,57 & 81,57 \\
Chalviande, coco, (Virola spp) & 67,35 & 6,75 & 74,1 \\
Ceiba, ceibo, (Ceiba insignis) & 30,63 & & 30,63 \\
Tamburo, bella María, Juan Colorado (Vochysia spp) $\left(^{*}\right)$ & 36,9 & 4,50 & 41,40 \\
Canelo (Nectandra reticulata) $\left(^{*}\right)$ & 14,12 & 6,94 & 21,06 \\
Colorado, manzano, tucuta, piaste (Guarea Kunthiana) $\left(^{*}\right)$ & 15,75 & & 15,75 \\
Otros & 12,15 & 2,41 & 14,56 \\
Total & 607,14 & 116,62 & $\mathbf{7 2 3 , 7 6}$ \\
Porcentaje & $\mathbf{8 4 \%}$ & $\mathbf{1 6 \%}$ & $\mathbf{1 0 0 \%}$ \\
\hline
\end{tabular}

Nota: Las especies marcadas con * son duras y semiduras, el resto son consideradas blandas.

Fuente: Elaboración propia basada en encuesta a hogares realizada entre febrero y julio de 2012.

tienden a dedicar una mayor superficie a cultivos, principalmente para el establecimiento de pastos.

Entre el 2006 y 2012, un mayor número de hogares ha convertido bosques a usos agrícolas en la provincia de Orellana (86) en comparación con la provincia de Napo (71). Es de esperar que en Orellana exista una mayor presión sobre los bosques nativos ya que en esta provincia los hogares tienen una mayor superficie de bosque nativos que en Napo. En ambas provincias el $64 \%$ de las parcelas desmontadas no fueron intervenidas para la extracción de madera, debido principalmente a la ausencia de especies valiosas, la falta de vías de acceso y la ausencia de compradores. Los desmontes se practican para la implementación de actividades agrícolas y pecuarias que proporcionan los bienes de consumo y contribuyen a la generación de ingresos de las familias de colonos e indígenas.

Los sistemas de producción en las fincas se caracterizan por ser relativamente diversificados, siendo la agricultura la actividad más común practicada por los finqueros. Por lo general, los hogares colonos presentan mayores ingresos monetarios que los hogares indígenas tanto en Orellana como en Napo, siendo estos ingresos más altos en Orellana debido a que los ingresos salariales fuera de la finca son el doble de los obtenidos en Napo. La principal fuente de ingresos en las dos provincias es el trabajo asalariado, que incluye tanto trabajo en otras fincas como contratos laborales fuera de las fincas o del área rural. De los 140 hogares que reciben ingresos por trabajo asalariado, 45 de estos los perciben por 
trabajar como motosierristas, lo que representa el $23 \%$ del total de los ingresos percibidos por salarios.

Entre un $64 \%$ y un $74 \%$ de los hogares entrevistados han recibido ingresos por venta de madera en Napo y Orellana principalmente entre 2004 y 2012, respectivamente. En cambio, en el último año en el cual fueron realizadas las entrevistas, únicamente el 53\% de los hogares entrevistados recibieron ingresos por venta de madera, debido a que no todos los hogares cortaron madera en ese periodo. Esto indica que el aprovechamiento de madera, y los ingresos que se obtienen de esa actividad, es relativamente irregular en el tiempo. En promedio, los ingresos por madera representan el $16 \%$ de los ingresos totales de todos los hogares entrevistados. Este ingreso difiere entre colonos e indígenas para las dos provincias. En Napo la venta de madera es mayor en los hogares colonos respecto a los hogares indígenas. En Orellana, los ingresos provenientes de la venta de madera son iguales para ambos grupos en términos absolutos. Por su parte, los indígenas de Orellana reciben aproximadamente el doble de ingresos por la venta de madera que sus pares de Napo, lo cual puede deberse a las mayores extensiones de bosque a las que estos grupos tienen acceso en Orellana en relación a Napo.

Las especies de mayor comercialización difieren por provincia, ya que Orellana presenta mayor extracción de especies valiosas que Napo según el reporte de la Oficinas Técnicas del MAE para 2011. En Napo las cuatro principales especies son laurel (Cordia alliodora), doncel (Otoba spp), balsa (Ochroma pyramidale) y sande rojo (Brosimun spp). En cambio, en Orellana se destacan el arenillo (Erisma uncinatum), chuncho (Cedrelinga catenaiformes), doncel (Otoba spp) y laurel (Cordia alliodora). En Orellana, la mayoría de aprovechamientos se llevan a cabo en bosques nativos y en Napo el $60 \%$ se realizan en bosques secundarios, áreas agroforestales, áreas silvopastoriles y realces.

Los hogares han implementado por su cuenta actividades de reforestación de especies valiosas para poder ser utilizadas en el futuro. Esto nos muestra por un lado el interés por las pérdidas del bosque y, por otro, que la reforestación probablemente es vista como un complemento a sus otras actividades productivas, lo que nos indica cómo ciertas actividades pueden ser manejadas por los finqueros. Las especies que son de mayor interés para los finqueros son el chuncho (Cedrelinga catenaiformes), caoba/ahuano (Swietenia macrophylla), guayacán (Tabebuia Chrysantha) y cedro (Cedrela odorata), entre otras. Estas son especies valiosas que tienen un mejor precio en el mercado por su madera, siendo ampliamente conocidas por los finqueros tanto en Orellana como en Napo, por lo tanto serían una fuente de ingreso en el futuro para los finqueros.

Para analizar el aprovechamiento y beneficio de los finqueros se procedió a realizar una tipología, que ha sido explicada en detalle anteriormente. Las estrategias utilizadas por los finqueros difieren por provincia. En Napo, el $86 \%$ de los finqueros intervienen o lideran las operaciones de aprovechamiento, mientras que este porcentaje es del $60 \%$ en Orellana. Esto nos indica que el resto es realizado exclusivamente por el intermediario sin que el finquero participe en la extracción, un procedimiento que es más común en Orellana. Esto se puede deber a la existencia de una red de intermediación más fuerte y organizada en Orellana que en Napo. Las características de negociación con los compradores son muy similares en ambas provincias, ya que la mayoría de finqueros vende su madera a través de un pedido de compra y el resto busca un comprador. En Orellana más de la mitad de los finqueros recibieron un adelanto de dinero, mientras que en Napo esta cantidad fue bastante menor. Este dinero contribuye a suplir las carencias de fuentes de financiamiento de los finqueros (cuadro 47). La mayoría de extracciones de madera se llevan a cabo en la propia finca y se venden dentro de la comunidad. Así, el comprador es quién se encarga del transporte de la madera desde la comunidad al mercado final.

Los aprovechamientos de madera sin un programa aprobado son $69 \%$ y $75 \%$ del total de aprovechamientos en Orellana y en Napo respectivamente. En general, los volúmenes de madera vendidos de aprovechamientos con programas aprobados son mayores que aquellos aprovechamientos que se realizan sin un programa aprobado. Una de las diferencias que se encuentra entre las estrategias de aprovechamiento entre provincias es que los intermediarios que realizan los aprovechamientos forestales con finqueros tienden a comprar con mayor frecuencia madera de origen 
Cuadro 47. Información comparativa entre Orellana y Napo

\begin{tabular}{lll}
\hline & Hogares de la provincia Napo & Hogares de la provincia Orellana \\
\hline $\begin{array}{l}\text { ¿Usted buscó al comprador o } \\
\text { recibió un pedido? }\end{array}$ & $56 \%$ se hace con un pedido de compra & $66 \%$ se hace con un pedido de compra \\
$\begin{array}{l}\text { ¿Entre operaciones vende al } \\
\text { mismo o distinto comprador? }\end{array}$ & $75 \%$ vende al mismo comprador & $50 \%$ vende al mismo comprador \\
$\begin{array}{l}\text { ¿Ha recibido dinero adelantado } \\
\text { por la compra de madera? }\end{array}$ & $15 \%$ ha recibido dinero adelantado & $65 \%$ ha recibido dinero adelantado \\
\hline
\end{tabular}

Fuente: Elaboración propia basada en encuesta a hogares realizada entre febrero y septiembre de 2012

informal en Orellana que en Napo, con la finalidad de completar la madera de programas aprobados que no llegaron a extraer el volumen autorizado debido a daños patológicos o mecánicos de los árboles. En Napo, el número de hogares que vende sin un programa de aprovechamiento es mayor en hogares de indígenas que colonos; por el contrario, en Orellana el número de hogares que venden sin un programa es mayor entre colonos en relación a indígenas.

Los gastos más frecuentes incurridos por los finqueros cuando ellos lideran la extracción son salarios, insumos, alquiler de animales, alimentación y repuestos. Los ingresos netos que reciben los finqueros que realizan la operación por su propia cuenta son mayores en Orellana que en Napo. Esto se puede deber a que dentro de este grupo se encuentran más familias indígenas en Napo, las cuales perciben ingresos más bajos que los indígenas de Orellana. Los ingresos netos por volumen de madera vendida en $\mathrm{m}^{3}$ por el grupo de intermediarios que realiza los aprovechamientos son menores en promedio con respecto a los aprovechamientos que los finqueros realizan por su propia cuenta tanto en Napo como en Orellana. Finalmente, se observa que los ingresos netos por $\mathrm{m}^{3}$ en Orellana son mayores que en Napo, esto se puede deber a que hay más maderas finas reportadas en las ventas en Orellana. 


\title{
El aprovechamiento forestal en pequeña escala
}

\author{
Elena Mejía, Guido Fernández, Marco Vinueza y Álvaro Fuentes
}

El aprovechamiento forestal de bosques nativos debe realizarse cumpliendo la normativa forestal vigente, la cual ha sido introducida brevemente en el capítulo 3. Para el aprovechamiento de los bosques nativos, la normativa dispone la implementación de los Programa de Corta y Aprovechamiento en operaciones en pequeña escala, generalmente asociadas a la corta de "madera aserrada" y los planes de conversión legal de la tierra. No obstante, como se ha sugerido en el capítulo 4, una parte importante de los aprovechamientos de madera no se realiza con programas de manejo aprobados.

Un aspecto asociado a los aprovechamientos de madera en pequeña escala consiste en la distribución de beneficios del aprovechamiento entre los diferentes actores que participan de la operación forestal, en especial los pequeños finqueros dueños del bosque. Por un lado, Mederski (2006) y FAO (2012) sugieren que los beneficios económicos obtenidos por los finqueros provenientes de las operaciones de aprovechamiento tienden a reducirse significativamente porque una parte importante es capturada por los intermediarios. Por otro lado, otros autores indican que los intermediarios cumplen un rol importante en el negocio de la madera y sin estos la comercialización sería más dificultosa (Palacios y Malessa, 2010; Vásquez, 2011; Medjibe y Putz, 2012). Estas perspectivas contrapuestas sugieren que se requiere de mejores datos empíricos sobre la distribución de beneficios en situaciones diversas de aprovechamiento forestal en la Amazonía ecuatoriana.

El análisis que aquí se ofrece contribuye a entender mejor la distribución de costos y beneficios según información empírica obtenida mediante el seguimiento de operaciones de aprovechamiento forestal a través de programas formales e informales a pequeña escala en las provincias de Napo y
Orellana. Los resultados obtenidos permiten caracterizar el desempeño económico y productivo de diferentes sistemas de aprovechamiento forestal. Los criterios utilizados para identificar distintos tipos de aprovechamiento se refieren a las modalidades de participación del finquero en estos y si los mismos han sido aprobados formalmente de acuerdo a la normativa forestal vigente.

Fueron seleccionadas un total de ocho comunidades en las provincias de Orellana y Napo para el levantamiento de información sobre el desempeño de las operaciones de aprovechamiento forestal en pequeña escala. Estas comunidades se encuentran localizadas en las carreteras principales pavimentadas y rutas secundarias por donde se moviliza la madera, particularmente en la vía los Aucas, vía los Zorros, vía Loreto, vía Pano, vía Misahuallí y vía Ahuano. En la medida de lo posible se escogieron comunidades donde también se realizó el relevamiento de la información socioeconómica a nivel de fincas analizada en el capítulo 5 de este documento, siguiendo una selección similar de comunidades kichwa, shuar y colonas.

La selección de los casos de estudio se basó en una tipología de cuatro formas diferentes de organización del aprovechamiento de pequeña escala que considera dos criterios básicos: el primero es la forma en la cual intermediarios y finqueros participan del proceso de aprovechamiento $y$, el segundo es si el aprovechamiento cumple con la normativa legal o no. Un total de ocho operaciones de corta han sido seleccionadas para el relevamiento de la información siguiendo la tipología del cuadro 48.

La información se recolectó en fichas prediseñadas y validadas previamente. Aunque la identificación de los casos siguió los criterios mencionados anteriormente, la selección de las operaciones 
Cuadro 48. Tipos identificados y número de casos seleccionadosa

\begin{tabular}{llc}
\hline Tipos & $\begin{array}{l}\text { Organización del aprovechamiento } \\
\text { (Participación de finqueros e intermediarios) }\end{array}$ & No. de casos \\
\hline 1 & El intermediario cubre los costos del PAFSI & 1 \\
& El intermediario cubre los costos del aprovechamiento \\
& El finquero no participa del aprovechamiento & 1 \\
\hline 2 & El intermediario cubre los costos del PAFSI & \\
& El finquero cubre los costos del aprovechamiento & 1 \\
\hline 3 & El finquero participa & 5 \\
\hline 4 & El finquero realiza PAFSI & \\
& El finquero cubre los costos del aprovechamiento & \\
& El finquero no hace uso de PAFSI & \\
\hline
\end{tabular}

Nota: a) La muestra fue de oportunidad debido a que dependió de la voluntad de participar de estos actores.

Fuente: Elaboración propia.

fue de oportunidad puesto que dependió de la voluntad de intermediarios y finqueros para contribuir con información. Las operaciones forestales fueron acompañadas en campo durante un periodo secuencial de seis meses entre marzo y agosto de 2012. El acompañamiento en cada uno de los casos estudiados concluyó cuando la madera fue puesta al borde del camino, que es hasta donde el finquero tiene cierto tipo de participación en el aprovechamiento de madera.

\subsection{Características de las operaciones forestales y sus actores}

Siguiendo la tipología se determinaron tres casos formales (tipo 1, 2, 3) y cinco informales (tipo 4). En general en todas las operaciones se evidenció que los principales limitantes para la corta y acarreo en el bosque son las condiciones climáticas y topográficas. En el cuadro 49 se presentan los ocho casos con sus principales características. A continuación se describen las características de estos casos.

- En el caso formal 1, el aprovechamiento se realizó en una comunidad indígena en donde se negoció un PAFSI con uno de los comuneros, quien decidió no participar de la corta y vender sus árboles en pie, debido a que sostiene otro negocio de venta de licor. En este sentido, el intermediario-maderero empleó personal contratado: dos operarios y tres acarreadores para movilizar la madera al borde de la vía. El transporte terrestre también fue arreglado por el intermediario quien contrató camiones de transporte para ubicar la madera en Coca y posteriormente en Huaquillas.

- En el caso formal 2, el aprovechamiento se realizó en una propiedad individual de un finquero colono. El finquero no participó en absoluto de la corta debido a problemas de salud, por esta razón vendió sus árboles en pie. El intermediario empleó tres operadores y dos acarreadores para el aprovechamiento. El transporte también corrió a cargo del intermediario. Este intermediario proviene de la Costa e inició su negocio como intermediario-transportista, para después encargarse de toda la operación.

- El caso formal 3 fue realizado en una comunidad indígena y liderada totalmente por un finquero cuya principal ocupación es el negocio de la construcción, por esta razón contrató personal esporádico para la corta y acarreo. El finquero realizó la legalización de la corta a través de un asesor forestal del MAE ${ }^{27}$. Igualmente, corrió con los costos de transporte fluvial y terrestre de la madera hasta el destino de venta en la ciudad del Coca.

- El caso informal 1 se realizó en la propiedad individual de una familia indígena, quienes aprovechan madera de manera esporádica debido a que no cuentan con más especies valiosas en sus bosques debido a la práctica de la

27 El Ministerio del Ambiente, para abaratar los costos de los finqueros durante la legalización, creó en 2011 la figura de los asesores forestales. 


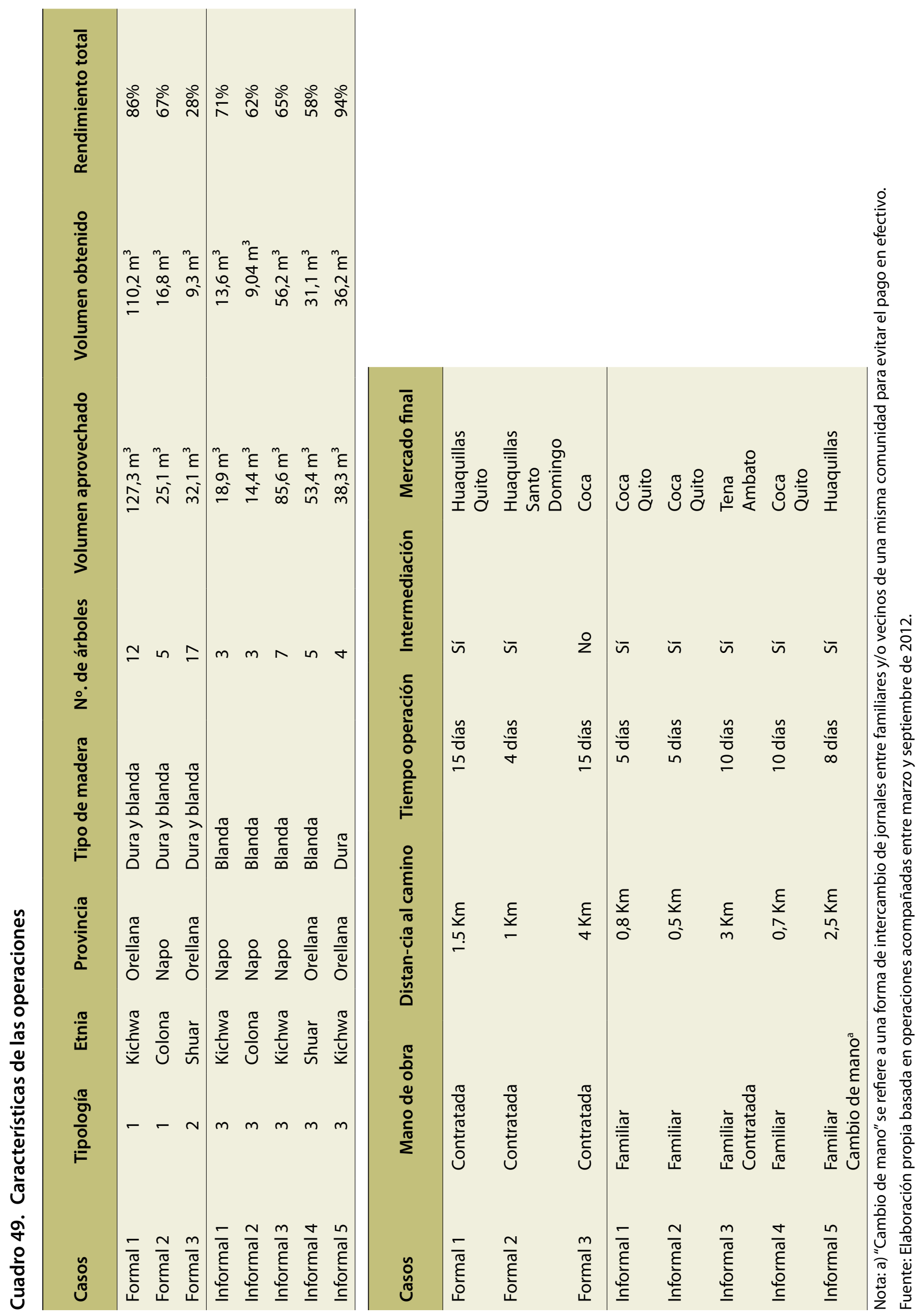


tala selectiva. Los costos de insumos, acarreo y mano de obra fueron absorbidos en su totalidad por el finquero. La madera fue comprada al borde de la vía por un intermediario transportista, quien había realizado un pedido de madera para encofrado.

- El caso informal 2 se realizó en la propiedad individual de una familia colona. La operación fue realizada por el finquero en su predio. Coincide que este finquero también es un intermediario-aserrador de la localidad. Normalmente, cuando el finquero actúa como intermediario corta pequeñas cantidades de madera de otros predios y los vende a un intermediario-transportista. En el caso estudiado, este vendió madera de encofrado para un pedido del mismo intermediario-transportista que compró la madera del caso informal 1.

- El caso informal 3 se llevó a cabo en una propiedad que no tiene acceso por vía terrestre sino únicamente a través del río. Esta familia aprovecha madera constantemente para su venta en un mercado de madera local, este ingreso proporciona efectivo que se utiliza para gastos de educación y víveres. El finquero realizó el aprovechamiento y la corta de madera utilizando mano de obra familiar en especial de su mujer, hijas e hijos. Contrató personal de arrastre (balseros) para transportar la madera río abajo hasta el mercado local de madera, en donde espera cada viernes a diferentes intermediarios-transportistas.

- El caso informal 4 se llevó a cabo en una comunidad indígena en una propiedad individual. El intermediario-transportista que realizó el pedido entregó un adelanto al finquero para la compra de gasolina y repuestos de la motosierra. El finquero realizó el aprovechamiento con la ayuda de su esposa e hijos, pero contrataron acarreadores con mulares para transportar la madera al borde de la vía.

- El caso informal 5 se llevó a cabo en un bosque comunal de una comunidad indígena. El finquero pidió permiso para el aprovechamiento de cuatro árboles de madera dura, para ser vendidos a un intermediario-maderero que realizaba una operación formal en la misma comunidad. La madera de este caso sirvió para completar los volúmenes faltantes en el programa legal, debido a que varios árboles no fueron aprovechables. El finquero aprovechó la madera con insumos administrados por el intermediario, utilizó mano de obra de vecinos y contrató acarreadores para sacar la madera al borde de la vía. El dinero del aprovechamiento fue utilizado para la compra de una motocicleta.

\subsection{Los costos de la legalidad en los programas de aprovechamiento}

Según los datos estimados en los casos de estudio, la decisión sobre realizar un aprovechamiento siguiendo la normativa depende de las conexiones de los finqueros con un intermediario-broker o intermediario-maderero, dependiendo de los destinos de los pedidos. Así mismo, en los casos formales 1 y 2 existió la participación de un intermediario para cubrir los costos de la aprobación de los programas de aprovechamiento. El cuadro 50 muestra estos costos.

Los costos asociados al proceso de legalización del aprovechamiento se dividen en dos grupos. Por una parte están los costos directos relacionados con pagos para cumplir con los requisitos de los Programas de Aprovechamientos Simplificados y de Corta del Ministerio del Ambiente. Por otra parte están los costos indirectos que no constituyen requisitos directos pero son necesarios para la realización de los trámites. En los casos en que los aprovechamientos se realizaron sin programas de aprovechamiento autorizados, los costos de transacción fueron mínimos por el hecho que se evitaron los costos de elaboración de los programas y el intermediario fue quien realizó el contacto directamente en la comunidad. Los costos de transacción incurridos por los intermediarios-madereros son difíciles de cuantificar, aunque el cuadro 50 presenta cifras referenciales.

Se estima que en promedio para legalizar un $\mathrm{m}^{3}$ de madera en la zona de estudio se necesitan entre $12,3 / \mathrm{m}^{3}$ y $6,8 / \mathrm{m}^{3}$ USD dependiendo el volumen de corta (cuadro 51). Estas estimaciones sugieren que los costos para legalizar los aprovechamientos tienden a ser más reducidos a medida que los volúmenes de madera aprovechada aumentan. Según los intermediarios entrevistados en el estudio detallado en el capítulo 3, esto hace que se prefieran aprovechamientos legales de al menos $100 \mathrm{~m}^{3} /$ madera aserrada. 
Cuadro 50. Costos asociados a la legalización de la madera en USD.

\begin{tabular}{lll}
\hline $\begin{array}{l}\text { Requisitos asociados a la aprobación de } \\
\text { un PAFSI }\end{array}$ & Costos directos & $\begin{array}{l}\text { Costos indirectos } \\
\text { (de transacción) }\end{array}$ \\
\hline Registro del predio & $\begin{array}{l}\text { 0,06 USD por hectárea } \\
10 \text { USD Trámites registro } \\
\text { propiedad } \\
10 \text { USD Trámites ante } \\
\text { notario }\end{array}$ & $\begin{array}{l}50 \text { USD Pago comunidad } \\
5 \text { USD Transporte } \\
10-15 \text { USD Pago jornal } \\
10 \text { USD Pago por ayuda e impresión } \\
15 \text { USD Trámites de RUC }\end{array}$ \\
\hline Registro del ejecutor & 50 USD (primera vez) & $\begin{array}{l}50 \text { USD Pago ejecutor } \\
\text { 5 USD Transporte } \\
10-15 \text { USD Pago jornal } \\
10 \text { USD Pago por ayuda e impresión } \\
15 \text { USD Trámites de RUC }\end{array}$ \\
\hline Inventario forestal & & $10-15$ USD Pago jornal \\
\hline Pago pie de monte/m $\mathrm{m}^{3}$ & & \\
\hline Pago regente $/ \mathrm{m}^{3}$ & 25 a 50 USD/día regente & \\
\hline Pago certificado cumplimiento de obligaciones & 5 USD & \\
\hline Total primera vez & 125 USD & 190 USD \\
\hline Total segunda vez & 35 USD & 150 USD \\
\hline
\end{tabular}

Nota: a) Se refiere a los costos indirectos para la realización de los trámites en el MAE, b) El pago al ejecutor se realiza cuando los intermediarios han sido sancionados y recurren a terceros para legalizar sus programas de aprovechamiento, c) La segunda vez se refiere a permisos donde el ejecutor está registrado y posee RUC, asimismo el propietario posee RUC o RISE.

Fuente: Elaboración propia basada en entrevistas realizadas entre marzo y septiembre de 2012.

Cuadro 51. Costos de legalización en zona de estudio para diferentes volúmenes de madera aprovechada.

\begin{tabular}{lcccccc}
\hline Volumen & Costos directos & Costos indirectos & Pie de monte & Regencia & Total & USD $/ \mathrm{m}^{3}$ \\
\hline $50 \mathrm{~m}^{3}$ & 125 & 190 & 150 & 150 & 615 & 12,3 \\
$100 \mathrm{~m}^{3}$ & 125 & 190 & 300 & 300 & 915 & 9,1 \\
$200 \mathrm{~m}^{3}$ & 125 & 215 & 600 & 600 & 1540 & 7,7 \\
$400 \mathrm{~m}^{3}$ & 125 & 215 & 1200 & 1200 & 2740 & 6,8 \\
\hline
\end{tabular}

Fuente: Elaboración propia basada en entrevistas realizadas entre marzo y septiembre de 2012.

\subsection{Decisiones de aprovechamiento, productividad y calidad de la madera}

Las decisiones de los finqueros para aprovechar un árbol fueron discutidas con ellos durante el levantamiento de los datos. En el caso de los aprovechamientos formales estas decisiones son normalmente realizadas por el regente o técnico forestal, quien es el encargado de marcar los árboles a ser aprobados. En el caso de los aprovechamientos informales, o que se realizan sin autorizaciones formales de aprovechamiento, esta decisión recae en el mismo finquero y a veces en el aserrador. El principal parámetro que usualmente se utiliza es que el árbol seleccionado pueda proveer al menos 15 tablones simples (aproximadamente $0,5 \mathrm{~m}^{3}$ ). Aunque esta regla fue observada en los cinco casos escogidos con aprovechamiento informal, esto no quiere decir que se aprovechen solo árboles de este volumen, sino que más bien éste constituye el criterio para definir el mínimo de corta. En el cuadro 49 se presenta el promedio de volumen aprovechado en los casos analizados. El criterio mencionado implica el supuesto que al menos este número de piezas por árbol logrará cubrir los costos asociados a la corta y dejarán un beneficio al finquero. 
Existen otros factores que determinan los volúmenes y especies a ser extraídos, que tienen que ver con la calidad de la madera. Según los intermediarios entrevistados durante los aprovechamientos en el bosque, existen mercados como los de Huaquillas, Quito y Guayaquil que demandan madera de buena calidad, que no tiene que presentar ningún defecto mecánico ni patológico. Además la madera debe estar bien dimensionada según los requerimientos del comprador. Estas exigencias se deben posiblemente al hecho que una parte de la madera enviada a Huaquillas es vendida fuera del país (recuadro 3 del capítulo 4) y que la madera de chuncho que se comercializa en Guayaquil se destina en su mayoría a la exportación después de ser transformada en puertas (Ministerio del Ambiente del Ecuador, 2011).

Los finqueros o aserradores prestan especial atención durante la corta y el aserrado cuando se trata de especies más valiosas como el caso del manzano fino, chuncho y arenillo, para evitar dańos y cortes incorrectos, así mismo rechazan trozas con defectos patológicos o con "ojos" 28 que restan el valor a la madera. Estas últimas son también aprovechadas aunque su valor comercial es menor y son consideradas de calidad media siempre y cuando correspondan a especies duras. Entre aserradores contratados y finqueros que realizan la corta, son los segundos quienes prefieren aprovechar al máximo las trozas "defectuosas", diversificando la venta con diferentes intermediarios, lo que únicamente ocurre cuando se trata de especies de valor comercial.

En el aserrío con motosierra se observó mayor desperdicio en operaciones formales que informales. La diferencia entre ambas se relaciona con el tiempo invertido en la corta y la selección de trozas. En las primeras se demoró en promedio un día y medio por árbol de madera blanda y dos días en un árbol de madera dura, siendo las cortas realizadas por aserradores y finqueros con experiencia. En el segundo caso, cuando se trata de aprovechamientos sin programas autorizados o informales, el aprovechamiento suele tardar más, cortándose en promedio un árbol de madera blanda en cuatro días y un árbol de madera dura en cinco días. Generalmente, durante los aprovechamientos informales los finqueros no

28 Se conoce como "ojos" a los huecos naturales del duramen. dedican todo su tiempo al aprovechamiento forestal, sino que también trabajan en otras actividades en sus fincas.

En el aprovechamiento con motosierras existe un debate referente a la eficiencia en el uso de motosierras para el aprovechamiento de madera (recuadro 4). Por lo general se considera, aunque con poca evidencia empírica, que su rendimiento es relativamente bajo y llevaría a menores ganancias para los finqueros (Vásquez, 2011; Vinueza, 2012). Además se sostiene que los aprovechamientos de gran escala de madera rolliza llevarían a desperdicios menores que los de pequeña escala que, en la mayoría de los casos, asierran la madera con motosierra dentro del bosque. Sin embargo, los datos analizados en este estudio sobre los árboles que presentaron desperdicio tanto en troza como aserrado $(n=23)$ muestran que el desperdicio por aserrado es menor que el desperdicio de trozas que no fueron aprovechadas debido a malformaciones patológicas o mecánicas. Existe una clara diferencia entre el aprovechamiento de tablas frente a tablones simples, siendo las primeras las que presentan mayores desperdicios en el aserrado (cuadro 52).

En cuanto a los porcentajes de rendimiento se puede apreciar que existen variaciones entre especies y es difícil evidenciar una tendencia, tal como muestra el cuadro 53. Estos rendimientos, como ya se mencionó, varían según el producto a aprovechar.

\subsection{Los costos y beneficios del aprovechamiento en pequeña escala}

Es difícil determinar los costos y beneficios para los aprovechamientos en pequeña escala debido a que distintos factores hacen que los costos fijos de estos aprovechamientos presenten una variación relativamente grande y estén asociados a condiciones específicas de cada aprovechamiento vinculadas a distancias a mercados, participación del finquero, tipo de mano de obra, distancia a la finca y especies disponibles, entre otros factores. Cada uno de los casos seleccionados tiene características únicas, lo que limita la posibilidad de establecer tendencias claras en cuanto a los costos y beneficios de estas operaciones.

Es importante resaltar que la variabilidad de los costos es relativamente alta para las diferentes 


\section{Recuadro 4. Los aserradores en el aprovechamiento de la madera}

Marco Vinueza, Santiago Alarcón y Amanda Onofa

En el único censo de aserraderos, industrias y depósitos de madera, efectuado por la Dirección Nacional Forestal en los años 1982 - 83, consta que entonces existían más de 500 aserraderos circulares, los mismos que paulatinamente fueron desplazados por las motosierras, que es la herramienta con la que se procesa la mayor cantidad de madera aserrada en el Ecuador (Vásquez, 2011). En tal sentido existe el paradigma que el uso de motosierras ejerce mayor presión sobre los bosques nativos que los aprovechamientos de gran escala mecanizados (ITTO, 2004; Barrantes, 2006; Viteri, 2010). En los últimos años la Amazonía se ha convertido en una de las principales fuentes de extracción de madera aserrada. La motosierra es utilizada no solo para el corte y troceado, sino además en el aserrado de madera dimensionada para consumo personal o para el ingreso a la cadena de producción. Un aserrador gana unos 40 USD por día, con 25 tablones simples aserrados ( $1 \mathrm{~m}^{3} /$ día), por un periodo de unos 21 días seguidos, dependiendo de la lejanía del bosque, el número de árboles y el estatus de legalidad. En los casos en los que son contratados por día de trabajo y no por número de piezas obtenidas, estos perciben un salario diario de 25 a 35 USD. Esto está por encima del salario básico del país, lo que lo hace atractiva esta actividad. Los aserradores tienden a renovar sus máquinas compradas a plazos en comercios locales en Puyo, Tena y Coca, siendo la tendencia a tener máquinas más pequeñas y con motores más rápidos, lo que permite cortar piezas de mejor calidad. En general, los aserradores piensan que su profesión no cuenta con la capacitación necesaria para mejorar los estándares de trabajo; en este sentido, existen aserradores que son conocidos como "profesionales" cuando dominan el corte de las piezas, desperdician menos madera y trabajan con rapidez, estos son los más cotizados para trabajar en envíos a mercados que demandan calidad como Quito, Guayaquil y Huaquillas.

\section{Cuadro 52. Diferencias entre promedios de desperdicios de troza y aserrado}

\begin{tabular}{lcc}
$\mathbf{n = 2 3}$ árboles & Promedio desperdicio troza con malformaciones $\mathbf{~ m}^{\mathbf{3}}$ & Promedio desperdicio aserrado $\mathbf{m}^{\mathbf{3}}$ \\
\hline Tablas & 3,48 & 2,95 \\
Tablón simple & 2,19 & 0,35 \\
\hline
\end{tabular}

Fuente: Elaboración propia basada en operaciones acompañadas entre marzo y septiembre de 2012.

operaciones forestales debido a las diversas dimensiones de los distintos productos que se obtienen. Para facilitar la comparación, los valores obtenidos se presentan en $\mathrm{m}^{3} \mathrm{y}$ en unidades de tabla, tablón simple y tablón doble (cuadro 55).

Tres son los factores variables que generalmente tienen una incidencia mayor sobre los costos y beneficios de los aprovechamientos de pequeña escala, entre ellos: 1) la participación del finquero en el aserrío, 2) la distancia promedio al camino y 3) el tipo de madera (dura o blanda) que es aprovechada. Estos factores inciden principalmente en los costos de mano de obra e insumos (cuadro 49).

El cuadro 54 muestra las diferencias en costos e ingresos entre especies blandas, semiduras y duras que fueron aprovechadas en las ocho operaciones forestales estudiadas. Las especies duras como manzano, chuncho, arenillo y copal son las que generan mayores ingresos por metro cúbico, estás especies fueron comercializadas en los mercados de Huaquillas y Quito. Las especies blandas como el doncel, guarango, sapote, ceibo y tamburo tienen valores menores, pero se comercializan bien en los mercados locales y externos como el de Ambato y Quito, especialmente en el sector de la construcción.

\subsubsection{Costos de las operaciones}

Los costos mayores corresponden a la mano de obra y los menores son los dedicados a pagar por los trámites de legalización del aprovechamiento e insumos. Sin embargo, estos últimos constituyen los principales limitantes de las operaciones formales para los pequeños productores debido a que, dichos planes, demandan un volumen de corta mayor para minimizar los costos por $\mathrm{m}^{3}$, como ya se indicó en el cuadro 50 de este capítulo. 
Cuadro 53. Rendimiento promedio en especies estudiadas

\begin{tabular}{|c|c|c|c|}
\hline Especie & $\begin{array}{l}\text { Volumen inicial } \\
\mathrm{m}^{3}\end{array}$ & $\begin{array}{l}\text { Volumen final } \\
\mathrm{m}^{3}\end{array}$ & Rendimiento \\
\hline Arenillo (Erisma uncinatum) $\left(^{*}\right)$ & 12,80 & 11,50 & $89,9 \%$ \\
\hline Cagua panela (Nectandra sp) $\left(^{*}\right)$ & 1,81 & 0,15 & $8,4 \%$ \\
\hline Canelo (Ocotea spp) & 2,30 & 0,78 & $33,8 \%$ \\
\hline Ceibo (Ceiba insignis) & 13,03 & 7,76 & $59,6 \%$ \\
\hline Chuncho (Cedrelinga catenaiformes) $(*)$ & 4,29 & 3,88 & $90,6 \%$ \\
\hline Coco (Virola spp) & 1,21 & 0,36 & $29,7 \%$ \\
\hline Copal (Dacryodes peruviana) & 10,30 & 6,66 & $64,6 \%$ \\
\hline Cruz caspi (Mauriri sp) & 1,69 & 0,21 & $12,4 \%$ \\
\hline Cuero de sapo (Parinari sp) & 1,82 & 1,75 & $96,0 \%$ \\
\hline Doncel (Otoba spp) & 6,99 & 6,34 & $90,7 \%$ \\
\hline Guarango (Acacia glomerosa) & 3,56 & 1,56 & $43,9 \%$ \\
\hline Guayabillo (Terminalia oblonga) & 3,50 & 1,89 & $54,0 \%$ \\
\hline Guayacán (Tabebuia guayacan) (*) & 4,19 & 0,72 & $17,2 \%$ \\
\hline Manzano fino (Guarea Kunthiana) $\left(^{*}\right)$ & 10,75 & 9,06 & $84,2 \%$ \\
\hline Mascarey (Hyeronima sp) & 7,69 & 2,47 & $32,1 \%$ \\
\hline Peine de mono (Apeiba membranácea) & 0,85 & 0,70 & $81,7 \%$ \\
\hline Pigue (Pollalesta discolor) & 1,08 & 0,99 & $91,1 \%$ \\
\hline Sande (Brosimun sp) & 11,25 & 5,34 & $47,5 \%$ \\
\hline Sangre (Otoba sp) & 2,53 & 0,26 & $10,4 \%$ \\
\hline Sapote (Sterculia sp) & 9,67 & 6,21 & $64,2 \%$ \\
\hline Tamburo (Vochysia spp) & 9,57 & 9,12 & $95,4 \%$ \\
\hline
\end{tabular}

Nota: Todas las especies marcadas con $\left(^{*}\right)$ son reconocidas como especies duras o de mayor valor comercial.

Fuente: Elaboración propia con base en operaciones acompañadas entre marzo y septiembre de 2012.

Por otro lado, en los aprovechamientos informales, los costos de mano de obra se convierten en un factor determinante para la corta de mayores volúmenes, en este sentido la operación informal con mayor número de árboles observada fue 15 árboles ${ }^{29}$, realizada por un intermediario-aserrador. Sin embargo, la tendencia de los casos analizados muestra que los aprovechamientos informales presentan en promedio 3 árboles/operación corta.

Es interesante destacar que, en las entrevistas realizadas a los finqueros, la mano de obra utilizada para el acarreo es considerada la más costosa. Para evitar este costo, especialmente en

29 Este aprovechamiento informal no fue analizado en este estudio debido a que al momento de realizar la visita de campo la madera ya había sido aprovechada y transportada; sin embargo, el propietario explicó sobre la corta. los aprovechamientos informales, las mujeres participan más activamente en las operaciones de aprovechamiento forestal, particularmente en las familias kichwas (Recuadro 5).

\subsubsection{Distribución de ingresos entre finqueros e intermediarios}

Los ingresos de los intermediarios son mayores que los de los finqueros, independientemente de si las operaciones forestales cuentan con autorización formal o no. En los casos formal 1 e informal 4, los costos son mayores que los ingresos de los finqueros. En el primer caso, los costos más altos no representaron una pérdida para el finquero debido a que estos fueron absorbidos en su totalidad por el intermediario, quien pagó el árbol en pie al finquero. En el segundo caso, sin embargo, el finquero perdió dinero debido a varios factores, entre ellos las especies seleccionadas 
Cuadro 54. Costos y precios de venta promedio de especies aprovechadas (en USD $/ \mathrm{m}^{3}$ )

\begin{tabular}{|c|c|c|c|c|}
\hline \multirow{2}{*}{ Especies $^{\mathrm{a}}$} & \multicolumn{2}{|c|}{$\begin{array}{c}\text { Con autorización (promedio } \\
\text { con base en } 3 \text { casos) }\end{array}$} & \multicolumn{2}{|c|}{$\begin{array}{c}\text { Sin autorización (promedio con } \\
\text { base en } 5 \text { casos) }\end{array}$} \\
\hline & Costos $\mathrm{m}^{3}$ & $\begin{array}{l}\text { Precios al borde } \\
\text { del camino }\end{array}$ & Costos $\mathrm{m}^{3}$ & $\begin{array}{l}\text { Precios al borde } \\
\text { del camino }\end{array}$ \\
\hline Arenillo (Erisma uncinatum) $\left(^{*}\right.$ ) & 47 & 40 & 49 & 140 \\
\hline Cagua panela (Nectandra sp) $(*)$ & 106 & 64 & & \\
\hline Canelo (Ocotea spp) & 96 & 192 & & \\
\hline Ceibo (Ceiba insignis) & 44 & 67 & 32 & 53 \\
\hline Chuncho (Cedrelinga catenaiformes) (*) & 76 & 133 & 75 & 192 \\
\hline Coco(Virola spp) & 101 & 64 & & \\
\hline Copal (Dacryodes peruviana) & & & 13 & 40 \\
\hline Cruz caspi (Mauriri sp) & 139 & 64 & & \\
\hline Cuero de sapo (Parinari sp) & 128 & 64 & & \\
\hline Doncel (Otoba spp) & 38 & 50 & 54 & 58 \\
\hline Guayabillo (Terminalia oblonga) & 90 & 70 & 34 & 40 \\
\hline Guarango (Acacia glomerosa) & 45 & 50 & & \\
\hline Guayacán (Tabebuia guayacan) (*) & 82 & 256 & & \\
\hline Manzano fino (Guarea Kunthiana) $\left(^{*}\right)$ & & & 21 & 168 \\
\hline Mascarey (Hyeronima sp) & & & 41 & 20 \\
\hline Peine de mono (Apeiba membranácea) & 99 & 64 & & \\
\hline Pigüe (Pollalesta discolor) & & & 32 & 60 \\
\hline Sande (Brosimun sp) & 104 & 64 & 33 & 61 \\
\hline Sangre (Otoba sp) & 51 & 36 & & \\
\hline
\end{tabular}

Nota: a) Estas especies corresponden a las más representativas encontradas en los casos analizados; muchas se repiten, por lo cual se escogió un promedio; b) Ingresos de venta sugeridos por el intermediario, regente o transportista según destino final de la madera. Todas las especies marcadas con $\left(^{*}\right)$ son reconocidas como especies duras o de mayor valor comercial.

Fuente: Elaboración propia basada en entrevistas realizadas entre marzo y agosto de 2012

(blandas) y el alto costo de mano de obra y acarreo debido a la lejanía del bosque aprovechado a la vía principal (cuadro 49).

En los ochos casos no existe suficiente información para establecer que los casos formales representan mayor ingreso por $\mathrm{m}^{3}$ para el finquero en comparación con los casos informales. Los mayores ingresos están más estrechamente ligados con las especies que son aprovechadas, puesto que las especies duras significan mayores ingresos, tal como lo indican los cuadros 54 y 55 . En ese sentido, los finqueros están condicionados, por una parte, por la calidad del bosque que poseen y, por otra parte, por los pedidos de los intermediarios que suelen especificar las especies solicitadas.
En general, en los casos analizados, los productores e intermediarios reciben un ingreso económico mayor a sus costos totales por operación. En los casos de aprovechamiento autorizados el intermediario recibe beneficios de entre el 50\% al $110 \%$ del valor invertido por $\mathrm{m}^{3}$. Como se ha discutido anteriormente, los beneficios también dependen de las especies aprovechadas y la participación del finquero en el aprovechamiento. Normalmente los aprovechamientos formales tienden a enfocarse en la extracción de maderas duras o una combinación de duras, semiduras y blandas. Según los intermediarios, realizar un programa de aprovechamiento formal para maderas blandas no es beneficioso. 
Cuadro 55. Costos y precios de venta promedio de especies aprovechadas para los casos de estudio (en USD/producto)

\begin{tabular}{|c|c|c|c|c|c|c|}
\hline & \multicolumn{3}{|c|}{ Con autorización ${ }^{\mathrm{a}}$} & \multicolumn{3}{|c|}{ Sin autorización ${ }^{b}$} \\
\hline & $\begin{array}{l}\text { Ingresos } \\
\text { finqueros }\end{array}$ & $\begin{array}{l}\text { Costos } \\
\text { unidad }\end{array}$ & $\begin{array}{l}\text { Beneficio } \\
\text { neto }\end{array}$ & $\begin{array}{l}\text { Ingresos } \\
\text { finqueros }\end{array}$ & $\begin{array}{l}\text { Costos } \\
\text { unidad }\end{array}$ & $\begin{array}{c}\text { Beneficio } \\
\text { neto }\end{array}$ \\
\hline \multicolumn{7}{|l|}{ Tablac } \\
\hline Arenillo & & & & 2,6 & 1 & 1,6 \\
\hline Ceibo & 0,8 & 0,5 & 0,3 & 0,8 & 0,5 & 0,3 \\
\hline Doncel & & & & 1,1 & 1,4 & $-0,3$ \\
\hline Guarango & 0,6 & 0,9 & 0,3 & 0,6 & 0,5 & 0,1 \\
\hline Sapote & & & & 1 & 0,6 & 0,4 \\
\hline \multicolumn{7}{|l|}{ Tablón simple ${ }^{d}$} \\
\hline Manzano fino & & & & 4,3 & 0,9 & 3,4 \\
\hline Chuncho & 6 & 2,4 & 3,6 & & & \\
\hline Arenillo & 2 & 2,3 & $-0,3$ & & & \\
\hline Guayacán & 8 & 2,6 & 5,4 & & & \\
\hline Canelo & 8 & 3 & 5 & & & \\
\hline Tamburo & 1,8 & 2,5 & $-0,7$ & & & \\
\hline Cuero de sapo & 2 & 4,0 & -2 & & & \\
\hline Cagua panela & 2 & 3,3 & $-1,3$ & & & \\
\hline Cruz caspi & 2 & 4,3 & $-2,3$ & & & \\
\hline Guabillo & 2 & 3,2 & $-1,2$ & & & \\
\hline Peine de mono & 2 & 3,1 & $-1,1$ & & & \\
\hline Sande & & & 0 & 0,5 & 1,6 & $-1,1$ \\
\hline Coco & 2 & 3,2 & $-1,2$ & & & 0 \\
\hline Copal & 1,2 & 2,6 & $-1,4$ & 1,2 & 0,4 & 0,8 \\
\hline Sapote & 2 & 3,2 & $-1,2$ & 1,2 & 0,5 & 0,7 \\
\hline Guarango & 2,5 & 3,1 & $-0,6$ & & & 0 \\
\hline Doncel & 2 & 1,9 & 0,1 & 1,2 & 0,5 & 0,7 \\
\hline Mascarey & & & & 1 & 2 & -1 \\
\hline \multicolumn{7}{|l|}{ Tablón doble ${ }^{e}$} \\
\hline Chuncho & 8 & 4,5 & 3,5 & & & \\
\hline Guayabillo & 1,8 & 2,7 & $-0,9$ & & & \\
\hline
\end{tabular}

Nota: a) Intermediario absorbe los costos de producción, b) Finquero absorbe los costos de producción, c) Madera dimensionadas en 2,4 $\mathrm{m} \times 0,25 \mathrm{~m} \times 0,025 \mathrm{~m}$, y $4 \mathrm{~m} \times 0,25 \mathrm{~m} \times 0,025$, d) Madera dimensionada en 2,4 $\mathrm{m} \times 0,25 \mathrm{~m} \times 0,5 \mathrm{~m}, \mathrm{y} 4 \mathrm{~m} \times$ $0,25 \mathrm{~m} \times 0,5$, e) Madera dimensionada en 2,4 $\mathrm{m} \times 0,25 \mathrm{~m} \times 0,10 \mathrm{~m}$.

Fuente: Elaboración propia basada en entrevistas realizadas entre marzo y agosto de 2012

En el caso formal en el que el finquero no participó de la extracción de la madera (caso formal 1) sus beneficios fueron un 30\% menores que si hubiera participado del aserrío, así lo demuestran los ingresos detallados por caso en la figura 15. En este sentido, la participación del finquero en el aserrío eleva el pago por la madera, debido a que esta se vende en piezas con un valor agregado dado por la mano de obra utilizada por el finquero y no sólo como madera en pie.

\subsubsection{Análisis de la distribución de beneficios entre actores del aprovechamiento}

En esta sección se detallan únicamente los beneficios que reciben los actores que participan 


\section{Recuadro 5. Participación de la mujer en actividades de aprovechamiento forestal: La mano de obra invisible en el caso de las mujeres kichwas}

Elena Mejía, Liliana Vásquez.

Una de las principales políticas propuestas en el Plan Nacional del Bien Vivir del Ecuador es garantizar la igualdad de condiciones y oportunidades para la plena participación de las mujeres, en especial en el acceso a los recursos naturales (Núñez, 2009; SENPLADES, 2009). En Ecuador, casi las tres cuartas partes (74\%) de las personas productoras y dueñas de las unidades de producción son hombres, aunque las mujeres constituyen el $42 \%$ de la población activa agrícola (III Censo Agropecuario Nacional, 2000, INEC). El 18,6\% de los hogares rurales está bajo responsabilidad económica exclusiva de mujeres. Las mujeres del campo son responsables del cultivo de gran parte de los alimentos y suelen compaginar sus tareas productivas en las fincas o negocios familiares con el cuidado de sus familias; y su contribución, además de no ser remunerada, es poco visible (FENOCIN; CNC, 2012; Nino, 2010).

En febrero y marzo de 2013 se realizaron 20 entrevistas a mujeres y 10 entrevistas a hombres, en cinco comunidades kichwas en las que se realizó el acompañamiento a las operaciones de corta, con el fin de entender mejor el acceso de estas mujeres a la tenencia de la tierra y las decisiones sobre el uso del bosque así como la distribución de los ingresos provenientes de la madera. Los resultados indican que las mujeres kichwas participan en el proceso de extracción de madera en forma conjunta con los hombres, sus actividades varían entre cocinar y llevar los alimentos al bosque, hasta acarrear en hombros tablas y tablones, acarrear mulares, ayudar en el trazado y delimitación de los cortes en los troncos y acarreo de materiales. Las mujeres no reciben una compensación por la ayuda en la actividad forestal y tampoco participan de la venta de madera, ni de la negociación con el intermediario. Los hombres consideran indispensable la ayuda de las mujeres, debido a que es una forma de reducir gastos en el pago de personal adicional para el aprovechamiento de madera, especialmente en cortas informales. El acceso al bosque y su aprovechamiento es similar entre ambos géneros, los productos sin embargo son diferenciados. La madera es masculina mientras que los cultivos anuales como yuca y plátano son femeninos, los cultivos perennes como el cacao son de ambos géneros. El conocimiento de la propiedad es igual entre géneros y generaciones, es decir que tanto hombres y mujeres de diferentes edades conoces los activos de sus bosques y chacras. No obstante, la tenencia de tierras presenta niveles análogos entre los dos géneros; las mujeres kichwas esperan tener acceso a la tierra de sus esposos, pero en las cinco comunidades visitadas las mujeres estaban adquiriendo derecho a la titularidad por herencia de sus padres o por ser viudas. En las zonas de estudio se observó que la tenencia de la tierra está asociada al manejo del bosque para aprovechamiento y comercialización.

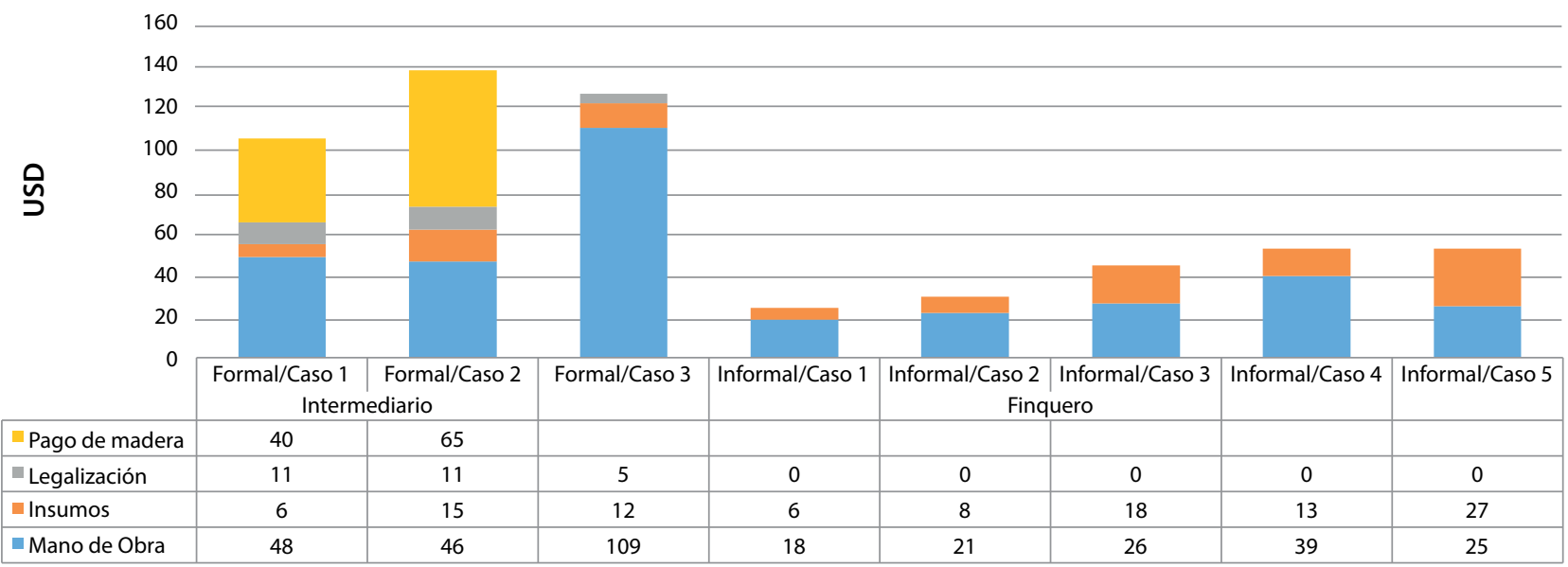

Figura 15. Distribución de costos por metro cúbico según principales ítems y participación del finquero, para 8 estudios de caso de aprovechamiento forestal en pequeña escala con y sin PAFSI (en USD). Basado en información de entrevistas realizadas entre marzo y agosto de 2012. 
del aprovechamiento. Además de los finqueros e intermediaros, se incluyen también los acarreadores $\mathrm{y}$ aserradores En la figura 16 se puede apreciar que son los intermediarios quienes obtienen beneficios mayores, independientemente de si los aprovechamientos cuentan con una autorización formal o no, o la participación del finquero en la corta, algo que también se evidencia en la figura 17. A diferencia del análisis de ingresos, los beneficios muestran la ganancia neta que recibe cada actor después de descontar los costos relacionados con su actividad. Por ejemplo, en el caso de aserradores se incluyen los costos de reparación y cambio de cadena durante el aprovechamiento. Usualmente estos últimos perciben ganancias moderadas de la corta de árboles a pesar de la idea bastante extendida de que ellos son quienes más se benefician de la corta. Por consiguiente, es importante distinguir al intermediario-aserrador del simple aserrador.

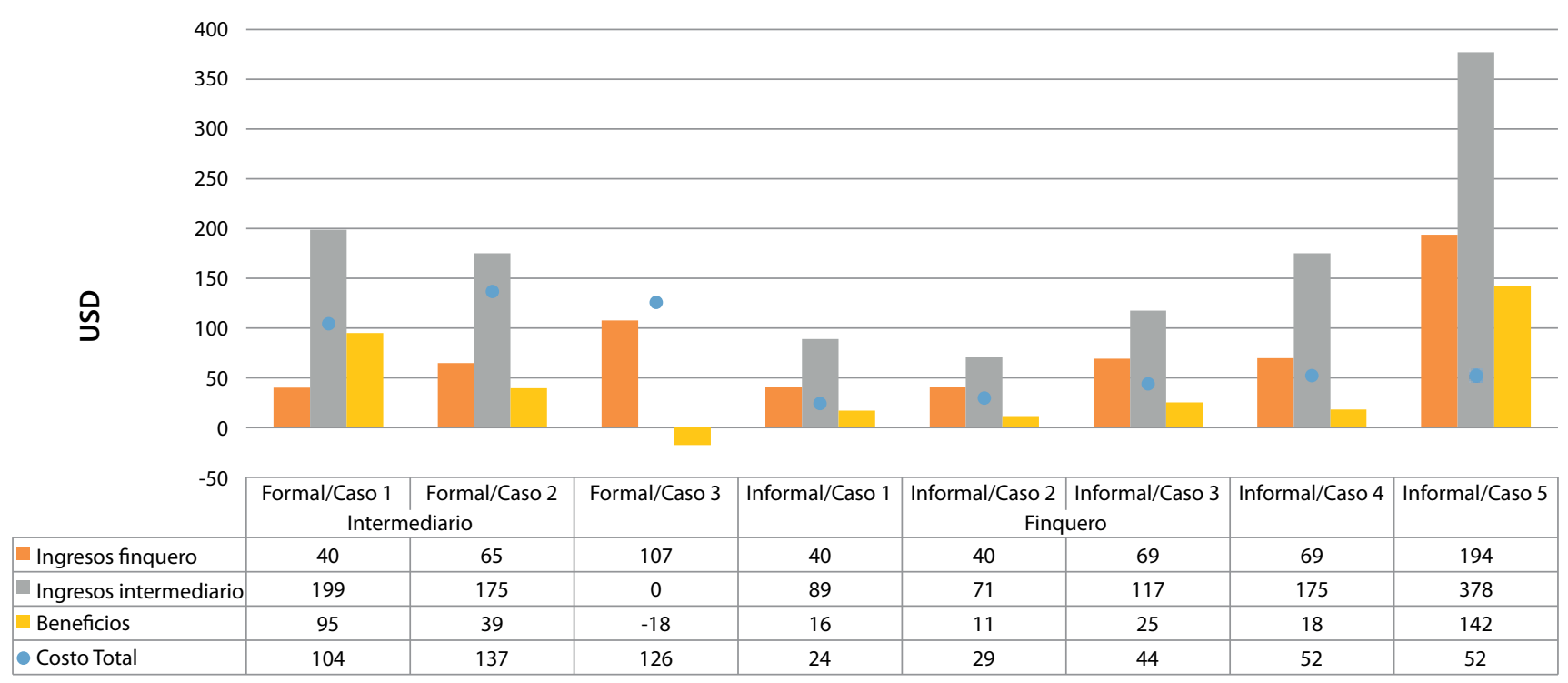

Figura 16. Diferencia de ingresos y costos entre operaciones artesanales formales e informales con intervención del finquero o intermediario $\left(\mathrm{USD} / \mathrm{m}^{3}\right)$. Elaboración propia basada en información de campo recolectada entre marzo y agosto de 2012.

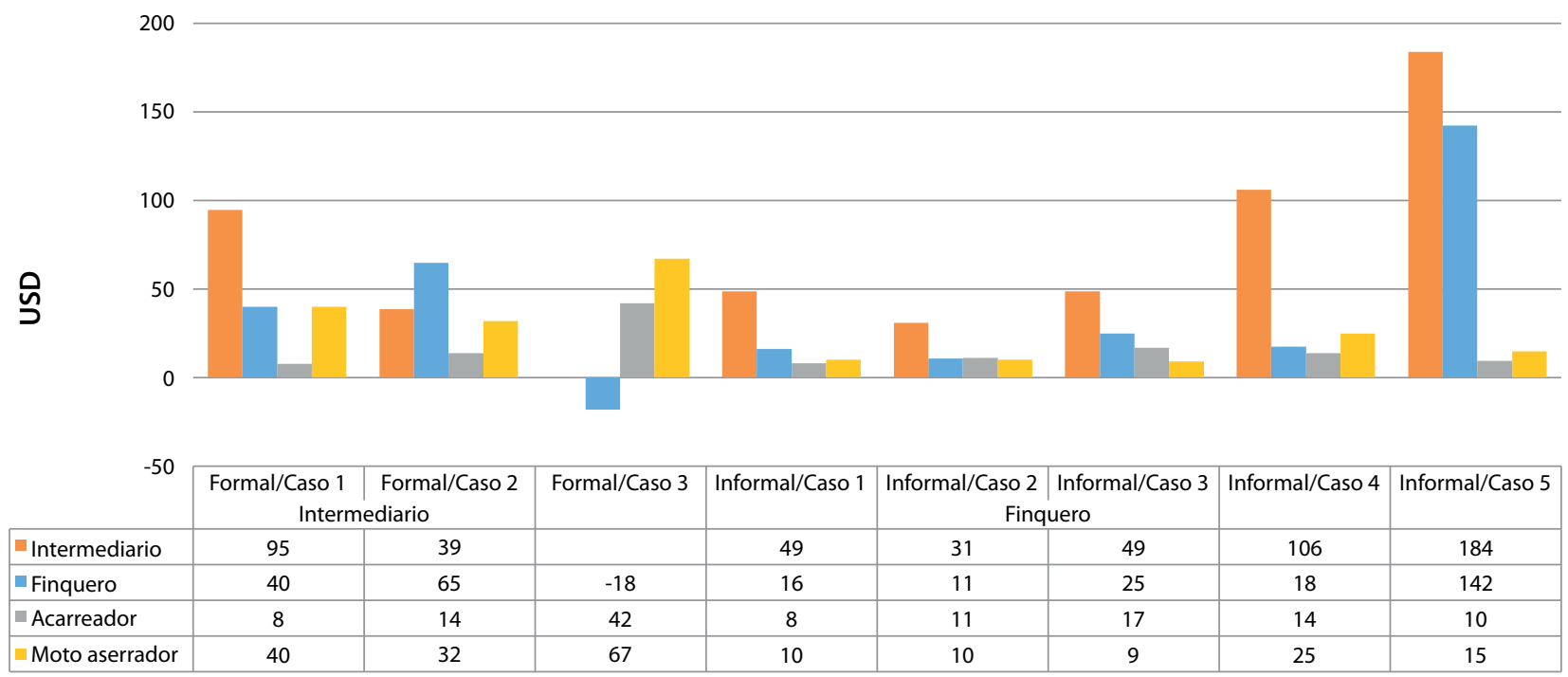

Figura 17. Distribución de beneficios entre los actores del aprovechamiento (USD $\left./ \mathrm{m}^{3}\right)$. Elaboración propia basada en información de campo recolectada entre marzo y agosto de 2012. 
En el caso de los aprovechamientos formales realizados por intermediarios, los beneficios llegan a ser mayores para el finquero que en los casos informales, excepto en el caso informal 5, donde únicamente se aprovecharon especies duras. En este último caso las ganancias del finquero son $53 \%$ mejores que los casos formales, lo cual reafirma el hecho de que es más importante la especie aprovechada que la legalidad de la corta en los niveles de beneficios del aprovechamiento. Sin embargo, las especies duras necesitan un pedido por parte de un intermediario que tenga la posibilidad de movilizar la madera, en caso contrario, la comercialización y transporte hacia la ciudad se dificultan para el finquero debido a que muchas veces esta madera no se comercializa localmente sino que se destina a otras provincias.

Los precios de la madera por $\mathrm{m}^{3}$ pagados al finquero $y$ al intermediario presentan diferencias entre $20 \%$ y $60 \%$ dependiendo del mercado y las especies. El porcentaje de ingresos es más proporcional entre finqueros e intermediarios cuando se aprovechan especies duras comercializadas y esas brechas son mayores cuando se trata de especies blandas. El hecho de que un aprovechamiento se realice informalmente o sin autorización respecto a los que cuentan con autorizaciones parece no afectar los ingresos finales. Estas diferencias más bien se explican por las especies que son aprovechadas (véanse nuevamente los cuadros 54 y 55 ).

Los intermediarios son quienes absorben los costos de los Programas de Aprovechamiento autorizados y los finqueros los que absorben los costos de los aprovechamientos informales, excepto en el caso formal 3, donde el finquero absorbió los costos del Programa de Aprovechamiento. En el segundo grupo, los aprovechamientos informales fueron marcados por la pérdida en el aprovechamiento de maderas blandas en tablas como en el caso del doncel (cuadro 55), aunque cuando se observa la totalidad de la corta se reportaron ganancias en los casos informales, debido a que otras especies de mayor valor o árboles de mayor volumen compensan las pérdidas.

Durante la fase del estudio los finqueros conocían estas pérdidas, sin embargo, seguían realizando la corta para poder cumplir con el pedido del intermediario y tener dinero en efectivo para destinarlo a la compra de víveres y gasolina para el siguiente aprovechamiento.

\subsection{Comparación de los beneficios para el finquero}

Existen varios estudios que analizan los costos y beneficios de diferentes métodos de aprovechamiento con el fin de determinar cuál es la mejor alternativa de lucro en el manejo forestal (Mederski, 2006; Bauch, et al., 2009; Spinellia, et al., 2099; Ghajar y Najafi, 2012). Estudios realizados de aprovechamientos en pequeña escala indican por lo general que son los finqueros quienes menos se benefician del aprovechamiento forestal (Hetsch, 2004; Díaz y Gatter, 2004; Espinoza, 2005). Los estudios de caso que aquí se presentan también demuestran esta tendencia con respecto a los intermediarios, quienes tienen maneras más eficientes de aprovechamiento al lograr economías de escala que resultan en mayores ganancias. Otros actores, como los aserradores y acarreadores, también tienen un beneficio mayor que el finquero en relación a la intensidad del aprovechamiento. Esta relación fue también observada por Hetsch (2004) en Pastza y Schlotzhauer (2012) en Napo. Sin embargo, en los casos 2 y 3 , el uso de mano de obra familiar hace que se reduzcan los costos de aserrío y acarreo.

Con respecto a los aprovechamientos formales e informales, en los ocho casos analizados no existe una clara tendencia que sugiera que los aprovechamientos formales proporcionen más ganancias para el finquero. Más bien son las especies comercializadas y los mercados de destino lo que diferencia los precios y, por consiguiente, las ganancias obtenidas. En este sentido se pueden apreciar que los estudios realizados por Gatter $e t$ al. (2005), concluyen también que las especies son fundamentales para los finqueros; sin embargo, algunos intermediarios-transportistas no tendrían especial interés en el valor de las especies pues aprovechan el trayecto de regreso después de haber comercializado otros productos.

Las extracciones forestales necesitan mano de obra intensiva, por esta razón también representan los costos más altos y es un factor limitante para la extracción. En los casos informales analizados, los finqueros realizan la corta de la madera utilizando mano de obra familiar, especialmente femenina, debido a que no existe un costo de oportunidad más alto para esta mano de obra. En este caso, los precios bajos de la madera o materia prima, en particular de las especies blandas de menor valor económico, son compensados por la mano de 
obra familiar de los finqueros. Esto explica porque los intermediarios que realizan aprovechamientos formales no están interesados en legalizar especies blandas y prefieren la compra de estas en mercados informales. Estas observaciones fueron también hechas por Southgate (2000) y Sierra (2001).

En general, son los mercados los que determinan la demanda de especies que son adquiridas y luego aprovechadas por los finqueros, además de la calidad y rapidez del corte. El mejor escenario de beneficios para el finquero es el aprovechamiento de especies de mayor valor comercial de manera informal a través de operaciones distribuidas a lo largo del año, seguidas de operaciones formales con participación del finquero en la corta. 


\section{Conclusiones}

El bosque, principalmente la madera, es una fuente importante de ingresos económicos para los hogares de la zona de estudio en la Amazonía ecuatoriana. Al igual que otros hogares alrededor del mundo (Mamo et al., 2007; CIFOR, 2011; Angelsen et al., 2011), los hogares analizados en las provincias de Napo y Orellana dependen en algún grado del dinero en efectivo de la venta de madera. El aprovechamiento de madera se realiza principalmente en los bosques primarios y los sistemas agroforestales. Esto indica que las familias poseen tierras con bosques nativos y árboles dentro de áreas intervenidas. Ambos son de similar importancia para la economía familiar pues se adaptan a las diferentes situaciones biofísicas y políticas que presenta la Amazonía.

Cuando se compara la situación del aprovechamiento de madera en las provincias de Napo y Orellana, que constituyen el centro principal de nuestro interés, se observa que en la primera los ingresos maderables provienen principalmente de áreas agroforestales, porque son asentamientos más antiguos donde ha existido una mayor intervención. En cambio, en la provincia de Orellana la madera proviene principalmente de bosques nativos, porque son asentamientos más recientes que disponen de áreas de bosque más extensas y relativamente menos intervenidas. La diferencia entre ambas provincias reside en las extensiones de usos de suelo y la prevalencia de especies valiosas que conservan aún los bosques nativos comparados con las áreas agroforestales; aunque en diferente medida, ambos usos del suelo generan ingresos para los hogares.

La madera de la Amazonía abastece principalmente a los crecientes mercados internos urbanos, aunque existe una parte que se dirige fuera del país, de la cual no se tienen estimaciones confiables. Los resultados de este trabajo sugieren que la comercialización está estructurada a través de redes relativamente complejas de intermediación, que operan a través de mecanismos formales e informales y cuyo principal objetivo es responder a las demandas de cantidad y calidad de los pedidos que son realizados por diferentes sectores de la industria. El mercado interno de madera, por lo menos al que se vinculan los productores e intermediarios de la Amazonía ecuatoriana, está liderado por depósitos de gran escala que son los que aglomeran la madera, en particular de especies de mayor valor comercial. Esta concentración de la demanda ya ha sido analizada por estudios previos realizados en el Ecuador (por ejemplo, véanse Sierra, 2001; Wunder, 2005; y Middleton, 2007). Lo anterior sugiere que la composición y estructura del mercado interno de la madera ha cambiado poco en los últimos años.

En vista de la creciente demanda doméstica de madera, el Estado ha procurado mejorar el control de la movilización de madera entre origen y destino a través del SAF, lo que ha constituido una pieza central de las políticas forestales. Actualmente, la implementación de un control más riguroso debido a diversas irregularidades detectadas en la forma en la cual se estuvo implementado este sistema, ha incrementado el tiempo y los costos asociados a la obtención de un permiso tanto de aprovechamiento como de corta, lo que también ha sido observado por otros estudios (véanse FAO, 2012 y Blandinieres et al., 2013). Asimismo, se evidencia que los pagos por pie de monte sumados a los costos de los permisos han interferido con los aprovechamientos y movilizaciones legales de pequeños volúmenes de madera. En este sentido, la preferencia por parte de finqueros e intermediarios es comercializar estos volúmenes de manera informal. Los volúmenes mayores a $50 \mathrm{~m}^{3}$ /aserrado son aprovechados por intermediarios que superan estas barreras a través precisamente de diluir los costos de tiempo y dinero en mayores volúmenes de corta. 
Es la persistencia de la informalidad del aprovechamiento y sus posibles consecuencias en la conservación de los bosques nativos de la Amazonía en el largo plazo lo que ha hecho que se mantenga un discurso de protección relativamente fuerte, tanto en el Estado como en los actores de la sociedad civil. A pesar de los esfuerzos realizados para conservar los bosques nativos, tanto en las regulaciones como en el sistema de control, se ha observado que prevalece el interés de los finqueros colonos e indígenas por negociar pequeños volúmenes de madera de especies de mayor valor comercial, como ya se mencionó, por lo general a través de negociaciones informales con los intermediarios. Una de las observaciones respecto a este comportamiento es que este tipo de arreglos otorga a los finqueros mayor poder de negociación y una distribución más equitativa de las ganancias con respecto a la de los intermediarios. En el caso de aprovechamientos formales, la preferencia de los productores es realizar la corta de la madera por sí mismos y que el intermediario se encargue de los gastos de legalidad, insumos y acarreo; así el aserrío garantiza mayores ganancias. En este caso los costos de legalidad son un problema para quienes aprovechan pequeños volúmenes y los volúmenes mayores se legalizan a través de los intermediarios.

Generalmente, la negociación y la distribución de los beneficios económicos en la Amazonía por corta de madera han sido percibidas como injustas, en especial para los finqueros que no pueden desligarse de los intermediarios y vender directamente a los diferentes mercados (Gatter y Romero, 2005; Añazco, et al., 2010; Palacios y Malessa, 2010; Ministerio del Ambiente del Ecuador, 2011; Schlotzhauer, 2012). Los resultados de este trabajo sugieren que la distribución de beneficios sí está estrechamente vinculada a la negociación que se establece entre finqueros e intermediarios. Esto representa un reto para muchos finqueros debido a varios factores como la información de precios, los costos de la operación y el acceso a mercados. Los resultados de este estudio muestran que las negociaciones entre productores e intermediarios pueden ser leales y desleales. Existen pérdidas monetarias para ambos actores por incumplimiento de los acuerdos verbales, en el caso de los intermediarios por falta de cumplimiento en los tiempos de la corta, y los productores por falta de cumplimiento en los pagos. Las negociaciones son más justas entre las partes cuando estas se conocen previamente y el productor entiende los precios.
Se piensa que la madera aserrada es cortada de manera ineficiente en comparación con aprovechamientos mayores y mecanizados (Wit et al., 2010; Vásquez, 2011; Pokorny et al., 2012). Nuestros hallazgos indican que, debido a la calidad incierta de los árboles en el bosque, es difícil determinar si la productividad de una operación depende del aserrío o de los dańos patológicos y mecánicos preexistentes. Lo que es notorio es que existe presión por parte de los intermediarios y finqueros sobre las especies de mayor valor comercial (semiduras y duras) porque compensan los costos de legalización, o representan una oportunidad de ganar más con menos. Respecto a este punto, al evaluar los sistemas formales no se puede asegurar que sean más sostenibles que los informales, ya que ambos prefieren maderas de alto valor comercial y además los ingresos no se reinvierten en mejorar la abundancia de las especies aprovechadas sino que se invierten en generar más cortas informales y formales.

Las estrategias de aprovechamiento se caracterizan por ser lideradas por los finqueros en ambas provincias y un poco menos de la mitad por los intermediarios en Orellana, estas estrategias son adaptadas en función de las características internas de los hogares. La participación exclusiva de los intermediarios en los aprovechamientos nos indica principalmente que los hogares tienen un limitado acceso al financiamiento para poder realizar estos aprovechamientos, especialmente cuando se trata de grandes volúmenes. Con respecto a los problemas de costos de transacción relacionados con las asimetrías de información y poder de negociación, estos no difieren de las estrategias de aprovechamiento adoptadas por los hogares; es decir, es un problema que tienen que afrontar todos los pequeńos finqueros en ambas provincias.

Es evidente que existe una diversificación de ingresos en los hogares tanto de colonos como de indígenas en ambas provincias. A pesar que la principal fuente de ingreso es el trabajo fuera de la finca, los ingresos por agricultura son considerados como la principal estrategia empleada por la mayoría de los hogares. Los ingresos forestales representan en promedio el 16\% de los ingresos totales de los hogares en ambas provincias y contribuyen principalmente a suplir las necesidades de los hogares creando liquidez para la economía familiar. Los factores que afectan la dependencia de los ingresos forestales de manera positiva son 
la etnia — colonos e indígenas-, posesión de activos - motosierras - y distancia a la ciudad principal. En cambio, los ingresos por agricultura y el trabajo fuera de la finca, además de la ubicación (provincia), tienen un efecto negativo sobre la dependencia de los ingresos forestales. Estos hallazgos apoyan los resultados existentes en la literatura citada. También se encontró que los hogares adoptan estrategias de conservación en sus fincas al sembrar especies de interés económico para los hogares.

En síntesis, este trabajo reúne diferentes perspectivas del aprovechamiento forestal desde el punto de vista de los usuarios del bosque. El esquema de gobernanza forestal se basa en la imposición vertical de normas sobre finqueros e indígenas que tienen dificultad para adaptarse a las prácticas exigidas, lo que constituye barreras para aprobar planes de aprovechamiento forestal. En general, los intermediarios han logrado superar esas barreras utilizando diferentes mecanismos, legales e ilegales, para satisfacer los pedidos de los compradores en las ciudades. Para el finquero existe una brecha entre lo que consigue producir por su propia cuenta de manera informal y lo que es capaz de producir con ayuda de un intermediario de manera formal, demostrando que para alcanzar la legalidad es importante suplir las necesidades de capital y conocimiento técnico.
Para superar las dificultades que enfrentan los diferentes usuarios locales, principalmente finqueros y comunidades indígenas, se precisan mayores esfuerzos en ajustar las regulaciones para adaptarlas mejor a las necesidades e intereses de estos actores, así como replantear el sistema de incentivos y financiamiento para el aprovechamiento forestal de pequeña escala, posiblemente privilegiando en el largo plazo las extracciones de menor volumen en bosques nativos y sistemas agroforestales, ya que es la opción que al parecer se ajusta mejor a las preferencias expresadas por los finqueros. En una línea complementaria, sería importante explorar estrategias de incentivos para apoyar actividades de reforestación y restauración forestal realizadas por los finqueros, incluyendo especies valiosas de interés para el productor y que podrían generar y/o mantener los ingresos forestales en el futuro.

Dado que los bosques tienden a degradarse con el tiempo son necesarias mejores políticas de incentivos, ya sea para mejorar los beneficios para los pequeños agricultores al aprovechar mejor sus recursos forestales o para adoptar estrategias que permitan una gestión más sostenible de los bosques. Sin embargo, las políticas deben mirar más allá de las fincas a las redes de mercado que configuran la decisión de los agricultores. 


\section{Referencias}

Adhikari, B., Di Falco, S. y Lovett, J. C., 2004. Household characteristics and forest dependency: evidence from common property forest management in Nepal. Ecological Economics, Volumen 48, pp. 245- 257.

Angelsen, A. y Kaimowitz, D., 1999. Rethinking the Causes of Deforestation: Lessons from Economics Models. The World Bank Research Observer, 14(1), p. 73-98.

Angelsen, A. y otros, 2011. Environmental income and rural livelihoods: global-comparative assessment. s.l., en Wye Global Conference.

Añazco, M., Morales, M., Palacios, W. y Vega, E., 2010. Sector Forestal Ecuatoriano: propuestas para una gestión forestal sostenible. Serie Investigación y Sistematización No 8, Programa Regional, Quito, Ecuador: ECOBONA-INTERCOOPERATION.

Banco Central del Ecuador, 2012. Estadisticas macroeconómicas, Quito: BCE.

Barbieri, A., Carr, D. y Bilsborrow, R., 2009. Migration within the Frontier: The Second Generation Colonization in the Ecuadorian Amazon. Population Research and Policy Review, Número 28, pp. 291-320.

Barrantes, G. C. H. V. M., 2006. El Bosque En El Ecuador Una Visión Transformada Para El Desarrollo y La Conservación., Quito: s.n.

Barrett, C., 2008. Smallholder market participation. Concepts and evidence from eastern and southern Africa. Food Policy, Volumen 33, pp. 299-317.

Bauch, S. C., Amacher, G. S. y Merry, F. D., 2009. Costs of harvesting, transportation and milling in the Brazilian Amazon: Estimation and policy implications. Forest Policy and Economics, Volumen 9, p. 903-915.

Bilsborrow, R. E., Barbieri, A. F. y Pan, W., 2004. Changes in Population and Land Use Over Time in the Ecuadorian Amazon. Acta Amazónica, 34(4), pp. 635-647.

Blandinieres, J. P., Betancur, L., Maradei, D. y Saraiva, G. P., 2013. Timber Trade Flows within to and from South America, Szkolna: EPDR.
Boltz, F., Holmes, T. P. y Carter, D. R., 2003. Economic and environmental impacts of conventional and reduced-impact logging in Tropical South America: a comparative review. Issue 5.

Brown, D. y otros, 2009. Legal Timber: Verification and Control in the Forest Sector, London: ODI.

CEPAL, 2011. Estadisticas de América Latina y el Caribe. [En línea]

Disponible en: http://websie.eclac.cl/infest/ ajax/cepalstat.asp?carpeta=estadisticas [Último acceso: 31 Agosto 2011].

Chommitz, K. M., 2007. At Loggerheads? Agricultural Expansion, Poverty reduction and Environment in the tropics.. Washington: World Bank.

CIFOR, 2011. Counting on the Environment. The contribution of forests to Rural Livelihoods, Londres: The Royal Society.

CLIRSEN, 2003. La Deforestación en el Ecuador, Quito: Centro de Levantamientos Integrados de Recursos Naturales por Sensores Remotos.

COMTRADE, 2011. Estadisticas de Comercio Exterior. [En línea]

Disponible en: legacy.intracen.org/ marketanalysis/Default.aspx

[Último acceso: 31 Agosto 2011].

Díaz, F. y Gatter, S., 2004. Estudio Comparativo del Desperdicio y Costo de Cepillado y Canteado de la Madera Aserrada a Pulso Vs. Aserrada con Marco Guía, de la Especie Dacroydes Peruviana (Copal), Macas: SFA.

Ecuador Forestal, 2007. Planeación Estratégica: Sub Sector Plantaciones Forestales Ecuador, Quito: CORPEI.

Espinoza, G., 2005. Análisis económico de la cadena de aprovechamiento, transformación y comercialización de tres productos de madera provenientes de bosques nativos de las regiones noroccidental y oriental del Ecuador., Quito: Colegio de Ingenieros Forestales de Pichincha CIFOP.

FAO, 1997. Las mujeres en la planificacion forestal del Ecuador, Quito: FAO. 
FAO, 2006. Andean Countries: An strategy for Forestry. Case Study: Ecuador, Roma: FAO.

FAO, 2010. Global Forest Resources Assessment. Roma:FAO.

FAO, 2012. Estudios Sectoriales: Evaluación del cobro o derecho de aprovechamiento de madera y otras tasas sobre el manejo forestal, Roma: FAO.

FENOCIN; CNC, 2012. Ley Orgánica de Tierras y Territorios, Quito: s.n.

Gatter, S. y Romero, M., 2005. Análisis Económico de la Cadena De Aprovechamiento, Transformación y Comercialización de Madera Aserrada Provenientes de Bosques Nativos en La Region Centro-Sur De La Amazonía Ecuatoriana, Macas: SFA.

Ghajar, I. y Najafi, A., 2012. Evaluation of harvesting methods for Sustainable Forest Management (SFM) using the Analytical Network Process (ANP). Forest Policy and Economics, Volumen 21, p. 81-91.

Gray, C., Bilsborrow, R., Bremner, J. y Lu, F., 2008. Indigenous land use in the Ecuadorian Amazon: a cross-cultural and multilevel analysis. Human Ecology Journal, Volumen 36, pp. 97-109.

Grijalva, J. y otros, 2012. Situación de los Recursos Forestales Genéticos del Ecuador, s.l.: Quito.

Hansen, C. P., 2011. Forest Law compliance and enforcement: The case of on-farm timber extraction in Ghana. Journal of Environmental Management, Volumen 92, pp. 575-586.

Hetsch, S., 2004. La Comercialización de Madera en la Provincia de Pastaza, s.l.: Universidad de Friburgo.

Hetsch, S., 2004. La Comercialización de Madera en la Provincia de Pastaza, Puyo: Universidad de Friburgo.

Holand, M. B. y otros, 2013. Complex Tenure and Deforestation: Implications for Conservation Incentives in the Ecuadorian Amazon. World Development.

Ibarra, E., Romero, M. y Gatter, S., 2008. Análisis del marco legal para el manejo forestal por pequeños productores rurales en la Amazonía ecuatoriana, La Paz: CIFOR, Servicio Forestal Amazónico.

INEC, 2011. Encuesta de Superficie y Producción Agropecuaria Continua (ESPAC).. [En línea] Disponible en: www.ecuadorencifras.com/ cifras-inec/main.html [Último acceso: 31 Agosto 2012].

ITTO, 2002. Tropical timber products Development of further processing in ITTO producer countries, Ginebra: ITTO.
ITTO, 2004. Consecusión del Objetivo 2000 y la Ordenación Forestal Sostenible en Ecuador. Misión de Diagnóstico establecida conforme la Decisión 2(XXIX), Interlaken: Organización Internacional de Maderas Tropicales.

ITTO, 2011. Country Profile Ecuador, Yokohama: Organización Internacional de las Maderas Tropicales (borrador inédito).

Izko, X., 2009. Mecanismos Financieros para el Sector Forestal en el Ecuador, Quito: FAO, OIMT/ITTO y OTCA.

Kaimowitz D, 2003. Forest law enforcement and rural livelihoods. International Forestry Review, 5(3), p. 199-210.

Kautz, M., 2005. Aprovechamiento de la madera en el territorio Shuar de la Cordillera del Cóndor, s.l.: Universidad de Dresden.

Key, N., Sadoulet, E. y Janvry, A., 2000. Transactions costs and agricultural household supply response. American Journal of Agriculture Economics, 82(2), pp. 245-259.

Kingman, S., 2007. Areas Protegidas y Pueblos Indigenas: Un Estudio de Caso en ECUADOR, Quito: FAO.

Kishor, N. y Damania, R., 2009. Crimen y justicia en el Jardín del Edén: Mejorar la Gobernabilidad y Reducir la corrupción en el Sector Forestal. En: Múltiples Caras de la Corrupción. Washington: Banco Mundial.

Lee, D., 2005. Agricultural sustainability and technology adoption: Issues and policies for developing countries. American Journal of Agriculture Economics, 87(1325-1334), p. 5.

Li, R. y Buongiorno, J., 2010. Long-term effects of eliminating illegal logging on the world forest industries, trade and inventory. Número 10.

MAGAP, 2000. III Censo Nacional Agropecuario. Ministerio de Agricultura, Ganadería, Acuacultura y Pesca, Quito: Ministerio de Agricultura y Ganadería.

Mamo, G., Sjaastad, E. y Vedeld, P., 2007. Economic dependence on forest resources: A case from Dendi District, Ethiopia. Forest Policy and Economics Journal, Volumen 9, pp. 916-927.

Mateo, R. G. y otros, 2013. A new spin on a compositionalist predictive modelling framework for conservation planning: A tropical case study in Ecuador. Biological Conservation, Número 160, p. 150-161.

Mederski, P. S., 2006. A comparison of harvesting productivity and costs in thinning operations with and without midfield. Forest Ecology and Management, Volumen 224, p. 286-296. 
Medina, G., Pokorny, B. y Campbell, B., 2008. Favouring local development in the Amazon: Lessons from community forest management initiatives, Bogor: CIFOR.

Medjibe, V. P. y Putz, F. E., 2012. Cost comparisons of reduced-impact and conventional logging in the tropics. Journal of Forest Economics, Volumen 18, p. 242-256.

Mejía, E. K., 2010. La descentralización del ambiente en Ecuador, Friburgo: Universidad de Friburgo.

Mena, C. F. y otros, 2011. Land use change on household farms in the Ecuadorian Amazon: Design and implementation of an agent-based model. Applied Geography, pp. 210-222.

Merino, J., 2010. Estudio Económico de dos Formas de Aprovechamiento Forestal del Pigue (Pollalesta discolor) en el canton Mera, provincia de Pastaza., Riobamba: ESPOCH.

Meza, J. A., 2010. Los programas forestales nacionales en América del Sur: Politica, legislación e institucionalidad - sistematización de la información, Santiago: FAO, Oficina Regional de la FAO para América Latina y el Caribe..

Middleton, A., 2007. Globalization, Free Trade, and the Social Impact of the Decline of Informal Production: The Case of Artisans in Quito, Ecuador. World Development, 35(11), pp. 1904-1928.

Ministerio del Ambiente del Ecuador, 2006. El Sistema Nacional Descentralizado de Control Forestal, Sao Paulo: MAE.

Ministerio del Ambiente del Ecuador, 2006. Transparencia Forestal, Lima: MAE.

Ministerio del Ambiente del Ecuador, 2010. Reservas de Biosfera del Ecuador: lugares excepcionales, Quito, Ecuador: GTZ/ GESOREN/DED-WCS- NCI-UNESCO.

Ministerio del Ambiente del Ecuador, 2011. Descripción de las Cadenas Productivas de Madera en el Ecuador. Quito. 95p, Quito: MAE-ITTO.

Ministerio del Ambiente del Ecuador, 2011. Gobernanza Forestal en el Ecuador, Quito: MAE-ITTO.

Ministerio del Ambiente del Ecuador, 2011. Supervisión y Verificación de los Recursos Forestales en el Ecuador, Quito: MAE-ITTO.

Ministerio del Ambiente del Ecuador, 2012. Linea Base de Deforestación del Ecuador Continental, Quito: Ministerio del Ambiente.

Moser, C. y Barrett, C., 2003. The disappointing adoption dynamics of a yield-increasing, low external-input technology: the case of SRI in Madagascar. Agricultural Systems, 76(3), pp. 1085-1100.

Navarro, G., Gatto, F. D. y Schroeder, M., 2009. Sistema Ecuatoriano Tercerizado de Control Forestal, Turrialba: CATIE.

Nino, A. C. B., 2010. Haciéndonos mi cuerpo: etnicidad, género y generación en un grupo napo kichwa. Quito: FLACSO.

Núñez, A. M., 2009. Estado de situación sobre las tierras indigenas y mujeres indígenas, La Paz: UNIFEM.

Owen, R. y Thiel, H., 2006. Andean Countries: A Strategy for Forestry. Case Studies - Volume III of V. Ecuador., Roma: FAO/World Bank Cooperative Programme, Latin America and the Caribbean Service, Investment Centre Division.

Pacheco, P., 2012. Smallholders and Communities in Timber Markets: Conditions Shaping Diverse Forms of Engagement in Tropical Latin America. Conservation and Society, 10(2), pp. 114-123.

Pacheco, P., Barry, D., Cronkleton, P. y Anne L., 2009. El papel de las instituciones informales en el uso de los recursos forestales, Bogor: CIFOR.

Pacheco, P., Jong, W. d. y Johnson, J., 2010. The evolution of the timber sector in lowland Bolivia: examining the influence of three disparate policy approaches. Forest Policy and Economics, Volumen 12, pp. 271-276.

Palacios, W., 2008. Análisis de la situación de la gobernabilidad y del cumplimiento de la legislación en el sector forestal en el Ecuador. Quito. Iniciativa para la aplicación de la legislación forestal en la Amazonía, Quito: ALFA-OTCA/MAE.. .

Palacios, W. y Malessa, U., 2010. Situación de las comunidades productoras forestales de la Amazonía ecuatoriana: obstáculos y oportunidades para comercializar madera legal, Quito: TRAFFIC.

Pichon, F., 1997. Colonist Land-Allocation Decisions, Land Use, and Deforestation in the Ecuadorian Amazon Frontier. Economic Development and Cultural Change, 45(4), pp. 707-744.

Pinedo-Vásquez, M. y otros, 2001. Post-Bool Logging in Amazonía. Human Ecology, 29(2), pp. 219-239.

PNC ONU-REDD Ecuador, 2013. Programa de Naciones Unidas para la Reducción de las Emisiones por Deforestación y Degradación del 
Bosque en los Paises en Desarrollo Documento del Programa Nacional Conjunto, Quito: ONU.

Pokorny, B. y Johnson, J., 2008. Community forestry in the Amazon: The unsolved challenge of forests and the poor, s.l.: ODI.

Pokorny, B., Johnson, J., Medina, G. y Hoch, L., 2012. Market-based conservation of the Amazonían forests: Revising win-win expectations. Geoforum, Volumen 43, pp. 387-401.

Robles, M., 2013. Incentivos en el sector forestal [Entrevista] (20 Marzo 2013).

Sadoulet, E. y Janvry, A., 2005. Quantity Development Policy Analysis. Baltimore: The Johns Hopkins University Press.

Salazar, F., 2006. Huaquillas es la puerta del comercio ilegal (Cámara de Comercio) [Entrevista] (27 Marzo 2006).

Schlotzhauer, P., 2012. Value chain analysis of wood utilization from the standing tree to the final product inside the Cantón Tena, Ecuador, Friburgo: Universidad de Friburgo.

SENPLADES, 2009. Plan Nacional para el Buen Vivir 2009-2013: Construyendo un Estado Plurinacional e Intercultural, Quito: Secretaria Nacional de Planificación.

Sherbinin, A. d. y otros, 2008. Rural household demographic, livelihoods and the environment. Global Environmental Change, Volumen 18, pp. 38-53.

Sierra, R., 2001. The role of domestic timber markets in tropical deforestation and forest degradation in Ecuador: Implications for conservation planning and policy. Ecological Economics, Issue 36, pp. 327-340.

Smith, J., Colan, V., Sabogal, C. y Snook, L., 2006. Why policy reforms fail to improve logging practices: The role of governance and norms in Peru.

Southgate, D., Salazar-Canelos, P., C. C. y Stewart, R., 2000. Markets, Institutions, and Forestry: The Consequences of Timber Trade Liberalization in Ecuador. 28(11).

Southgate, D., Sierra, R. y Brown, L., 1991. The Causes of Tropical Deforestation in Ecuador: A Statistical Analysis. World Development, 19(9), pp. 1145-1151.

Southgate, D., Wasserstrom, R. y Reider, S., 2009. Oil development, deforestation and indigenous populations in the Ecuadorian Amazon. In Meeting of the Latin American Studies Association, Río de Janeiro: LASA.
Spinellia, R., Ward, S. M. y Owende, P. M., 2099. A harvest and transport cost model for Eucalyptus spp. fast-growing short rotation plantations. Biomass and bioenergy, Volumen 33, p. 1265-1270.

Tandazo y Gatter, 2004. Manual para el Manejo Forestal en Fincas, s.l.: s.n.

Terán, C., 2012. La industria forestal en el Ecuador, Quito: s.n.

Thiel, H. y Trelles, M., 2008. Análisis Preliminar de la Aplicación de la Legislación Forestal en la Cuenca Amazónica, Quito: Organización del Tratado de Cooperación Amazónica.

Vásquez, E., 2004. La Industria Forestal Del Ecuador, Quito: COMAFORS.

Vásquez, E., 2011. Propuesta de un Plan de Mejora Competitiva Valorada de la Cadena de Madera Aserrada, Quito: Ministerio de Industrias y Productividad.

Vinueza, M., 2012. La evolución del Sistema Nacional de Control Forestal [Entrevista] 2012.

Viteri, A., Cuenca, P. y Cordero, V., 2010. Documento de Análisis del Sector Forestal en el Contexto De Adaptación y Mitigación sa Cambio Climático Del Sector Uso De Suelo, Cambio De Suelo, Y Silvicultura Forestal) En El Ecuador, Quito: UNDP.

Wit, M. y otros, 2010. Chainsaw milling: supplier to local markets - a synthesis. ETFRN News, Volumen 52, pp. 7-27.

Wollni, M., 2006. Coping with the Coffee Crisis; an Analysis of the Production and Marketing Performance of Coffee Farmers in Costa Rica. Development Economic and Policy, Volumen 57, p. 173.

Wunder, S., 1996. Los Caminos de la Madera. Una investigación de los usos domésticos y comerciales de los productos de la madera, y su relación con el proceso de deforestación, Quito: DDA, INTERCOOPERATION y UICN.

Wunder, S., 2000. The Economics of Deforestation: The Example of Ecuador, Basingstoke: Macmillan.

Wunder, S., 2003. Ecuador. En: Oil Wealth and the Fate of the Forest. A comparative study of eight tropical countries. Londres: Routledge.

Wunder, S., 2005. Macroeconomic Change, Competitiveness and Timber Production: A Five-Country Comparison. 33(1). 


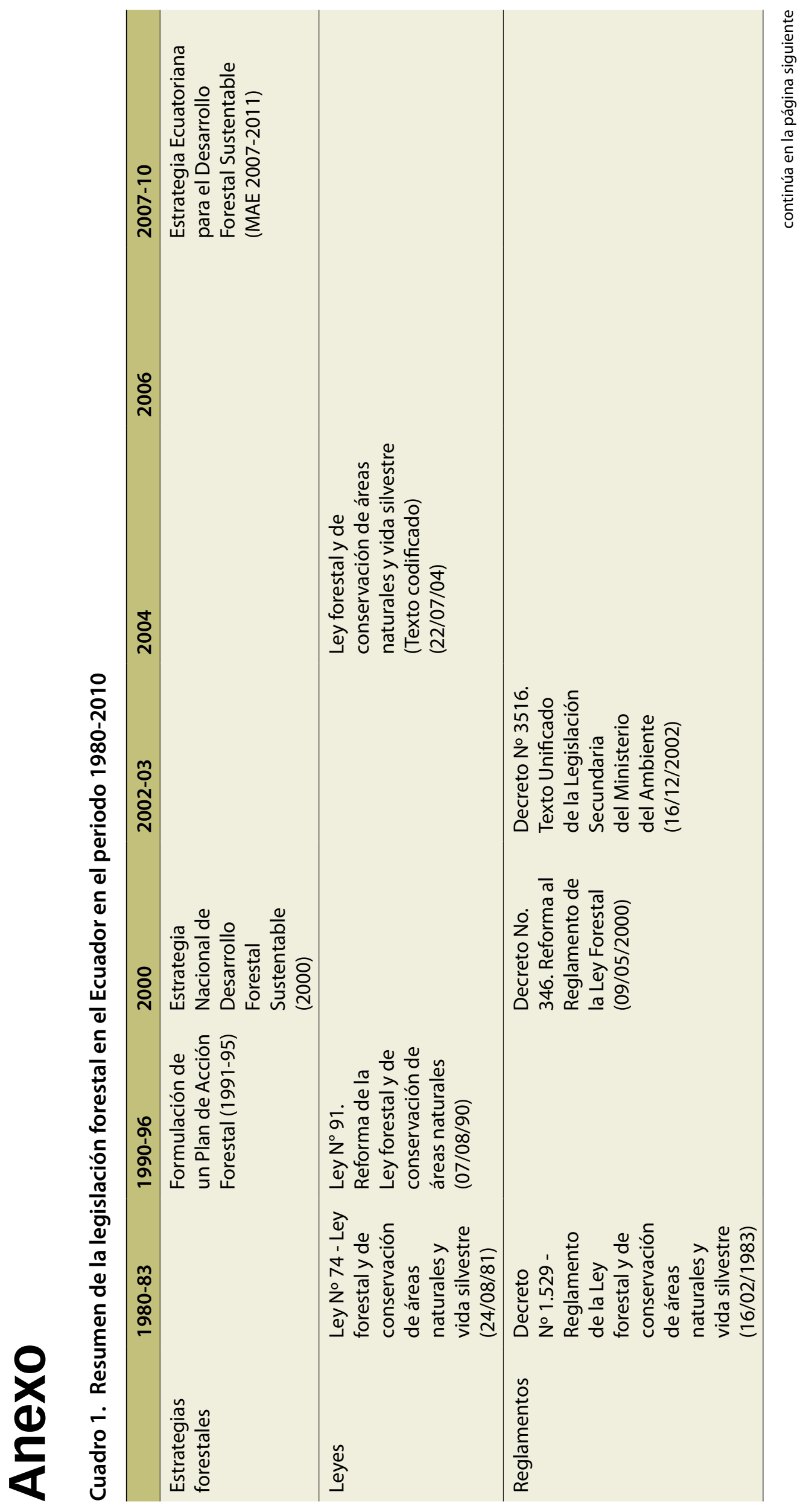




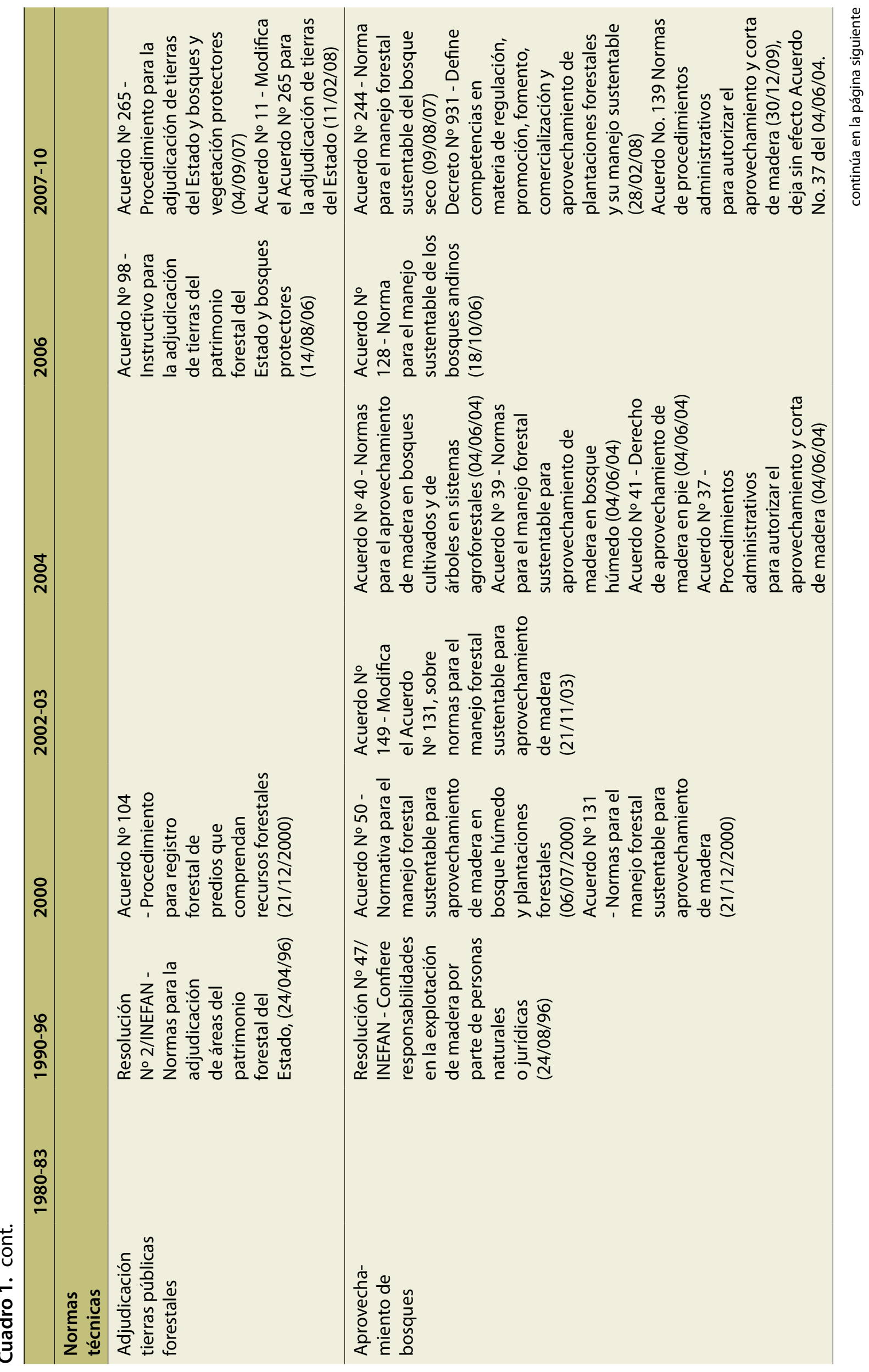




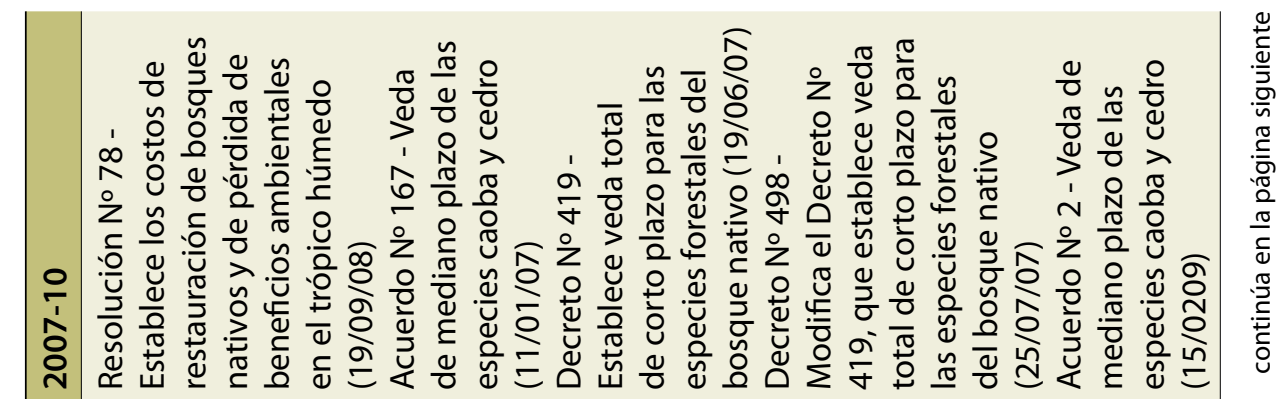

ষ্ণ

ㅇํํ

음

m.

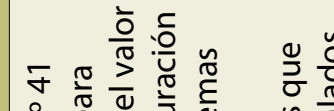

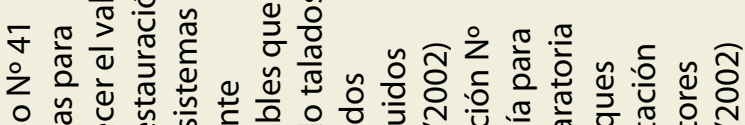

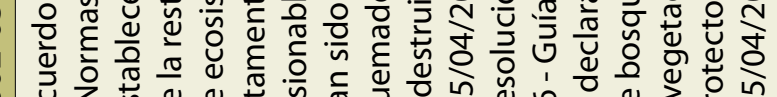

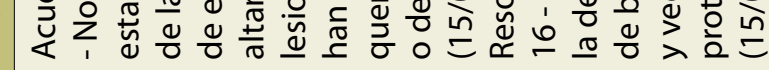

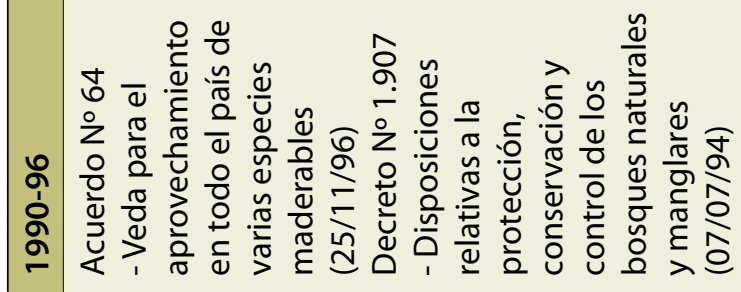

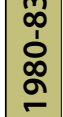

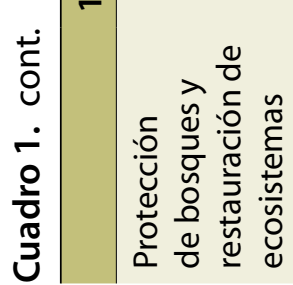



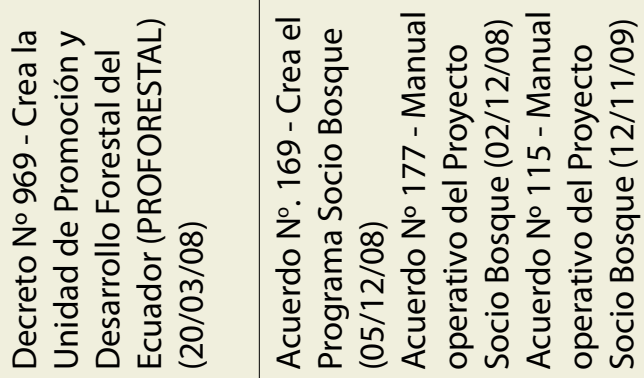

ষ্ণ

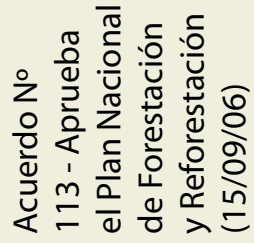

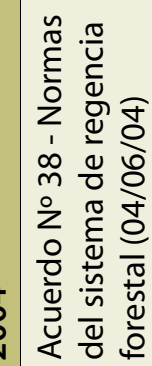

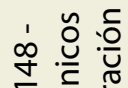

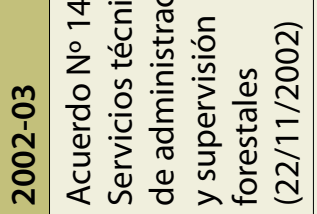

옹

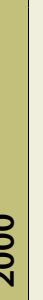

\section{.}

$$
\text { . }
$$



Los Documentos ocasionales de CIFOR contienen resultados de investigación relevantes para la silvicultura tropical. Su contenido es revisado por pares interna y externamente.

Ecuador es un país rico en recursos naturales, la mayor parte de estos recursos se encuentra en la Amazonía. La madera es uno de los recursos más importantes obtenidos de los bosques nativos. La mayor parte de la madera se consume en el mercado interno, el cual se ha duplicado en los últimos cinco, años y una menor proporción se destina a un mercado transfronterizo, cuya dimensión es todavía desconocida. La madera aprovechada en la Amazonía proviene bosques de comunidades nativas localizados en pequeñas propiedades rurales o fincas. Los finqueros venden su madera de manera formal pero también a través de transacciones informales. Las redes de intermediación de la madera, en el área rural, están a cargo de intermediarios que legalizan la madera que se oferta en el mercado a través de diferentes medios, mientras que los mercados urbanos están dominados por grandes procesadores y distribuidores. La creciente demanda urbana también contribuye a la informalidad debido a que los intermediarios no son capaces de suministrar todos los pedidos con madera proveniente de aprovechamientos legales. El aprovechamiento de la madera es importante puesto que contribuye a aproximadamente el 19\% del ingreso total promedio de los hogares rurales y, con ello, proporciona dinero en efectivo a estos hogares para satisfacer algunas necesidades básicas de la familia.

\begin{tabular}{|c|c|c|}
\hline CGIAR & $\begin{array}{l}\text { PROGRAMA DE } \\
\text { INVESTIGACIÓN SOBRE } \\
\text { Bosques, Árboles y } \\
\text { Agroforestería }\end{array}$ & $\begin{array}{l}\text { Esta investigación fue realizada por CIFOR como parte del Programa de Investigación de CGIAR sobre } \\
\text { Bosques, Árboles y Agroforestería (CRP-FTA). El objetivo del programa es mejorar el manejo y uso de los } \\
\text { bosques, la agroforestería y los recursos genéticos de los árboles a lo largo del paisaje, desde bosques } \\
\text { hasta plantaciones. CIFOR dirige el programa CRP-FTA en asociación con Bioversity International, } \\
\text { CIRAD, el Centro Internacional de Agricultura Tropical y el Centro Mundial de Agroforestería. }\end{array}$ \\
\hline
\end{tabular}

cifor.org

blog.cifor.org

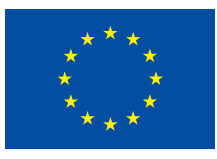

\section{Centro para la Investigación Forestal Internacional (CIFOR)}

CIFOR impulsa el bienestar humano, la conservación ambiental y la equidad mediante investigación orientada a ayudar en el diseño de políticas y prácticas que afectan a los bosques de los países en vías de desarrollo. CIFOR es un miembro del Consorcio CGIAR. Nuestra sede central se encuentra en Bogor, Indonesia, y contamos con oficinas en Asia, África y Sudamérica. 